Strategic Approaches at the Corridor and Network Level to Minimize Disruption from the Renewal Process

SHRP 2 RENEWAL RESEARCH 


\section{TRANSPORTATION RESEARCH BOARD 2014 EXECUTIVE COMMITTEE*}

\section{OFFICERS}

CHAIR: Kirk T. Steudle, Director, Michigan Department of Transportation, Lansing

VICE CHAIR: Daniel Sperling, Professor of Civil Engineering and Environmental Science and Policy; Director, Institute of Transportation Studies,

University of California, Davis

EXECUTIVE DIRECTOR: Robert E. Skinner, Jr., Transportation Research Board

\section{MEMBERS}

Victoria A. Arroyo, Executive Director, Georgetown Climate Center, and Visiting Professor, Georgetown University Law Center, Washington, D.C. Scott E. Bennett, Director, Arkansas State Highway and Transportation Department, Little Rock

Deborah H. Butler, Executive Vice President, Planning, and CIO, Norfolk Southern Corporation, Norfolk, Virginia (Past Chair, 2013)

James M. Crites, Executive Vice President of Operations, Dallas-Fort Worth International Airport, Texas

Malcolm Dougherty, Director, California Department of Transportation, Sacramento

A. Stewart Fotheringham, Professor and Director, Centre for Geoinformatics, School of Geography and Geosciences, University of St. Andrews, Fife, United Kingdom

John S. Halikowski, Director, Arizona Department of Transportation, Phoenix

Michael W. Hancock, Secretary, Kentucky Transportation Cabinet, Frankfort

Susan Hanson, Distinguished University Professor Emerita, School of Geography, Clark University, Worcester, Massachusetts

Steve Heminger, Executive Director, Metropolitan Transportation Commission, Oakland, California

Chris T. Hendrickson, Duquesne Light Professor of Engineering, Carnegie Mellon University, Pittsburgh, Pennsylvania

Jeffrey D. Holt, Managing Director, Bank of Montreal Capital Markets, and Chairman, Utah Transportation Commission, Huntsville, Utah

Gary P. LaGrange, President and CEO, Port of New Orleans, Louisiana

Michael P. Lewis, Director, Rhode Island Department of Transportation, Providence

Joan McDonald, Commissioner, New York State Department of Transportation, Albany

Abbas Mohaddes, President and CEO, Iteris, Inc., Santa Ana, California

Donald A. Osterberg, Senior Vice President, Safety and Security, Schneider National, Inc., Green Bay, Wisconsin

Steven W. Palmer, Vice President of Transportation, Lowe's Companies, Inc., Mooresville, North Carolina

Sandra Rosenbloom, Professor, University of Texas, Austin (Past Chair, 2012)

Henry G. (Gerry) Schwartz, Jr., Chairman (retired), Jacobs/Sverdrup Civil, Inc., St. Louis, Missouri

Kumares C. Sinha, Olson Distinguished Professor of Civil Engineering, Purdue University, West Lafayette, Indiana

Gary C. Thomas, President and Executive Director, Dallas Area Rapid Transit, Dallas, Texas

Paul Trombino III, Director, Iowa Department of Transportation, Ames

Phillip A. Washington, General Manager, Regional Transportation District, Denver, Colorado

\section{EX OFFICIO MEMBERS}

Thomas P. Bostick, (Lt. General, U.S. Army), Chief of Engineers and Commanding General, U.S. Army Corps of Engineers, Washington, D.C. Alison J. Conway, Assistant Professor, Department of Civil Engineering, City College of New York, New York, and Chair, TRB Young Members Council

Anne S. Ferro, Administrator, Federal Motor Carrier Safety Administration, U.S. Department of Transportation

David J. Friedman, Acting Administrator, National Highway Traffic Safety Administration, U.S. Department of Transportation

John T. Gray II, Senior Vice President, Policy and Economics, Association of American Railroads, Washington, D.C.

Michael P. Huerta, Administrator, Federal Aviation Administration, U.S. Department of Transportation

Paul N. Jaenichen, Sr., Acting Administrator, Maritime Administration, U.S. Department of Transportation

Therese W. McMillan, Acting Administrator, Federal Transit Administration

Michael P. Melaniphy, President and CEO, American Public Transportation Association, Washington, D.C.

Victor M. Mendez, Administrator, Federal Highway Administration, and Acting Deputy Secretary, U.S. Department of Transportation

Robert J. Papp, (Adm., U.S. Coast Guard), Commandant, U.S. Coast Guard, U.S. Department of Homeland Security

Cynthia L. Quarterman, Administrator, Pipeline and Hazardous Materials Safety Administration, U.S. Department of Transportation

Peter M. Rogoff, Acting Under Secretary for Policy, U.S. Department of Transportation

Craig A. Rutland, U.S. Air Force Pavement Engineer, Air Force Civil Engineer Center, Tyndall Air Force Base, Florida

Joseph C. Szabo, Administrator, Federal Railroad Administration, U.S. Department of Transportation

Barry R. Wallerstein, Executive Officer, South Coast Air Quality Management District, Diamond Bar, California

Gregory D. Winfree, Assistant Secretary for Research and Technology, Office of the Secretary, U.S. Department of Transportation

Frederick G. (Bud) Wright, Executive Director, American Association of State Highway and Transportation Officials, Washington, D.C.

\footnotetext{
${ }^{\star}$ Membership as of February 2014 .
} 


\title{
Strategic Approaches at the Corridor and Network Level to Minimize Disruption from the Renewal Process
}

\author{
LAWRenCe Pesesky \\ DANE ISMART \\ Deborah Matherly \\ The Louis Berger Group, Inc. \\ Chris Huffman \\ Huffman Corridor Consulting \\ Yi-Chang Chiu \\ HONG ZHENG \\ ERIC NAVA \\ University of Arizona \\ VINAY DiXIT \\ BRIAN WOLSHON \\ Louisiana State University \\ ESSAM RADWAN \\ WILLIAM SAMPSON \\ JuAn MORALES \\ Juan Morales Associates \\ ERIC Perry \\ SAIC \\ Ed Bromage AND Lindsay Bromage \\ E. J. Bromage LLC
}




\section{Subject Areas}

Construction

Highways

Operations and Traffic Management 


\section{The Second Strategic Highway Research Program}

America's highway system is critical to meeting the mobility and economic needs of local communities, regions, and the nation. Developments in research and technology-such as advanced materials, communications technology, new data collection technologies, and human factors science-offer a new opportunity to improve the safety and reliability of this important national resource. Breakthrough resolution of significant transportation problems, however, requires concentrated resources over a short time frame. Reflecting this need, the second Strategic Highway Research Program (SHRP 2) has an intense, large-scale focus, integrates multiple fields of research and technology, and is fundamentally different from the broad, mission-oriented, discipline-based research programs that have been the mainstay of the highway research industry for half a century.

The need for SHRP 2 was identified in TRB Special Report 260: Strategic Highway Research: Saving Lives, Reducing Congestion, Improving Quality of Life, published in 2001 and based on a study sponsored by Congress through the Transportation Equity Act for the 21st Century (TEA-21). SHRP 2, modeled after the first Strategic Highway Research Program, is a focused, time-constrained, management-driven program designed to complement existing highway research programs. SHRP 2 focuses on applied research in four areas: Safety, to prevent or reduce the severity of highway crashes by understanding driver behavior; Renewal, to address the aging infrastructure through rapid design and construction methods that cause minimal disruptions and produce lasting facilities; Reliability, to reduce congestion through incident reduction, management, response, and mitigation; and Capacity, to integrate mobility, economic, environmental, and community needs in the planning and designing of new transportation capacity.

SHRP 2 was authorized in August 2005 as part of the Safe, Accountable, Flexible, Efficient Transportation Equity Act: A Legacy for Users (SAFETEA-LU). The program is managed by the Transportation Research Board (TRB) on behalf of the National Research Council (NRC). SHRP 2 is conducted under a memorandum of understanding among the American Association of State Highway and Transportation Officials (AASHTO), the Federal Highway Administration (FHWA), and the National Academy of Sciences, parent organization of TRB and NRC. The program provides for competitive, merit-based selection of research contractors; independent research project oversight; and dissemination of research results.
SHRP 2 Report S2-R11-RW-1

ISBN: 978-0-309-12981-7

(c) 2014 National Academy of Sciences. All rights reserved.

\section{Copyright Information}

Authors herein are responsible for the authenticity of their materials and for obtaining written permissions from publishers or persons who own the copyright to any previously published or copyrighted material used herein.

The second Strategic Highway Research Program grants permission to reproduce material in this publication for classroom and not-for-profit purposes. Permission is given with the understanding that none of the material will be used to imply TRB, AASHTO, or FHWA endorsement of a particular product, method, or practice. It is expected that those reproducing material in this document for educational and not-for-profit purposes will give appropriate acknowledgment of the source of any reprinted or reproduced material. For other uses of the material, request permission from SHRP 2.

Note: SHRP 2 report numbers convey the program, focus area, project number, and publication format. Report numbers ending in " $w$ " are published as web documents only.

\section{Notice}

The project that is the subject of this report was a part of the second Strategic Highway Research Program, conducted by the Transportation Research Board with the approval of the Governing Board of the National Research Council.

The members of the technical committee selected to monitor this project and to review this report were chosen for their special competencies and with regard for appropriate balance. The report was reviewed by the technical committee and accepted for publication according to procedures established and overseen by the Transportation Research Board and approved by the Governing Board of the National Research Council.

The opinions and conclusions expressed or implied in this report are those of the researchers who performed the research and are not necessarily those of the Transportation Research Board, the National Research Council, or the program sponsors.

The Transportation Research Board of the National Academies, the National Research Council, and the sponsors of the second Strategic Highway Research Program do not endorse products or manufacturers. Trade or manufacturers' names appear herein solely because they are considered essential to the object of the report.

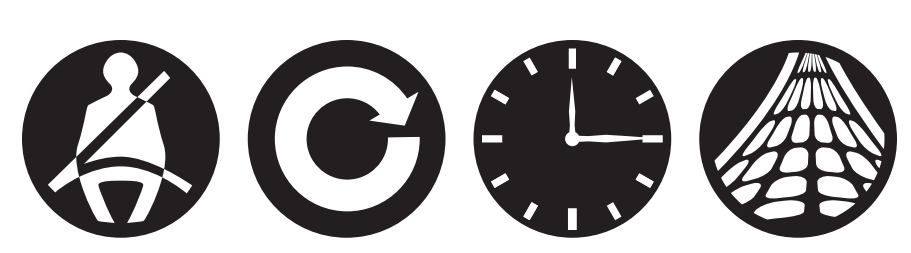

\section{SHRP 2 Reports}

Available by subscription and through the TRB online bookstore: www.TRB.org/bookstore

Contact the TRB Business Office:

202-334-3213

More information about SHRP 2: www.TRB.org/SHRP2 


\section{THE NATIONAL ACADEMIES Advisers to the Nation on Science, Engineering, and Medicine}

The National Academy of Sciences is a private, nonprofit, self-perpetuating society of distinguished scholars engaged in scientific and engineering research, dedicated to the furtherance of science and technology and to their use for the general welfare. On the authority of the charter granted to it by Congress in 1863, the Academy has a mandate that requires it to advise the federal government on scientific and technical matters. Dr. Ralph J. Cicerone is president of the National Academy of Sciences.

The National Academy of Engineering was established in 1964, under the charter of the National Academy of Sciences, as a parallel organization of outstanding engineers. It is autonomous in its administration and in the selection of its members, sharing with the National Academy of Sciences the responsibility for advising the federal government. The National Academy of Engineering also sponsors engineering programs aimed at meeting national needs, encourages education and research, and recognizes the superior achievements of engineers. Dr. C. D. (Dan) Mote, Jr., is president of the National Academy of Engineering.

The Institute of Medicine was established in 1970 by the National Academy of Sciences to secure the services of eminent members of appropriate professions in the examination of policy matters pertaining to the health of the public. The Institute acts under the responsibility given to the National Academy of Sciences by its congressional charter to be an adviser to the federal government and, on its own initiative, to identify issues of medical care, research, and education. Dr. Victor J. Dzau is president of the Institute of Medicine.

The National Research Council was organized by the National Academy of Sciences in 1916 to associate the broad community of science and technology with the Academy's purposes of furthering knowledge and advising the federal government. Functioning in accordance with general policies determined by the Academy, the Council has become the principal operating agency of both the National Academy of Sciences and the National Academy of Engineering in providing services to the government, the public, and the scientific and engineering communities. The Council is administered jointly by both Academies and the Institute of Medicine. Dr. Ralph J. Cicerone and Dr. C. D. (Dan) Mote, Jr., are chair and vice chair, respectively, of the National Research Council.

The Transportation Research Board is one of six major divisions of the National Research Council. The mission of the Transportation Research Board is to provide leadership in transportation innovation and progress through research and information exchange, conducted within a setting that is objective, interdisciplinary, and multimodal. The Board's varied activities annually engage about 7,000 engineers, scientists, and other transportation researchers and practitioners from the public and private sectors and academia, all of whom contribute their expertise in the public interest. The program is supported by state transportation departments, federal agencies including the component administrations of the U.S. Department of Transportation, and other organizations and individuals interested in the development of transportation. Www.TRB.org

www.national-academies.org 


\section{SHRP 2 STAFF}

Ann M. Brach, Director

Stephen J. Andrle, Deputy Director

Neil J. Pedersen, Deputy Director, Implementation and Communications

Cynthia Allen, Editor

Kenneth Campbell, Chief Program Officer, Safety

JoAnn Coleman, Senior Program Assistant, Capacity and Reliability

Eduardo Cusicanqui, Financial Officer

Richard Deering, Special Consultant, Safety Data Phase 1 Planning

Shantia Douglas, Senior Financial Assistant

Charles Fay, Senior Program Officer, Safety

Carol Ford, Senior Program Assistant, Renewal and Safety

Jo Allen Gause, Senior Program Officer, Capacity

James Hedlund, Special Consultant, Safety Coordination

Alyssa Hernandez, Reports Coordinator

Ralph Hessian, Special Consultant, Capacity and Reliability

Andy Horosko, Special Consultant, Safety Field Data Collection

William Hyman, Senior Program Officer, Reliability

Linda Mason, Communications Officer

Reena Mathews, Senior Program Officer, Capacity and Reliability

Matthew Miller, Program Officer, Capacity and Reliability

Michael Miller, Senior Program Assistant, Capacity and Reliability

David Plazak, Senior Program Officer, Capacity and Reliability

Rachel Taylor, Senior Editorial Assistant

Dean Trackman, Managing Editor

Connie Woldu, Administrative Coordinator

\section{ACKNOWLEDGMENTS}

This work was sponsored by the Federal Highway Administration in cooperation with the American Association of State Highway and Transportation Officials. It was conducted in the second Strategic Highway Research Program (SHRP 2), which is administered by the Transportation Research Board of the National Academies. The project was managed by Monica Starnes, Senior Program Officer for SHRP 2 Renewal.

The work on this project was led by a team from the Louis Berger Group, Inc., with Larry Pesesky, principalin-charge; Dane Ismart, principal investigator; and Deborah Matherly, project management coordinator.

The researchers and authors of this report are Dane Ismart, principal investigator, Orlando, Florida; Chris Huffman, co-principal investigator, Huffman Corridor Consulting, Lawrence, Kansas; Yi-Chang Chiu, co-principal investigator, Hong Zheng, and Eric Nava, University of Arizona, Tucson; Brian Wolshon and Vinay Dixit, co-principal investigator, Louisiana State University, Shreveport (Dixit is now with the University of South Wales, Sydney, Australia); Essam Radwan, Orlando, Florida; William Sampson, Tallahassee, Florida; Juan Morales, Juan Morales Associates, Reston, Virginia; Eric Perry, SAIC, Oak Ridge, Tennessee; Ed Bromage and Lindsay Bromage, E. J. Bromage LLC, Needham, Massachusetts.

The authors also acknowledge the contributions of the four groups of participants in the workshops and pilot studies that provided critical input and guidance as to needed content and focus early in the project development and to critical user-friendly features such as error checks and range messages once the software was near completion. 


\section{F O R E W O R D}

Monica A. Starnes, PhD, SHRP 2 Senior Program Officer, Renewal

As our highway infrastructure continues to age, there is the imperative need to renew the entire network while keeping it operational. Moreover, many highway corridors and regional networks are becoming ever more congested. As a result there is an increasing need to (1) examine various construction alternatives within those corridors and networks to determine the potential disruption and/or benefit that alternative renewal activities may have over time and (2) examine the effect of constructing multiple corridors concurrently or in sequence. Without an evaluation of the various construction alternatives during the program and project development process, negative impacts on the traveling public and the local communities may increase dramatically.

The research project that produced this report focused on answering the following related questions:

- How should highway reconstruction projects be set in space and time to minimize disruption to the traveling public, businesses, and adjacent communities?

- What is the traffic impact on the regional network when multiple corridors are being considered for renewal?

- Are there strategies that may minimize impacts on the corridor and/or regional network?

At the onset, literature reviews and evaluations of existing modeling tools were undertaken to define the path forward. Based on the existing needs and current gaps in modeling tools for highway networks, the research team set out to develop a modeling tool that would sequence programs of renewal projects in ways that maximize available resources, minimize disruptions to the traveling public and to adjacent land uses, and recognize political priorities. The team approached the objective by developing a tool that would first look at top-level analysis (sketch planning and macro-level analyses), but that would also have the capability to go down to the mesoscopic scale in order to provide a more detailed assessment of various construction strategies on the network.

The resulting product is the Work Zone Impact and Strategy Estimator (WISE) software. WISE can evaluate the impacts of various highway renewal strategies on a given networkstrategies using such means as day-night operations, innovative contracting, advanced maintenance of traffic plans, and public information programs. WISE can aid decision making by assessing reconstruction activity sequencing given limited resources and other constraints.

During the course of the project, the team held several focus group workshops with stakeholders to assess the intended capabilities and limitations of WISE. I personally want to thank Mr. Tom Kane, former executive director of the Des Moines Area Metropolitan Planning Organization (MPO), for his insightful observations and guidance during those workshops. His executive and strategic perspective of what MPOs are facing on a daily basis with regard to renewing their networks was invaluable to this project.

WISE has been developed as an open-source software that will be freely available to its users. I invite you to download it, try it, and if possible, adopt it within your organization. 
1 Executive Summary

4 Chapter 1 Background

$4 \quad$ Problem Statement and Research Objective

Evolution of the Project from One Task to the Next

6 Chapter 2 Study Approach

6 Summary

6 Literature Review

14 Identification of Management Strategies and Measures of Success

17 Analysis of Interviews

21 Correlation Analysis

Software Products and Applications

Summary of Major Findings from Interviews

Final Evaluation

Chapter 4 Conclusions and Recommendations Development of New Software Tools Workshops-Test of Software Tools Development of Training Materials Next Steps

\section{Glossary}

40 References

41 Appendix A Detailed Literature Review

69 Appendix B Results of the Software Evaluation

83 Appendix C Interview Matrix

87 Appendix D Work Zone Sequencing

93 Appendix E Traffic Tool Analysis 


\section{Executive Summary}

Program managers within state departments of transportation (DOTs) and metropolitan planning organizations (MPOs) are charged with distilling a chaotic universe of identified renewal needs into a logically sequenced program of manageable projects over a period of years. In addition, program managers are tasked with sequencing programs of projects in ways that maximize available resources, minimize disruptions to the traveling public and to adjacent land uses, and recognize political priorities. Over the past several years, substantial progress has been made in the areas of performance measurement, maintenance of traffic, mitigation of congestion in work zones, and alternative contracting and construction techniques. All of this progress has been made in studies and planning designed to minimize, manage, and mitigate disruption to traffic and commerce arising from renewal programs. However, in reality, performance measures are applied largely at the project level, and impacts are not analyzed at the program (mesoscopic) level. The products of this SHRP 2 Renewal project include both a software tool that will assist program managers at DOTs and MPOs in sequencing programs of projects and the training materials on applying that tool.

Task 1 of this project identified the universe of published works that may be applicable to the products of this project. During the Task 2 literature analysis, 135 documents from Task 1 were identified as being "highly relevant" to this project and were reviewed to extract critical information. In Tasks 3, 4, and 5, a similar data set was extracted through interviews with DOTs, MPOs, and other key stakeholders. This allowed the research team (the team) to draw comparisons and identify differences between theory and practice. The team observed that the gap between the state of the art (identified in Tasks 1 and 2) and the state of the practice (identified in Tasks 3 and 4) is quite pronounced and varies widely across the country (Figure ES.1).

Available software platforms with capabilities similar to those considered in this project were identified and analyzed. The lessons learned from the team's review of the various software platforms and packages provided an excellent basis and critical information for the proposed Work Zone Impact and Strategy Estimator (WISE) tool. As a result of software package reviews, the team concluded the following:

1. Microsimulation software packages that are part of software tool suites with multiple simulation models where one can migrate between macroscopic analysis and microscopic analysis (e.g., VISUM-VISSIM, TRANSCAD-TRANSMODELER, and CUBE) perform best for evaluating regional network impacts. TRANSIMS contains many analysis capabilities, but it is not user friendly.

2. Among the nonproprietary software programs, the Oregon software system performs extremely well. Also performing well are DynusT and QuickZone.

3. Establishing a database of strategies and alternatives that includes production rates and costs would enhance the capabilities of an evaluation tool for assessing work zone impacts on the existing traffic. 


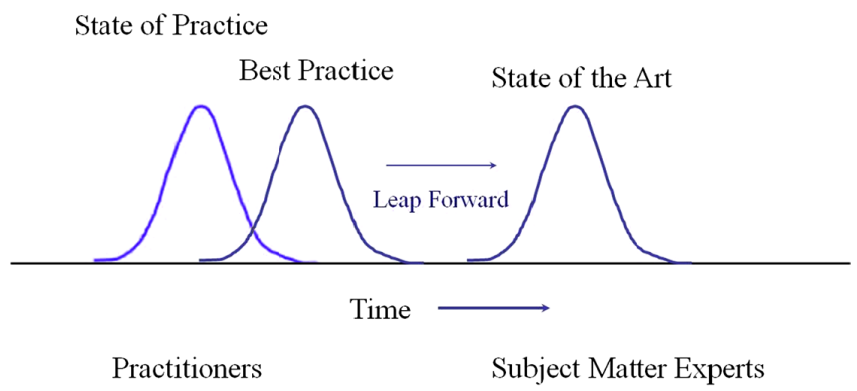

\section{Figure ES.1. Advancing the state of the practice to the state of the art by decreasing the implementation gap.}

4. Many of the software work zone packages are designed to evaluate impacts on the basis of the formation of queues, rather than the potential reduction of travel speeds.

5. Nonproprietary software packages are capable of playing an important role in evaluating and determining the impacts of maintenance of traffic strategies.

6. STEAM, LCCA, and QuickZone are the most robust estimation tools, and variants of these software packages are proposed to be used as part of WISE. DynusT's router capabilities are useful for studying the impact of intelligent transportation systems (ITS) and capacity changes.

7. SSAM is a useful tool for part of the microscopic evaluation and preliminary engineering and design phases of renewal projects, especially through its capability to estimate safety surrogate measures of performance.

8. Several state DOTs have developed their own spreadsheet-based tools. Although these tools use very coarse estimation procedures, they are easy to use and will serve as templates in the development of the WISE process.

9. WISE is extremely user-friendly, provides flexibility, and can accept inputs from pavement management systems (PMSs) and travel demand models (TDMs).

10. Most of the software, including QuickZone and STEAM, estimate the impacts of work zones as a snapshot comparison between the conditions before and after construction. On a gross level, this process estimates road user cost. The proposed WISE tool considers the excessive road user costs resulting from prolonged renewal activity.

The team identified commercially available software tools and evaluated several that were nonproprietary and easily available. The major thrust of this analysis focused on their potential to be utilized as components of the WISE tool envisioned under this project.

WISE is intended to be used to develop and sequence programs of renewal projects in the Planning Module and to assist in the application of the "Work Zone Rule" in the Operations Module. The WISE tool includes both Planning and Operations Modules and may be applied over large networks or upon complex corridors. The WISE software tool utilizes basic network geometry (link, node, and number of lanes) and basic traffic volume information from virtually any platform, once it is converted to a NEXTA format. Detailed instructions for conversion of network and traffic data into NEXTA formats are included in the WISE Users Guide provided as part of this project.

In the Planning Module, static assignment (user supplied or WISE supplied) is coupled with information regarding the planning characteristics of the program, a user-defined library of demand-based and duration-based renewal strategies, and basic project information. Optimal project sequencing is developed based on user and agency costs. Traffic diversion resulting from projects can be computed by WISE or entered manually by the user for each project. Later, in the Operations Module, the DynusT Dynamic Traffic Assignment platform computes a diversion of 
traffic based on more specific work zone information. The Planning and Operations Modules perform a "handshake" with one another seamlessly, and the user is not required to re-enter network or traffic data, although additional detail may be added any time it becomes available. The Graphical User Interface (GUI) includes a number of validation checks, as well as user support features.

The WISE software, as well as the Users Guide and Instructional Materials, will be further developed and improved in real-life pilot tests in Phase 4 of this project. The team envisions Phase 4 as an opportunity to fully test and improve the stability and rigor of the WISE code, to more completely develop and integrate the Users Guide and the training materials, and to develop business cases for the application of the WISE tool. Although the Users Guide and the Participants Workbook will remain stand-alone documents, the Users Guide is envisioned as a companion to the Participants Workbook, improving the user's comfort with WISE's functionality. 


\section{Background}

\section{Problem Statement and Research Objective}

The United States' highway system is aging and must be rebuilt while vehicles are driving on it, people are living next to it, and the nation relies on it for commerce and the connections important to safety, security, and quality of life. The need to develop a consistent, systematic approach to completing highway projects quickly and cost-effectively, while simultaneously minimizing, managing, and mitigating disruption to the community and adjacent land uses, is a critical element of highway renewal planning. Research in the renewal focus area, as part of the Second Strategic Highway Research Program (SHRP 2), addresses this need.

For more than a decade, the transportation planning community has been using the concept of corridor and network management to describe transportation status and future needs for transportation improvements. However, transportation corridor and network analyses at the planning stage may not consider the entirety of infrastructure needs within that corridor and/or network. The analysis may not consider the impact that different project sequencing or execution strategies can have on the overall budget, disruptions to the traveling public and on commerce, and impacts on the local community during execution of the program of improvements. Decisions made during planning may not fully recognize the redistribution of traffic due to restrictions or closures, adequately recognize or mitigate disruptions, and optimize opportunity costs in contractor overhead, materials costs, or interest burden on program funds. Planning decisions may also overlook opportunities to minimize both the number and duration of construction or maintenance interventions.

Program managers within state Departments of Transportation (DOTs) and Metropolitan Planning Organizations (MPOs) are charged with taking identified renewal needs and distilling them into a logically sequenced program of manageable projects over a multi-year period. During the past several years, substantial progress has been made in the areas of performance measurement, maintenance of traffic, mitigation of congestion in work zones, and alternative contracting and construction techniques-all designed to minimize, manage, and mitigate disruption to traffic and commerce arising from renewal programs.

However, much of the research and most of the practical applications exist at the project level. Tools and techniques to assist program managers in selecting and weighting performance measures and in sequencing a program of projects for corridors or networks so as to address impacts are essentially nonexistent. The following are the two objectives of this project:

1. To develop a software tool that will allow a program manager to assess the impacts of a renewal program and compare different sequencing scenarios of projects, in light of desired performance objectives. The intended purpose of this tool is to create a more fully informed decisionmaking process regarding program sequencing and allocation of limited resources.

2. To develop training in the use and application of this software tool and system.

\section{Evolution of the Project from One Task to the Next}

The team worked to incorporate lessons learned in each task into subsequent tasks. Work in Tasks 1 and 2 confirmed suspicions that the vast majority of the research done in this field has been at the project (microscopic) rather than the corridor or network (mesoscopic) level. However, the team learned that there has been work on the logical selection and weighting of performance measures that apply directly to this project. The team also found comparative analyses of commercially available simulation programs that have contributed to this project. 
In Tasks 3, 4, and 5, the team determined that a large amount of separation exists between the state of the art (literature) and the state of the practice. The wide variance in practices was surprising to team members, particularly with regard to interaction between DOTs and MPOs in development of renewal programs. It became apparent during the interview process that performance measures are considered at the project level, but rarely at the corridor or network level. Regional megaprojects that involve multiple jurisdictions provide useful insights into such considerations. The Maricopa County Association of Governments, Missouri DOT, and Virginia DOT have unusually strong mandates for management of renewal activities and performance measures, which provide useful insights into business models that are relevant to this project.

The work in Tasks 1 through 5 brought awareness and clarity to a number of issues. One unanticipated finding in the initial work plan is that DOTs, even in less urbanized areas of the country, depend heavily upon the outputs of their pavement management systems (PMSs) and bridge management systems (BMSs) to identify the "universe of need" for renewal programs. Significant resources have been committed to developing and maintaining these systems, and the products of this research must not call for abandoning, or even significantly modifying, those platforms. Interviewees also asserted that the software tool developed under this project must not require significant amounts of new data, lengthy or complex calibration procedures, or additional personnel.

These findings have driven the software evaluation taxonomy in Tasks 6 and 7 and have heavily influenced the development of the WISE tool in Phase 2 of this project. The initial workshops conducted under Task 12 provided approximately 25 key stakeholders the opportunity to verify the assumptions and the lessons learned by the team and assisted in the development of a much clearer vision of WISE (capabilities and requirements). These workshops served as the capstone for the requirements-gathering phase of this project, and they helped to ensure the development of useful and capable products. 


\section{Study Approach}

\section{Summary}

Task 1 of this project identified the universe of published works that may be applicable to the products of this project. The team availed itself of the Transportation Research Information Services (TRIS) database; the University of Arizona, Louisiana State University, and University of Central Florida library systems; the SHRP 2 projects currently under way; and the personal knowledge and experience of the team members. Articles, search results, data screenings, and notes were loaded to a SharePoint site, where they were collated into a consistent framework. There are also ongoing efforts such as the Federal Highway Administration (FHWA) Highways for Life program, whose purpose is to "accelerate the adoption of innovations and new technologies, thereby improving safety and highway quality while reducing congestion caused by construction.”

During the literature analysis, 135 documents were identified as being "highly relevant" to this project and were reviewed to extract critical information. In later tasks, a similar data set was extracted through interviews with DOTs, MPOs, and other key stakeholders. This allowed the team to make comparisons and identify differences between the literature and practice. The team attempted to contact representatives of all 50 state DOTs, as well as 22 MPOs, eight committees of the Transportation Research Board (TRB), and a number of other key stakeholders. The team completed interviews with 11 MPOs and 14 DOTs and made contact with all eight TRB committees that cover potentially relevant subject matter for the project.

Team members interviewed staff of DOTs and MPOs and other potential users of the products of this research in order to extract a "typical" business model for the sequencing of renewal programs and to develop an understanding of strategies and performance measures being utilized to mitigate work zones impacts. One of the principal purposes of this work was to compare and contrast actual practice with what was found in Task 2. Another objective was to begin documenting the requirements for the software product of this project and to review these requirements during the initial round of workshops described in Task 12 (described in this chapter's Software Products and Applications section). The primary purpose of Task 12 was to "check" the team's assumptions regarding the state of the practice and to identify what is necessary to create a useful and applicable software-based process. Task 12 was the capstone of the requirements-gathering stage of this project.

\section{Literature Review}

Team members leveraged their own knowledge with a review of literature in order to fully investigate state, local, and federal regulations, policies, and guidelines that can be actively used to minimize transportation disruption during renewal activities. This section details the process for reviewing materials and the conclusions reached. The full literature review is available in Appendix A.

\section{Structure of the Literature Review}

\section{Categories}

The information collated for this report is divided into several categories for more meaningful review of results. The categories include network-corridor analysis, modeling and software, performance measures, asset management, work zone control strategies, project delivery and procurement, innovative construction techniques, nighttime versus daytime work zones, other SHRP 2 projects and publications, and an "other" category. It is worth noting that a search was also made for software packages that may perform some of the functions desired for this project. Summary findings are presented, but the complete tools or software descriptions and analysis are more completely described in Appendix B. 


\section{Organization Within Each Category}

Each category is further subdivided to better define needed information. Most of these categories are self-explanatory, but the team believes that the following subcategories merit some explanation:

- Description: This field offers a brief narrative description of the publication, including a brief synopsis of the results.

- Relevance: This field provides the team's qualitative assessment of the relevance of the identified document to this project. Items of high relevance and some items of moderate relevance were further analyzed in subsequent tasks. While it is important to be aware of the items of low relevance, further analysis of those items is not intended at this time.

- Organization: References are first sorted by relevance (high, moderate, and low) and within each grouping alphabetically by title.

\section{Summary of Major Findings}

\section{Preponderance of Results: Focus on Project Level}

As anticipated, the team found vastly more publications on project and work zone congestion and impact and comparatively little from the corridor or network perspective. The relative absence of such information underscores the need for this work.

\section{Strengths and Weaknesses of Literature Findings Among Major Categories}

It is interesting that searches based upon keywords such as performance measure, asset management, and modeling (particularly econometric modeling) netted many of the same publications. While it is possible to have one publication truly applicable to more than one search category, the team was concerned that multiple indexing may mean that the category of the work is unclear. The team therefore used its judgment to assign a paper or source to a single category deemed most relevant. Another element is the fact that important sources of information, such as FHWA's Highways for LIFE Innovator publication and the National Highway Institute (NHI) Innovations webinar series are constantly injecting new, potentially relevant materials into the mix. The possibility that the findings under this search had become outdated prior to completion of the project cannot be ignored.

\section{Major Findings by Category}

\section{Network-Corridor Analysis}

The majority of the network-level literature analysis focuses on project management systems (PMSs) and decision criteria for replacement or repair. Network-level optimization techniques have been developed and tested in Arizona (AZNOS) (Wang, Zaniewski, and Delton 1994), Saskatchewan, Canada (Gerke, Dewald, and Gerbrandt 1998), and Hungary (Gaspar Jr. 1994), with a variety of tools introduced to aid decision making. Tools include budget allocation (Salem district), analysis of construction productivity (CA4PRS; Lee 2000, 2002), network scheduling tools such as URMS (Chen, Weissmann, Dossey, and Hudson 1993), case studies (FHWA 2004), and many theoretical studies. However, there is a gap in the literature and descriptions of methods to incorporate traffic impacts at the corridor or network level. Furthermore, the team looked for but could not document any systems to analyze scenarios for developing and programming many projects according to user-provided performance measures.

\section{Modeling and Software}

A major portion of the effort to compile the literature review was devoted to identifying and classifying software modeling tools that are commercially available, assessing their capabilities, and identifying gaps in those capabilities that this research must address. This analysis and review process forms the basis for Task 6 and is more fully developed in the interview- and findings-related sections of this chapter. Some of the initial findings are as follows.

The team determined that the scope and type of tools utilized to make decisions depend on the stage of the project's development. The type of tool used depends upon the available information and the decisions that need to be made. At the planning stage, the decisions are concerned with highlevel program requirements of renewal prioritization, schedule, budget, and contracts, while simultaneously considering traffic impact. Because of the limited data and information available at the planning stage regarding specific projects, sketch-planning analytical models are used, essentially to conduct preliminary traffic demand estimation, carry out impact analyses, and conduct asset management. Sketch-planning and analytical macroscopic models are appropriate to this level of analysis.

At the preliminary engineering and design phase, more information is available regarding the projects that have been selected and scheduled for construction, and a more detailed impact analysis can be conducted by testing demand management, traveler information, construction logistics, and safety strategies. A mesoscopic modeling approach is usually utilized at this stage to evaluate traffic impacts and safety. This type of modeling deals with a group of cars traveling through an arterial or grid network, or a combination of arterial and grid systems. The advantage of this approach is the ability to carry the assessment to a lower resolution without compromising the network geometric and control attributes. 
At the construction stage, even more information and data are available. The analysis is site-specific and needs to evaluate traffic merging due to lane closings and other more sitespecific characteristics of maintenance of traffic strategies. This usually requires a microscopic analysis. Table 2.1 presents the various software tools available for work zone analysis, classified by scope and use.

The scope of this project specifically focuses on the renewal of corridors and networks and assessment of the impact of work zones on the performance of these types of facilities. It is fairly clear that our efforts will be focused on the top level (sketch planning and macro-level analyses) with the ability to go one level down to carry out a more detailed evaluation of the system (mesoscopic-scale modeling) with a remote possibility for the need to go down to the microscopic level.

\section{Performance MeAsures}

Putting the keywords "performance measures" into a transportation search database yields hundreds of results. Like the network-corridor analysis search, the vast majority of the relevant publications focus on the project level. Within the project level, the major focus is on the single performance measure of safety. Reports regarding the analysis of work zones for safety and delay have been documented, as have reports of the use of ITS for real-time driver information as a delay mitigation tool.

Although these are important works, and safety and delay are two of the most obvious performance measures, there are reports and works that discuss many other performance measures. The team reviewed other literature on transportation system performance measures (including econometric considerations such as cost of delay), land use performance measures (including transportation-related measures like maintenance of market area), and customer service performance measures (e.g., availability of alternate routes through and access to zones of construction).

The 2008 FHWA Work Zone Self Assessment report states that a few states use inputs from independent contractors or contractor associations to provide construction process input to reduce impacts of work zones. Even fewer states consider the resources of the contractor in the designing of the traffic management plan and scheduling. There is an identified need to develop performance measures to evaluate the contractor's past performance in following the contractual agreements $(\mathrm{A}+\mathrm{B}$ or I/D, etc.) and the inclusion of the contractor's opinions early in the planning process.

The team sought publications regarding best practices for incorporating performance measures of renewal projects into system and corridor program development and management, but they were difficult to find. However, the SHRP 2 C02 Performance Measurement Framework for Highway Capacity Decision Making report was recently completed, and it was incorporated in the team's review subsequent to the initial submittal of the literature review. The report includes nonrecurring systems performance measurements as part of its framework and is highly relevant in establishing performance measures for the renewal process.

\section{Asset Management}

Like the keywords "performance measures," the keywords "asset management" also produced a myriad of results. In refining the universe of preliminary results, 16 publications were located with high to moderate relevance to this project. Publications such as NCHRP Report 545 (Cambridge Systematics, PB Consult, and System Metrics Group 2005) and the 2009 work of Sharma et al., Developing a Traffic Closure Integrated Linear Schedule for Highway Rehabilitation Projects (Sharma, McIntyre, Gao, and Nguyen 2009) hold significant promise to add value to this project.

The team also looked for works that consider transportation system assets (publicly held assets), business and going concern assets (privately held assets), and customer assets (time management and lost productivity), but none could be documented.

\section{WORK ZONE CONTROL STRATEGIES}

Literature on various work zone strategies offers a wide array of information from planning strategies to work zone operations throughout the nation. The literature is focused on three main areas: ITS, speed management, and incident management in work zones. The bulk of the literature discusses how states have adopted ITS to help maintain mobility safely through work zones.

These ITS strategies and practices include automated work zone information, dynamic lane merge, lane closure strategies, and speed management in various states including Michigan, North Carolina, Minnesota, Texas, Illinois, Arizona, Ohio, and Washington. The literature also discusses state-specific lane closure and demand management practices in Colorado, Vermont, Oklahoma, California, Indiana, Missouri, and Wiscon$\sin$. Another area of focus in the literature is on controlling speeds throughout work zones to keep speed differentials down to limit the number of crashes. Law enforcement plays an important role in work zones and is useful in ensuring the safety of the workers by providing escorts, slowing down vehicles, and supervising safety on the site. The last area of focus is on incident management practices to help alleviate traffic congestion-related crashes in work zones.

\section{Project Delivery and Procurement}

The literature in this area focuses on contracting strategies for agencies. The reports address innovative contracting techniques such as best value, $\mathrm{A}+\mathrm{B}$ (cost-plus-time) bidding, and incentive/disincentive (I/D) provisions, and how agencies can best manage risk associated with multiple techniques. 
Table 2.1. Classification of Software Analysis Tools for Potential Use in Analyzing Work Zones

\begin{tabular}{|c|c|c|c|c|c|c|c|c|}
\hline & $\begin{array}{l}\text { Integration with } \\
\text { Travel Demand } \\
\text { Models }\end{array}$ & $\begin{array}{c}\text { Analytic } \\
\text { Deterministic } \\
\text { Traffic Impact } \\
\text { Tools }\end{array}$ & $\begin{array}{l}\text { Traffic Signal } \\
\text { Optimization }\end{array}$ & Life-cycle Cost & Safety Impact & $\begin{array}{l}\text { Corridor-Network } \\
\text { Level Operational } \\
\text { Analysis }\end{array}$ & $\begin{array}{l}\text { Environmental } \\
\text { Impact }\end{array}$ & Traffic Impact \\
\hline $\begin{array}{l}\text { Sketch } \\
\text { planning }\end{array}$ & IDAS, QuickZone & $\begin{array}{l}\text { IDAS, QuickZone, } \\
\text { Ohio DOT } \\
\text { Spreadsheet }\end{array}$ & $\mathrm{n} / \mathrm{a}$ & PEAT, QuickZone & $\begin{array}{l}\text { Quadro, Road } \\
\text { Safety Risk } \\
\text { Manager }\end{array}$ & QuickZone & $\mathrm{n} / \mathrm{a}$ & IDAS, QuickZone \\
\hline $\begin{array}{l}\text { Analytical: } \\
\text { Macroscopic }\end{array}$ & MicroBENCOST & $\begin{array}{l}\text { MicroBENCOST, } \\
\text { HCS, LCCA, } \\
\text { Quewz, } \\
\text { CA4PRS }\end{array}$ & $\mathrm{HCS}$ & $\begin{array}{l}\text { LCCA, CA4PRS, } \\
\text { EAROMAR, } \\
\text { HDM-4 }\end{array}$ & Safety Analyst & Cube Voyager & $\begin{array}{l}\text { StratBENCOST, } \\
\text { MicroBENCOST, } \\
\text { LCCA, CA4PRS, } \\
\text { EAROMAR, } \\
\text { HDM-4 }\end{array}$ & $\begin{array}{c}\text { LCCA, HCS } \\
\text { CA4PRS }\end{array}$ \\
\hline $\begin{array}{l}\text { Simulation: } \\
\text { Mesoscopic }\end{array}$ & $\begin{array}{l}\text { DYNASMART, } \\
\text { DynusT, } \\
\text { DYNAMEQ, } \\
\text { VISTA, } \\
\text { TransModeler, } \\
\text { Cube Avenue, } \\
\text { AIMSUN }\end{array}$ & $\mathrm{n} / \mathrm{a}$ & $n / a$ & $\mathrm{n} / \mathrm{a}$ & SafeNet & $\begin{array}{l}\text { DYNASMART, } \\
\text { DynusT, } \\
\text { DYNAMEQ, } \\
\text { VISTA, } \\
\text { TransModeler, } \\
\text { Cube Avenue, } \\
\text { AIMSUN }\end{array}$ & $\begin{array}{l}\text { DYNASMART, } \\
\text { DynusT, } \\
\text { DYNAMEQ, } \\
\text { TransModeler, } \\
\text { Cube Avenue, } \\
\text { AIMSUN }\end{array}$ & $\begin{array}{l}\text { DYNASMART, } \\
\text { DynusT, } \\
\text { DYNAMEQ, } \\
\text { VISTA, } \\
\text { TransModeler, } \\
\text { Cube Avenue, } \\
\text { AIMSUN }\end{array}$ \\
\hline $\begin{array}{l}\text { Simulation: } \\
\text { Microscopic }\end{array}$ & $\begin{array}{l}\text { VISSIM, } \\
\text { TransModeler }\end{array}$ & $\mathrm{n} / \mathrm{a}$ & $\begin{array}{l}\text { Synchro, } \\
\text { TRANSYT-7F }\end{array}$ & $\mathrm{n} / \mathrm{a}$ & $\begin{array}{l}\text { Surrogate Safety } \\
\text { Assessment } \\
\text { tool }\end{array}$ & $\begin{array}{l}\text { VISSIM, CORSIM, } \\
\text { Paramics, } \\
\text { TransModeler }\end{array}$ & $\begin{array}{l}\text { VISSIM, CORSIM, } \\
\text { Paramics, } \\
\text { TransModeler, } \\
\text { TRANSYT-7F, } \\
\text { Synchro, } \\
\text { SimTraffic }\end{array}$ & $\begin{array}{l}\text { VISSIM, } \\
\text { CORSIM, } \\
\text { Paramics, } \\
\text { TransModeler }\end{array}$ \\
\hline
\end{tabular}


Other techniques consider factors including contract duration, schedule, quality, safety, public satisfaction, and cost.

These methods are explained to help agencies make efficient, informed decisions, especially when faced with increasing public demand and reduced staff numbers. The literature considers not only long-term construction projects, but also maintenance contracts for the life of the facility.

\section{InNOVATIVE CONSTRUCTION TECHNIQUES}

The literature in this area discusses fabrication methods for concrete and asphalt pavement reconstruction that reduce rehabilitation time. Several research papers in this area describe the use of new materials (concrete for reinforcement, asphalt, steel, and composites) and methodologies for rapid rehab projects such as methods to reduce on-site fabrication. There is also a body of knowledge that discusses rapid testing methods that are nondestructive. These methods help to reduce the impact on traffic during the testing period. There is a need to be able to evaluate the cost and quality of these construction methods and to assess modular techniques for evaluating performance and durability.

New robotic technologies are being developed such as robots to produce material, construct highways, and test for quality. There also are new vehicles and equipment available that reduce the time to set up work zones, are safer for the workers, and reduce overall construction time.

\section{NightTIMe Versus Daytime Work Zones}

The majority of the literature on nighttime versus daytime work zones focuses on several key areas: operations, crash rates, management practices, work zone crash reporting, night work alternatives, safety strategies, planning, setup and removal, and noise.

The recurring themes in most of this literature are the safety aspect of nighttime work zones and safety practices for nighttime work zones. A few pieces of literature focus on recommended practices to safely set up and maintain work zones.

The literature makes recommendations on how to plan, execute, operate, and take down a work zone during nighttime operations. A few of the studies concentrate on crash rate comparisons of nighttime versus daytime work zones. One study details how to determine crash rates for both nighttime and daytime work zones along with guidance on developing management practices that promote safety and mobility.

\section{Other SHRP 2 Projects ANd Publications}

Based on discussions with the principal investigators and SHRP 2 staff, three SHRP 2 projects have been identified as "highly relevant," meaning that (a) the topic is closely related to the current project and is expected to have significant impact on SHRP 2 R11 as it moves forward and (b) the project is far enough along to contribute meaningful results to the SHRP 2 R11 work effort during the study time frame. The team has sought close coordination with three principal SHRP 2 projects: SHRP 2 C02, L03, and L11. SHRP 2 C02, initiated in February 2007 and completed, is A System-Based Performance Measurement Framework for Highway Capacity Decision Making. The report, which has been completed and released, includes an inventory of performance measures for nonrecurring congestion in work zones; relevant measures were incorporated in this project. SHRP 2 L03 is nearing completion and details the strategic implications for dealing with nonrecurring events that may apply to work zones. The team monitored this closely. Likewise, SHRP 2 L11 is complete; its evaluation of performance measures and strategies was applicable to Task 2 and further tasks.

Many of the other SHRP 2 projects that on the surface seem relevant began almost simultaneously with this project. These include SHRP 2 C10A, C10B, C07, and L05. Project L11, Evaluating Alternative Operations Strategies to Improve Travel Time Reliability, was near completion at the project onset and was highly relevant to identifying strategies pertinent to the renewal process. Although several of the SHRP 2 projects are listed as low to low or moderate relevance, because of the timing, the team continued to monitor them, maintaining up-to-date information and keeping in contact with the principal investigators.

\section{OTHER}

This category provides a collection of procedures, policies, guidelines, presentations, and case studies that describe some of the more comprehensive approaches employed in work zone planning and management. These include procedures on cost estimation and decision making, as well as policies that address lane closures, liability, and safety. There are also case studies that focus on life-cycle benefits and costs, as well as detailing a major bridge reconstruction project. The information included herein provides a broad perspective of how different agencies have approached the many facets of work zone situations covering a variety of overarching issues.

\section{Approach}

Team members examined the 135 "highly relevant" literature sources identified in Task 1 in order to extract strategies and performance measures being used to mitigate work zone impacts. This information was compiled into a matrix and provided a snapshot of the strategies being used and how or whether their various results are being measured. This information contributed to the activities of Tasks 3 and 4, during which interviews elicited comparable information from actual practice. This process bridged the gaps encountered between the established literature and actual practice and facilitated analysis and comparisons between theory and practice. The 
interviews continued to inform and expand the matrix started under this task. The full matrix created under this task is available in Appendix C. The elements identified in each literature source were as follows:

- Study purpose (planning, design, or operations);

- Study focus (project, corridor, or network);

- Strategies identified (to mitigate impacts of renewal activities);

- Performance measures identified (to measure various strategies); and

- Comments.

\section{Study Purpose (Planning, Design, or Operations)}

Many (if not most) transportation activities can be classified into three principal categories of activity: planning, design, and operations. Therefore, the first element identified in each reviewed document was the principal activity category of the study. It is possible for some of the documents to apply to all three categories of activities.

\section{Study Focus (Project, Corridor, or Network)}

The focus of this research project is on the management and mitigation of impacts to the traveling public and to nearby land uses at the corridor and network levels. Each document from Task 1 was reviewed to determine its primary focus. The purpose of SHRP $2 \mathrm{R} 11$ is to develop tools to assist the decision-making process in the sequencing of multiple projects over a corridor or network, rather than at the project level.

\section{Strategies Identified (to Mitigate Impacts of Renewal Activities)}

Six strategies are identified in the $\mathrm{R} 11$ renewal project request for proposals (RFP) and in the work plan:

- Total versus partial shutdown;

- Incentive/disincentive;

- Short-duration closures;

- Grouping nontraffic tasks;

- Programming by element; and

- Constructability versus project delivery.

The review matrix that was developed as part of Task 2 focused on the six strategies. However, the literature review identified many other strategies that could have potential applicability to this project, including

- Early, late, or dynamic lane merge;

- Work zone speed control and calming;
- Work zone ITS, warning lights, or markings; and

- Pavement programming, design, and materials.

These strategies appear to be primarily useful in project or operations applications that are not the focus of R11. Although these strategies primarily have an effect at the project level, if they are instituted on a regional basis for renewal projects, then they may have a cumulative impact at the network level.

An additional strategy identified in the literature review is public involvement and information. There are many examples of well-conducted and extensive public involvement and informational programs to advise the public of major renewal construction efforts that resulted in significant traffic diversions and improved traffic network flow. The impact of public information programs on reducing the impacts of the renewal program is included as part of the evaluation tools developed for this study.

\section{Performance Measures}

Performance measures can take on a practically infinite variety of forms. The 135 reports reviewed revealed a huge variety of potential performance measures, which the team banded into 16 categories in the matrix:

- Maximize Cash Flow (from federal funds);

- Maximize Overall System Performance Rating;

- Minimize Delays (high peak-hour flows);

- Ensure Accessibility (to sensitive land uses);

- Minimize Daytime Disruption (commercial areas);

- Minimize Nighttime Noise (residential areas);

- Maximize Accessibility (partial closure);

- Minimize Length of Disruption (full closure);

- Minimize Delivery Time to Final Product;

- Maximize Safety and Mobility;

- Maximize Efficiency, Capacity, and Quality of Flow;

- Manage Life-Cycle Costs;

- Maximize Production Rates;

- Maximize Customer Satisfaction;

- Maximize Asset Value and System Condition; and

- Minimize Environmental Impacts.

These strategies and performance measures from the literature were compared to the strategies and performance measures extracted from the stakeholder interviews conducted under Tasks 3 and 4 and then integrated and resolved in Chapter 3 of this report. Some of these performance measures are quantitative such as delay in seconds or hours or noise measures in decibels, while others are qualitative in nature such as customer satisfaction. Development of a topology of performance measures that allows maximum flexibility to the user of the tool, yet remains statistically 
reliable, is a particular challenge. The team is especially mindful of gaps between literature and practice in performance measurement, because this understanding shaped the development of the tool.

\section{Comments}

This section allows the reader to quickly reference the key points in the critical documents that relate to specific strategies or measures.

\section{Summary of Major Findings}

The team made every effort in the literature review to identify only those documents that were not focused on operations of work zones within a project. The 135 documents identified as "highly relevant" focused on planning and/or design at the network and/or corridor levels. However, the team found that approximately 94 of the documents identified as "highly relevant" (69.6\%) included information on work zone operations, including 53 documents (39.2\%) focused primarily, if not solely, upon work zone operations.

Although the matrix (Appendix C) identifies strategies named in the RFP and the work plan, the literature is replete with a number of other strategies that appear to be more applicable to the operation of project-specific work zones. Although these strategies are not included in the matrix, the team has considered them carefully in the development of the research products, especially when they may be applied as part of systematic application for all renewal projects.

Other strategies, such as public involvement and information, are very applicable to this project and require additional attention in the research products. Providing information
Table 2.2. Amount of Literature That Looks at the Different Project Stages and Their Scale

\begin{tabular}{|l|c|c|c|}
\hline & Network & Corridor & Project \\
\hline Planning & 24 & 30 & 42 \\
\hline Design & 4 & 8 & 11 \\
\hline Operations & 2 & 12 & 33 \\
\hline
\end{tabular}

Note: Some of the 135 documents fit into multiple categories.

about alternate routes and schedules has proven useful in mitigating and managing the impacts of renewal programs.

From the literature review, the team found that work zone impacts were not typically assessed at a network or corridor level, but rather were evaluated on the basis of whether or not they were significant. However, the strategies that were applied to mitigate these significant impacts were implemented at a corridor or network level and are therefore relevant to this study. Most network-level strategies were evaluated and considered at the planning level (as depicted in Table 2.2 and Figure 2.1), while corridor-level strategies were evaluated and considered either in the planning level or design level of implementation.

Several documents identified in Task 1 with specific regard to performance measures contribute significantly to this project. One of the most significant documents is the SHRP 2 C02 report, Performance Measurement Framework for Highway Capacity Decision Making. SHRP 2 C02 states that the decision to add capacity "typically engages many stakeholders in an array of policy, planning, fiscal, public involvement, and engineering activities that are staged over a lengthy time period and involve consideration of many factors ranging from environmental impacts to safety concerns." The team believes

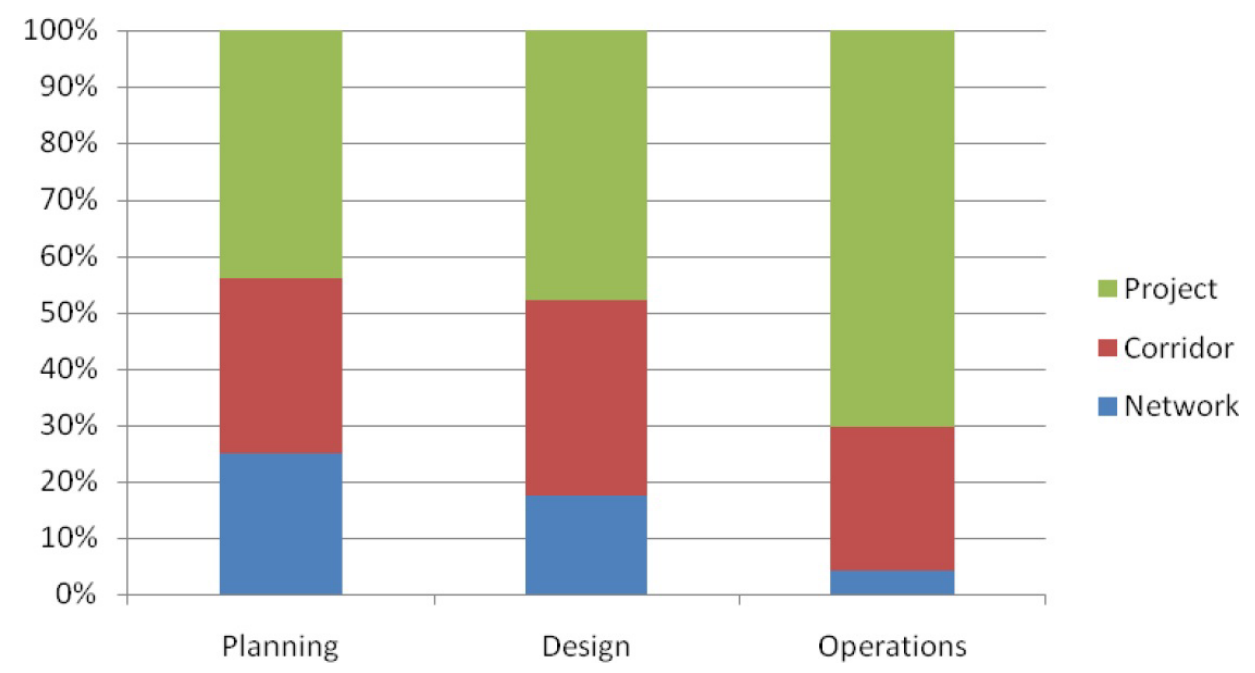

Figure 2.1. Percentage of studies at different levels (project, corridor, network) during different stages of program delivery. 
that the work completed under SHRP $2 \mathrm{C} 02$ provides a very useful foundation and framework for performance measure selection under renewal programs and that much of the work is transferable.

Another significant finding in the performance measures arena (discussed more fully later in this chapter) is that a survey of state DOTs found that most of the attention in performance measurement applies to operations of work zones within specific projects. However, several states have undertaken significant work in performance measurement outside of the project level, and these states have received considerable attention in Tasks 3 and 4. These states include, but are not limited to, Minnesota, Missouri, Florida, Arizona, and California.

Of the 135 reviewed documents, 10 were identified as directly relevant to subsequent tasks of this project. These 10 key documents are briefly summarized here.

- Identifying the Appropriate Contract Types for Highway Maintenance and Rehabilitation Projects on the Basis of Project Characteristics. Traditional versus innovative contracts are analyzed in this report using simultaneous equation models. This work will provide useful insights into cost-benefit decision making with regard to innovative contracting. Use of calendar completion versus working day completion contracts as well as incentive or disincentive clauses in contracts shifts some of the risk of late completion onto the contractor, but agencies may pay a significant premium for such a shift. A technique to evaluate the costbenefit of such contracting options will be important to the tools developed under this project.

- Developing a Realistic-Prototyping Road User Costs Evaluation Tool for FDOT. This report, prepared for the Florida
Department of Transportation, outlines a software tool developed to calculate RUCs for various scenarios using readily available data. Estimating RUCs for adverse travel is an especially important element of this project, as are the scenario analysis capabilities presented in this report. This report will also likely tie into the evaluation of innovative contracting options discussed in the previous entry.

- Scheduling of Lane Closures Using Genetic Algorithms with Traffic Assignments and Distributed Simulations. This report presents findings of scheduling of lane closures, particularly the redistribution of traffic across a network as a result of such closures. The genetic algorithms presented will provide useful insights into sequencing multiple lane closures so that traffic is not redistributed onto already bottlenecked portions of the network.

- Roads Software Tools (HDM-4). The glossary of this document contains a definition of program management that the team believes could frame a great deal of the work on subsequent tasks. Table 2.3 presents useful guidance in "brightlining" application of program management assisted in the decision-tree development for the tool developed in Phase 2 of this project.

- Analytical Tools for Asset Management, NCHRP 545. This report provides a very useful framework for evaluating trade-offs in decision-making processes in transportation program development. Evaluation of trade-offs is critical to selection and weighting of performance measures. This is the foundation of development of scenario analysis and comparison models.

- Tool Summary Sheet, NCHRP 20-57. This sheet summarizes capabilities and limitations of 11 modeling software packages - including HDM-4, HERS/ST, and STEAM — that

Table 2.3. Scope of Road Management Functions

\begin{tabular}{|l|l|l|l|l|}
\hline $\begin{array}{l}\text { Management } \\
\text { Function }\end{array}$ & \multicolumn{1}{|c|}{$\begin{array}{c}\text { Nature and Scope of } \\
\text { Actions Involved }\end{array}$} & Network Coverage & \multicolumn{1}{|c|}{$\begin{array}{c}\text { Time } \\
\text { Horizon }\end{array}$} & $\begin{array}{c}\text { Management Staff } \\
\text { Concerned }\end{array}$ \\
\hline Planning & $\begin{array}{l}\text { - Defining road standards that } \\
\text { optimize the use of resources } \\
\text { Determining the budget required } \\
\text { to support defined standards }\end{array}$ & Entire network & $\begin{array}{c}\text { Long term } \\
\text { (strategic) }\end{array}$ & $\begin{array}{c}\text { Senior managers and } \\
\text { policy makers }\end{array}$ \\
\hline Programming & $\begin{array}{l}\text { Determining the work program that } \\
\text { can be undertaken within the } \\
\text { budgetary period }\end{array}$ & $\begin{array}{c}\text { Sections likely to need } \\
\text { treatment }\end{array}$ & $\begin{array}{c}\text { Medium term } \\
\text { (tactical) }\end{array}$ & $\begin{array}{c}\text { Managers and } \\
\text { budget holders }\end{array}$ \\
\hline Preparation & $\begin{array}{l}\text { - Design of works } \\
\text { Preparation and issue of contract } \\
\text { or work instruction }\end{array}$ & $\begin{array}{c}\text { Contract of work } \\
\text { packages }\end{array}$ & Budget year & $\begin{array}{c}\text { Engineers, technical } \\
\text { and contracts } \\
\text { staff }\end{array}$ \\
\hline Operations & $\begin{array}{l}\text { Undertaking tasks as part of works } \\
\text { activity }\end{array}$ & $\begin{array}{c}\text { Subsections where works } \\
\text { are taking place }\end{array}$ & Ongoing & Works supervisors \\
\hline
\end{tabular}

Source: Road Software Tools: Highway Development and Management Model (HDM-4; http://www.worldbank.org/transport/roads/rd_tools/ hdm4.htm). 
evaluate econometric and other parameters. This sheet assisted in the identification and evaluation of commercially available software products called for under Task 5 of this project.

- Lane Closure Policy Development, Enforcement, and Exceptions: A Survey of Seven State Transportation Agencies. This report provides a very useful summary of performance measure selection by several state DOTs and was useful in developing the performance measure topology, as part of the software tool for this project. It also helped identify interview candidates for Tasks 3 and 4.

- Selection and Evaluation of Alternative Contracting Methods to Accelerate Project Completion. The report presents a methodology for identifying, evaluating, and selecting alternative contracting procedures. The strategy of minimizing timeto-delivery is specifically identified. This work assisted in developing scenario indexing capabilities during Phase 2 of the R11 project, which are described in Chapter 3 of this report.

- Guidance for Cost Estimation and Management for Highway Projects During Planning, Programming and Preconstruction, NCHRP 574. This report was very helpful in building scenario analysis capabilities for the software product in Phase 2 of this project. Analyzing complex variables of material costs, labor costs, and right-of-way costs with imprecise or incomplete information at the planning and program management stages is inherently difficult and uncertain. WISE can evaluate and compare the overall systemwide user and agency costs resulting from the implementation of the renewal program. This evaluation can include changes in completion time, innovative contracting, and updating of estimated project costs.

- SHRP 2 C02: Performance Measurement Framework for Highway Capacity Decision Making. This related SHRP 2 project report provides a decision-making framework with regard to performance measures that will help to formulate the topology of performance measures as well as to guide in the selection of performance measures for the R11 project.

\section{Other Work Relevant to This Task}

\section{SHRP 2 Capacity Project C01 and Capacity Project $\mathrm{CO} 2$}

SHRP 2 Capacity Project C01 (A Framework for Collaborative Decision Making on Additions to Highway Capacity) and Capacity Project C02 (A System-Based Performance Measurement Framework for Highway Capacity Decision Making) will develop and eventually implement a web-based resource and highway decision-making web-based tool. The results of R11 and the subsequent tools for evaluating the impacts of renewal projects should be incorporated and integrated within web-based resources established for the $\mathrm{C} 01$ and C02 SHRP 2 projects.

\section{FHWA Work Zone Mobility and Safety Program}

A review of the materials created by the FHWA Work Zone Mobility and Safety Program was conducted specifically on the development of strategies and performance measures for work zones. Pertinent and important information identified by the FHWA program includes these areas:

- Performance measurement development;

- Work zone traffic management guidance and examplesstate-developed traffic management resources (New Jersey, Ohio, Oregon, and Pennsylvania DOTs);

- Peer-to-peer program for work zones; and

- Work zone mobility and safety self-assessments (includes an assessment by the state DOTs on the integration of work zone mobility and safety as part of the planning process).

\section{Identification of Management Strategies and Measures of Success}

\section{General}

In Tasks 3, 4, and 5, team members interviewed staff from DOTs and MPOs and other potential users of the products of this research in order to extract a "typical" business model for the sequencing of renewal programs and to develop an understanding of strategies and performance measures being utilized to mitigate work zone impacts. One of the principal purposes of this work was to compare and contrast actual practice with what was found in the literature in Task 2 . Another was to begin the documentation of requirements for the software product of this project. That work was finalized in the initial round of workshops described in Task 12, the culmination of the requirements-gathering stage of this project. The summary of the interviews appears as a matrix in Appendix C.

\section{Approach}

The team attempted to contact representatives of all 50 state DOTs, as well as 22 MPOs, eight TRB committees, and a number of other key stakeholders. Interviews were completed with staff from 11 MPOs and 14 DOTs, and contact was made with all eight TRB committees that cover subject matter that is potentially relevant to the project. The interview matrix 
depicts the same information derived in Task 2, but also tracks what is happening in practice. (See Appendix C for complete interview matrices.) The matrix categories are summarized in the following list.

- Interviewee Focus (planning, design, or operations);

- Performance Measure Focus (project, corridor, or network);

- Strategies Identified (to mitigate impacts of renewal activities);

- Performance Measures Identified (to measure various strategies); and

- Comments.

\section{Interviewee Focus (Planning, Design, or Operations)}

The team found it particularly challenging to identify the most appropriate person within a DOT or MPO to interview. The team began with the designated SHRP 2 point-of-contact and asked for assistance in identifying appropriate interviewees. In many cases, team members were handed off to various members of the organization. The team found that the responses to questions varied considerably based upon the interviewee's perspective (i.e., planning, design, or operations). The team found that, for the renewal process, it is possible for programming and impact analysis activities to take place within the planning, design, or operations functions of an organization, or in some combination of those functions.

\section{Performance Measure Focus: Project, Corridor, or Network (the Where, When, and How)}

The focus of this research project is on the management and mitigation of impacts to the traveling public and to nearby land uses at the corridor and network levels. Therefore, the interviewees were queried to determine the primary focus of strategies and performance measures for renewal activities within their organizations. Based on the team's interviews, renewal impacts are only rarely quantified at the network level, and if so, then they are usually considered as part of the planning functions. Rather, work zone impacts are most commonly quantified at the project level during the design and operations phases. There is considerable opportunity to expand consideration of impacts to land uses and to redistribute traffic onto alternate routes, both at the corridor and network levels, as part of the planning functions. There also is opportunity to increase coordination among projects, in order to consider and mitigate corridor and network impacts through staging and other strategies during the design and operation phases.

Figure 2.2 illustrates the program stages and the respective analyses that take place during them. Scheduling and transportation management plans (TMPs) dramatically increase in detail and precision, with performance measures and software tools compressing from the macro to the micro scale, as planning moves toward construction. As identified in the team's interviews, linkage and ownership of the "meso" scale of analysis are rare.

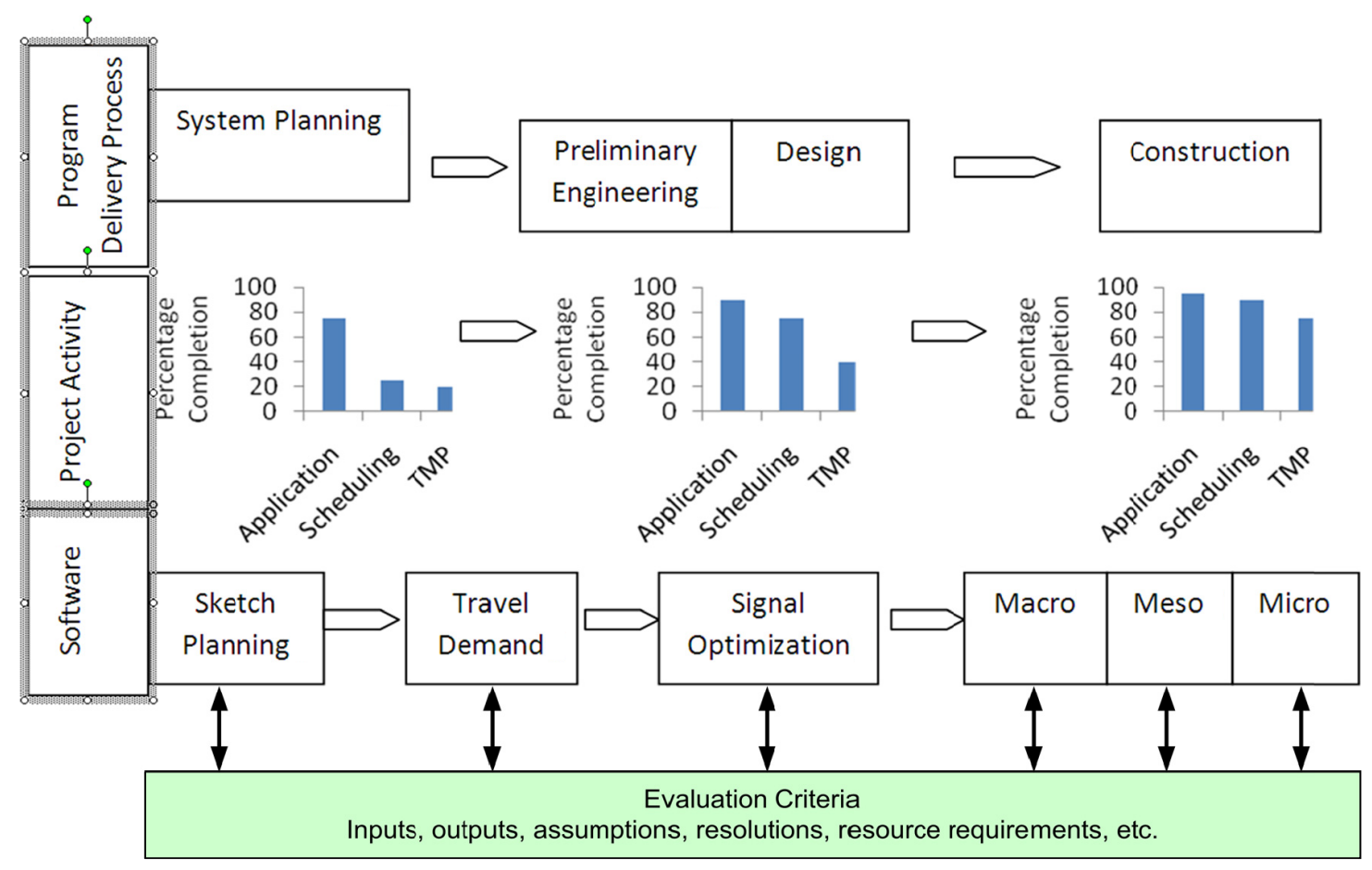

Figure 2.2. Program stages and analysis. 
Based on the interviews, most design and construction evaluation focuses on microscopic congestion issues and associated performance measures at the project level, while most congestion management evaluation looks at longerrange major projects, such that neither evaluation may interact with the other on a regular basis. The MPO, in effect, looks into the future through a telescope, while the construction manager looks at the near term through a microscope, and only in a few cases has the state or MPO identified a corridor manager or someone to look at the near-term, broader picture in a systematic fashion. In those rare cases in which someone is charged with looking at the broader picture, that person typically does not have a tool to help them make sense of the very different perspectives of the planner and the construction manager, not to mention the different objectives, strategies, performance measurements, and tools that are likely to be employed to achieve those objectives.

The evolving understanding has resulted in recognition of one of the key challenges of this project: to bridge the gap between the MPO planner's understanding of the regional Transportation Improvement Program, regional networks, and congestion (and associated mitigation tools and strategies) and the DOT program and construction managers' intimate understanding of the PMS and BMS, along with construction techniques and work zone strategies. The team worked to help bridge that gap with tools and information sources that are familiar to representatives of both entities (MPOs and DOTs), in order to arrive at interpretations of congestion and mitigation strategies that are understandable and acceptable to both groups during the planning, design, and construction stages.

Figure 2.3 identifies the three major model types appropriate for renewal. As noted in the interviews, MPOs typically employ regional "macro" models of networks and traffic volumes to forecast regional air quality, as well as congestion and broader traffic flow, with appropriate performance measures. Design, construction, and program managers typically employ microscopic models to simulate options for intersection design, signal timing, and minor reroutings. The gap between the micro and macro scales is best met via mesoscopic models. In most cases, tools and models that easily migrate information and data from one platform to another, without extensive learning curves and data assimilation, are not available.

\section{Strategies Identified (to Mitigate Impacts of Renewal Activities)}

Six strategies were identified in the RFP and in the work plan:

- Total versus partial closures;

- Incentive/disincentive;

- Short-duration closures;

- Grouping nontraffic tasks;

- Programming by element; and

- Constructability versus project delivery.

The review matrix that was developed as part of these tasks focused on the six strategies. However, the interviews also identified other project-based, construction-oriented strategies that could have potential applicability to this project:

- Early, late, or dynamic lane merge;

- Work zone speed management;

- Work zone ITS;

- Warning lights or markings;

- Pavement programming, design, and materials;

- Daytime or nighttime work;

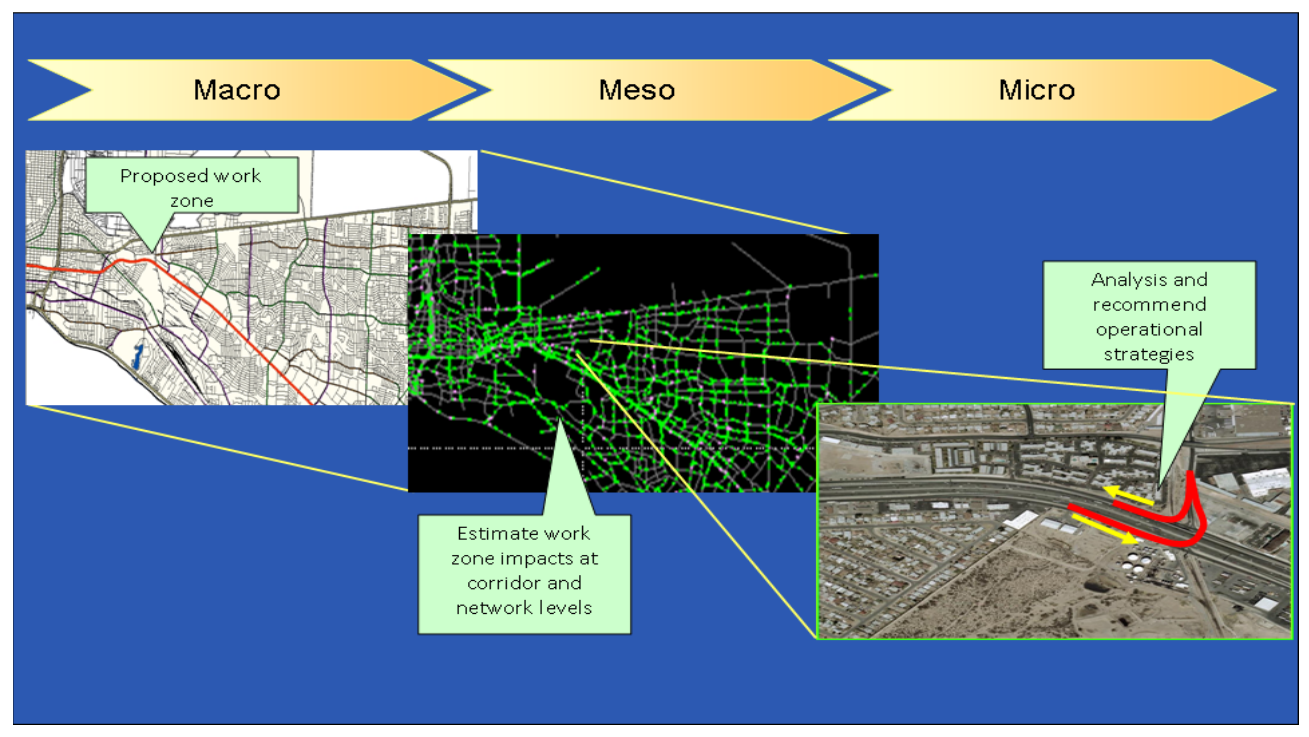

Figure 2.3. Software model types relevant to renewal projects. 
- Scheduling around critical events or sensitive land uses (e.g., schools, hospitals); and

- Improving parallel roads.

These strategies appear to be primarily useful in project or operations applications, which are not the focus of this project. Although these strategies primarily have an effect at the project level, if they are instituted on a regional basis for renewal projects, then they may have a cumulative impact at the network level.

Broader TMP strategies that are more typical for MPO regional planning, but also have applications for network and corridor congestion, include congestion-management techniques such as public information and travel demand management programs (e.g., ridesharing, telecommuting, staggered work hours). There are many examples of well-conducted and extensive public involvement and informational programs advising the public of major renewal construction efforts that have resulted in significant traffic diversions and improved traffic network flow. The impacts of a TMP, including public information programs on reducing the impacts of the renewal program, are included as part of the congestion management process (CMP) evaluation tools provided for this study.

\section{Performance Measures to Evaluate Various Strengths (the What)}

Performance measures can take on a practically infinite variety of forms. The customers and stakeholders interviewed revealed a huge variety of potential performance measures. To assist in comparing these performance measures to those found in the literature, the measures are banded into 16 categories in the matrix:

- Maximize Cash Flow (from federal funds);

- Maximize Overall System Performance Rating;

- Minimize Delays (high peak-hour flows);

- Ensure Accessibility (to sensitive land uses);

- Minimize Daytime Disruption (commercial areas);

- Minimize Nighttime Noise (residential areas);

- Maximize Accessibility (partial closure);

- Minimize Length of Disruption (full closure);

- Minimize Delivery Time to Final Product;

- Maximize Safety and Mobility (including worker safety);

- Maximize Efficiency, Capacity, and Quality of Flow (impacts to levels of service, LOS);

- Manage Life-Cycle Costs;

- Maximize Production Rates;

- Maximize Customer Satisfaction (stakeholder or community support);

- Maximize Asset Value and System Condition; and

- Minimize Environmental Impacts (air quality impacts).
While some of these performance measures can be quantified (e.g., delay in seconds or hours or noise measures in decibels), others are qualitative in nature, such as customer satisfaction. Developing a topology of performance measures that allows maximum flexibility to the user of the tool, while remaining statistically reliable, is a particular challenge. The team was mindful of gaps between literature and practice in performance measurement, because this understanding shaped the development of the tool.

\section{Analysis of Interviews}

The interviews provided major insights that guided the development of the workshops and will influence the development of the tool(s) in subsequent tasks. Highlights from the interviews that relate to potential users of the tool(s) and to specific strategies or measures are summarized in this section.

\section{Definitions}

The first step to understanding how MPOs and DOTs analyze the corridor and network level impacts of renewal processes was to understand how they define "networks" and "corridors."

DOT and MPO staff provided various definitions of networks that can be broadly classified as

- Funding jurisdiction: For example, in Hawaii, state roads are considered to be part of a different network than county roads and federal aid roads.

- Functional classification of roadways: Several transportation agencies identified a network as composed of roadways that have higher functional classifications, such as arterials, significant corridors, beltways, and interstates.

- All hard transportation assets: Such assets are a "system" of transportation nodes and links that includes roadways, transit, rail, and all other transportation assets.

The definitions associated with corridors were better formed than for networks and were associated with the following:

- Sections of roadway that had more than one segment or one intersection; and

- Primary routes such as interstates or major arterials.

It is important to note that a majority of the interviewees indicated that they consider work zone impacts and that they conduct analyses as part of the planning processes at the network level. Further examination, however, indicates that analysis of pavement condition (PMS) is typically conducted as part of the planning functions, and analysis of work zone impacts arising from air quality requirements is typically held out as a quantitative network-level analysis. These network-level analyses and work zone impacts are distinct from analyses of the 


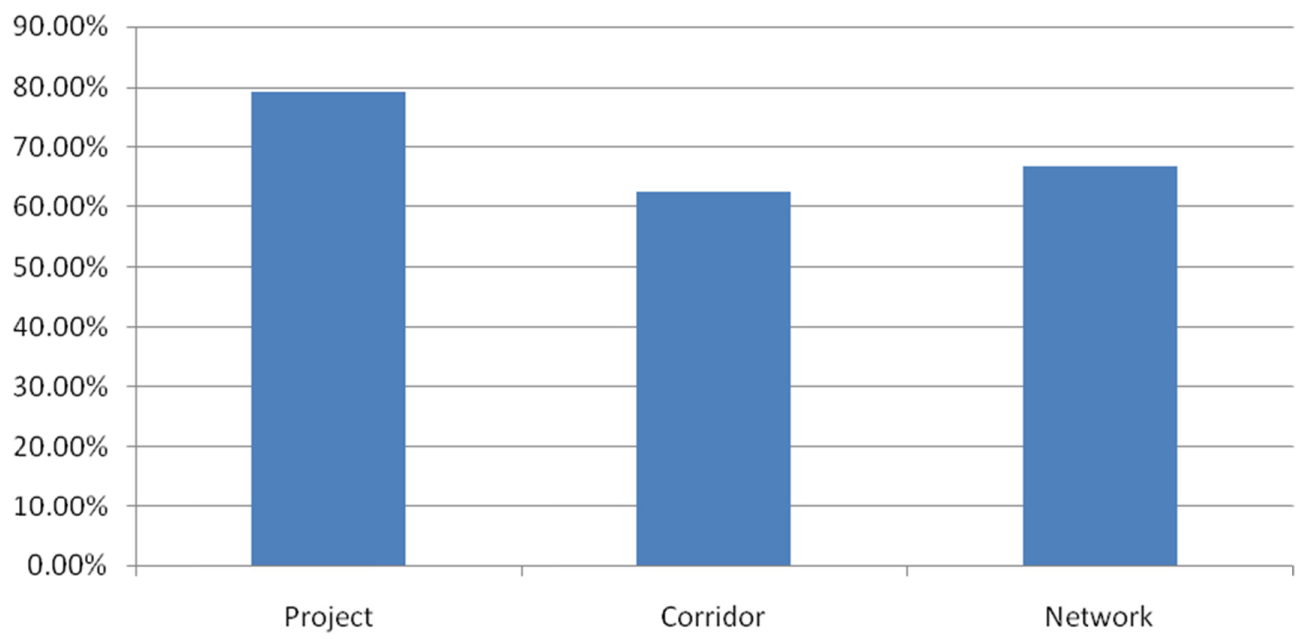

Figure 2.4. Percentage of interviewees using PMS, BMS, or CMP as their understanding of project, corridor, or network analysis.

impacts of sequencing programs of projects across corridors and networks.

An analysis of the interview data set indicates that the majority of the work zone impact assessments are made at a project level, followed by the network and then finally the corridor level. This is shown in Figure 2.4. Some interviewees picked more than one assessment level for their jurisdictions.

Although a significant number of interviewees indicated that they were conducting network-level impact assessment, the network-level analyses were limited to pavement analysis systems and considered only budget and schedules. It was only in the case of highly urbanized MPOs, like Saint Louis and Houston, where more elaborate network-level impact analyses on traffic from renewal activities were addressed.

For work zones, congestion, safety, and delay (road user costs) are commonly analyzed. Figure 2.5 shows the percentage of interviewees who use PMS, BMS, or CMP for project evaluation. Very few analyze the impact of work zones at all stages of their projects. A majority of interviewees consider work zone impact at the planning stage as a by-product of traffic impact assessment within the limited context of air quality macroscopic planning. However, this level of assessment does not generate the depth of analysis that is sought for construction staging and coordination of decisions across a network. Fewer agencies and MPOs conduct analysis in the operational and design phases, and these analyses are usually at the microscopic project level.

\section{Performance Measures}

Based on the literature review, the team identified several key performance measures and strategies. The team also

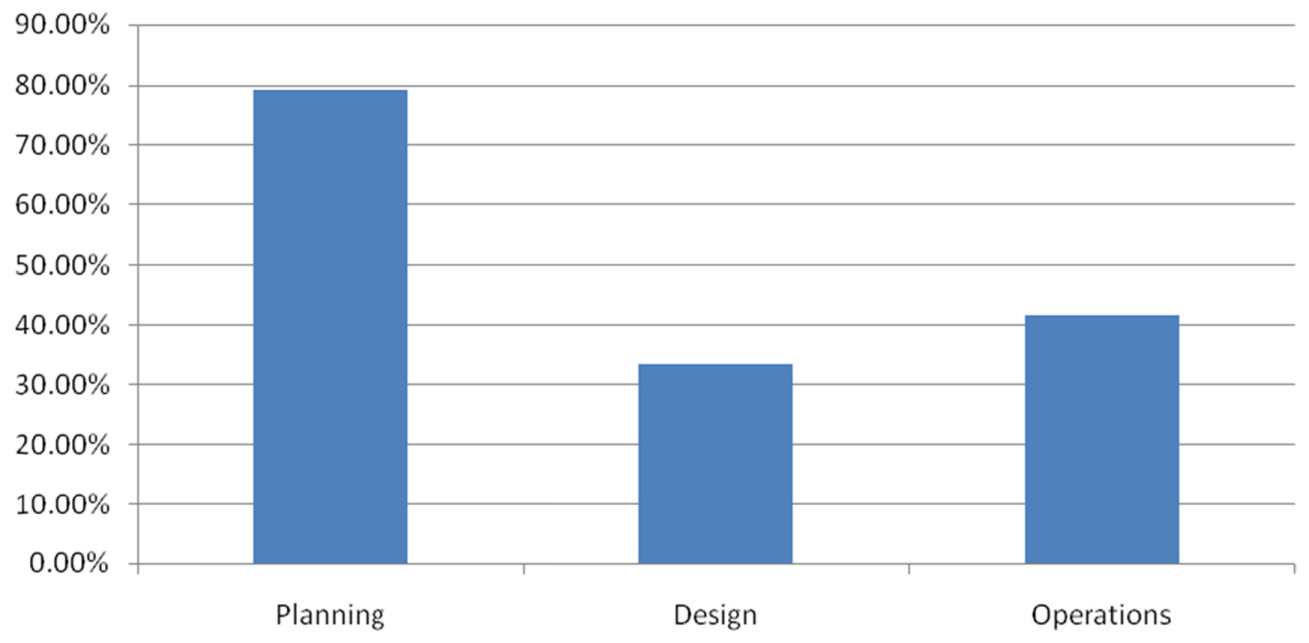

Figure 2.5. Percentage of interviewees considering work zones as a by-product of macroscopic air quality analysis at planning stage and maintenance-of-traffic microscopic impacts at design and operations stages. 
conducted additional analysis to better understand which performance measures are used to evaluate renewal impacts, which strategies are implemented to reduce these impacts, and at which stage of the project and at what level are these impacts considered. Consistent with the findings on levels of analysis (Figure 2.4) and planning stages (Figure 2.5), performance measures were primarily identified within the contexts of the PMS, BMS, and CMP and are not specifically applicable to renewal coordination as required for this project.

Safety and mobility were found to be the most used performance measures, with almost $83 \%$ of the respondents utilizing them. Minimizing daytime disruptions was the second most used measure, followed by minimizing delay, customer satisfaction, maximizing overall system performance (pavement), quality of flow, partial closure, maximizing accessibility, and maximizing cash flow. The summary results are shown in Figure 2.6.

Other identified performance measures can be broadly classified as qualitative and quantitative.

\section{Qualitative}

- Population data to evaluate equity;

- Equity and political considerations, which play an important role in project selection; and

- Impact on neighborhoods (Delaware Valley Regional Planning Commission).

\section{Quantitative}

- Safety (e.g., crash rates, fatality rate, exposure rate);

- Freight flow (e.g., heavy truck percentage, origins, and destinations);

- Budget;

- Schedule;

- Number of work change orders;

- Population data to evaluate equity;

- Road user costs (e.g., anywhere between $\$ 7$ to $\$ 22$ for value of time per hour of delay per person were observed);

- Pavement condition surveys; and

- Facility level of service.

\section{Strategies}

\section{Main Strategies}

The three main strategies employed were short-duration closures, incentive/disincentive contracts, and total versus partial closures (see Figure 2.7).

In the figure, the strategy "grouping nontraffic tasks" refers to coordinating items such as utility relocations, sidewalk replacements, and lighting or other enhancements to minimize impacts from potential multiple (noncoordinated) disruptions.

The strategy "programming by element" involves consideration of multiple facilities or special jurisdictions within the

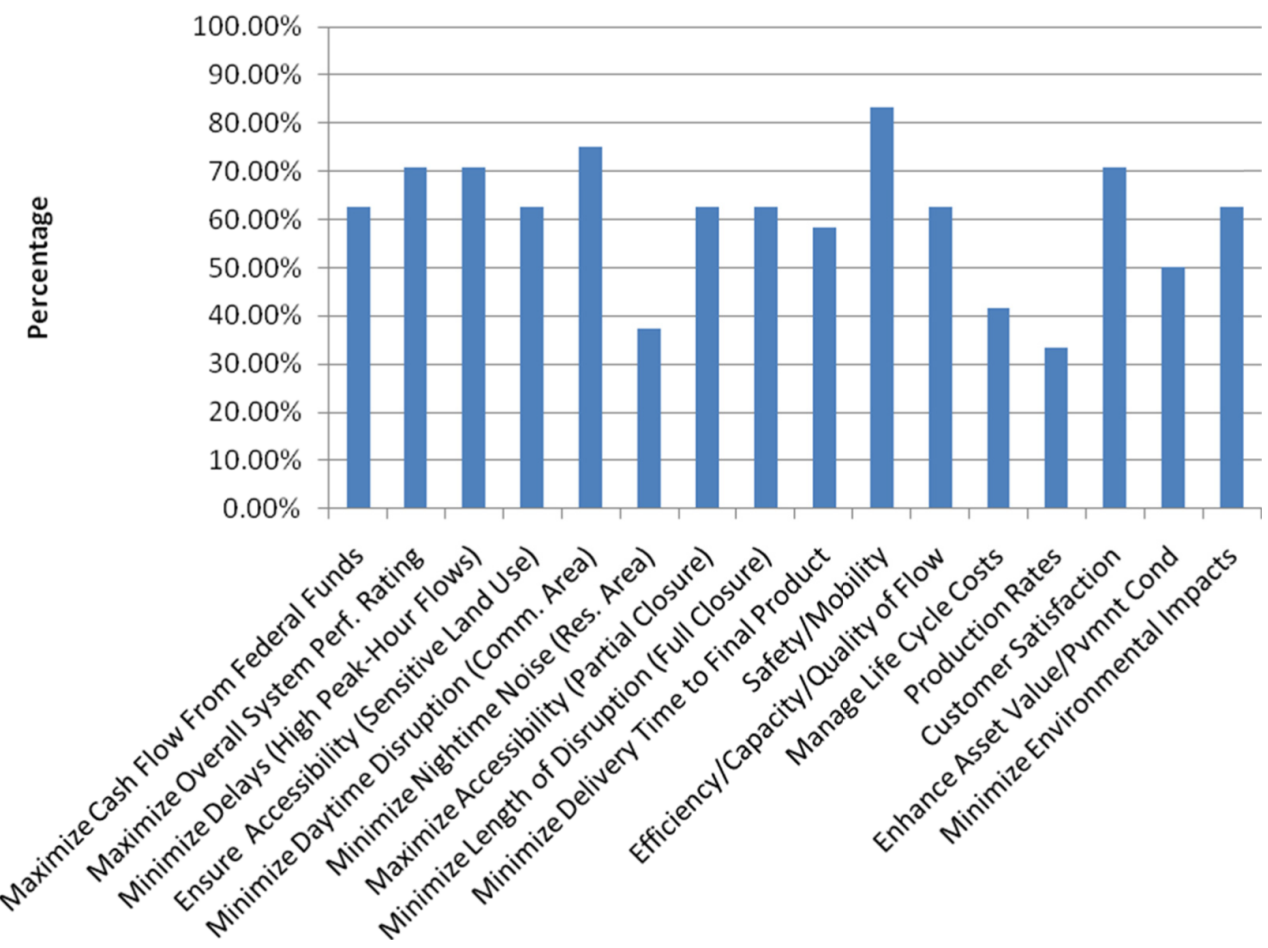

Figure 2.6. Percentage of interviewees using performance measures within the contexts of PMS, BMS, or CMP. 


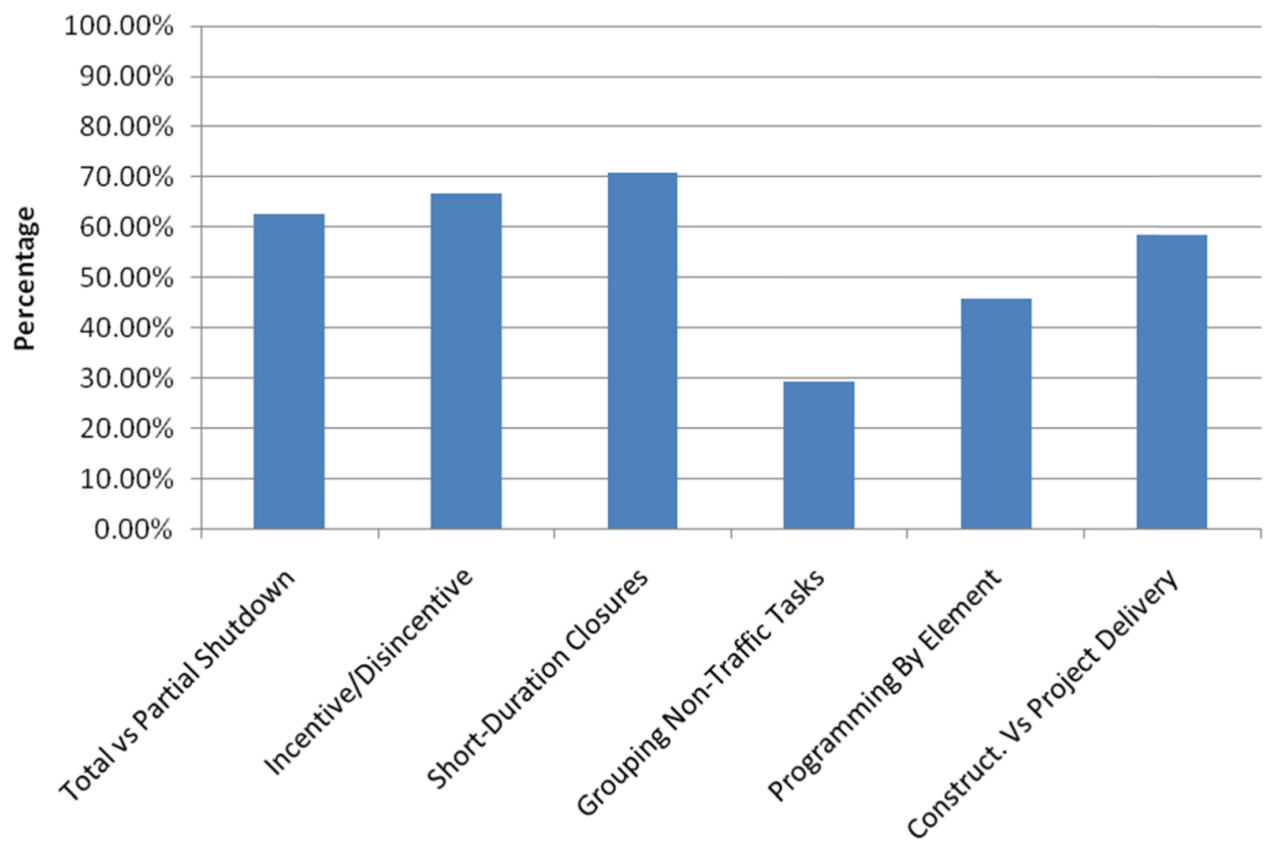

Figure 2.7. Percentage of interviewees utilizing various strategies to minimize impact on traffic from renewal within the context of PMS, BMS and/or CMP.

sequencing of a program. For instance, disruption of a major corridor may be preceded by improvement to secondary (relief) routes, which may be preceded by addressing critical "choke points." A renewal of a freeway or principal arterial corridor may be preceded by improvement of one or more relief routes that will accommodate diversion of traffic from the primary corridor. Improvement of these relief routes may be preceded by improvement of river bridges or railroad crossings that include special jurisdictional consideration. Interviewees who program by element report much stronger correlations to the performance measures.

The strategy "constructability versus project delivery" refers to complex projects and programs that may require several design iterations to ensure that they can be built as envisioned. Also, it may be critical that the construction sequencing proposed by a complex project or program is the most efficient sequencing available, given other restrictions. Project delivery may dictate that speed is of the essence in program delivery, and consultants and contractors are much more responsible for figuring out sequencing. Constructability and project delivery are not mutually exclusive, but they are somewhat contradictory, and most DOTs and MPOs attempt to strike a balance between the two.

\section{Other Strategies}

Strategies revealed in the interviews are summarized and organized in the following subsections by the phase in which they are primarily introduced.

\section{Initial Planning and Prioritization}

- Innovative prioritization methods:

o Voter initiative sets priorities (Maricopa).

- Cooperative basis is used for development of transportation plan (Pima, TRANSCOM): Prioritize based on levels, wherein critical projects are built first based on funding availability, and the next level is built when funds are available. This provides more flexibility in accommodating renewal impacts (Greater AZ), and these decisions are based on traffic counts and safety.

- Project scale: It was found that the cost and schedule of a project influence whether or not the impacts of the renewal process will be considered. For instance, work zone impact analysis cannot be justified for a short-term and low-cost work zone (e.g., 1 day). In order to evaluate such projects, several DOTs have set up thresholds, which are rules of thumb and vary by state. For example, in Texas, thresholds are based on the functional classification of roadways; usually, any construction on an interstate requires a work zone impact analysis. In Wisconsin, it is based on a ratio of 10:1 for the cost of the project to the road user costs.

- Coordination and communication among agencies to analyze the impact of construction on a network or corridor: These were found to be a significant issue, especially between DOTs and MPOs. Some agencies identified that having "hard asset" communication infrastructures, such as optical fiber connections between traffic management 
centers, and data sharing provides for easy sharing of information and analyzing impacts of renewal across jurisdictions. This was found to be true in Texas and Missouri.

\section{Planning Through Construction}

- Context sensitive solutions (CSS): The public and decision makers are involved in the planning process in the early stages of the program. Public hearings and other strategies are considered.

- Public involvement: Webinars significantly increased the participation in Missouri.

- Other transportation demand management such as car pools, transit, and flexible work hours.

- Public-private partnership: These overcome financing hurdles but are complicated by additional stakeholders and other constraints.

PlanNing, Design, and Operations

- Construct in parallel to build temporary road relief: This improves capacity on parallel routes (e.g., DVRPC, UTAH).

- Utilizing opportunity to improve parallel arterial routes.

- Grouping projects in one location to minimize disruptions. This was observed in Colorado.

\section{Design and Operations Phase}

- Organizational structure: In most states the performance assessment by project managers is based on maintaining the budget and project schedule and having minimal change orders. This form of assessment disconnects project managers and the users from the performance measures used to evaluate overall project management. Any kind of renewal impact analysis (probably) increases the cost of the project and affects the sequencing, which may explain why analysis of renewal impacts has not been incorporated seamlessly into the decision-making process. In order to overcome the discontinuity problem, the Missouri DOT has assigned Corridor Managers to coordinate and evaluate impacts along a corridor more efficiently.

\section{Operations Phase}

- Congestion management using ITS deployment such as dynamic lane merges.

- Dynamic message signs and websites to inform drivers about alternative routes, travel times, and so forth, which are employed to manage demand.

- Contractor-conscious planning, which can promote the safety of workers.

\section{Correlation Analysis}

It is particularly interesting to note that despite the generally subjective nature of interviews there is considerable correlation between strategies and performance measures.
Details of the correlation analysis are provided in Tables 2.4, 2.5, and 2.6.

The team observed that the strongest correlations are attributable to jurisdictions that program by element, which allows planners to consider many more factors when analyzing individual elements. (See discussion of Figure 2.7 for a more complete description of programming by element.) The team also found that agencies that conducted network-level impact assessments usually conducted them at the planning stage.

The correlation analyses indicate that the performance measures commonly used to evaluate various strategies focus on the program level and consider maximizing cash flow, overall system performance, accessibility through partial closures, safety and mobility, managing life-cycle costs, minimizing delivery time, and achieving customer satisfaction. See Tables 2.4, 2.5, and 2.6.

At a network level, one of the critical performance measures is minimizing delivery time, which is most likely a product of the project sequencing from the PMS. Customer satisfaction is also utilized as a performance measure during network-level analyses. At a corridor level, minimizing disruption time is a significant performance measure.

Minimizing the length of disruption and maximizing accessibility are the performance measures consistently used for all strategies that were studied. Most performance measures are utilized in the programming-by-element strategy, which could be attributed to the ability of planners to consider many more factors when analyzing individual elements, as opposed to multiple elements together.

\section{Software Products and Applications}

The interviews revealed that many software products are being used for project impact analysis, such as STEAM, HERS, CA4PRS, AIMSUN, and MITSUM. In addition, several DOTs, MPOs, and Councils of Governments (e.g., in New York, New Jersey, Utah, Iowa, and Oregon) have developed their own Microsoft Excel-based spreadsheet tools. One of the key findings was that, because most of the decisions are made at the planning level and in conjunction with PMS, the number of inputs required by the tool should be minimal. For this reason, several of the existing models are not being utilized. The interviews also revealed that any proposed work zone impact tools should require minimal inputs and should recognize that the amount of information available is limited, such as the known effects of incentive/disincentive contracts on traffic delays.

Design and operations engineers are also using macro travel demand models used by planners and micro-simulations. Because there appears to be a general lack of ownership for 
Table 2.4. Correlation Matrix Between the Strategies Identified and the Performance Measures

\begin{tabular}{|c|c|c|c|c|c|c|c|c|c|c|c|c|c|c|c|c|}
\hline & $\begin{array}{c}\text { Maximize } \\
\text { Cash } \\
\text { Flow } \\
\text { From } \\
\text { Federal } \\
\text { Funds }\end{array}$ & $\begin{array}{l}\text { Maximize } \\
\text { Overall } \\
\text { System } \\
\text { Perf. } \\
\text { Rating }\end{array}$ & $\begin{array}{c}\text { Minimize } \\
\text { Delays } \\
\text { (High } \\
\text { Peak- } \\
\text { Hour } \\
\text { Flows) }\end{array}$ & $\begin{array}{c}\text { Ensure } \\
\text { Accessibility } \\
\text { (Sensitive } \\
\text { Land Use) }\end{array}$ & $\begin{array}{l}\text { Minimize } \\
\text { Daytime } \\
\text { Disruption } \\
\text { (Comm. } \\
\text { Area) }\end{array}$ & $\begin{array}{c}\text { Minimize } \\
\text { Nighttime } \\
\text { Noise } \\
\text { (Res. } \\
\text { Area) }\end{array}$ & $\begin{array}{c}\text { Maximize } \\
\text { Accessibility } \\
\text { (Partial } \\
\text { Closure) }\end{array}$ & $\begin{array}{c}\text { Minimize } \\
\text { Length of } \\
\text { Disruption } \\
\text { (Full } \\
\text { Closure) }\end{array}$ & $\begin{array}{c}\text { Minimize } \\
\text { Delivery } \\
\text { Time to } \\
\text { Final } \\
\text { Product }\end{array}$ & $\begin{array}{l}\text { Safety/ } \\
\text { Mobility }\end{array}$ & $\begin{array}{c}\text { Efficiency/ } \\
\text { Capacity } \\
\text { Quality of } \\
\text { Flow }\end{array}$ & $\begin{array}{l}\text { Manage } \\
\text { Life } \\
\text { Cycle } \\
\text { Costs }\end{array}$ & $\begin{array}{l}\text { Production } \\
\text { Rates }\end{array}$ & $\begin{array}{l}\text { Customer } \\
\text { Satisfaction }\end{array}$ & $\begin{array}{c}\text { Enhance } \\
\text { Asset } \\
\text { Value/ } \\
\text { Pvmnt } \\
\text { Cond }\end{array}$ & $\begin{array}{l}\text { Minimize } \\
\text { Environmental } \\
\text { Impacts }\end{array}$ \\
\hline $\begin{array}{l}\text { Total vs Partial } \\
\text { Shutdown }\end{array}$ & 0.67 & 0.49 & 0.32 & 0.50 & 0.22 & 0.10 & 0.50 & 0.50 & 0.43 & 0.41 & 0.17 & 0.33 & 0.39 & 0.49 & 0.29 & 0.50 \\
\hline $\begin{array}{l}\text { Incentive/ } \\
\text { Disincentive }\end{array}$ & 0.41 & 0.38 & 0.38 & 0.41 & 0.27 & 0.04 & 0.41 & 0.41 & 0.34 & 0.25 & 0.07 & 0.10 & 0.16 & 0.38 & 0.22 & 0.41 \\
\hline $\begin{array}{l}\text { Short-Duration } \\
\text { Closures }\end{array}$ & 0.49 & 0.45 & 0.26 & 0.49 & 0.34 & 0.16 & 0.49 & 0.49 & 0.43 & 0.30 & 0.14 & 0.21 & 0.29 & 0.63 & 0.32 & 0.49 \\
\hline $\begin{array}{l}\text { Grouping Non- } \\
\text { Traffic Tasks }\end{array}$ & 0.33 & 0.24 & 0.24 & 0.15 & -0.01 & 0.27 & 0.51 & 0.51 & 0.01 & 0.31 & 0.51 & 0.40 & 0.34 & 0.24 & 0.29 & 0.15 \\
\hline $\begin{array}{l}\text { Programming } \\
\text { By Element }\end{array}$ & 0.56 & 0.44 & 0.26 & 0.39 & 0.01 & 0.51 & 0.72 & 0.72 & 0.30 & 0.44 & 0.72 & 0.76 & 0.60 & 0.44 & 0.60 & 0.39 \\
\hline $\begin{array}{l}\text { Constructability } \\
\text { versus } \\
\text { Project } \\
\text { Delivery }\end{array}$ & 0.43 & 0.43 & 0.26 & 0.43 & 0.17 & -0.01 & 0.43 & 0.43 & 0.35 & 0.36 & -0.07 & 0.07 & 0.09 & 0.43 & 0.21 & 0.43 \\
\hline Project & 0.69 & 0.62 & 0.22 & 0.50 & 0.07 & 0.23 & 0.50 & 0.50 & 0.45 & 0.66 & 0.31 & 0.46 & 0.39 & 0.62 & 0.35 & 0.50 \\
\hline Network & 0.33 & 0.32 & 0.32 & 0.33 & 0.04 & 0.27 & 0.17 & 0.33 & 0.43 & 0.41 & 0.33 & 0.17 & 0.39 & 0.49 & 0.13 & 0.33 \\
\hline Corridor & 0.07 & 0.20 & 0.38 & 0.24 & 0.09 & 0.39 & 0.07 & 0.41 & 0.34 & 0.04 & 0.24 & 0.10 & 0.34 & 0.20 & 0.22 & 0.24 \\
\hline Planning & 0.11 & 0.02 & 0.22 & 0.11 & 0.07 & 0.03 & -0.08 & -0.08 & 0.26 & -0.05 & 0.11 & -0.11 & 0.18 & 0.22 & -0.21 & 0.11 \\
\hline Design & -0.14 & -0.08 & -0.08 & -0.32 & -0.34 & -0.34 & -0.14 & 0.04 & -0.43 & 0.13 & 0.21 & -0.21 & -0.47 & -0.08 & -0.32 & -0.32 \\
\hline Operation & -0.17 & 0.04 & -0.14 & -0.33 & -0.22 & -0.10 & 0.00 & -0.17 & -0.26 & 0.00 & 0.00 & -0.17 & -0.39 & 0.04 & -0.13 & -0.33 \\
\hline
\end{tabular}

Note: The shading identifies correlations greater than 0.40 . 
Table 2.5. Correlation Between Stage and Scale of Project and Strategies

\begin{tabular}{|l|c|c|c|c|c|c|}
\hline & $\begin{array}{c}\text { Total vs Partial } \\
\text { Shutdown }\end{array}$ & $\begin{array}{c}\text { Incentive/ } \\
\text { Disincentive }\end{array}$ & $\begin{array}{c}\text { Short-Duration } \\
\text { Closures }\end{array}$ & $\begin{array}{c}\text { Grouping } \\
\text { Non-Traffic Tasks }\end{array}$ & $\begin{array}{c}\text { Programming } \\
\text { By Element }\end{array}$ & $\begin{array}{c}\text { Constructability vs } \\
\text { Project Delivery }\end{array}$ \\
\hline Project & 0.50 & 0.16 & 0.42 & 0.35 & 0.50 & 0.26 \\
\hline Network & 0.33 & 0.07 & 0.32 & 0.15 & 0.23 & 0.10 \\
\hline Corridor & 0.24 & 0.31 & 0.20 & 0.10 & 0.16 & 0.17 \\
\hline Planning & -0.08 & -0.03 & -0.18 & -0.07 & -0.07 & -0.31 \\
\hline Design & -0.14 & -0.20 & -0.08 & 0.15 & -0.09 & -0.08 \\
\hline Operation & -0.17 & -0.24 & 0.04 & -0.15 & -0.23 & 0.07 \\
\hline
\end{tabular}

Note: The shading identifies correlations greater than 0.40

Table 2.6. Correlation Between Stage of Project and Scale

\begin{tabular}{|l|c|c|c|}
\hline & Planning & Design & Operation \\
\hline Project & 0.12 & 0.18 & -0.11 \\
\hline Network & 0.50 & 0.04 & 0.00 \\
\hline Corridor & 0.16 & -0.20 & -0.07 \\
\hline
\end{tabular}

Note: The shading identifies correlation greater than 0.40 .

mesoscopic models, any mesoscopic model that is developed should minimize the number of inputs (to be as consistent as possible with existing systems such as BMS, PMS, and CMP) and should be targeted toward both groups (macroscopic planners and microscopic design and operations managers).

\section{Summary of Major Findings from Interviews}

1. The team found that responses from DOTs fell into three major bands:

- DOTs in highly urbanized areas (New York, Virginia, and New Jersey) place a great deal of emphasis on mitigation of impacts at the planning stage, and many have software tools and established coordination programs already in place to assist them. Those that do not have software tools often rely upon consultants for such analyses.

- DOTs in moderately urbanized areas (Missouri, Kansas, Ohio, and New Mexico) are concerned about mitigation of impacts, either because of the emergence of congestion issues or because of recently applicable regulations (air quality nonattainment, for example). However, these DOTs consider them largely at the project level and do not typically quantitatively analyze such impacts at the network level as part of planning functions.

- DOTs in less urbanized areas (South Dakota, Wyoming, and Mississippi) are concerned about mitigation of impacts, but not at the program or even the corridor level. Population densities and traffic volumes are low enough that congestion-based mitigations are not typically warranted, and other performance measures are of higher priority (such as pavement condition).

2. Most DOT interviewees rely heavily upon their PMS, BMS, congestion management system (CMS), and travel demand model (TDM) to identify the universe of need. It is critical that the products of this project accept outputs from and not require significant modification to these systems.

3. In many cases, DOT organizational structures and practices tend to focus on and reward narrowly focused project performance (e.g., project completion on budget and on schedule, limited change orders) rather than broaderbased corridor or network performance, such as delays, congestion, or public convenience (e.g., road user costs). Exceptions may be found in highly urbanized areas such as the Northern Virginia Megaprojects or the New York Metropolitan Area TRANSCOM, where project interdependencies and coordination are considered vital to maintaining traffic flow.

4. The team found divergent perspectives from the MPO representatives interviewed. Many MPOs have little or no authority over the sequencing of programs within their bounds. More common, however, is a sense of confusion regarding the roles and responsibilities of DOTs and MPOs, that is, each believes the other to be responsible for handling analysis and mitigation of program impacts. It is uncommon for an MPO to have direct authority over project sequencing and to have a program in place for mitigation of impacts. One significant exception to this is Maricopa County, Arizona, which does have authority over project sequencing and mitigation and has developed a business process for dealing with such issues.

5. Some DOTs and many MPOs rely upon a CMP within metropolitan regions. These programs take into account congested areas and look at alternatives for retrofitting roads at choke points or for providing people with route or mode choices. Currently, areas with an urbanized population of more than 200,000 are required to utilize data (i.e., level of service, travel times, volume-to-capacity ratios) 
to analyze their transportation networks and identify projects and studies that will increase mobility. By using the CMP to pinpoint the congested areas within a network, the MPO can provide input to states and localities to share with the public on alternate routes or strategies for motorists during renewal activities.

6. A region's status as to air quality conformity or nonconformity is often a trigger for a mandatory traffic impact analysis for renewal projects. This may or may not lead to consideration of parallel projects in the corridor or region, or to potential ripple effects from multiple concurrent projects. However, the traffic impact analysis mandated by air quality conformity requirements may well be one of the more promising thresholds for those agencies that will find useful the tools developed in this project. Metropolitan regions that are in nonattainment or maintenance for pollutants must decide upon ways to reduce the number of vehicles on the road and ease congested areas. The U.S. Environmental Protection Agency recently proposed to strengthen the standards for ground-level ozone, making it even more critical to curb mobile source emissions, particularly from idling cars. Techniques such as advanced warning signs to divert traffic prior to reaching a construction area, offering discounts on public transit during construction, and ensuring early awareness of projects through public meetings are tools to lessen congestion and maintain air quality during renewal activities.

7. Some interviewees indicated an awareness of potential impacts to nearby land uses as a result of renewal projects, but none indicated such impacts as a significant factor utilized, or even considered, in the development (sequencing) of programs.

\section{Target Audience}

As discussed in the Summary of Major Findings for the interviews, DOTs fall into three principal bands:

- Highly urbanized;

- Moderately urbanized; and

- Less urbanized.

Many, although not all, highly urbanized DOTs have business processes and software tools in place to assist in the sequencing of programs in order to minimize, manage, or mitigate impacts to roadway users. Although highly urbanized areas have software tools such as travel demand models, they do not all have tools that specifically evaluate maintenance of traffic strategies. Less urbanized DOTs are primarily concerned with performance measures such as pavement condition. In these cases, it is not necessary to prioritize the consideration of congestion-based impacts.
In consideration of these factors, the team believes that the target audiences for this project's products are most appropriately defined as follows:

1. Program managers for DOTs in highly and moderately urbanized areas of the country, where population density and congestion are enough so that mitigation of congestionbased impacts is a very high priority; and

2. Program managers for MPOs, particularly where consensus must be reached between multiple member jurisdictions, in order to sequence projects in the Transportation Improvement Plan (TIP).

The identified target audiences are subject to modification and must not be interpreted as excluding more urbanized or less urbanized DOT program managers. The team took care to include appropriately diverse key stakeholders in the initial workshops in order to validate these target audience definitions.

The following major findings focus upon the identified primary target audiences.

1. Most interviewees described a program sequencing business model that was almost entirely qualitative.

2. As noted in Major Finding 2, most DOT interviewees rely heavily upon their PMS and BMS to identify the universe of need. This is typically the first step in establishing a program of projects, and significant resources have been committed to the development and maintenance of these systems. It is imperative that this project's products accept outputs from and do not require significant modification to these systems.

3. CMPs and TDMs are similarly important elements of MPOs, and it is imperative that this project's products accept outputs from and do not require significant modification to these systems as well.

4. This project's products must not rely upon the collection and maintenance of new data and must not require complex or extensive calibration efforts.

5. This project's products will likely be most useful if they are based upon a readily available software platform such as Excel.

6. Management of expectation is important. The general business process of the interviewees in the development and execution of programs is described as follows:

- Universe of need is established.

- Projects are sequenced.

- Projects are programmed.

- Projects are designed and constructed.

This project's products are not designed to replace PMSs, BMSs, CMSs, or TDMs in identifying the universe of need. Nor are they designed to replace the public and political decision processes in sequencing programs. Rather, they are designed to inform the decision-making processes and to 
provide a rational basis for final sequencing and estimating the impacts of maintenance of traffic strategies.

\section{Evaluation of Tools}

Traffic analysis tools that have the potential to be used to study work zone impacts and strategies were identified based on functional classifications and characteristics. Their evaluation determined the functionalities that are critical for a work zone evaluation tool and how they can be incorporated in the framework for a work zone evaluation tool. It was also critical to understand whether some of these software tools are open source or nonproprietary so that they can be combined with the new software to make it more robust and easy to use. (Traffic analysis tools are listed by category in the glossary.)

\section{Geographic Scale}

The geographic scale of a work zone becomes important when attempting to model potential traffic impacts. A variety of software packages for modeling different-sized networks exist across a broad spectrum. Software on the lower end of the spectrum, such as HCS, describes traffic with simple in-out patterns and is a good match for isolated work zones. Other types of software capable of modeling entire regional road systems would be a good fit for network (grid) and regional work zones where detours may need to be analyzed.

The geographic scale of a work zone is determined by both the size and impact of any potential roadwork. The main types of work zone geographic scales fall into four main categories: isolated, corridor (pipe), network (grid), and regional. (See glossary for definitions.)

\section{FUNCTIONALITY}

Software tools are utilized to make decisions regarding planning, operations, construction management, and logistics. Based upon each field's purpose, the functionality ranges from cost-benefit analysis to traffic impacts and delay to efficient material transport and management.

\section{METHODOLOGY}

The Traffic Analysis Tool primer (ops.fhwa.dot.gov/traffic analysistools/tat_vol1/vol1_primer.pdf) developed by FHWA provided the starting point for a list of 130 software tools considered in this project. These tools were classified based on the transportation modeling categories (i.e., sketch planning, travel demand model, traffic signal optimization, analytic/ deterministic, macroscopic, mesoscopic, microscopic, and whether it is a tool suite). From the identified packages that were listed, a "short list" of 35 packages that have been used, or have the potential to be used, in work zone analysis was compiled. The 35 packages were rated based on (1) the total number of characteristics available in the software and (2) the characteristics important to the evaluation of their capability to evaluate the impacts of work zone impacts. Of the 35 packages, the top 13 nonproprietary and state DOT software packages were evaluated in detail. The results of the software evaluation are tabulated in Appendix B.

\section{Final Evaluation}

\section{General}

Software tools that are nonproprietary and easily available were evaluated. The software packages were selected for further evaluation based on their potential to be utilized as a component of the WISE tool. The tools were studied in depth to determine the used inputs and the generated outputs that would be useful and could be incorporated into WISE. An analysis of software tools appears in Appendix B and more complete descriptions and screenshots are in Appendix E.

\section{Findings}

1. Microsimulation software, which is part of a software tool suite that has multiple simulation models through which one can migrate between macroscopic and microscopic analysis (e.g., VISUM-VISSIM, TRANSCADTRANSMODELER, and CUBE), performed the best. TRANSIMS showed a lot of capabilities but was not user friendly.

2. Among nonproprietary software, the software developed by Oregon performed extremely well, followed by Dynus T and QuickZone.

3. A database of strategies and alternatives that include production rates and costs would make the tools more powerful.

4. Work zone impacts due only to queues are being evaluated, but impacts due to lower speed limits are not.

5. Leveraging nonproprietary software for evaluating and determining strategy would be the most effective way to create the WISE tool set.

6. STEAM, LCCA, and QuickZone were found to be the most robust estimation tools. DynusT's router capabilities are useful to studying the impact of ITS and capacity changes.

7. SSAM was evaluated for microscopic evaluation, preliminary engineering (PE), and design phases of the projects.

8. Several state DOTs have developed their own spreadsheetbased tools. Although these tools use very coarse estimation procedures, they are easy to use.

9. WISE was designed to be extremely user-friendly, flexible, and able to accept inputs from PMSs and travel demand models.

10. Most of the software packages, such as QuickZone and STEAM, estimate the impact of work zones as a snapshot comparison between the area before and after construction. This process crudely estimates road user cost, and similarly the WISE tool takes into consideration the excessive road user cost resulting from the prolonged renewal activity. 


\section{СHAPTER 3 \\ Tool Recommendations and Applications}

\section{Work Zone Impact and Strategy Estimator Tool (WISE) and Its Framework}

The Work Zone Impact and Strategy Estimator tool (WISE) is intended to be a decision support system used by planners and engineers to evaluate the impacts of work zones and to determine strategies to reduce these impacts. The WISE software can evaluate the impact of multiple projects that have been incorporated into the Transportation Improvement Program and the network. Therefore, the level of effort required to conduct analysis is minimal.

Because WISE will be used by agencies to adhere to the FHWA's Work Zone Rule, Section 630.1010, it was developed based on the definitions and guidelines proposed in the Work Zone Rule.

Because of the Work Zone Rule's definitions of significant projects, there is a need to evaluate and determine whether projects will have a significant traffic impact. Stipulations in the rule use words such as "tolerable" impacts and engineering "judgments," allowing state DOTs and MPOs to define what is considered tolerable. Therefore, the WISE tool's users can determine thresholds for delays and queue lengths. The framework for the WISE tool is described in the following sections. The overall concept and framework for the WISE tool, including the design of software modules and functionalities, were improved based on input from workshop participants.

\section{System Engineering Development Process}

The overall WISE software development process follows the "V" diagram as shown in Figure 3.1. The V diagram illustrates a useful life-cycle process for software and model development that first identifies the user needs, next specifies the use requirements, and then uses these requirements for specification design. The actual coding of the software takes place after these steps. Once the software is produced, several subsequent steps commence to ensure that the robustness and validity of the developed software are consistent with the original defined needs and functional requirements.

\section{User Requirement Specification and Concept of Operations}

Drawing from the workshop experiences, the team envisioned that WISE would be used for purposes of planning, operations, or both. The WISE software is designed to accommodate both purposes in a manner that requires a modest level of effort from an experienced user. Figure 3.2 illustrates the overall software model system design, with boxes representing the individual modules and arrows representing the functional or data flow relationships. The following sections discuss two user cases-planning and operations - and provide explanations of individual modules.

\section{User Case: Planning}

In the planning mode, the decision maker has information regarding the list of projects and their attributes and the traffic network. This mode is concerned with developing a desirable work zone schedule over a planning time frame to optimize the intended objectives (such as minimize the traffic impact of the work zones on the entire network, or user or agency costs). This module will consider factors such as nighttime-daytime and weekend-weekday schedules to develop a tentative schedule for the projects. At the planning level, all route diversions will be calculated using static assignment. The impacts will be evaluated only for peak period traffic.

The WISE planning mode recommends the optimal schedule for carrying out construction projects. The user is able to specify the flexibility for each work zone project's start time and duration. For example, one could fix schedules of certain 


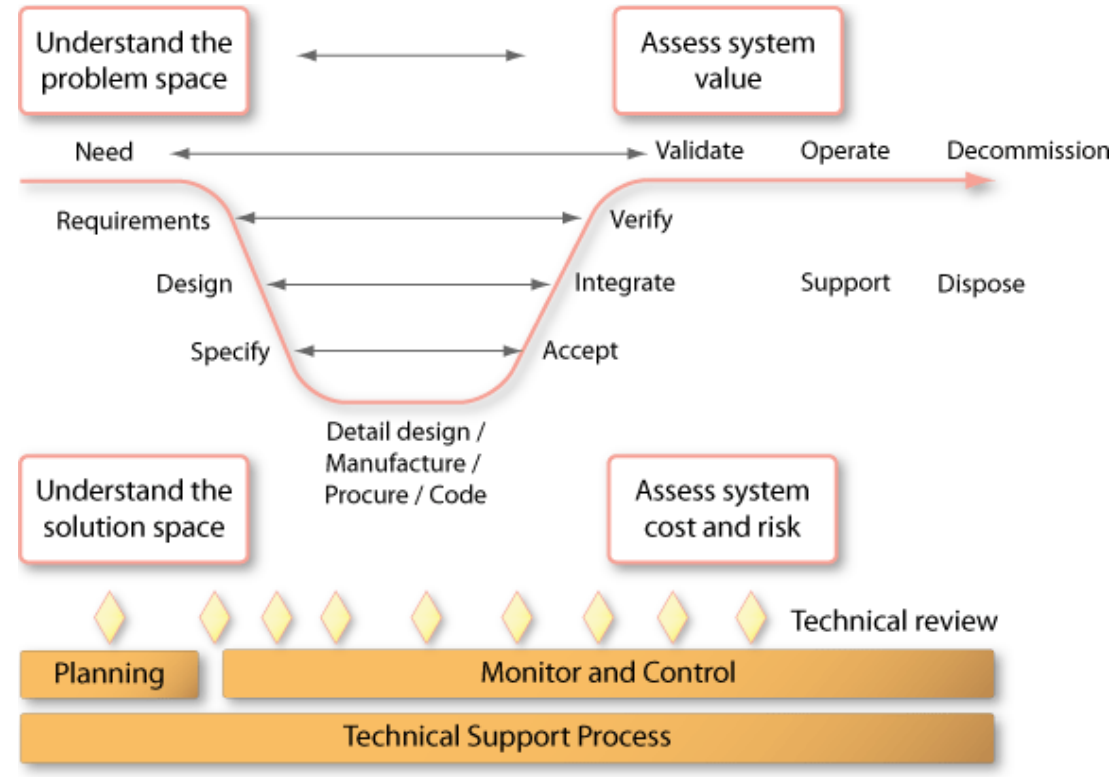

Figure 3.1. WISE software development process $V$ diagram (source of recode).

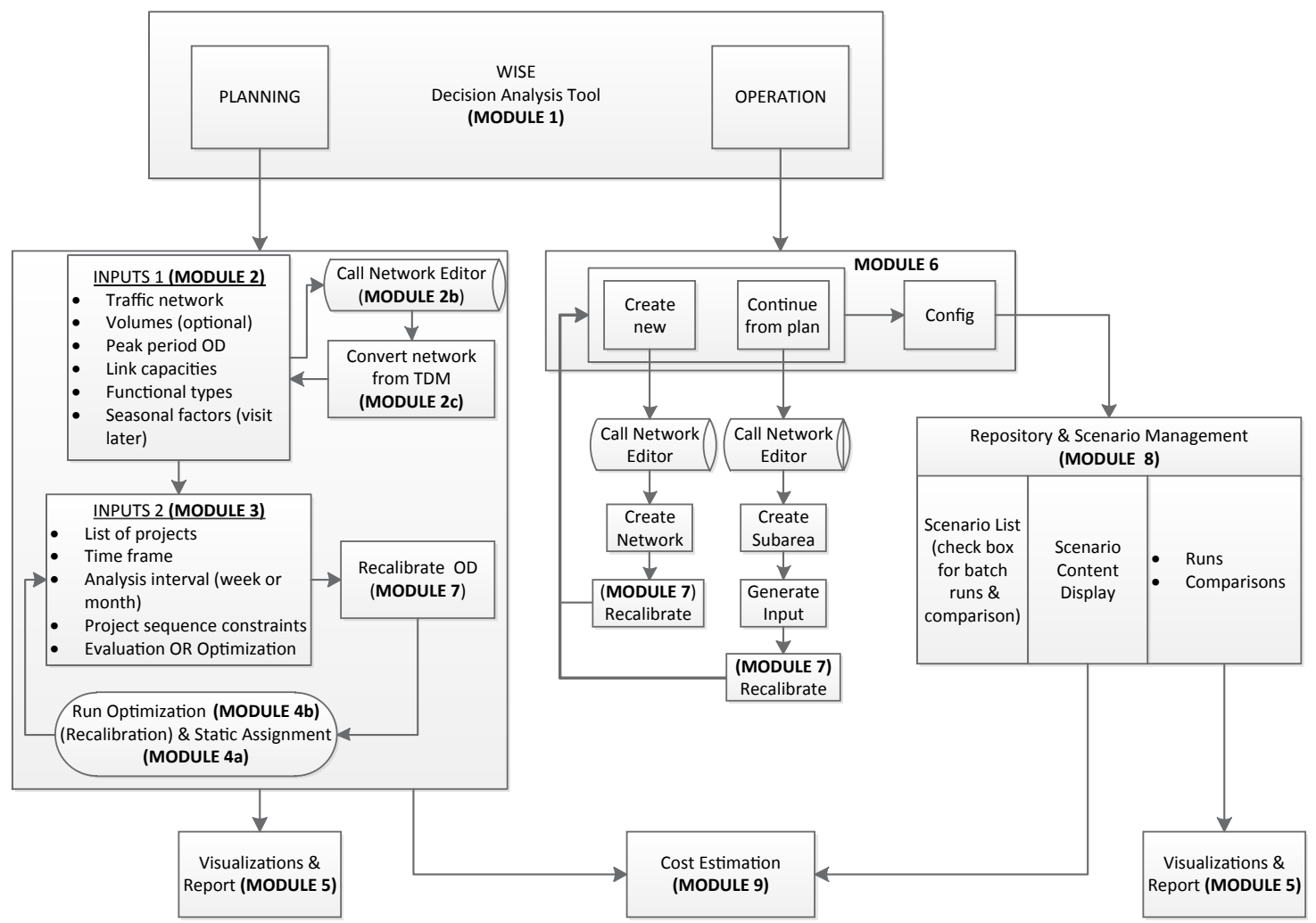

Figure 3.2. WISE model system software architecture. 
projects that are problematic because of other deadlines or because of budget constraints. This module can optimize the scheduling based on various constraints as well as conduct a what-if analysis.

The planning mode produces various measures of effectiveness (MoEs) and cost estimates to aid in the decisionmaking process.

\section{User Case: Operations}

In the operations mode, it is anticipated that the decision maker has obtained the scheduling decisions in terms of start times and duration for all work zone projects of interest. This mode is further concerned with various operational strategies to mitigate the work zone impact. Various work zone contracting strategies such as lane rental can also be evaluated in this mode.

An underlying assumption in WISE's development is that only a limited number of work zones are considered in the operations mode. If multiple work zones are considered simultaneously, then it is primarily because planning decisions lead to multiple, temporally overlapped, and spatially interrelated work zones.

The operations mode focuses on "what-if" scenario analysis, in contrast to the planning mode, which seeks the optimal working staging schedule through the proposed scheduling algorithm. The user will be provided with several strategy options that will result in a new scenario. Ideally, the user will create multiple scenarios within which a certain amount of network, control, and demand changes could be made and evaluated. The traffic mitigation strategies that can be evaluated in this mode include signal retiming, signal coordination, dynamic message signs at existing locations, or new locations for mandatory or advisory diversions.

The operations mode produces various MoEs and cost estimates to aid in the decision-making process.

\section{WISE Design Concept and System Modules}

\section{Particular Modules}

\section{Module 1: WISE System Shell Program}

This is the overall shell program managing the interprocedural calls between all submodules. The development of the module emphasizes the usability and stability of the program. This module was programmed from scratch.

\section{Module 2a: Planning-Input (Transportation Network)}

The input for the planning analysis consists of a list of projects, as well as the transportation network, with traffic volumes or origin-destination demand matrices, link capacities, functional types, and seasonal factors. The inputs generated in this module are used by Module $2 \mathrm{~b}$. Some of this information can be extracted from Module 2c, and users have the ability to input further details.

\section{Module 2b: Planning-Network Editor}

The network editor performs separate tasks for the planning and operations modes. In the planning mode, the editor is used to import the travel demand model data set to the WISE format, which allows for quick conversion of the local travel demand planning model for the WISE planning model operations.

In the operations mode, the editor is used to perform the subarea cut from the regional model. It is anticipated that only a subset of the work zone projects will be further analyzed in this mode, and the scope of the network should be trimmed down in order to perform more detailed traffic flow/driver choice analysis that provides the traffic dynamic realism needed for the operations analysis. This reduction process also addresses the issue of scalability that was repeatedly raised during the workshops.

\section{Module 2c: Planning-Network Converter (from Travel Demand Model)}

The designed network converter considers the fact that a variety of travel demand models are available in the market and their software and input-output data may be changed regularly. The import process should be universally applicable, not tailored toward specific TDM software, so that the longlasting robustness and applicability of network conversion capability are not hindered by incompatible TDM version updates. The network conversion approach adopts the following simple steps:

- Export from TDM to plain text files.

- Populate Excel given existing templates.

- Import Excel into network model.

The team assumes that the WISE user will be able to complete the conversion steps via DOT/MPO internal and joint resources.

\section{Module 3: Planning-Input 2 (Work Zone Projects)}

Through this module, the user is able to manage a list of projects and constraints on the time frame, nighttime or daytime, and start time, as well as whether optimization or an evaluation needs to be conducted. 


\section{Module 4a: Planning-Static Regional Traffic Assignment}

This module performs a static traffic assignment on the entire regional model and works in conjunction with the Module $4 \mathrm{~b}$ work zone scheduling module. The static traffic assignment algorithm was developed and enhanced from a currently existing template algorithm. The entire algorithm includes a shortest path algorithm, a network loading algorithm, and a traffic assignment procedure. The network loading includes the traditional BPR (Bureau of Public Roads) type of speed-volume and link cost functions. Travel times are evaluated based on assigned flow. Intersection delays are reflected in the link capacity. The user can specify the convergence criterion and the maximum number of iterations for assignment.

If additional accuracy for estimating potential traffic diversion due to construction delays is desired, then the user can apply the DynusT model as part of the operational function, develop diversion estimates in the operational function, and rerun the Planning Module. Applying diversion estimates from the Operations Module is an explicit choice in the Planning Module.

\section{Module 4b: Planning-Work Zone Scheduling}

The problem of work zone staging or scheduling arises in the case of a planning user who must decide on the optimal schedule (i.e., start time and duration) of all considered work zone projects and must consider various constraints such as minimum and maximum of start time, end time, and duration. The user can select the objectives to consider, which would be to minimize user cost, agency cost, external costs, etc. Unique to this problem formulation is the consideration of the temporal domain spanning the period of interest, such as months or years.

A traffic analysis subperiod is specified. This period is proposed to be either in weeks or months, considering seasonal demands and environmental conditions such as weather. The general formulation and algorithm structure have been developed and validated.

\section{Module 5: Planning and Operation-Analysis Visualization and Reporting}

Both the work zone planning and operations decisions need to be assessed based on the defined MoEs. The user is allowed to choose the MoEs of interest, which include

1. Travel time, delay, queue lengths;

2. Throughput;

3. Road user cost;
4. Agency cost; and

5. Length of disruption.

The visualization and reporting mechanisms include

1. Network-level statistics and comparison;

2. Link-level statistics and comparisons between multiple links or the same link in different scenarios;

3. Animations of various time-varying statistics, such as density, speed, flows, and vehicle trajectories;

4. Space-time speed contour profile for a defined corridor or route;

5. Time-varying travel time for a specific defined corridor or route; and

6. Time-varying speed profile for a specific defined corridor or route.

\section{Module 6: Operations-Subarea Scenario Configuration}

Using the network editor, a user can cut out a subarea for which analysis regarding diversion and other strategies can be conducted. The challenge in this task is to manage several subarea networks. The users are able to input an entire week's traffic volume on an hourly basis as well as seasonal factors. The OD (origin-destination) matrices are recalibrated or re-estimated to ensure correct traffic assignment.

\section{Module 7: Operations-Model Calibration}

For both regional and subarea networks, the user has the option to perform calibration if he or she has necessary data and is willing to go through this optional step. In the planning user case, the calibration focuses on the OD trip calibration or estimation because the calibration of the BPR function parameters is time-consuming and these values are generally available from the MPO. In the operations mode, the calibration could include both traffic flow model calibration and OD trip calibration or estimation.

The calibration or estimation of OD trips aims to minimize the discrepancy between simulated/assigned link flows and observed traffic data. The recommended method is a onenorm formulation that minimizes the sum of the absolute values of simulated and actual counts for all links. The constraints include the upper and lower bound between the calibrated OD results. More details about this formulation are included in the WISE Users Guide.

\section{Module 8: Operations-Repository and Scenario Management}

Through this module, the user can manage the different scenarios being evaluated and can run and compare various 
strategies at the same time. The user can choose from several strategies to implement for different renewal projects, which will result in a new scenario. The following strategies are provided in a drop-down menu:

1. Public involvement: $\mathrm{X}$ agency cost results in $\mathrm{Y}$ reduction in demand.

2. Traffic diversion: The user inputs the diversion in the network editor and associates an agency cost.

3. Night-day: The user can close lanes based on time of day.

4. Full closure: The user can close all lanes for several days.

5. Contraflow lanes, shoulder use: The user can code these into the network, based on time of day.

6. ITS: The impact of dynamic message signs on traffic can be evaluated with respect to the agency cost.

7. Innovative contracts. The road user cost output can be used to develop innovative contracts such as incentive/ disincentive, $\mathrm{A}+\mathrm{B}$, or lane rental. Recommendations on such contracts would be provided as part of the output, if the user chooses to pursue this strategy.

8. Scenario management. The user can click on each scenario, and a summary of the scenario will be displayed. Multiple scenarios can be selected simultaneously, which will help the user to easily manage and compare the scenarios.

\section{Module 9: Planning and Operation-Cost Estimation}

Both the work zone planning and operations decisions need to be assessed based on the defined MoEs. The user will be provided summary output of the MoEs discussed in Module 5.

\section{Testing and Validation}

The WISE system was regularly tested at the module or component level throughout the development phase. However, the overall system should be tested as a whole with a user in an actual work zone planning context. This will be accomplished in Phase 4 pilot tests. Phase 4 will be completed in 2013.

\section{Overall Structure and General Purpose of the WISE Tool}

Participants were supportive of the scheme of inputs from two primary sources. It was suggested that WISE is most useful as a tool that takes a set of already defined projects (from the long-range transportation plans, TIPs, Statewide Transportation Improvement Programs (STIPS), and management systems, as well as politically defined projects) and sequences them in a way that optimizes the identified performance measures as weighted by the user. Participants identified a number of management systems, including PMS, BMS, CMS, safety management, and construction program management (CPM)

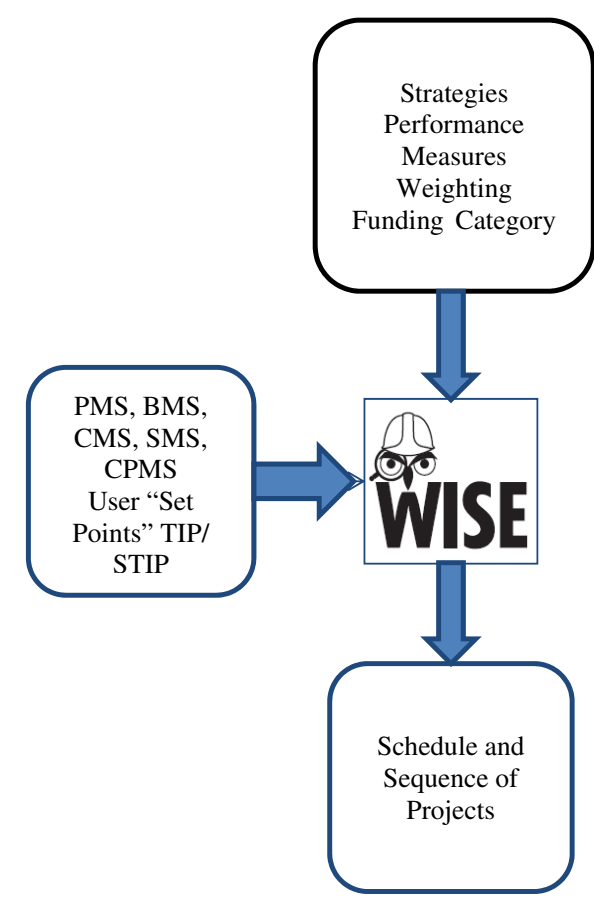

Figure 3.3. Basic WISE purpose.

systems, as tools by which projects are defined and initially scoped. See Figure 3.3 for the basic purpose of WISE.

Participants also noted that additions of projects from a variety of user "set point" inputs are a critical part of the input. Politically earmarked projects or projects with motivations such as social equity are not easily accounted for within most management systems. The participants value the ability to amend the project lists with these inputs.

With projects identified, the second element of inputs comes into play. Participants find value in the ability to select (check or uncheck) strategies that are appropriate to them and to select and "weight" performance measures that will play into the sequencing algorithms. Participants suggested that the ability to consider funding category eligibility will also add value. In addition, economic development factors may require specific consideration in the sequencing algorithms. Participants stated that multiple iterations of WISE to sequence projects by category of funds and then overall will add value to the process. The team confirmed that a number of macroscopic tools provide information regarding traffic diversions of corridors or networks and that a number of microscopic simulation tools are very useful in analyzing maintenance of traffic on a projectby-project basis. There is a significant absence, however, in terms of a mesoscopic tool that assists the user in sequencing renewal projects at the program level. See Figure 3.4.

Although WISE will not be internally integrated with TDMs or simulation models, it will provide data that are compatible with macroscopic and microscopic proprietary and nonproprietary software input and will assist in the 


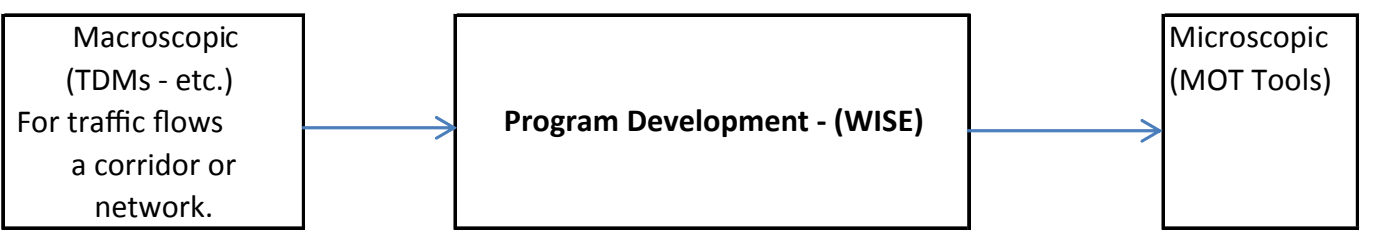

Figure 3.4. Sequencing renewal projects.

formulation of a coherent program of projects that can then be analyzed for impacts.

Participants confirmed the team's foundational assumptions, including the following:

- Existing management systems (PMS, BMS, CMS, CPMs, etc.) represent a significant investment of resources to develop and maintain, and WISE must not require the abandonment —or even significant modification of - those systems.

- WISE must not require the user (agency) to add personnel in order to operate it. The addition of personnel is unfeasible given current and foreseeable budget constraints.

- WISE must not require a large up-front capital expenditure for procurement, licensing, or annual support.

- WISE must rely upon existing or easily obtained data sources. Gathering additional data is difficult for the same budgetary reasons that exist with adding personnel.

- WISE must not require extensive or complicated calibration. The team heard repeatedly that WISE must be simple and intuitive to use and must be robust enough to deal with a lack of detailed inputs.

The participants' input led the team to develop the following purpose statement for WISE:

The WISE tool will focus upon federal aid-eligible networks and corridors (functionally classified as arterial, expressway, or freeway). The WISE tool will generate sequences of projects that maximize throughput of traffic throughout the corridor or network and will assist in the allocation of funding categories for renewal programs. Outputs of WISE will be spatially enabled and will inform decision making with regard to scheduling and selection of strategies.

\section{The Features of Scalability and Modularity}

Meriting special consideration are issues raised by the participants regarding the modularity and scalability of WISE. Participants represented the two key focus areas of planning and operations, and their conceptions of the uses and applications of WISE reflected this dichotomy.

Planning interests described WISE as a tool that will take defined renewal projects from the long-range transportation plans, TIPs, STIPs, or management systems; build in user set points (e.g., user-defined constraints such as "Project Segment ' $\mathrm{A}$ ' must be built first, or Project B is near a hospital where 24/7 access must be maintained"); overlay the network and traffic forecasts from TDMs; and, as output, sequence a program of projects based upon selected strategies and weighted performance measures. At this stage the strategies considered would only be those that would significantly impact the cost and/or the construction time of the projects. Little, if any, additional information as to the scope of these projects will be available at this initial stage, and the initial sequence of projects that are output from WISE will be used to guide additional discussions with key stakeholders and will iterate down to a final program that will be used to amend a transportation plan, TIP, or STIP, or will be handed down to the design phase for further analysis.

Another potential strategic planning application involves initial sequencing of a program that is then used by program and fiscal managers to match the projects identified with available funding sources. These users may iterate WISE numerous times to resequence the overall program for particular funding eligibility considerations and will "schedule" the program given this additional information. It may, depending upon the business model in question, be necessary to return the program to the executive level for endorsement.

At the operations level, additional information regarding project scope, duration, and cost is available. This level will also have additional information regarding land uses and impacts to economic development, as well as improved travel demand, diversion, and maintenance of traffic information. This level will be concerned primarily with evaluating strategies to minimize impacts and will consider various scheduling scenarios against various strategies and costs so that a more finite cost-benefit analysis can be used to make final project scoping decisions. It may be necessary at the operations level to send a rescheduled program up the line for direction about the need for additional expenditures or for endorsement of the new schedule.

Thus, the issue of scalability applies to the seamless transfer between the planning and operations modules of WISE. It is critical that WISE have the capability to iterate essentially the same network or corridor, but adding in additional detailed information as it becomes available. The same renewal program of projects may be resequenced multiple times and 
with varying levels of detail. WISE must be scalable (from a regional analysis to a major corridor analysis) according to the level of available detail and the focus of the user. Transferring from the sketch-planning level to corridor level and back again is a critical capability for the WISE program. Another critical capability is the recognition of changing user needs and focus of the program development process.

In this way, WISE may function as a scope management tool for a renewal program as much as for any other purpose. There is also an exciting possibility for WISE to function as an asset management tool and a life-cycle cost analysis tool at the program level; however, these capabilities are beyond the scope of this project.

The issue of modularity is more difficult to define and discuss, but it is no less important. The concept of a Planning Module and an Operations Module (driven by the user's focus and the availability of detailed information) has already been discussed here. Other issues of modularity, however, also merit discussion. These include, but are not limited to

- A module that will allow users to work directly with the various management systems rather than a set of defined projects that arose from such systems after some form of post-processing;

- A module that will take basic network (link-node) information and traffic flows from a TDM and will allow for more complete analysis of diversion due to closures arising from multiple, concurrent renewal projects;

- A module that will generate input files to microsimulation models to allow for more complete analysis of maintenance of traffic during construction; and

- A module that will generate input files to a GIS to allow for graphical display of WISE results.

These subsequent modules are not included in WISE as developed thus far. However, WISE includes the capability to add such modules under subsequent projects. The opensource coding for WISE will support such capabilities.

\section{The Inputs and Outputs of WISE}

The question of inputs is most clearly discussed in the context of the planning and operations modules (functions) that were stressed by the participants. The functional requirements for the inputs of the Planning Module (function) are expressed as follows:

- User-defined "set-points" are accommodated. These setpoints (constraints or projects around which others must flex) may include

○ Earmark or other political mandates;

$\circ$ Limitations as to construction season;
O Limitations as to special event seasons (during which disruption is intolerable); and

- Sensitivity of land uses, such as hospitals that cannot be cut off by renewal activities.

- A project from TIPs, STIPs, or CPMs—rather than direct input from other management systems-is the most likely source of projects for the WISE sequencing algorithms.

- The input format for project data is simple to write and must include location-referencing system attributes for each record to maintain the capability of spatial displays of outputs.

- Inputs must include, to the degree that data are available, major strategies, construction techniques, and materials that may significantly impact project duration or cost. Where local data are not available, default values are provided so that WISE is not "stopped."

The functional requirements for the inputs of the Operations Module (function) depend in large part on the availability of more detailed data and are expressed as number of lanes available or to be closed and duration of closure (i.e., number of days or number of hours). These additional inputs allow for comparison of strategies (e.g., short-duration closure, full closure, $\mathrm{A}+\mathrm{B}$ contracting) and of the cost of a given strategy against the user costs (e.g., agency cost versus road user cost).

For both modules, the desired output is a sequence of renewal projects that maximize traffic throughput and most effectively meet user-defined performance measures. Other outputs may include the size and location of queuing across the network or corridor and traffic throughput. It is also suggested that measures of effectiveness be considered in terms of "delta" (change) from one sequencing scenario to another, or from one strategy to another. This approach frees WISE from provision of finite answers for each MoE and allows for a direct comparison of schedules and strategies. Measurement of the relative effectiveness of any given combination of sequence and strategy may be related to the function (Planning Module or Operations Module) as shown in Table 3.1.

The team finds it particularly interesting that participants believed that the list of performance measures identified in Tasks 1 through 4 should be condensed into those in Table 3.1. Additionally, participants believed that safety-a performance measure that permeates the literature-should not be included in WISE. While the importance of safety is axiomatic, participants stated that for the purposes of sequencing renewal projects and comparing strategies, safety does not play a direct or measurable role. Or, put another way, participants could not envision a measure of effectiveness for safety that would drive selection of strategy or project sequencing for renewal programs. However, the team anticipates that a safety value will be included in the measures of effectiveness. 
Table 3.1. Measurement of the Relative Effectiveness of Any Given

Combination of Sequence and Strategy

\begin{tabular}{|l|c|c|}
\hline $\begin{array}{l}\text { Performance Measure } \\
\text { User set points such as: }\end{array}$ & Planning Module & Operations Module \\
\hline Ensuring accessibility & Yes & Yes \\
\hline Minimize daytime disruptions (commercial areas) & Yes & Yes \\
\hline Minimize night noise (residential areas) & Yes & Yes \\
\hline Minimize delays and queues & Yes & Yes \\
\hline Maximize throughput & Yes & Yes \\
\hline Maximize production rates & No & Yes \\
\hline Minimize length of disruption & Yes & Yes \\
\hline Comparison of agency cost vs. road user cost & Yes & Yes \\
\hline
\end{tabular}

The Phoenix participant group included a number of key stakeholders with extensive modeling and software development experience. These stakeholders contributed ideas for the programming of the WISE tool that include the following:

- Modeling diversion behavior is critical, especially from an analytical standpoint. Using percentage diversion values results in vague estimates. There should be an input for type of road user (e.g., tourist, commuter) to appropriately model route choice. There also was discussion of determination of diversions and routing techniques or algorithms and the possibility of using an equilibrium-based model when examining the network level, especially in congestion scenarios.

- The method to model various technologies in the planning level is ensuring that a certain percentage increase in agency cost results in a certain percentage reduction in duration of construction.

- The software should have the ability to read network and traffic data from TransCAD, CUBE, or other planning software. It should also have the ability to read ESRI shape files, a capability available in most TDMs.

- The software should have the flexibility to be rerun with different scenarios quickly and efficiently (iteration module).

- There will be cases when hourly volume data are not provided or available. A limited selection of predetermined 24-hour profiles should be provided, as well as guidance for appropriate selection. With these profiles, the user should input the annual average daily traffic (AADT) and default hourly factors.

- The focus at this point should be on deterministic models.

- The WISE process should be able to handle large to medium networks. It should also be able to rerun and iterate between various scenarios fairly easily.
- Spatial enablement of outputs is an important program management capability but is challenged by a lack of any sort of standard location-referencing scheme (LRS).

- The WISE process should be limited to CPMs or STIP or TIP inputs to overcome the challenges of working across numerous management systems, although these other management systems could still provide certain inputs.

- It is very difficult to identify a measure of effectiveness for safety as a performance measure in such an application as WISE. Examining the vehicle miles or vehicle hours traveled (VMT and VHT) as surrogate safety measures may be possible under this scope. Given the political mandates for safety, some safety MoE will be included.

\section{Where WISE Will Integrate Into Business Practices}

As discussed in the Amplified Work Plan, the primary target audiences for WISE are state DOTs and MPOs. The results of the interviews in Tasks 3 and 4 narrowed this audience to MPOs and to state DOTs in moderately dense populated states; however, a number of challenges that complicate efforts at integration remain. These challenges include, but are not limited to, the following:

- DOTs differ in terms of being operationally centralized or decentralized.

- MPOs differ in terms of the area of the metropolitan statistical area (MSA) and the number of member jurisdictions.

- Extents of MPO and DOT jurisdiction and responsibility differ greatly, particularly regarding planning and renewal activities.

- Bureaucratic organizations are typically very vertical in their lines of communication, making integration of a scalable tool such as WISE challenging. 
Although it is beyond the scope of this project, interjurisdictional integration (DOT to MPO) is seen as one of the greatest potential benefits of a tool such as WISE. The responsibilities for development, scheduling, and administration of renewal programs within MPO areas vary widely across the country. Those responsibilities are almost universally unclear. Those interviewed in Tasks 3 and 4, as well as workshop participants, conveyed a sense of confusion and uncertainty with regard to such responsibilities and who or what bears them. However, the team will pursue the integration of the WISE process into the results of the capacity-building SHRP 2 projects.

The focus of integration in this project, however, is upon where within a given organization a tool such as WISE will live and by whom it will be utilized. Participants related a number of possibilities, such as the following:

- The Ohio DOT describes an Office of Program and Modeling as well as an advisory board known as the Transportation Review Advisory Committee that may utilize the planning function of WISE as a tool for high-level program development and scheduling.

- The Virginia DOT describes WISE as a tool for its Transportation Planning Bureau.

- The Kansas DOT has an Office of Program Management within its Bureau of Transportation Planning that matches identified projects with available funding and schedules the program.

- The Chief Engineer of the Washington, D.C., Council of Governments uses the operations function of WISE to evaluate strategies in terms of agency cost versus road user cost.

- The Delaware Valley Regional Planning Commission (DVRPC) requires the WISE scalability so that the when and how of project scheduling can be determined at the district level. The need to iterate the same basic set of projects many times is clear in this application.

- In the operations phase, Louisiana DOT has both a "Plan in Hand" (at about 30\% to $50 \%$ of design) and a Constructability Review (at about $50 \%$ to $75 \%$ of design) when additional decisions and modifications to schedule and design are made. WISE would be useful in analyzing impacts of such decisions on parallel projects in the network.

- Participants also suggested investigation of the TRANSLINK program of Vancouver, British Columbia, for its capabilities and integration features.

Given the disparity of this information, the team will add integration features to the case studies developed and will include integration as a training module. Recommendations for case studies include Philadelphia area I-95 corridor, LA DOT (Los Angeles), and potential applications to the California freeway system renewal programs. 


\section{онAвтER A \\ Conclusions and Recommendations}

\section{Development of New Software Tools}

The software was developed in two separate components: graphical user interface and computational interface. There are three major functions of the software: (1) the Planning Module; (2) the Operations Module; and (3) the "handshake" between the two.

The software development process was extensive. The development of WISE itself, incorporating projects and strategies into network dynamics for the Planning Module, was innovative and required groundbreaking work. One major challenge involved incorporating the universe of potential performance measures discovered in Phase 1, none of which is universal to the target audiences in their application, importance, and overall costs into a computer program that is rigorous and temporally valid. The solution to this daunting challenge was the development of the Project Strategies tab in the Planning Module of WISE. This tab allows each user to develop and maintain its own library of demand-based and duration-based strategies and to apply them on a project-byproject basis. Another major challenge involved the development of a heuristic sequencing algorithm that could take a large number of projects over a complex network and compute a sequence of projects without requiring hours and hours of computing time. The solution to this challenge was the development of the heuristic algorithm utilizing TABU methodology to reduce the number of computational possibilities and to provide a stable solution in many fewer iterations. The WISE program and capabilities are addressed in the Users Guide and in the Instructional Materials (WISE PowerPoint presentation, Participants Workbook, and Instructors Guide). The purpose of this section is to provide additional background and detail on one of the key innovations in the software development-namely overcoming excessive run times.

Another major challenge was to develop an effective graphical user interface (GUI). The GUI as developed has numerous error and boundary checks, as well as logic checks and help buttons. The software can evaluate continuous day and night construction schedules, as well as other distinct analysis periods. The GUI development and system check tests are addressed in the WISE Users Guide.

Approximately midway through the process, the team identified a significant problem. Run times to find a solution to the work zone sequencing problem were requiring many hours of processing time. A solution to this issue is addressed in Appendix D, Work Zone Sequencing.

\section{Development of Guidance for Software Tool Selection}

The WISE Users Guide provides instructions and background detail on the workspace, Planning Module, Operations Module, and the "handshake" between the two, as well as detailed information on how to load and convert a network and how to load traffic data. It also includes some details on the algorithm used to sequence projects.

\section{Workshops-Test of Software Tools}

The challenges to the software development led the team to expand the planned workshops. In addition to the two scheduled workshops, one focused on the Planning Module and one on the Operations Module, the team convened a dry run in advance of the first workshop to provide additional opportunity to work out "bugs" and improve the software and training materials.

- The dry run to evaluate the Planning Module was held on November 30, 2011, in Baton Rouge, Louisiana.

- The first workshop of the second series of workshops, to review the Planning Module of the software, was held on December 13-14, 2011, in Fairfax, Virginia. Participants 
viewed presentations on the Planning Module and its components. Extensive comments on the WISE GUI and the need for error checks reinforced the team decision to place additional focus and emphasis on the user interface.

- The second workshop of the second series of workshops was convened on February 28-29, 2012, in Houston, Texas, at the Texas DOT offices. Participants viewed presentations on the improvements made to the WISE GUI and its internal error and boundary checks, the Planning Module, and the Project Sequencing Algorithm, the Operations Module and DynusT (the engine for the Operations Module), and the interactions between the two modules. There was extensive discussion and interaction, with recommendations for improvements to the system.

- After this workshop, the team convened a webinar for the SHRP 2 panel and other interested parties.

\section{Development of Training Materials}

Training materials consisting of a PowerPoint presentation, a Participants Workbook, and an Instructors Guide have been completed. Preliminary training materials were reviewed at the dry run and at the two workshops.

\section{Next Steps}

Phase 4 has been initiated. For the model verification phase of the WISE product, the team envisioned two test sites and sought sites with good DOT/MPO working relationships, because availability of data and access to experts in both agencies are essential to success. The two sites selected are the Arizona DOT/Phoenix, Arizona (Maricopa Association of Governments) and the Iowa DOT/Des Moines Area MPO, Iowa. The geographic variation of these sites helps assure thorough verification of the WISE product for use by the widest possible target audience. As part of the verification process for each of these test areas the WISE program will be used to recreate the impacts of the recently completed renewal and expansion of the Phoenix freeway regional system and the renewal of the Des Moines, Iowa I-235 Corridor. The team also envisioned two sites for building WISE business cases and applications. These two sites will be the New York Metropolitan Area and the Orlando, Florida, Metropolitan Area.
Based on the lessons learned, the team will revise the WISE Users Guide and the training materials to improve clarity and usefulness. This effort also provides an opportunity to further improve the rigorousness and stability of the WISE program and the GUI.

The research team envisions development of as many as four "business cases" from these verification and pilot applications that will document the flexibility of the WISE tool and will help to assure the widest possible range of application by the target audience. The team foresees development of business cases such as the following:

1. A DOT or MPO has a universe of identified renewal needs from management systems or other inputs. A public process must now be utilized to develop a program of renewal projects. WISE is utilized as a sketch-planning tool to develop an initial program sequence from a "blank sheet" and to inform the public process and the decision-making process.

2. A DOT or MPO has a set of renewal projects, each with an identified location and a preliminary scope. Some information is now available regarding likely fiscal year programming of at least some projects, and some instances of project precedence have been identified. WISE is utilized to refine the sequence of program projects and to identify instances where specific demand-based or duration-based strategies should be utilized.

3. A renewal project is now in the design phase of its development and has been handed off to engineering staff. The engineering staff members utilize the network and project information already developed in the Planning Module of WISE but apply the data now in the Operations Module to analyze Dynamic Traffic Assignment (DTA)-based traffic diversion under a variety of MOT scenarios. An acceptable MOT scenario is selected, and the program sequence is re-evaluated to verify the placement of the project within the renewal program.

4. A renewal project has suffered significant delay because of issues with the construction contractor. Completion of this renewal project by the required date is no longer possible, and this renewal project is precedent to at least one subsequent renewal project. The remaining program of projects must now be resequenced, and the estimated program cost must be compared to the original estimated program cost for the purpose of assessing liquidated damages. 


\section{Glossary}

\section{Classification of Software Functionalities}

\section{Transportation Modeling Categories}

analytical and deterministic. Analytical and deterministic tools are usually based on the procedures found in the Highway Capacity Manual. The resulting factors from these tools, such as capacity, density, Levels of Service (LOS), delay, and queue, are based on empirical equations derived from field data and small-scale experiments. This type of tool is able to analyze small-scale effects, but it is not practical for large-scale, network applications.

simulation: macroscopic. Macroscopic simulation models use the fundamental traffic qualities of speed, volume, and density on a sectional basis (i.e., network links), which means that tracking individual cars in a macroscopic model is impossible. They require less detailed network link data to operate than microscopic models, but they do not offer as much detail.

simulation: mesoscopic. Mesoscopic simulation models provide middle ground between the macro- and microscopic approaches. Mesoscopic models typically are able to track individual vehicles, but they also rely on speed, volume, and density relationships to determine the movement of these vehicles.

simulation: microscopic. Microscopic simulation models are capable of tracking individual vehicles on a secondby-second basis and capture the ways that these vehicles interact with each other. This means that these models employ car-following and lane-changing algorithms to determine individual vehicle behaviors.

(simulation) tool suite. A tool suite is a computer software package that combines two or three of the simulation types previously described. In this way, a user is able to easily model a network with different fidelities when necessary.
Examples include VISSIM with VISUM and TransCAD with TransModeler.

- Corridor (pipe) work zone. A corridor work zone (or pipe work zone) is any road work that occurs along a major highway segment. An example of this type of work zone would be an interstate widening or repaving project. This type of work zone is slightly larger in size and has the potential to cause more traffic disruption on the regional level.

- Isolated work zone. An isolated work zone can be thought of as a single point within a much larger network. Examples of isolated work zones can include rural lane closures or redesigned intersections. This type of work zone is small in size and should have minimal impact on traffic over the regional network.

- Network (grid) work zone. A network work zone (or grid work zone) is any project that involves construction on connected, interdependent roads with multiple access points. This type of construction may also require one or more viable alternate routes. Examples include interstate reconstruction, full roadway closures, and work zones in urban centers. This type of work zone is large and will disrupt traffic patterns on a large scale. However, the impact is usually restricted to an urban area.

- Regional work zone. A regional work zone is similar to a network work zone in that it involves construction on connected and interdependent routes and may require detours. The difference between the two is the size of the traffic impacts. Regional work zones will cause regionallevel traffic impacts, which could mean disrupting several urban areas or several towns in a region.

sketch planning. Sketch-planning tools provide a rough estimate of the effects of any transportation improvements. They typically require only very basic information, such as traffic counts and capacity analysis. 
traffic signal optimization. Traffic signal optimization software packages are tools used to develop signal-timing plans at both isolated locations and synchronized corridors or grids. These tools also require basic information such as traffic counts for intersections.

travel demand model. Travel demand models are mathematical models used to determine the travel patterns based on demand. Originally, these types of models were developed to determine the impact of infrastructure improvements. They forecast specific outputs, such as mode choice, destination choice, and route choice.

\section{Functionality}

construction management. Construction management involves the overall planning, coordination, determination of resource requirements, and implementation of the project. Determination of time-of-day for construction, project design and optimal construction scheduling, and traffic impact analysis are considered as part of the analysis to estimate the impact of management strategies.

logistics. Logistics involves determining efficient practices to transport materials and optimal scheduling to reduce operational and storage costs. The work zone logistics involve determining the duration of the closure of lanes, construction techniques, and how the workers will put up the cones, etc.

operations. Operations involve analysis of current management and safety of traffic and other users. Operations typically involve planning and maintaining signs, signals, pavement markings, and lighting. The management of intelligent transportation systems and safety initiatives to improve driver behavior are considered. Determination of traffic measurements such as delay, speed, occupancy, levels of service, queue lengths, and others are used to evaluate the behavior and functionality of traffic operations and management.

planning. Planning involves making long-term decisions and goals. The involvement of all users of the system is normally considered as part of the process, as improvement strategies are evaluated to improve the overall functionality of the system. Forecasting of future demand growth, employment, and land use are normally considered, as well as estimating impacts of proposed future improvements.

\section{Users and Proprietary Issues}

engineers. Use by engineers typically involves studying traffic impacts from an operational aspect, as well as the planning process of project-specific construction and operational management strategies. Project design and coordination are topics considered by the engineers interested in actual implementation of such strategies. planners. Use by planners typically involves the advanced long-term planning of strategies of a road network depicting various projects to improve systemwide functionality. Demand forecasting, employment, and land use strategies are topics of interest for such planners, as well as system effects and air quality issues based upon traffic and population growth.

proprietary. Proprietary software is defined as software that is licensed under exclusive legal right of the developer and/or owner. The user is given the right to use the software under license agreements and restricted from tampering and modifying such software. Other software may be termed as open source or freeware, meaning the use and licensing is more liberal in use, study, and changes and improvements of software to users. Freeware refers more to the free use of software, while open source is focused on the community use and development of software to benefit the overall software community.

\section{Data Inputs}

cost of various strategies. Different construction strategies have different implications on life-cycle costs. Use of fast construction material and techniques can result in reduction in the period of time work zones are implemented but may require higher regular maintenance costs during the life cycle of the project. These costs and benefits need to be evaluated at a life-cycle level.

pavement. As identified in the interviews in the earlier tasks, the pavement management systems of most DOTs and MPOs play a critical role in determining projects and project sequencing. Therefore, it is critical to determine software tools that require pavement inputs and how they are utilized.

production rate for various strategies. Several construction strategies identified during the interviews have different production rates depending on the materials being used, the construction technique, weather, and night versus day, all of which have a significant effect on the duration of work zone.

traffic. Traffic data include volume counts, speeds, travel time, and density and are used to calibrate and validate simulation models.

\section{Dynamic Demand Changes}

departure time choice. Departure time choice is usually a facet of the mode choice a traveler must make. For instance, a traveler using a passenger car may depart at any time, while a traveler using bus transit must wait until the next bus arrives in order to depart.

destination change. A destination change occurs when a traveler diverts to a destination other than the one originally intended when the trip began. 
en route diversion. A diversion that occurs when a traveler decides to alter his or her route during the trip, because of a number of factors including ITS signs warning of impending congestion, radio announcements, word-of-mouth, or approaching traffic congestion first-hand.

induced or foregone demand. Induced demand (latent demand) is a phenomenon that occurs when traffic volumes increase in reaction to facility Levels of Service (LOS) and/or capacities that increase. Foregone demand is the opposite effect, where facilities with low LOS and/ or capacities experience lower volumes because of traveler hesitancy to use such facilities.

mode shift. Any shift a traveler makes in mode in order to complete a trip is an action that could be part of an overall trip plan or due to dissatisfaction with the current mode.

pretrip route diversion. This type of diversion occurs when a traveler decides to alter his or her route before the trip begins.

\section{Measure of Effectiveness}

agency cost. A figurative cost is typically a constructionrelated cost to a government agency (usually the Transportation Department) faced by delay in construction and construction costs.

environmental impact. The environmental impact is directly related to the amount of emissions that vehicles make during trips. This measure is especially relevant when a large amount of congestion is present.

queue length and delay. Queue lengths and delays are used as measures of effectiveness to evaluate the type and level of impact a work zone will have.

road user cost. A figurative cost ascribed to all road users who face delays and congestion. This cost represents the negative impact of such road conditions and the road user's preference to avoid such costs.

safety surrogates. Any data set that can act as a surrogate to safety. For example, speed variance, number of lane changes, and conflicting points are all considered safety surrogates.

traffic conditions. Traffic conditions represent a broad data set used by traffic engineers and planners to assess the traffic conditions (e.g., speed, delays, accelerations, lane changing) on any particular roadway.

\section{Resource Requirements}

animation or presentation. The ability of the software to make animations or presentations is very important for traffic simulation to present results and also to locate trouble spots in the network.

availability of source code or algorithm. Open source software is any computer program that allows fellow developers to see the actual code that makes up the software. This makes it much easier for developers in similar areas to calibrate. Open source software is usually free or donation-based.

computational speed. The computational speed of software is a measure of the amount of time it takes to execute all the required steps from start to finish. Most can be done in a matter of minutes, but more complicated systems can take several hours.

cost. The cost of software is the price that the developer and/ or publisher ask the user to pay for their product. This is the opposite of nonproprietary software, which is available for free or by donation.

effort in application. The amount of effort required in transferring an existing network or data set into the newer system.

Excel based. Excel-based software uses Microsoft Excel as a window into which the software is entered. This means that the software is merely an extension of Excel, rather than unique software.

level of effort for training. This is a measure of the software's ease of use. Easy software can be understood after only a few demonstrations, but more complicated software may require several days of training. As a general rule, open source software is usually more complex and less user-friendly than commercially developed software.

memory. The amount of memory a given program will take up is a measure of the size (in bytes) of the program and its files.

transferability of data to other packages. The ability of data to be exchanged across multiple packages is important in order to coordinate output between packages. This is usually facilitated by either converting the file or relying on a universal file format.

\section{Strategies}

Based on the literature review and interviews conducted, the team identified several work zone strategies to minimize impact. Software tools were evaluated based on whether they have the ability to evaluate the following strategies:

- Constructability versus project delivery;

- Daytime-nighttime work;

- Early and late dynamic merging;

- Grouping nontraffic tasks;

- Improve parallel roads;

- Improve signal timing;

- Incentive/disincentive;

- Pavement programming;

- Programming by element;

- Scheduling under critical events or sensitive land use;

- Short-duration closures;

- Total versus partial shutdown;

- Work zone ITS; and

- Work zone speed management. 


\section{References}

Cambridge Systematics, PB Consult, and System Metrics Group. NCHRP Report 545: Analytical Tools for Asset Management. Transportation Research Board of the National Academies, Washington, D.C., 2005.

Chen, X., J. Weissmann, T. Dossey, and W. R. Hudson. URMS: A Graphical Urban Roadway Management System at Network Level. In Transportation Research Record No. 1397, TRB, National Research Council, Washington, D.C., 1993, pp. 103-111.

FHWA (Federal Highway Administration). Summary of Case Study Experience. Mitigating Traffic Congestion: The Role of Demand-Side Strategies. Publication FHWA-HOP-05-001. FHWA, U.S. Department of Transportation, 2004.

Gaspar, Jr., L. Compilation of First Hungarian Network-Level Pavement Management System. In Transportation Research Record No. 1455, TRB, National Research Council, Washington, D.C., 1994, pp. 22-30.

Gerke, R. J., C. M. Dewald, and R. Gerbrandt. Use of Highway Network Level Data for a Project Level Life Cycle Analysis. Crossroads 2000 Proceedings. Center for Transportation Research and Education, Iowa State University, Ames, 1998, pp. 135-138.
Lee, E.-B. Construction Productivity and Constraints for Concrete Pavement Rehabilitation in Urban Corridors. In Transportation Research Record: Journal of the Transportation Research Board, No. 1712, TRB, National Research Council, Washington, D.C., 2000, pp. 13-22.

Lee, E.-B. Construction Productivity Analysis for Asphalt Pavement Rehabilitation in Urban Corridors. In Transportation Research Record: Journal of the Transportation Research Board, No. 1813, Transportation Research Board of the National Academies, Washington, D.C., 2002, pp. 285-294.

Sharma, H., C. McIntyre, Z. Gao, and T.-H. Nguyen. Developing a traffic closure integrated linear schedule for highway rehabilitation projects. Journal of Construction Engineering and Management, Vol. 135, No. 3, 2009, pp. 146-155.

Wang, K. C. P., J.Zaniewski, and J. Delton. Analysis of Arizona DOT's New Pavement Network Optimization System. In Transportation Research Record No. 1455, TRB, National Research Council, Washington, D.C., 1994, pp. 91-100. 


\section{ABBE \\ Detailed Literature Review}

\section{Corridor and Network Analysis Techniques Publications}

Akyildiz, S. Development of New Network-Level Optimization Model for Salem District Pavement Maintenance Programming. Thesis. Virginia Polytechnic Institute and State University, Blacksburg, 2008. http://scholar.lib.vt.edu/theses/ available/etd-08282008-121858/unrestricted/Sercan Akyildiz_Thesis.pdf

Relevance: High

Description: This thesis presents the development and implementation of a network-level pavement maintenance optimization model which can be used by maintenance managers as a decision-making tool to address the maintenance budget allocation issue.

Anastasopoulos, P., S. Labi, and B. McCullouch. Identifying the Appropriate Contract Types for Highway Maintenance and Rehabilitation Projects on the Basis of Project Characteristics. Source Data: Transportation Research Board Annual Meeting 2009 Paper \#09-2203. 2009.

Relevance: High

Description: In this study, highway project data from the U.S.A. and abroad are analyzed using simultaneous equation models for the traditional and innovative contract types. These models are estimated by three-stage least squares while duly accounting for the interrelationships between contract duration, length and cost. The results suggest that a number of factors significantly affect the contract characteristics, such as the number of different maintenance activities incorporated in the contract, contract duration, length, and cost, and the asset type that is being preserved or maintained.

Aultman, S., and A. Lari. Advanced Acquisition of Right-ofWay: Best Practices and Corridor Case Studies. 2009. http://
conservancy.umn.edu/bitstream/48936/1/Sara\%20Break iron\%20Aultman.pdf

Relevance: Low

Description: This study documents MnDOT's current advanced acquisition practices and investigates the appreciation rates of parcels adjacent to transportation corridors. The corridor case studies showed that the effect of being adjacent to a transportation corridor is heterogeneous across the three corridors studied.

Bakó, A., and K. Ambrus-Somogyi. Maintenance and Rehabilitation Systems of Infrastructures Management. Acta Polytechnica Hungarica. 2005. http://bmf.hu/journal/ Bako_4.pdf

Relevance: High

Description: The paper briefly discusses some elements (monitoring of trial sections, asset value calculation) and several models (urban and motorway PMS, network level, multi-stage highway PMS, BMS). The formal construction of a combined PMS-BMS system is also presented where Markovian type deterioration process is supported and can be solved by Linear Programming.

Berkow, M., C. Monsere, P. Koonce, R. Bertini, and M. Wolfe. Prototype for Data Fusion Using Stationary and Mobile Data: Sources for Improved Arterial Performance Measurement Transportation Research Record: Journal of the Transportation Research Board, No. 2099. 2009.

Relevance: Moderate

Description: This paper describes the results of a case study from Portland, Oregon, that extracted improved arterial performance measures by combining data from traffic signal system detectors and from buses acting as probe vehicles. The paper includes recommendations for expanding the techniques to other corridors, using higher resolution, real-time 
transit location data, and online implementation of an arterial travel time information system.

Chen, X., J. Weissmann, T. Dossey, and W. R. Hudson. URMS: A Graphical Urban Roadway Management System At Network Level. TRR. 1993.http://pubsindex.trb.org/view .aspx?id $=383230$

Relevance: High

Description: The objective of the system is to assist in scheduling maintenance and rehabilitation (M\&R) projects at the network level. URMS works in graphics mode and is characterized by simplicity, flexibility, and user-friendliness. In URMS, management sections can be composed of one or more street blocks. Pavement condition index, which is derived from seven types of distress, is the main calculation variable used in the system. Other evaluation indexes include pavement age, mixed average daily traffic, and truck average daily traffic.

Chootinan, P., A. Chen, M. Horrocks, and D. Bolling. A MultiYear Pavement Maintenance Program Using a Stochastic Simulation-Based Genetic Algorithm Approach. Transportation Research Part A: Policy and Practice. 2006. www.science direct.com/science?_ob=ArticleURL\&_udi=B6VG74J4B94S-2\&_user $=108 \_$rdoc $=18 \_\mathrm{fmt}=$ \&_orig $=$ search \&

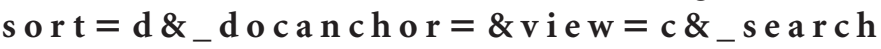
StrId $=1050530562 \&$ _rerunOrigin $=$ google $\&_{-}$ acct $=$ C000050221\&_version $=1$ \&_urlVersion $=0$ 0\&_userid $=$ 10\&md5=e2320588c2336156bcacf09acd90df54

Relevance: High

Description: The objective of this paper is to introduce a multi-year pavement maintenance programming methodology that can explicitly account for uncertainty in pavement deterioration. This is accomplished with the development of a simulation-based genetic algorithm (GA) approach that is capable of planning the maintenance activities over a multiyear planning period.

FHWA. Summary of Case Study Experience. 2004. http://ops .fhwa.dot.gov/publications/mitig_traf_cong/sum_experience .htm

Relevance: High

Description: Transportation Corridor Planning and Construction Mitigation case studies.

Florida DOT.Analysis of Work Zone MOT Data Collection and Usage Procedures. 2002. www.dot.state.fl.us/research-Center/ Completed_Proj/Summary_CN/FDOT_BC395_rpt.pdf

Relevance: Low

Description: The goal of the research described herein was to identify and correct deficiencies in the collection and use of maintenance of traffic data for construction work zones, including revising the current MOT accident report form. Current FDOT construction office procedures for collecting and utilizing data on maintenance of traffic, vehicular crashes and incidents in work zones were studied. Based on this study and the data collection procedures followed by other states, a new paper form was developed. To overcome limitations in the current procedures, the entire system was computerized and a client-server database and web-based data entry forms were developed.

Gaspar, L., Jr. Compilation of First Hungarian Network-Level Pavement Management System. TRR. 1994. http://pubsindex .trb.org/view.aspx?id $=424728$

Relevance: High

Description: The first Hungarian network-level pavement management system relies on Markov transition probability matrices. A combined condition parameter is applied taking into consideration the bearing capacity, the unevenness, and the surface quality scores. The matrix variables are pavement type, traffic volume, and intervention variants. The system can be used to calculate the funds needed for highways at various condition levels, for the regional distribution of given amounts of money at a minimum cost to the national economy, and for the determination of the economic and technical consequences of subsequent modifications in funds distribution. Several trial runs have proved the practicability of the system.

George, K. P., W. Uddin, P. J. Ferguson, A. B. Crawley, and A. R. Shekharan. Maintenance Planning Methodology for Statewide Pavement Management. TRR. 1994. http:// pubsindex.trb.org/view.aspx?id $=424741$

Relevance: Moderate

Description: Four major subsystems are identified: (a) a pavement management system inventory and monitoring data base, (b) condition data analysis accomplished through interface program, (c) a maintenance, planning, and budgeting (MPB) program, and (d) a priority ranking of rehabilitation projects.

Gerke, R. J., C. M. Dewald, and R. Gerbrandt. Use of Highway Network Level Data for a Project Level Life Cycle Analysis. 1998 Transportation Conference Proceedings. 1998. www .ctre.iastate.edu/pubs/crossroads/135use.pdf

Relevance: High

Description: The subject of this paper covers a project that was successfully commenced in 1997 and completed in 1998. This paper discusses the development of a method to use network level PMS data for a project level life cycle costing analysis. The method was successfully applied to a variety of road 
conditions and structures that make up the primary highway network in Saskatchewan, Canada.

Golabi, K., and P. Pereira. Innovative Pavement Management and Planning System for Road Network of Portugal. ASCE. 2003. http://cedb.asce.org/cgi/WWWdisplay.cgi?0301569

Relevance: Moderate

Description: In this paper, the writers discuss the development of a comprehensive pavement management system and its implementation in Portugal.

Lee, E.-B. Construction Productivity Analysis for Asphalt Pavement Rehabilitation in Urban Corridors. TRR. 2002. http://trb.metapress.com/content/n678m57m518815h6/

\section{Relevance: High}

Description: Explains how factors in asphalt road construction affect construction production (CA4PRS).

Lee, E.-B. Construction Productivity and Constraints for Concrete Pavement Rehabilitation in Urban Corridors. TRR. 2000.http://trb.metapress.com/content/k46g576u71m68r38/

Relevance: High

Description: Explains how factors in concrete road construction affect construction production (CA4PRS).

Li, N., R. Haas, and M. Huot. Integer Programming of Maintenance and Rehabilitation Treatments for Pavement Networks. TRR.2007.http://trb.metapress.com/content/n533h20315317 $386 / ? \mathrm{p}=3008 \mathrm{~b} 6 \mathrm{e} 408 \mathrm{c} 143 \mathrm{~d} 2 \mathrm{a} 3 \mathrm{fe} 62 \mathrm{c} 8948 \mathrm{c} 55 \mathrm{a} 5 \mathrm{sp} \mathrm{i}=26$

Relevance: Moderate

Description: A new approach to multiyear maintenance and rehabilitation (M\&R) optimization programming for pavement network management is discussed; the approach can be used to help highway agencies make strategic decisions in choosing the optimal investment for their pavement networks. The M\&R treatments are standardized in terms of costs, benefits, and performance impacts on the existing pavements.

Maze, T. Synthesis of Procedures to Forecast and Monitor Work Zone Safety and Mobility Impacts. 2005. www.ctre .iastate.edu/reports/work_zone_mobility.pdf

Relevance: High

Description: This report provides a synthesis of what is currently being done by STAs across the country to plan, manage, operate, and evaluate work zone safety and mobility. The research to develop this synthesis was broken into three distinct steps. The first step was to review the literature regarding work zone safety and mobility strategies. The second was to conduct interviews with staff members at 30 STAs. The last step was to conduct more detailed case studies of three STAs.
Mbwana J. R. and M. A. Turnquist. Optimization Modeling for Enhanced Network-Level Pavement Management System. TRR. 2007. http://trb.metapress.com/content/j557u57277 $8 \mathrm{w} 212 \mathrm{x} /$

Relevance: Moderate

Description: A new formulation of a network-level pavement management system (PMS) model is described, which includes the identification of specific network links in the optimization. This model uses Markov transition probabilities for pavement condition modeling, as have several previously developed PMS models.

Miller, M., L. Novick, Y. Li, and A. Skabardonis. San Diego I-15 Integrated Corridor Management (ICM) System: Phase I. 2008. www.path.berkeley.edu/PATH/Publications/PDF/ PRR/2008/PRR-2008-33.pdf

Relevance: High

Description: In this report, the authors described the Stage One work of the federally sponsored U.S. DOT. Integrated Corridor Management Program for the I-15 Corridor in San Diego County, California, between State Route 52 in the city of San Diego and State Route 78 in the city of Escondido.

Morales, J. M. Work Zone Traffic Impact Analysis Course. FHWA by ATSSA. 2009.

Relevance: High

Description: The objectives of the course are to provide guidance to agencies and/or individuals considering work zone traffic impact analysis; to provide a broad, fundamental understanding of how analytical tools can be used to support work zone traffic impact analysis; to list and discuss some available tools for work zone impact analysis.

Morcous, G., and Z. Lounis. Maintenance Optimization of Infrastructure Networks Using Genetic Algorithms. 2004. www.sciencedirect.com/science?_ob=ArticleURL\&_ udi $=$ B6V20-4DS6YJ7-1\&_user $=108 \_r d o c=1 \& \_f m t ~=\&$ orig $=$ search \&_sort $=d \& \_d o c a n c h$ or $=\& v i e w=c \&$ acct $=$ C000050221\&_version $=18 \_$urlVersion $=0$ \&_userid $=$ 10\&md5=ecdbf1e3be0a75bec7a110b0bcfdbbb 9

Relevance: Moderate

Description: This paper presents an approach to determining the optimal set of maintenance alternatives for a network of infrastructure facilities using genetic algorithms. Optimal maintenance alternatives are those solutions that minimize the lifecycle cost of an infrastructure network while fulfilling reliability and functionality requirements over a given planning horizon.

Pereira, P., J. Pais, E. Freitas, H. M. Ribeiro Dias da Silva, and J. Oliveira. The Road Network Rehabilitation for the 21st Century: A Global Vision on Innovation in Road Rehabilitation, 
Intersections, 2007. http://repositorium.sdum.uminho.pt/ handle/1822/7949

Relevance: High

Description: This article intends to be an approach to road network rehabilitation in the context of the new challenges for the near future. Firstly, the current methodology used in the maintenance and rehabilitation and its impact on the pavement life cycle costs is presented. Secondly, the role of innovation at the service of society in the field of road engineering is presented in order to assure a high level of the ride quality, as well as a sustainable construction and rehabilitation of road pavements.

QuickZone Case Studies. http://ops.fhwa.dot.gov/wz/ traffic_analysis/quickzone/index.htm\#case.Various DatesCurrently Online. FHWA contact: Deborah Curtis at deborah.curtis@fhwa.dot.gov.

Relevance: Moderate

Description: To better understand the performance of QuickZone in mitigating congestion due to work zones, FHWA created a series of case studies highlighting the use of QuickZone on real-world projects. There are eight sites featured in the case studies.

Samson, M., and T. Shibayama. Management of Pavement Network Maintenance and Rehabilitation Planning Using Shuffled Complex Evolution. 2007.http://library.jsce.or.jp/ jsce/open/00524/2007/14-0143.pdf

Relevance: Moderate

Description: This paper presents an optimization of segment-linked maintenance and rehabilitation plan for a pavement network.

Shrestha, C. B. Developing a Computer-aided Methodology for District Road Network Planning and Prioritization in Nepal. International Journal of Transport Management. 2003. www.sciencedirect.com/science?_ob $=$ ArticleURL\&_ udi $=$ B6W83-4BNMFJ7-1\&_user $=10 \& \_r d o c=1 \& \_\mathrm{fmt}=$ \& orig $=$ search \&_sort $=d \& \_d o c a n c h o r=\& v i e w=c \&$ acct $=$ C000050221\&_version $=18 \_$urlVersion $=0$ \&_userid $=$ $10 \& \mathrm{md} 5=43 \mathrm{c} 4764223 \mathrm{ea} 882 \mathrm{e} 34 \mathrm{e} 3380 \mathrm{~d} 6 \mathrm{ca} 67 \mathrm{f} 7 \mathrm{e}$

Relevance: Low

Description: This paper proposes a computer-aided methodology for planning and prioritizing district transportation networks. The methodology has two versions, one for developed areas and another for underdeveloped areas.

Sirirangsi, P., D. Satirasetthavee, and P. Herabat. NetworkLevel Maintenance Planning Using Pavement Valuation. Journal of the Eastern Asia Society for Transportation Studies. 2003. www.easts.info/2003journal/papers/0956.pdf
Relevance: High

Description: The integration of asset valuation concept with existing management systems is explored in this study in order to illustrate how to apply the estimated pavement value in maintenance planning. The pavement value is calculated based on the cost approach. Prioritization and optimization are used to determine optimal network-level maintenance planning by using pavement values.

Wang, K., J. Zaniewski, and J. Delton. Analysis of Arizona DOTs New Pavement Network Optimization System. TRR. 1994. http://pubsindex.trb.org/view.aspx?id $=424737$

Relevance: High

Description: The new NOS is named AZNOS, which stands for Arizona Network Optimization System. NOS has been the primary instrument used by ADOT in planning its highway preservation program since 1980 .

Minnesota DOT. Work Zone Mobility Impact Assessment Decision Tree. 2007. www.dot.state.mn.us/trafficeng/work zone/wzmobility/WZ-ImpactAssessmentDecisionTree.pdf

Relevance: High

Description: This report looks at how mobility impact is incorporated into work zone analysis.

Zhang, W-B. Study of Integrated Corridor Management for San Francisco Bay Area I-880 Area Corridor. 2008. www.path .berkeley.edu/PATH/Publications/PDF/PRR/2008/PRR2008-30.pdf

Relevance: High

Description: The I-880 Corridor in the San Francisco Bay Area is a multimodal corridor that includes a robust freeway network, major arterials carrying high volumes of local traffic, a rail and bus transit network, and heavy freight traffic. This report summarizes the findings of three reports dealing with the I-880 Integrated Corridor Management (ICM) program. The three studies focused on (1) the concept of operation, (2) sample data for analysis, modeling and simulation, and (3) systems requirements.

\section{Corridor and Network Modeling Publications}

Chang, Y. Y., O. Sawaya, and A.Ziliaskopoulos. A Tabu Search Based Approach for Work Zone Scheduling. 2000. www.work zonesafety.org/files/documents/database_documents/00901 .pdf

Relevance: High

Description: This paper introduces a work zone scheduling methodology, which is intended to be used as a decision-aid 
tool for transportation planners that have to undertake a number of work zones larger than the available number of construction crews during a given time period. Two traffic assignment approaches are used to evaluate the traffic delay caused by work zone combinations, and a Tabu Search methodology is employed to select the schedule with the least total traffic delay. The approach is implemented and tested on an example network and on a large-scale realistic network, the Columbus, Ohio, urban network. The results show that substantial network improvements can be obtained by accounting for work zone impacts and implementing appropriate schedules.

\section{Chatterjee, I., P. Edara, S. Menneni, and C. Sun. Replication of Work Zone Capacity Values in a Simulation Model.TRIS. 2009.}

\section{Relevance: High}

Description: This study provides the practitioner a simple method for choosing appropriate values of driving behavior parameters in the VISSIM micro-simulation model to match the desired field capacity for work zones operating in a typical early merge system. The two most significant car-following parameters and one lane changing parameter were selected and varied to obtain different work zone capacity values. CC1 is the desired time headway, CC2 is the longitudinal following threshold during a following process, and the safety distance reduction factor is representative of lane changing aggressiveness. Additionally, for each recommended set of driving behavior parameters, lane distribution of the closed lane at different points upstream of the taper is collected. It was verified that the recommended parameter values not only produce the desired capacities but also create traffic conditions consistent with traffic flow theory.

Chu, L., H. X. Liu, and W. Recker. Using Micro-simulation to Evaluate Traffic Delay Reduction from Workzone Information Systems. 2007. www.dot.ca.gov/newtech/roadway/ca4prs/ czw_workshop/docs/Lianyu_Chu_UC\%20Berkley.pdf

Relevance: High

Description: Describes evaluation of delay from information systems at work zones using microsimulation.

Edara, P. K., and B. H.Cottrell, Jr. Estimation of Traffic Mobility Impacts at Work Zones: State of the Practice. 2006. www .workzonesafety.org/files/documents/database_documents/ 07-0255.pdf

Relevance: High

Description: Assessing the safety and mobility impacts of work zones across the project development phases of road construction and maintenance projects is an emphasis area of the Federal Highway Administration's Final Rule on Work Zone Safety and Mobility (Final Rule). Specifically, the design phase of developing traffic control plans requires a traffic analysis to estimate queue lengths, travel times, and delays to determine lane closure times. State departments of transportation (DOTs) are required to comply with the requirements of the Final Rule by October 2007. To this end, this study was conducted to provide the Virginia Department of Transportation (VDOT) with the state-of-the-practice tools for estimating the traffic mobility impacts at work zones. The conclusions in this study should help VDOT and other state DOTs choose the appropriate tool(s) for estimating the traffic impacts in and around work zones.

Elefteriadou, L., M. Jain, and K. Heaslip. Impact of Lane Closures on Roadway Capacity Part B, Arterial Work Zone Capacity. 2008. www.dot.state.fl.us/research-center/ Completed_Proj/Summary_RD/FDOT_BD545_61_B.pdf

Relevance: High

Description: The purposes of this study are twofold. First, diversion behaviors at work zones were modeled in a discrete choice modeling framework. We conducted a stated preference survey to collect data on drivers' diversion propensity and then calibrated a binary logit model. The model provides a better understanding of drivers' diversion behaviors at work zones and can be used to forecast diversion rates in a work zone traffic analysis. Second, we proposed two procedures, namely open-loop and closed-loop, to apply the calibrated binary logit model to compute the RTF. An excel tool was developed to facilitate the computation.

FHWA. Traffic Analysis Tools Volume VIII: Work Zone Modeling and Simulation-A Guide for Decision-Makers. 2008. http://ops.fhwa.dot.gov/wz/traffic_analysis/tatv8_ wz/tatv8workzone.pdf

Relevance: High

Description: This document is intended to provide guidance to decision-makers at agencies and jurisdictions considering the role of analytical tools in work zone planning and management. It is often unclear what kind of analytical approach may be of most value, particularly in light of complex data requirements and staff training. The decision to create an analytical capability to support decision making can be a significant investment and deserves careful consideration. In the end, work zone analysis should never be used to make key decisions but instead developed as a trusted resource for understanding the potential mobility impacts and using this information to inform key decisions.

FHWA. Traffic Analysis Tools Volume IX: Work Zone Modeling and Simulation-A Guide for Analysts. 2009. http://ops .fhwa.dot.gov/wz/traffic_analysis/tatv9_wz/tatvol_9.pdf

Relevance: High

Description: This volume provides specific guidance to the analyst, researcher, or manager in charge of conducting a 
specific work zone analysis project or who has been charged with developing an overall work zone modeling program or approach. This volume includes numerous case study examples, discussion and analysis designed to provide the prospective work zone analyst with information pertaining to the selection of a transportation modeling approach (including the identification of opportunities for use, managing technical risk and examples) as well as specific project applications (including constructability, scheduling and transportation management plan design and evaluation).

FHWA. Work Zone Analysis Leaflet. 2009. http://ops.fhwa .dot.gov/wz/traffic_analysis/wza_leaflet/wza_leaflet.htm

Relevance: Low

Description: Brief, easy-to-read overview of work zone analysis and how modeling and simulation can be used as part of the analysis.

Gou, J., L. Zhang, J. Altman, and W. Davis. QuickZone Improvement for Rural Freeway and Model Validation. 2009. http://pubsindex.trb.org/view.aspx?id=881550

Relevance: High

Description: This paper describes an improvement made to QuickZone work zone software. The change incorporates delays from the deceleration before a work zone, slow moving speed along the work zone, acceleration after the work zone and stochastic delay within the work zone area.

Hadi, M., Y. Xiao, H. Ozen, and P. Alvarez. Evaluation Tools to Support ITS Planning Process: Development of a Sketch Planning Tool in FSUTMS/Cube Environment. 2009. www .dot.state.fl.us/research-center/Completed_Proj/Summary_ PL/FDOT_BD015_19.pdf

Relevance: High

Description: This research project investigates the development of tools and procedures to perform sketch-planning evaluation of the costs and benefits of ITS alternatives (work zone management) within the Florida Standard Urban Transportation Model Structure (FSUTMS) modeling environment.

Harb, R. Safety and Operational Evaluation of Dynamic Lane Merging in Work Zones. Thesis. University of Central Florida, Orlando, 2009.

Relevance: High

Description: Utilizes traffic simulation to evaluate various kinds of dynamic merge strategies

Hardy, M., and K. Wunderlich. Traffic Analysis Tools Program Support: Work Zone Traffic Analysis Strategies, Work Zone Analysis Primer. FHWA by Noblis (600 Maryland Ave,
SW Suite 755, Washington, DC 20024) Contract DTFH6105-D-00002, Project No. 04050002-01. January, 2008 (draft).

Relevance: High

Description: This document is intended to provide guidance to agencies and jurisdictions considering the role of modeling and simulation tools in work zone planning and management. It describes the various levels and types of analysis tools available. The focus is not on a one time tool selection activity, but rather on a more complete vision that seeks highvalue opportunities for modeling and simulation. It describes which tools are available for corridor studies.

Hassanein, A. Planning and Scheduling Highway Construction Using GIS and Dynamic Programming. 2004. http:// universityofarizona.worldcat.org/oclc/56064690\&referer= brief_results

Relevance: High

Description: This paper presents a model designed to integrate the planning and scheduling phases of highway construction projects, focusing primarily on the planning aspects. The model automatically generates the work breakdown structure (WBS) and precedence network respecting job logic and stores a list of construction operations typically encountered in highway projects. The generated network can subsequently be modified to suit the unique requirements of the project being considered. An object-oriented model is developed for planning highway construction operations. The model employs resource-driven scheduling in order to suit the repetitive nature of this class of projects. It accounts for (1) resource availability; (2) multiple preceding and succeeding activities; (3) transverse obstructions; (4) activities with varying quantities of work along the highway length; (5) the impact of inclement weather on crew productivity; and (6) the beneficial effect of the learning curve. At the core of the model is a relational database designed to store available resources and their respective unavailability periods. The model enables both: (1) activities executed by own force and (2) activities subcontracted out. The model is incorporated in a prototype software that operates in the Microsoft Windows environment and generates schedules in both graphical and tabular formats. An example project is analyzed to demonstrate the features of the developed model.

Heaslip, K., A. Kondyli, D. Arguea, L. Elefteriadou, and F. Sullivan. Estimation of Freeway Work Zone Capacity Using Simulation and Field Data. Source Data: Transportation Research Board Annual Meeting 2009 Paper \#09-0287. 2009.

Relevance: High

Description: In this study, CORSIM (Version 5.1) was used to develop a comprehensive database for various work zone scenarios. Field data was used to complement model validation. 
The observed capacities were compared to those predicted by the new analytical models as well as those estimated by the HCM 2000.

Kang, K-P., and G-L. Chang. Lane-Based Dynamic Merge Control Strategy Based on Optimal Thresholds for Highway Work Zone Operations. 2009. www.workzonesafety.org/node/9711

Relevance: High

Description: Despite the potential effectiveness of the dynamic late merge (DLM) control, most existing DLM systems, based on static thresholds, cannot best perform under time-varying traffic conditions. This paper presents an advanced dynamic merge control, called a lane-based dynamic merge control model and its operational algorithm, which is based on the optimized control thresholds that take into account the interactions among the speed, flow, and available work zone capacity. The focus of this study is on how to select the control variables and to determine their optimal thresholds in response to traffic flow dynamics. Evaluation results with extensive simulation experiments have shown the promising properties of the proposed dynamic merge control and its operational algorithm.

Khanta, R. P. Evaluation of Traffic Simulation Models for Work Zones in the New England Area. Thesis. University of Massachusetts, Amherst, 2008. http://scholarworks.umass .edu $/$ cgi $/$ viewcontent.cgi? article $=1262 \&$ context $=$ theses

Relevance: High

Description: These packages include, for example QueWZ, QuickZone, CORSIM and VISSIM. This research evaluates the capabilities of these simulation packages to determine whether or not these packages produce reasonable impact estimates. The research concludes with a set of recommendations to assist transportation professionals in selecting the most appropriate simulation package for a particular work zone project.

Larking, J. and M. Hardy. QuickZone-A Work Zone Delay Estimation and Analysis Tool. 2002. SAIC has a copy.

Relevance: High

Description: This presentation gives an overview of the QuickZone software package and walks through three examples of how to use the software.

Lee, E.-B. Application of Macro- and Microscopic Simulations for the Traffic Planning of Urban Highway Reconstruction. 2004. http://trb-forecasting.org/papers/2005/ADB40/ 05-1552_Lee.pdf

Relevance: High

Description: The case study introduced in this paper applied dual traffic simulation models (macro- and microsimulation) to develop a comprehensive traffic management plan (TMP) for the Interstate-15 (I-15) Devore reconstruction (a 4.2 kilometer stretch) with high traffic volume. Paper No: 05-1552.

Lee, H.-Y. Optimizing schedule for improving the traffic impact of work zone on roads. 2009. www.science direct.com/science?_ob=ArticleURL\&_udi=B6V204 WG JKK 7-2\&_user $=10 \& \_$rdoc $=1 \&$ f m t $=\&_{\text {_ }}$ orig $=$ search\&_sort $=d \&$ decanchor $=\&$ view $=c \& \_s e a r c h$ StrId $=1066688384 \&$ \& rerunOrigin $=$ google \& acct $=$ C000050221\&_version $=18 \_u r l$ Version $=0$ \&_userid $=$ $10 \&$ md5 $=89$ cdd89f6a6338bb675cedc42d6e20f 1

Relevance: High

Description: Many different types of construction projects set up work zones on roads. Especially in urban areas, lane closures as a result of work zones have a considerable impact on local traffic. However, for a construction project that consists of several work zones and several work crews, the traffic impact may be improved by appropriate scheduling. Therefore, this paper proposed a scheduling model based on the route-changing behavior of road users. The proposed model calculates the traffic delay of vehicles by microscopic simulation, and applies team ant colony optimization to search for a near-optimal schedule. The project planner then ensures that the contractor executes the activities according to the near-optimal schedule. The proposed model is applied to schedule a sewer system construction project in a city. The results of the study indicate that with the proposed model the total traffic delay is reduced by $11.1 \%$ when compared with a schedule proposed by the project planner.

\section{Lu, J. J., Z. Wang, and X. Wang. Integrated Work Zone Safety Management System and Analysis Tools. 2009. www.dot .state.fl.us/research-center/Completed_Proj/Summary_ CN/FDOT_BD544_26_rpt.pdf}

Relevance: High

Description: A CORSIM-based preliminary evaluation of the DLM system at freeway work zones was produced to demonstrate if DLM has positive impacts on traffic operations or safety under certain traffic conditions.

Ma, W., R. L. Cheu, and D-H. Lee. Scheduling of Lane Closures Using Genetic Algorithms with Traffic Assignments and Distributed Simulations. 2004. http://cedb.asce.org/ cgi/WWWdisplay.cgi?0408112

Relevance: High

Description: In past research, several versions of hybrid genetic algorithm-simulation methodology have been proposed that aim to minimize a network's total traffic delay while scheduling multiple lane closures. The genetic algorithm is used as a search engine for generation of lane closure schedule, while a microscopic traffic simulation model is employed to calculate the 
total network travel time under each lane closure scenario. A difficulty in implementing this methodology practically is the long computing time required, due to the many simulation runs needed to evaluate the average total network travel time of each feasible schedule. This paper applies the precondition technique, standard error criterion, and termination criterion to reduce the number of necessary simulation runs. As a further improvement, traffic simulations are distributed in different processors of a multiprocessor machine. To further reduce the computing time, a two-stage hybrid genetic algorithm methodology has been proposed in this paper. This two-stage methodology consists of a hybrid genetic algorithm-traffic assignment methodology as the first stage, followed by a hybrid genetic algorithm-distributed simulation methodology as the second stage. The traffic assignment model is used to replace the traffic simulation model in the estimation of total network travel time in stage 1 . The applications of the improvement techniques have been demonstrated through a hypothetical problem involving 20 lane closure requests in a network consisting of 986 links, 397 nodes, and 22 origin-destination zones. Together, these improvement techniques contributed to up to $87 \%$ reduction in waiting time for a solution of the example problem.

Nassar, K., W. Thabet, and Y. Beliveau. Simulation of Asphalt Paving Operations Under Lane Closure Conditions. 2003. www.sciencedirect.com/science/article/B6V20-48V898S2/2/6efa20d92bf0d12876189671185c25b7

Relevance: Moderate

Description: Lane closures during paving operations on rural two-lane roads usually restrict the continuity of paving operations, causing delay in paving time and thus affecting the production rates. This paper presents a simulation model that was developed to assess the impact of the different variables on paving operations under lane closure conditions. The model developed is a high-fidelity computer simulation that incorporates an animation interface. The model involves traffic simulation as well as the construction process itself, and allows users to study the interaction between the two. Variables such as distance from plant, number and types of trucks, traffic volume, length of lane closure, maximum allowable work zone speed, and lane closure strategies are incorporated in the model. Users of the model can adjust these variables according to any particular project and consequently measure the effect on production rates and cost. A construction-oriented discrete event simulation language, Stroboscope, was used to develop the model and a 3D animation was developed to visually simulate the construction process for visual verification. The model was then used on a case study to evaluate paving operations. Sensitivity analyses were conducted using the simulation model to investigate the effects of the different variables on productivity and cost.
Ng, S. T. and Y. Zhang. Optimizing Construction Time and Cost Using Ant Colony Optimization Approach. 2007. http://link.aip.org/link/?QCO/134/721/1

Relevance: High

Description: Time and cost are the most important factors to be considered in every construction project. In order to maximize the return, both the client and contractor would strive to optimize the project duration and cost concurrently. Over the years, many research studies have been conducted to model the time-cost relationships, and the modeling techniques range from the heuristic methods and mathematical approaches to genetic algorithms. Despite that, previous studies often assumed the time being constant leaving the analyses based purely on a single objective-cost. Acknowledging the significance of time-cost optimization, an evolutionary-based optimization algorithm known as ant colony optimization is applied to solve the multi-objective time-cost optimization problems. In this paper, the basic mechanism of the proposed model is unveiled. Having developed a program in the Visual Basic platform, tests are conducted to compare the performance of the proposed model against other analytical methods previously used for time-cost modeling. The results show that the ant colony system approach is able to generate better solutions without utilizing much computational resources which provides a useful means to support planners and managers in making better time-cost decisions efficiently.

Porter, R. J. and J. M. Mason. Modeling Speed Behavior of Passenger Cars and Trucks in Freeway Construction Work Zones: Implications on Work Zone Design and Traffic Control Decision Processes. 2008. www.workzonesafety.org/ node/9110

Relevance: High

Description: Current work zone design and traffic control guidance is based on desirable speed outcomes; knowledge related to actual speed outcomes of design and traffic control decisions is limited. The objective of this research is to investigate relationships among speed behavior, roadway geometrics, and traffic control in freeway construction work zones. Four speed measures are modeled: 85th percentile passenger car speed, 85th percentile truck speed, passenger car speed deviation, and truck speed deviation. The research objective is accomplished through specification and estimation of a first-order autoregressive seemingly unrelated regression model to account for contemporaneous correlations between equation disturbances and positive autocorrelation. Data for model estimation were collected at 119 locations in 17 Pennsylvania and Texas work zones. Model estimation results show that several work design and traffic control features influence speed magnitudes and deviations. Findings also indicate that relationships among speed magnitude, speed 
deviation, work zone design, and traffic control are more complex than general engineering intuitions expressed in current work zone design guidance.

Qian, H. and S. Jing. Optimizing Work Zones for Two-Lane Urban Road Maintenance Projects Paper. 2007. http://qhxb .lib.tsinghua.edu.cn/myweb/english/2008/2008e5/644-650.pdf

Relevance: High

Description: Road maintenance work brings costs to the government and delays to users. The setting up of work zones often leads to severe congestion during peak hours, especially in busy urban areas. A road maintenance delay model is presented here that includes consideration of excessive traffic flow and non-motorists. A trial-and-error method is used to find the optimal work zone length and the best work starting time to minimize the total cost of maintenance and delays. A numerical example with a sensitivity analysis is also given. The results show that optimal starting time is not sensitive to the flow speed and the increase of work zone speeds sharply reduces the total cost when the road is congested.

Schnell, T., J. Mohror, F. Aktan, and T. Diptiman. Evaluation of Traffic Flow Analysis Tools applied to work zones based on flow data collected in the field. 2007. http://trb .metapress.com/content/b4j470k111w65118/

Relevance: High

Description: Evaluates and studies QueWZ, HCS, Synchro, CORSIM, ITRAF, TRAFVU.

Schnell, T. On the Accuracy of Commercially Available Macroscopic and Microscopic Traffic Simulation Tools for Prediction of Workzone Traffic. http://ops.fhwa.dot.gov/ wz/workshops/sheet $4 . h t m$

Relevance: High

Description: The Ohio Department of Transportation (ODOT) has identified the maintenance of traffic (MOT) as a top priority to serve the motoring public as part of a department strategic initiative. A key component of this strategy is to ensure that traffic flows efficiently through work zones. This paper describes work that was performed for ODOT to determine if commercially available traffic simulation models could be calibrated to yield accurate queue length and delay time predictions for planning purposes in freeway work zones. Four work zones on multi lane freeways were selected by ODOT for collection of the calibration data. Traffic flow video records were obtained at the four selected work zones using two ODOT video recording vans equipped with $15 \mathrm{~m}$ masts. Traffic flow parameters were extracted from the video records using the Mobilizer-PC software package. The traffic simulation/prediction tools that we investigated included the Highway Capacity Software (HCS),
Synchro, CORSIM (under ITRAF and TRAFVU), NetSim, and a macroscopic model called QueWZ92. Simulation models were constructed with all models for the selected work zones, and the simulated queue lengths and delay times were compared to the data that was extracted from the field data with Mobilizer-PC. The results of this study indicated that the microscopic simulation packages could not be calibrated to the oversaturated conditions that existed at the work zones. The calibrated microscopic simulation packages underestimated the actual length of the queues that formed in the real world. The macroscopic QueWZ92 produced more accurate estimates than the microscopic packages.

Sharma, H., C. McIntyre, Z. Gao, and T-H. Nguyen. Developing a Traffic Closure Integrated Linear Schedule for Highway Rehabilitation Projects. 2009. http://cat.inist.fr/?a Modele $=$ afficheN\&cpsidt $=21242995$

Relevance: High

Description: In recent years, the state departments of transportation have implemented a number of highway rehabilitation projects across the country. These projects differ fundamentally from new highway projects in that they require an uninterrupted flow of traffic throughout both the duration and geometric length of the project. Synchronization of traffic closure with the construction activities is crucial in such projects to avoid the traffic conflicts and prevent idle time for equipment and labor. Although most highway rehabilitation projects involve predominantly linear activities, the techniques of linear scheduling are not readily applicable to highway rehabilitation projects due to the conflict between the work zone and traffic flow. This paper documents the development of a traffic closure integrated linear schedule (TCILS) that addresses both traffic closure and work progress issues. The TCILS generates a single schedule for both the construction activities and the associated traffic closures. Visual and graphical features are also applied in the system, which makes it particularly applicable for highway rehabilitation projects. An actual concrete pavement rehabilitation project using the TCILS is presented as a sample of application. The findings from the sample project, although they are limited, show that the TCILS can be applied to an actual project. With recommended future development, the system is believed to be beneficial for both construction practitioners and academics.

Song, Z. and Y. Yin. Impact of Lane Closures on Roadway Capacity Part C, Modeling Diversion Propensity at Work Zones. 2008.www.dot.state.fl.us/research-center/Completed_ Proj/Summary_RD/FDOT_BD545_61_C.pdf

Relevance: High

Description: FDOT develops method to focus on two-lane roadway work zones, where one lane is closed and traffic flow must alternate on the one lane. 
Traffic Analysis and Tools. Version 4-February 3, 2006Compiled by AHB20(2) on Freeway Simulation. 2006. AHB20: Freeway Operations Research Circular.

Relevance: High

Description: Describes the state of the art and practice and various simulation software.

Washburn, S., T. Hiles, and K. Heaslip. Impact of Lane Closures on Roadway Capacity Part A, Development of a Twolane Work Zone Lane Closure Analysis Procedure. 2008. www .dot.state.fl.us/research-center/Completed_Proj/Summary_ RD/FDOT_BD545_61_A.pdf

Relevance: High

Description: Current FDOT arterial work zone capacity estimation procedure does not account for various operating and work zone characteristics of the facility. The objectives of this research are to 1) identify the various geometric and traffic factors that might impact the capacity of the arterial work zone and 2) develop analytical model(s) and methods to estimate its capacity.

Zhu, Y. and I. Ahmad. Developing a Realistic-Prototyping RUC Evaluation Tool for FDOT Report. 2009. www.dot.state .fl.us/research-center/Completed_Proj/Summary_CN/ FDOT_BD015-20_rpt.pdf

Relevance: High

Description: The goal of this study is to develop a prototyping Road User Cost (RUC) calculation tool utilizing a limited number of data inputs. The tool can be used for specific construction projects for determining the incentive/disincentive values for contractors. In addition to the review of existing related literature, comparisons were performed among Florida Department of Transportation (FDOT) methodologies, and also among the existing tools, such as the Arizona Department of Transportation (ADOT) model, the Queue and User Cost Evaluation of Work Zones (QueWZ) model, and the QuickZone model.

\section{Program/Network/Corridor Performance Measure Publications}

Al-Kaisy, K. Evaluation of the Effectiveness of Single-Lane Two-Way Traffic Control at Maintenance and Reconstruction Zones. 2006. www.scopus.com/record/display.url?eid=2-s2$.0-33846697382 \& v i e w=$ basic\&origin $=$ inward\&txGid $=n 7 j p$ ik4NIXRclWBq4urextM:2

Relevance: High

Description: This paper presents a study on evaluating traffic control at single-lane closures on two-lane two-way highways. Four traffic control strategies were investigated by this study.
Those strategies involved fixed-time control, fixed-queue control, "static optimum" or convoy rule, and adaptive control.

Anderson, S. D., G. L. Ullman, and B. C. Blaschke. Process for Selecting Strategies for Rehabilitation of Rigid Pavements under High Traffic Volumes. TRR. 2007.http://trb.metapress .com/content/645203246526w320/

Relevance: High

Description: A process that integrates both the pavementrelated and the non-pavement-related aspects of MRR strategy selection is described. A framework that provides the basis for a review of the literature and the collection of data on current practices is presented.

Cambridge Systematics. PEAT Estimate Benefits and Costs of Transportation Investments. Website. www.camsys.com/ pro_planpro_peat.htm. None

Relevance: Moderate

Description: The Priority Economic Analysis Tool (PEAT) is designed to help agencies prioritize competing investment alternatives. PEAT enables agencies to analyze preservation and improvement projects for highways, bridges, and intersections using an economic approach that considers both agency and road user costs. PEAT helps answer two fundamental questions: (1) is a project a good investment; (2) and if so, when should it be implemented? PEAT has been adapted successfully by the Ministry of Transportation of Ontario.

Cottrell, B. Assessment of Advance Warning Signs for Flagging Operations. 2008. http://ops.fhwa.dot.gov/wz/work shops/accessible/Cottrell_paper.htm

Relevance: Moderate

Description: The purpose of this research project was to assess and compare the motoring public's understanding of the existing and proposed advanced warning signs for work zone flagging operations. The study consisted of a literature review and a survey of motorists. Over 3,600 multiple-choice surveys were successfully mailed out to randomly selected Virginia residents of which 38 percent were returned. The survey results indicated that the proposed sign was for the most part understood by Virginia drivers and appeared to be effective at conveying its message.

FHWA. Comparative Analysis Report: The Benefits of Using Intelligent Transportation Systems in Work Zones. 2008. http://ops.fhwa.dot.gov/wz/its/wz_comp_analysis/index.htm

Relevance: High

Description: The purpose of this study is to highlight "before and after" or "with and without" analyses that quantify the mobility and safety benefits of using ITS applications for work zone traffic management. The study focused on sites 
that provided an opportunity for comparison of traffic conditions both with and without ITS.

FHWA. Construction Management Practices in Canada and Europe. 2005.http://international.fhwa.dot.gov/construction_ mgmt/pl05010.pdf

Relevance: High

Description: The team's recommendations for possible implementation in the United States include developing risk assessment and allocation techniques, using qualifications in procurement, piloting early contractor involvement, applying alternate bids and designs in procurement, conducting preproposal meetings, and using appropriate alternative payment methods.

FHWA. Surrogate Safety Assessment Model (SSAM). 2008. Contact: Joe Bared, (202) 493-3314, joe.bared@fhwa.dot .gov. www.tfhrc.gov/safety/pubs/08049/index.htm

Relevance: Low

Description: This TechBrief summarizes the research and development of the Surrogate Safety Assessment Model (SSAM), a technique combining microsimulation and automated conflict analysis, which analyzes the frequency and character of narrowly averted vehicle-to-vehicle collisions in traffic, to assess the safety of traffic facilities without waiting for a statistically abovenormal number of crashes and injuries to actually occur.

FHWA. Transportation Performance Measures in Australia, Canada, Japan and New Zealand. 2004. http://international .fhwa.dot.gov/performance/04transperfmeasure.pdf

Relevance: Moderate

Description: Discusses the various performance measures associated to safety and operations, and advises the best practices.

FHWA. Work Zone Impacts Assessment: An Approach to Assess and Manage Work Zone Safety and Mobility Impacts of Road Projects.2006.http://ops.fhwa.dot.gov/wz/resources/ final_rule/wzi_guide/sec8.htm

Relevance: High

Description: This guide is designed to help transportation agencies develop and/or update their own policies, processes, and procedures for assessing and managing the work zone impacts of their road projects throughout the different program delivery stages.

FHWA. Work Zone Self Assessment. 2008. http://ops.fhwa .dot.gov/wz/decision_support/self-assess.htm

Relevance: Moderate

Description: The Work Zone Mobility and Safety Self Assessment (WZ SA) tool consists of a set of questions designed to assist those with work zone management responsibilities in assessing their programs, procedures, and practices against many of the good work zone practices in use today.

Gabler, E. Economic Analysis: Applications to Work Zones. Presentation. 2008.http://ops.fhwa.dot.gov/wz/workshops/ accessible/Gabler.htm

Relevance: Very High

Description: This presentation discusses economic analysis to determine improved performance, greatest net benefit, optimal timing, best alignment, and best implementation strategy.

Lee, E.-B. Knowledge-Based Scheduling Analysis Software for Highway Rehabilitation and Reconstruction Projects. TRR. 2006. http://trb.metapress.com/content/g63027lw75010767/

Relevance: High

Description: Describes the optimization model, the scheduling techniques and production techniques in (CA4PRS).

Lee, E.-B. Productivity Aspects of Urban Freeway Rehabilitation with Accelerated Construction UCB Report. 2007.http:// repositories.cdlib.org $/ \mathrm{cgi} /$ viewcontent.cgi article $=6913 \mathrm{\&}$ context $=$ postprints

Relevance: High

Description: This report is important in (a) understanding productivity rates during construction and (b) scheduling.

Lee, E.-B. Streamlined Strategies for Faster, Less TrafficDisruptive Highway Rehabilitation in Urban Networks. TRR. 2009. http://trb.metapress.com/content/966u481363707r34/

Relevance: High

Description: Provides validation of the CA4PRS software.

Li, Q. and A. Kumar. National \& International Practices in Decision Support Tools in Road Asset Management. 2003. http://eprints.qut.edu.au/26876/1/26876.pdf

Relevance: Low

Description: This report investigates criteria for road asset management.

MacDonald, C. and National Asphalt Pavement Association. Maine DOT's Innovative Plans Result in Rapid Construction, Satisfied Motorists. Available from UC Berkeley Transportation Library through interlibrary loan or document delivery. 2009.

Relevance: High

Description: The Maine DOT introduced a new management scheme on I-295 to carry out a re-paving project without reducing the facility capacity. The project was completed in 20 days instead of shutting down the facility for 13 weeks. 
Mahoney, K. M., R. J. Porter, D. R. Taylor, B. T. Kulakowski, and G. L. Ullman. Design of Construction Work Zones on High-Speed Highways. Report NCHRP 581. 2007. http:// onlinepubs.trb.org/onlinepubs/nchrp/nchrp_rpt_581.pdf

Relevance: High

Description: This report presents the findings of a research project to develop guidance for designing geometric features of construction work zones on high-speed highways. The report will be of particular interest to practitioners responsible for the design of construction work zones.

Mannisto, V., and R. Tapio. Infrastructure Management System: Case Study of the Finnish National Road Administration. TRR. 1995. http://pubsindex.trb.org/view.aspx?id $=424742$

Relevance: Low

Description: This case study looks at an infrastructure management tool.

Maze, T. Iowa's Evaluation of the Wizard CB Alert System. 2008. http://ops.fhwa.dot.gov/wz/workshops/accessible/ Maze.htm

Relevance: Moderate

Description: This paper reports on the evaluation of one technology intended to manage vehicle speed in and around work zones on interstate highways. The technology tested is the Wizard CB Alert System.

Minnesota DOT. Evaluation of 2004 Dynamic Late Merge System. 2004. www.dot.state.mn.us/trafficeng/ workzone/2004DLMS-Evaluation.pdf

Relevance: Moderate

Description: This report offers an evaluation of late merge.

Sarasua, W. Traffic Impacts of Short Term Interstate Work Zone Lane Closures: The South Carolina Experience. Presentation. 2008. http://ops.fhwa.dot.gov/wz/workshops/ accessible/Sarasua.htm

Relevance: High

Description: Method to evaluate delays, through field measurement, impact of truck percentages, and capacity at work zones.

Shi, J., Z. Li, and M. Snyder. Highway Work Zone Safety Audits at the Construction Stage. 2009. http://pubsindex .trb.org/view.aspx?id $=881215$

Relevance: Low

Description: This paper presents the guidelines for highway work zone safety audits at the construction stage. After a brief description of the key features of work zone safety audit, an eight-step audit process is presented.
Sikow, C., K. Tikka, and J. Aijo. Impact Analysis of Road Keeping: Case Study of Lapland District in Finland. TRR. 1995. http://pubsindex.trb.org/view.aspx?id $=424732$

Relevance: High

Description: A network-level pavement management system was used to allocate and optimize funds for rehabilitation and to analyze the development of the condition of the network with nonoptimal funds. Summer and winter maintenance were analyzed by an analytical hierarchical process. As to investments, in addition to a traditional cost-benefit analysis, indirect economic effects were studied with a regionalized input-output model.

Ullman, G. L., R. J. Porter, and G. J. Karkee. Implementation Guide for Monitoring Work Zone Safety and Mobility Impacts. TTI Report. 2008. http://tti.tamu.edu/documents/ 0-5771-P1.pdf

Relevance: High

Description: This implementation guide describes the conceptual framework, data requirements, and computational procedures for determining the safety and mobility impacts of work zones in Texas.

Ullman, G. L., R. J. Porter, and G. J. Karkee. Monitoring Work Zone Safety and Mobility Impacts in Texas. TTI Report. 2008. http://tti.tamu.edu/documents/0-5771-1.pdf

Relevance: High

Description: For mobility-based measures, researchers recommend that Texas DOT target the collection of queue length and travel time delay data caused by temporary lane closures. Researchers developed graphs that indicate combinations of work zone length (or work zone segment length), average daily traffic, normal crash rate, and work zone phase or project direction that will most likely allow for reasonable inferences to be made regarding the relative level of safety being maintained within the project.

Vadakpat, G., S. Stoffels, and K. Dixon. Road User Cost Models for Network-Level Pavement Management. TRR. 2007. http://trb.metapress.com/content/82328v2g87605272/

Relevance: High

Description: One of the most important ingredients in the LCCA process, at either a network level or a project level, is the determination of road user cost (RUC) during maintenance and rehabilitation operations.

World Bank. Road Software Tools (HDM-4). www.worldbank .org/transport/roads/tools.htm. 2002.

Relevance: High

Description: A software package which serves as the primary tool for the analysis, planning, management and appraisal of 
road maintenance, improvements and investment decisions. Tool comes out of Europe and does what CA4PRS is trying to do here.

Wu, Z. and G. W. Flintsch. Performance-Based Network-Level Optimization for Pavement Management in Public-Private Partnerships. TRB. 2008. http://pubsindex.trb.org/view .aspx $?$ id $=848472$

Relevance: High

Description: This paper proposes a practical decision-support model for determining optimal network-level maintenance policies based on goal programming. The implementation of the model in a simple case study showed that its application is practical for supporting the management of pavement networks to achieve specific performance targets while controlling costs. The proposed model can help balance the private sector's goals, resource limitations, and performance targets under a warranty contract.

Zwahlen, H. Improved Work Zone Design Guidelines and Enhanced Model of Traffic Delays in Work Zones. 2009. http://ntlsearch.bts.gov/tris/search.do?new $=\& b 1=9 \& f 1=$ au\&t1 $=$ Zwahlen $\% 2 C+$ Helmut + T\&d $=$ tr

Relevance: High

Description: This project developed a digital computer simulation model to model the traffic through a freeway work zone situation. It also included a diversion analysis to determine the effects of closed ramps. Finally, guidelines for ramp management and ramp metering were established on a 24/7 basis giving special considerations to freeway mainline throughput and local traffic access to freeway.

\section{Asset Management (Econometric) Publications}

Anderson, S. D., and G. L. Ullman. Reducing and Mitigating Impacts of Lane Occupancy during Construction and Maintenance (NCHRP 293). 2000. http://onlinepubs.trb .org/onlinepubs/nchrp/nchrp_syn_293.pdf

Relevance: Moderate

Description: This report of the Transportation Research Board provides information on programming and planning, design, contract, construction, and maintenance techniques, methods, and processes used to reduce lane occupancy during construction and maintenance activities.

Austroads. Integrated Asset Management Guidelines for Road Networks. 2002. www.onlinepublications.austroads .com.au/script/Details.asp?.DocN=AR0000004_0904

Relevance: Moderate

Description: This document presents guidelines for road agencies for the development and implementation of an
Integrated Asset Management framework for managing road networks, as part of each agency's overall business planning cycle.

Bai, Y. and Y. Li. Reducing Work Zone Crashes by Using Vehicle's Warning Flashers as a Warning Sign. 2009. www.work zonesafety.org/files/documents/database_documents/ publication9297.pdf

Relevance: High

Description: The research project evaluates the effectiveness of a traffic warning sign that is assembled by using the emergency warning flashers of the vehicles in one-lane, two-way work zones. This warning sign was named as the Emergency Flasher Traffic Control Device (EFTCD). It works in the following fashion: When a vehicle enters a one-lane, two-way work zone where stopping is required for waiting to pass the work zone, the driver is required to turn on its emergency warning flashers to warn the following vehicles of the work zone stopping condition. The EFTCD is flexible and cost effective and may particularly benefit those work zones that are frequently moved due to the construction progress.

Belobraydich, T. Reducing Exposure of Short-term Utility Work Zones through Effective Safety Planning. Paper \& Presentation. 2004-2006. http://ops.fhwa.dot.gov/wz/ workshops/accessible/Belobraydich.htm

Relevance: Moderate

Description: Telecommunications, electric, gas, water and other utility companies throughout the USA are confronted daily with the need to work safely and effectively on or near the roadway. The majority of their distribution plant access facilities are proximate to roadways and right-of-ways. Utility maintenance work activities involve manholes, cabinets, control panels, poles and other operating plant features that are often located adjacent to or directly in streets, roadways, intersections, and highways. With substantial increases in traffic volumes, road construction activity, driver distractions and other human factor elements impacting the road user, many utility field personnel encounter unprecedented exposure on a daily basis. Additionally, the recent attention to repairing the deteriorating infrastructure of roads and bridges in the USA often results in a substantial concentration of activity by road contractors, DOT's, utilities, etc., on the same portion of roadway, which is often already overflowing with high-density traffic. The ubiquitous work zone can create road user orange overload. Users become numb to actual and present dangers based on past encounters with unreliable, inconsistent, non-uniform work zone traffic control information and consequently develop a tendency to react only as visual warnings and their actual observations indicate. In addition, the visual noise of outside user distractions like billboards and commercial signs 
are densest in heavy traffic commercial areas - the same areas that require frequent utility maintenance work.

Cambridge Systematics, PB Consult, and System Metrics Group. Analytical Tools for Asset Management. 2005. NCHRP Report 545.

Relevance: High

Description: This report presents two tools developed to support tradeoff analysis for transportation asset management. These software tools and the accompanying documentation are intended for state departments of transportation (DOTs) and other transportation agencies to help them improve their ability to identify, evaluate, and recommend investment decisions for managing the agency's infrastructure assets.

Cambridge Systematics. Tools Summary Sheet. 2005.http:// knowledge.fhwa.dot.gov/tam/aashto.nsf/All+Documents/ 4678 B D 6 ACF 8485C585256F1 C006FAB30/\$FILE/ Task4AppC.pdf

Relevance: High

Description: Summary of available tools for asset management.

Copp, R. Transportation Management Plans: Effectiveness Study. Paper\&Presentation. 2004-2006. http://ops.fhwa.dot .gov/wz/workshops/accessible/Copp_ppt.htm

Relevance: Moderate

Description: Gives effectiveness study of Caltrans Transportation Management Plans.

Duffy, K. A. Traffic Incident Management at the Big Dig. Presentation. 2004-2006. http://ops.fhwa.dot.gov/wz/ workshops/accessible/Duffy.htm

Relevance: High

Description: Case study to keep the roadways traversing Boston open and flowing at pre-construction levels.

FHWA. Best Practices. 2009. http://ops.fhwa.dot.gov/wz/ practices/practices.htm

Relevance: Moderate

Description: Shortlists case studies from various DOTs, e.g., CALTRANS.

Gayle, S. Making Work Zones Work Better By Linking Planning and Operations. Presentation. 2004-2006. http://ops .fhwa.dot.gov/wz/workshops/accessible/Gayle.htm

Relevance: High

Description: Effective management of transportation systems maximizes system performance through a coordinated and integrated decision making approach to construction, operation, preservation, and maintenance of transportation facilities, with the goal of providing safe, efficient, and reliable transportation to all users.

Kansas DOT. Pavement Management Information System. 2006-2009. www.ksdot.org/matreslab/pmis/reports.asp

Relevance: Moderate

Description: A website including Kansas DOT's Network Optimization System during 2006-2009 with all the decision maps for the lane closure district.

Leonard, J. Mitigating Traffic Impacts on Utah's I-15. Presentation. 2004-2006. http://ops.fhwa.dot.gov/wz/workshops/ accessible/leonard.htm

Relevance: High

Description: Case study for reconstruction on I-15 in Utah.

Sharma, H., C. McIntyre, Z. Gao, and T-H. Nguyen. Developing a Traffic Closure Integrated Linear Schedule for Highway Rehabilitation Projects. TRIS. 2009.

Relevance: High

Description: This paper documents the development of a traffic closure integrated linear schedule (TCILS) that addresses both traffic closure and work progress issues. The TCILS generates a single schedule for both the construction activities and the associated traffic closures. Visual and graphical features are also applied in the system, which makes it particularly applicable for highway rehabilitation projects. An actual concrete pavement rehabilitation project using the TCILS is presented as a sample of application. The findings from the sample project, although they are limited, show that the TCILS can be applied to an actual project. With recommended future development, the system is believed to be beneficial for both construction practitioners and academics.

Ullman, G. Enforcement-Friendly Work Zones. Paper\& Presentation. 2004-2006. http://ops.fhwa.dot.gov/wz/ workshops/accessible/Ullman.htm

Relevance: High

Description: Law enforcement presence in work zones has long been recognized as one of the most effective speed reduction methods available to transportation officials. Unfortunately, high labor costs, manpower shortages, and the many other demands placed on law enforcement makes universal enforcement presence at all work zones impossible. In addition, most states have enacted higher fines for violations in work zones. While designed to improve motorist compliance, some of these higher fine structures include certain stipulations that create unintended difficulties for enforcement personnel. Further complicating the problem is the fact that the actual design of, 
and activities within, many work zones makes effective enforcement extremely difficult. Long work zones that have no emergency shoulders on either side of the roadway offer no place for enforcement personnel to position their vehicles to monitor traffic or to pull over violators to issue a citation. Consequently, officers attempting to stop a violator are forced to either follow the violator completely through the work zone before activating their emergency lights and pulling the violator over, or activating their lights within the work zone and risk the chance that the motorist will then stop in the moving lane of traffic.

Warren, D. Variable Speed Limits. Presentation. 2004-2006. http://ops.fhwa.dot.gov/wz/workshops/accessible/Warren .htm

Relevance: High

Description: A slide in the presentation shows the concept the variable speed limits for work zone control.

\section{Work Zone Control Strategies Publications}

Ackles, M. Trip Planning: More than Just Road Signs. Presentation. 2008. http://ops.fhwa.dot.gov/wz/workshops/ sheet2.htm

Relevance: Moderate

Description: Presentation discussing case studies, and roles of various ITS and control features.

Anderson, S. Concepts for Enhancing the Effectiveness of Traffic Control Plans. Paper\&Presentation. 2008. http://ops .fhwa.dot.gov/wz/workshops/accessible/Anderson_ull.htm

Relevance: High

Description: An important principle in TCP development is to recognize early on that temporal and spatial requirements for a project directly influence the ability of the contractor to perform construction efficiently. Discusses the various ways to incorporate traffic control into work zones.

Balke, K. Traffic Incident Management in Construction and Maintenance Work Zones Report. 2009. www.ops.fhwa.dot .gov/publications/fhwahop08056/fhwahop08056.pdf

Relevance: Low

Description: This study addresses the concerns of managing traffic incidents within a work zone. A description of techniques and strategies that can be used to handle incidents in work zones is presented.

Benz, R. J., D. W. Fenno, and A. P. Voigt. Accelerating Major Freeway Reconstruction Projects: The Houston Experience. TRR. 2007. http://trb.metapress.com/content/3749520pm $321 \mathrm{k06k} /$
Relevance: High

Description: Several steps in the planning, execution, and evaluation of the I-45 Pierce Elevated reconstruction in Houston provide a strong framework for preparing for projects that affect critical links in the nation's transportation system. Traffic modeling helped to prepare for construction by first developing delay numbers for the estimated user cost used in the A + B bidding. Second, preconstruction modeling identified bottlenecks that were temporarily remediated at strategic locations. Finally, modeling provided speed and travel time data used in mounting a public information campaign.

Chang, G. L., and University of Maryland. ITS Applications in Work Zones to Improve Traffic Operations and Performance Measurements. 2009. http://ntlsearch.bts.gov/tris/ search.do? $\mathrm{b} 1=1 \& \mathrm{f} 1=0 \& \mathrm{t} 1=\mathrm{au} \% 3 \mathrm{~A} \% 22 \mathrm{chang}+\mathrm{gang}+\mathrm{len}$ $\% 22 \& r=1 \& d=\operatorname{tr} \& p=2 \& z=1 \& s=\& o=\& n e w=n$

Relevance: Moderate

Description: This study was carried out for the Maryland State Highway Administration to evaluate the performance of License Plate Recognition (LPR) technology and its reliability to support the travel time estimation applications on local arterials.

CDOT. Colorado Department of Transportation Region 1 Lane Closure Strategy-Second Edition Report. 2009. www .dot.state.co.us/Traffic_Manuals_Guidelines/Work_Zones/ Lane_Closure_Strategies/R1_Lane_Closure_Report.pdf

Relevance: Low

Description: Discusses lane closure strategies in Region 1 in Colorado.

CDOT. Colorado Department of Transportation Region 3 Lane Closure Strategy-Second Edition Report. 2009. www .dot.state.co.us/Traffic_Manuals_Guidelines/Work_Zones/ Lane_Closure_Strategies/R3_Lane_Closure_Report.pdf

Relevance: Low

Description: Discusses lane closure strategies in Region 3 in Colorado.

CDOT. Colorado Department of Transportation Region 4 Lane Closure Strategy-Second Edition Report. 2009. www .dot.state.co.us/Traffic_Manuals_Guidelines/Work_Zones/ Lane_Closure_Strategies/R4_Lane_Closure_Report.pdf

Relevance: Low

Description: Discusses lane closure strategies in Region 4 in Colorado.

CDOT. Colorado Department of Transportation Region 5 Lane Closure Strategy-Second Edition Report. 2009. www 
.dot.state.co.us/Traffic_Manuals_Guidelines/Work_Zones/ Lane_Closure_Strategies/R5_Lane_Closure_Report.pdf

Relevance: Low

Description: Discusses lane closure strategies in Region 5 in Colorado.

CDOT. Colorado Department of Transportation Region 6 Lane Closure Strategy-Second Edition Report. 2005. www .dot.state.co.us/Traffic_Manuals_Guidelines/Work_Zones/ Lane_Closure_Strategies/R6_Lane_Closure_Report.pdf

Relevance: Moderate

Description: Discusses lane closure strategies in Region 6 in Colorado.

Colorado DOT. I-70 Mountain Corridor PEIS Construction Traffic Impact Mitigation Strategies Report. 2005. www.i70mtncorridor.com/documents/12 construction Mitigation.pdf

Relevance: High

Description: This paper addresses mitigation strategies that have been used around the country, often with favorable results and with full support from construction contractors. Following is a brief synopsis of various strategies that can be implemented individually and, more likely, in combination with each other, in the I-70 Mountain Corridor.

Dunston, P., B. Savage, and F. Mannering. Weekend Closure for Construction of Asphalt Overlay on Urban Highway. 2000. http://scitation.aip.org/getabs/servlet/GetabsServlet ?prog=normal\&id =JCEMD4000126000004000313000001 \&idtype $=$ cvips\&gifs $=$ yes

Relevance: High

Description: The Washington State Department of Transportation implemented a pilot project to evaluate the option of a full weekend closure-closure of all lanes in a single direction throughout designated weekend hours-as an alternative to nighttime closures.

Fang, C. F. Portable Intelligent Traffic Management System for Work Zones and Incident Management Systems: Best Practice Review. 2008. http://universityofarizona.worldcat .org/oclc/423473375\&referer=brief_results

Relevance: High

Description: Reviews several portable ITS systems for work zones and incident management.

Faquir, T. Safer Work Zones Through ITS. Presentation. 2008. http://ops.fhwa.dot.gov/wz/workshops/sheet3.htm

Relevance: Moderate

Description: Presentation discussing case studies, and roles of various ITS and control features.
FHWA. Design and Construction Strategies. http://ops.fhwa .dot.gov/wz/construction/index.htm

Relevance: High

Description: Describes methods and case studies for design and construction strategies.

FHWA. Full Road Closure for Work Zone Operations-A Cross-Cutting Study. 2003. http://ops.fhwa.dot.gov/wz/ resources/publications/FullClosure/CrossCutting/its.htm

Relevance: High

Description: This report discusses using a full road closure as an option for construction, why to use full road closure, and the benefits and lessons learned from various case studies throughout the US.

FHWA. Public Information and Outreach Strategies. http:// ops.fhwa.dot.gov/wz/publicinfostrategies.htm

Relevance: High

Description: Describes strategies to improve work zone safety and mobility by public information and outreach strategies.

FHWA. Work Zone ITS. http://ops.fhwa.dot.gov/wz/its/ index.htm

Relevance: High

Description: Discusses practices and use of ITS in work zones.

FHWA. Work Zone Traffic Management Guidance and Examples. http://ops.fhwa.dot.gov/wz/traffic_mgmt/wztmg .htm

Relevance: High

Description: Provides information about developing and implementing Transportation Management Plans (TMPs), including how and where a TMP fits into project delivery processes, possible components of a TMP, descriptions of work zone management strategies.

FHWA Office of Operations. Intelligent Transportation Systems in Work Zones a Case Study: Dynamic Lane Merge System: Reducing Aggressive Driving and Optimizing Throughput at Work Zone Merges in Michigan. 2004. http://universityofarizona.worldcat.org/wcpa/oclc/70129 711 ?page $=$ frame\&url $=$ http://ops.fhwa.dot.gov/wz/ technologies/michigan/michigan.pdf\%26checksum\%3D 07942839a1714ea85b9439a6d5464246\&title = \&linktype $=$ digitalObject\&detail $=$

Relevance: Moderate

Description: Presents a case study for evaluating dynamic late merge. 
FHWA Office of Operations. Intelligent Transportation Systems in Work Zones a Case Study: Real-Time Work Zone Traffic Control System: Using an Automated Traffic Information System to Reduce Congestion and Improve Safety During Reconstruction of the I-55 Lake Springfield Bridge in Illinois. 2004. http://universityofarizona.worldcat.org/ wcpa/oclc/70129682? page $=$ frame\&url $=$ http://ops.fhwa. dot.gov/wz/technologies/springfield/springfield.pdf\%26c hecksum\%3D75099e50495064d1a23e9974cd761dab\&title $=$ \&linktype $=$ digitalObject $\&$ detail $=$

Relevance: Moderate

Description: The RTTCS consisted of portable dynamic message signs (DMSs), portable traffic sensors, and portable closed-circuit television (CCTV) cameras linked via wireless communications to a central workstation. The system monitored traffic along I-55, automatically generated messages on the DMSs based on predefined thresholds, provided data for a real-time congestion map displayed on IDOT's website, and provided congestion/incident detection alerts for IDOT staff.

FHWA Office of Operations. Intelligent Transportation Systems in Work Zones a Case Study: Work Zone Travel Time System: Remove Congestion With the Use of a Traffic Management Contract Incentive During the Reconstruction of Arizona State Route 68. 2004. http://university ofarizona.worldcat.org/wcpa/oclc/70129705?page $=$ frame \&url=http://ops.fhwa.dot.gov/wz/technologies/arizona/ arizona.pdf\%26checksum\%3D93cf888ff88363073b00d 23 dc4b376f 1 \&title $=$ \&linktype $=$ digitalObject $\&$ detail $=$

Relevance: Moderate

Description: Arizona DOT decided to include an incentive/ disincentive provision in the project contract to encourage the contractor to minimize work zone delays. ADOT needed a way to measure performance related to the provision and turned to ITS to help. They used a travel time system to measure travel time.

Finley, M. D., G. L. Ullman, and C. L. Dudek. Sequential Warning-Light System for Work-Zone Lane Closures. 2007. http://trb.metapress.com/content/100314n6888q1752/

Relevance: High

Description: Research performed to assess the effectiveness of a flashing warning-light system for use at work-zone lane closures is summarized. The system is composed of a series of interconnected, synchronized flashing warning lights that produce the illusion of motion. Researchers investigated motorist understanding and perceived usefulness of various designs of the warning-light system and the potential of this system to yield significant operational or safety benefits in actual work zone applications. Results from proving ground and field studies show that the flashing warning-light system used in the work zone lane closure is perceived positively and is not confusing to the motoring public.

Fitzsimmons, E., N. Oneyear, S. Hallmark, N. Hawkins, and T. Maze. Synthesis of Traffic Calming Techniques in Work Zones. 2009. www.ctre.iastate.edu/smartwz/reports/2009hallmark-calming.pdf

Relevance: High

Description: The objective of this research is to summarize the effectiveness of different traffic calming treatments for reducing speeds in work zones. This project identified work zone traffic calming treatments for which information has not been well summarized, identified state of the art and new technologies for work zone traffic calming, and synthesized research related to the above mentioned items.

Fontaine, Michael. Innovative Traffic Control Devices to Improve Safety at Rural Short-Term Maintenance Work Zones. Paper\&Presentation. 2008. http://ops.fhwa.dot .gov/wz/workshops/accessible/Fontaine.htm

Relevance: Low

Description: Texas DOT and the Federal Highway Administration (FHWA) sponsored a Texas Transportation Institute (TTI) research project to determine if innovative traffic control devices could improve safety at short-term rural maintenance work zones. This project examined several innovative countermeasures to determine if they would produce a positive safety benefit at short-term rural work zones.

Hansen, A. Work Zone Operational Enhancements Integrating ITS into a Design Build Project. 2008. http://ops .fhwa.dot.gov/wz/workshops/sheet5.htm

Relevance: Moderate

Description: Presentation discuses case studies, and roles of various ITS and control features.

Hardy, M. A Work Zone Delay Estimation and Analysis Tool. Presentation. 2008. http://ops.fhwa.dot.gov/wz/ workshops/sheet4.htm

Relevance: High

Description: Presentation discussing case studies, and roles of various ITS and control features.

Kite, S. Smart Work Zone Deployment on I-95. Presentation. 2008. http://ops.fhwa.dot.gov/wz/workshops/sheet2 .htm

Relevance: Moderate

Description: Presentation discussing case studies, and roles of various ITS and control features. 
Klatt, M. P. ITS \& Traffic Control. Presentation. 2008.http:// ops.fhwa.dot.gov/wz/workshops/accessible/Klatt.htm

Relevance: Moderate

Description: Presentation discussing case studies, and roles of various ITS and control features.

Kochevar, K. Intrusion Devices-New and Emerging Technology in Worker Safety. Paper\&Presentation. 2008. http://ops .fhwa.dot.gov/wz/workshops/sheet3.htm

Relevance: Moderate

Description: Presentation discussing case studies, and roles of various ITS and control features.

LaRue, C. Full Freeway Closures. Paper\&Presentation. 2008. http://ops.fhwa.dot.gov/wz/workshops/sheet5.htm

Relevance: High

Description: Presentation discusses case studies, and roles of various ITS and control features.

Lee, E.-B.Automated Work Zone Information System (AWIS) on Urban Freeway Rehabilitation: California Implementation. TRB. 2006. https://www.workzonesafety.org/files/ documents/database_documents/Research3075.pdf

Relevance: High

Description: The project implemented the Automated Work Zone Information System (AWIS) to reduce peak hour delay during construction by changing road user's travel patterns and diverting traffic to detour routes.

Lee, E.-B. Dynamic Approach to Public Outreach for Minimizing Traffic Inconvenience in Urban Highway Rehabilitation. TRR. 2006. http://pubsindex.trb.org/view.aspx?id =777104

Relevance: High

Description: Road users were benefited by the use of the Automated Work Zone Information System (AWIS), which provided interactive real-time travel estimates on- and offsite (project website). Media coverage and outreach materials were proactively utilized to win public support for the "Rapid Rehabilitation" strategy.

Lee, E.-B. Planning Urban Highway Reconstruction with Traffic Demand Affected by Construction Schedule. ASCE. 2005. http://scitation.aip.org/getabs/servlet/GetabsServlet ?prog=normal\&id $=$ JTPEDI000131000010000752000001 \&idtype $=$ cvips\&gifs $=$ yes

Relevance: High

Description: This paper introduces an integrated approach to the development of construction and traffic management plans for the reconstruction of high-volume urban freeways.
Lee, E.-B. Pre and Post construction Analysis of Interstate-15 (Devore) Concrete Pavement Reconstruction Project. Report to CALTRANS. 2005. www.its.berkeley.edu/pavemen tresearch/PDF/4.6_I-15\%20Devore_RR_Stg6-03-31-2009.pdf

Relevance: High

Description: This Rapid Rehab project adopted state-of-thepractice technologies to accelerate construction, to mitigate traffic disruptions, and to propagate project information.

Li, Y., and Y. Bai. Effectiveness of Temporary Traffic Control Measures in Highway Work Zones. 2009. www.sciencedirect .com/science/article/B6VF9-4T4WKX8-1/2/847593d8bbe29 5dda78b661219701e9a

Relevance: Moderate

Description: In this study, researchers evaluated the effectiveness of several commonly used TTC methods including flagger/officer, stop sign/signal, flasher, no passing zone control, and pavement center/edge lines.

Livingston, J. Work Zone Operational Enhancements. Presentation. 2008. http://ops.fhwa.dot.gov/wz/workshops/ sheet5.htm

Relevance: High

Description: Presentation discusses case studies, and roles of various ITS and control features.

Luttrell, T. Benefits of Using Intelligent Transportation Systems in Work Zones: A Summary Report. 2008. http:// universityofarizona.worldcat.org/wcpa/oclc/259462824?p age $=$ frame\&url $=$ www.ops.fhwa.dot.gov $/ w z / i t s / w z \_i t s \_$ benefits_summ/wz_its_benefits_summ.pdf\%26checksum \%3D5ed27b85f064fafced65ed19e8c22256\&title=\&linktype $=$ digitalObject\&detail $=$

Relevance: High

Description: Discusses various ITS strategies to reduce work zone impacts and identifies their benefits.

Maryland DOTD. Transportation Management Plans: Guidelines for Development, Implementation, and Evaluation. 2006. www.marylandroads.com/OOTS/06TMPGuidelinesRev5.pdf

Relevance: Moderate

Description: Guidelines for development, implementation and evaluation of traffic management plans.

Maryland State Highway Plans. Summary of Work Zone Impact Management Strategies. 2006. www.marylandroads .com/OOTS/09SummaryofWorkZoneManagement Strategies.pdf

Relevance: Moderate

Description: Describes all management strategies used in Maryland. 
Maze, T. Lane Closure Policy Development, Enforcement, and Exceptions: A Survey of Seven State Transportation Agencies. 2007. www.ctre.iastate.edu/smartwz/reports/ 2007-maze-lane_closure.pdf

Relevance: High

Description: The research synthesizes best lane closure practices by conducting survey of seven states.

Maze, T. Speed Reduction Strategies. Presentation. 2008. http://ops.fhwa.dot.gov/wz/workshops/sheet4.htm

Relevance: Moderate

Description: Presentation discussing case studies, and roles of various ITS and control features.

Maze, T. Synthesis of Practices for Mitigating the Impact of Work Zones on Traffic. 2007. www.ctre.iastate.edu/ smartwz/reports/2007-maze-mitigate-impact.pdf

Relevance: Moderate

Description: This synthesis identifies and discusses many frequently used strategies and many strategies that are relatively new to several agencies.

Maze, T. Synthesis of Procedures to Forecast and Monitor Work Zone Safety and Mobility Impacts. 2005. www.intrans .iastate.edu/reports/work_zone_mobility.pdf

Relevance: Moderate

Description: This report provides a synthesis of what is currently being done by STAs across the country to plan, manage, operate, and evaluate work zone safety and mobility.

McCoy, P. Dynamic Late Merge Control Concept for Work Zones on Rural Freeways. Paper\&Presentation. 2008. http:// ops.fhwa.dot.gov/wz/workshops/sheet4.htm

Relevance: Moderate

Description: Presentation discussing case studies, and roles of various ITS and control features.

Michigan DOT. Guidance for Work Zone Safety and Mobility. 2008. www.michigan.gov/documents/mdot/mdot_WZSM_ policy_FINAL_AS_APPROVED_BY_CRAM 120808 _ 259537_7.pdf

Relevance: High

Description: Discusses safety and mobility practices in Michigan.

Minnesota DOT. Guidelines for Changeable Message Sign (CMS) Use. 2000. www.dot.state.mn.us/trafficeng/work zone/cms-use-guidelines.pdf

Relevance: Low

Description: The Changeable Message Sign (CMS) system is part of Minnesota DOT's Traffic Management System. The primary component is a device that is designed to display words, numbers or symbols which can be changed on command either remotely or on-site. The purpose of the CMS is to communicate real-time roadway or traffic information to travelers, as conditions warrant, so they may react to those conditions in a safe and timely manner.

Minnesota DOT. Metropolitan District Lane Closure Manual. None. www.dot.state.mn.us/metro/trafficeng/laneclosure/ index.html

Relevance: Moderate

Description: Guidebook for lane closure during work zones in Minnesota.

North Carolina DOT. Work Zone Speed Limit Reduction Guideline for NC Highway Construction and Maintenance Activities. 2006. www.ncdot.org/doh/preconstruct/wztc/ DesRes/English/SpeedOrd/WZOrdinance.pdf

Relevance: High

Description: The objective of this guideline in NC is to identify the appropriate speed limit reduction for work being performed on full control of access facilities in maintenance and construction work zones.

Outcalt, W., and Colorado DOT/FHWA. Work Zone Speed Control. 2009. www.dot.state.co.us/Publications/PDFFiles/ workzonespeed.pdf

Relevance: High

Description: This research provides the Colorado Department of Transportation with methods for effective management traffic speed in the vicinity of work zones. Safety and traffic engineers and maintenance planners can use it to plan effective traffic control in work areas.

Outcalt, W. Work Zone Speed Control Final Report. 2009.www .dot.state.co.us/publications/PDFFiles/workzonespeed.pdf

Relevance: Moderate

Description: A literature search found 17 studies relating to work zone speed control and investigating the use of variable message signs (VMS), presence of law enforcement, and various signing methods. However, none provided current documentation of the effectiveness of the use of a VMS in conjunction with the presence of a law enforcement officer who was ticketing violators. The study found that the most dependable method of ensuring compliance with posted work zone speed limits is through the presence of law enforcement in the work zone, citing speeders.

Pant, P. Smart Work Zone Systems. Paper\&Presentation. 2008. http://ops.fhwa.dot.gov/wz/workshops/sheet2.htm

Relevance: Moderate

Description: Presentation discussing case studies, and roles of various ITS and control features. 
Paracha, J. MD QuickZone-A Work Zone Traffic Analysis Tool. Presentation. 2008. http://ops.fhwa.dot.gov/wz/ workshops/sheet4.htm

Relevance: Moderate

Description: Presentation discussing case studies, and roles of various ITS and control features.

Radwan, E. Evaluation of Safety and Operational Effectiveness of Dynamic Lane Merge System in Florida. 2009. www.dot.state.fl.us/research-center/Completed_Proj/Sum mary_CN/FDOT_BD548-24_rpt.pdf

Relevance: High

Description: Two Simplified Dynamic Lane Merging Systems (SDLMSs) are suggested for deployment and testing on short term work zones. The first SDLMS is a simplified dynamic early merge system (early SDLMS) and the second SDLMS is a simplified dynamic late merge system (late SDLMS).

Savolainen P., D. McAvoy, V. Reddy, J. Santos, and T. K. Datta. Evaluation of Motorist Awareness System. Source Data: Transportation Research Board Annual Meeting 2009 Paper \#09-1968. 2009.

Relevance: Moderate

Description: The objective of this study was to determine the effects of a Motorist Awareness System (MAS) on vehicle speeds in highway work zones. Spot speed studies were conducted prior to, within, and near the end of work zones along Interstate 10 and Interstate 95 in Florida which utilized the traditional Maintenance of Traffic plan and the MAS plan.

Schexnayder, C. Effective Noise Control during Nighttime Construction. Paper\&Presentation. 2008. http://ops.fhwa .dot.gov/wz/workshops/sheet5.htm

Relevance: Moderate

Description: Presentation discussing case studies, and roles of various ITS and control features.

Schrock, S., M. Becker, and T. Mulinazzi. Examination of Effectiveness of Early Merge Work-Zone Signing. 2009. http://pubsindex.trb.org/view.aspx?id=882451

Relevance: Moderate

Description: This study examines the 2007 early merge practice adopted by the state of Oklahoma. Measures of effectiveness examined included the number and percentage of traffic that remained in the closed lane and the number of conflicts that occurred at the merge area.
Sperry, R. Effectiveness of Dynamic Messaging on Driver Behavior for Late Merge Lane Closures.2009.http://university ofarizona.worldcat.org/wcpa/oclc/319537847?page $=$ frame $\&$ url=www.intrans.iastate.edu/reports/driver_behavior_ lane_merge.pdf\%26checksum\%3Deab456b565a56ac9e70b1 6681e7ce573\&title $=\&$ linktype $=$ digitalObject $\&$ detail $=$

Relevance: Moderate

Description: Discusses how DMS helps improve merging behavior at work zones.

Ullman, G. Designing for Speed, Congestion, and Delay in the Work Zone. Presentation. 2008. http://ops.fhwa.dot .gov/wz/workshops/accessible/ullman_speed.htm

Relevance: High

Description: Discusses control measures in order to incorporate effects of speed, congestion and delay.

Ullman, G. L., and S. D. Schrock. Improving Traffic Control Effectiveness in Complex Work Zones. TTI Report. 2003. http://tti.tamu.edu/documents/4021-2.pdf

Relevance: High

Description: Four key steps, hazard visibility assessment, expectancy violation determination, information load analysis, and information needs specification are described in the context of traffic control at potentially complex work zones.

Ullman, G. L., P. A. Barricklow, R. Arredondo, E. R. Rose, and M. D. Fontaine. Traffic Management and Enforcement Tools to Improve Work Zone Safety. TTI Report. 2002. http:// tti.tamu.edu/documents/2137-3.pdf

Relevance: High

Description: This report presents the results of research to investigate the feasibility and effectiveness of the late-merge lane closure strategy and the CB Wizard technology at work zones in Texas. One traffic management technology recently introduced into the market place that has the potential to directly communicate with drivers of large trucks is the CB Wizard.

United States Joint Program Office for Intelligent Transportation Systems. Intelligent Transportation Systems in Work Zones a Case Study: Work Zone Traffic and Incident Management System: Keeping Traffic Moving During Reconstruction of the Big I, a Major Interstate-Interstate Interchange in Albuquerque. 2004. http://universityofarizona.worldcat.org/ wcpa/oclc/56781535? page $=$ frame\&url $=$ www.itsdocs.fhwa .dot.gov//JPODOCS/REPTS_TE/13941.html\%26checksum \%3Ddd66b86588503e993027 d58f1a83ce48\&title = \&link type $=$ digitalObject $\&$ detail $=$ 
Relevance: Moderate

Description: The use of ITS for the Big I proved to be very successful in mitigating the effects of construction on traffic mobility and safety. The NMSHTD plan called for the use of ITS during construction, and also allowed some of the system components to be made a permanent part of the freeway management system for the Big I. This case study is one example of how ITS is being implemented across the nation to help agencies better manage traffic while performing necessary infrastructure improvements.

Vermont Agency of Transportation. Work Zone Safety \& Mobility Guidance Document. 2007. www.aot.state.vt.us/ progdev/Documents/Design/WorkZoneSafetyAndMobility GuidanceDocument/WorkZoneSafetyMobilityGuidance Document.pdf

Relevance: High

Description: Describes Vermont's traffic management practices.

Virginia DOT. Final Report Improving Night Work Zone Traffic Control. 1999. www.virginiadot.org/vtrc/main/ online_reports/pdf/00-r8.pdf

Relevance: Moderate

Description: The objective of this study was to examine traffic control for night work zones from the perspective of both agencies and motorists. This was accomplished by investigating practices of state departments of transportation, identifying the problems associated with traffic control for night work zones, and identifying potential strategies to resolve them.

Yang, N., G-L. Chang, and K-P. Kang. Simulation-Based Study on a Lane-Based Signal System for Merge Control at Freeway Work Zones. 2009. http://scitation.aip.org/getabs/ servlet $/$ GetabsServlet?prog=normal\&id $=$ JTPEDI0001350 00001000009000001 \&idtype $=$ cvips\&gifs $=$ yes

Relevance: High

Description: This paper presents a new lane-based signal merge (LBSM) control system for freeway work zone operations. The experimental results show that under heavily congested traffic conditions the LBSM can outperform all existing control strategies with respect to the work zone throughput, the average vehicle delay, the average stop delay, and the average number of stops.

\section{Project Delivery and Procurement}

AASHTO. Accelerating Project Delivery. 2007. www.trans portation1.org/tif7report/tif7.pdf
Relevance: Moderate

Description: This AASHTO report explores why highway construction projects take so long to be completed.

Anastasopoulos, P., S. Labi, and B. McCullouch. Identifying the Appropriate Contract Types for Highway Maintenance and Rehabilitation Projects on the Basis of Project Characteristics. Source Data: Transportation Research Board Annual Meeting 2009 Paper \#09-2203. 2009.

Relevance: High

Description: In this study, highway project data from the U.S.A. and abroad are analyzed using simultaneous equation models for the traditional and innovative contract types. These models are estimated by three-stage least squares while duly accounting for the interrelationships between contract duration, length and cost. The results suggest that a number of factors significantly affect the contract characteristics, such as the number of different maintenance activities incorporated in the contract, contract duration, length, and cost, and the asset type that is being preserved or maintained.

Anderson, S. D., and I. Damnjanovic. Selection and Evaluation of Alternative Contracting Methods to Accelerate Project Completion. TRB's National Cooperative Highway Research Program (NCHRP) Synthesis 379. 2009.

Relevance: High

Description: Selection and Evaluation of Alternative Contracting Methods to Accelerate Project Completion explores the process for selection of alternative contracting methods that can potentially accelerate project completion. The report also examines factors associated with selecting one type of alternative contracting technique over another.

Bayraktar, M. E., and M. Hastak. A Decision Support System for Selecting the Optimal Contracting Strategy in Highway Work Zone Projects. 2009. www.sciencedirect.com/science/ article/B6V20-4W1SGFJ-1/2/8d5552048d4916a596c4a9754a 5 fecd7

Relevance: High

Description: Highway work zone projects are challenging for state highway agencies and contractors as they are often located in urban areas and impact local traffic, business community, and neighborhood leading to a multiparty involvement. There is a dynamic relationship between the involved parties and the performance of any highway work zone project is governed by this dynamic relationship. This paper presents a decision support system to assist state Departments of Transportation in selecting suitable contracting strategies for highway work zone projects by considering, at a macro level, the interrelationships between the stakeholders as well as the critical factors impacting 
the project. The proposed methodology supplements the current project decision-making process with regard to important project performance variables such as cost, schedule, quality, safety, and public satisfaction.

Cabana, G., G. Liautaud, and A. Faiz. Area Wide PerformanceBased Rehabilitation and Maintenance Contracts for LowVolume Roads. Transportation Research Record, Vol. 1652. 1999. http://trb.metapress.com/content/q252552g42217185/

Relevance: High

Description: The new approach encompasses either routine maintenance activities alone or integrated contracts involving both the rehabilitation and routine maintenance of road networks.

FHWA. Contracting Strategies. http://ops.fhwa.dot.gov/ wz/contracting/index.htm

Relevance: High

Description: Case studies and examples of various contracting strategies.

FHWA. Primer on Contracting for the 21st Century. 2006. www.transportation.org/sites/construction/docs/ Primer\%20on\%20Contracting\%202006.pdf

Relevance: Moderate

Description: This document, which was prepared by the Contract Administration Task Force of the AASHTO Subcommittee on Construction, lists various contracting and contract administration techniques that are currently being used by various contracting agencies in their transportation programs.

Franklin, C., and S. Berry. Requirements, Choices, and Issues in Work Zone Monitoring. TRIS Order Document: http:// library.its.berkeley.edu. Find a library where document is available. 2009.

Relevance: High

Description: This article provides summary of rules set by FHWA for work zone monitoring, which went into effect October 12,2007 . They are intended to provide greater safety and mobility of work zones during various stages of roadway projects.

Kent, D. Innovative Contracting Techniques that Consider Driver Impact, Use of A+B Bidding. Paper\&Presentation. 2004-2006. http://ops.fhwa.dot.gov/wz/workshops/ sheet6.htm

Relevance: High

Description: Contains presentations and papers to present several contracting methods for work zones.
Molenaar, K. R., and G. Yakowenko. Alternative Project Delivery Procurement, and Contracting Methods for Highways. ASCE Publication. http://cedb.asce.org/cgi/WWWdisplay .cgi?0700001

Relevance: High

Description: Faced with increasing public demand and reduced staff numbers, federal, state, and local agencies are seeking to improve the efficiency and effectiveness of publicsector project delivery. This book provides a comprehensive and objective presentation of these methods. It also provides vital information on design-build, construction management at risk, performance-based road maintenance contracts, bestvalue procurement, quality-based contractor qualification, warranty contracting, and incentive/disincentive contracting. It is essential reading for the road construction industry.

New Jersey DOT. New Jersey Road User Cost Manual. 2001. www.state.nj.us/transportation/eng/documents/RUCM/ pdf/RUCManual.pdf

Relevance: Moderate

Description: This manual will familiarize the analyst with work zone and traffic characteristics, explain the possible work zone related road user cost components that can occur, and provide a step by step procedure to determine road user costs. Example problems, default hourly traffic percentages, and computation worksheets are also provided to aid the analyst with the road user cost computations.

Pakkala, P. Innovative Project Delivery Methods for Infrastructure. Report from Finland. 2002. http://alk.tiehallinto .fi/julkaisut/pdf/pakkalae5.pdf

Relevance: High

Description: This study, called "Innovative Project Delivery Methods for Infrastructure-An International Perspective," attempts to demonstrate practices and methods that can be utilized by client organizations to more effectively secure products and services. The goal is to share some of the most innovative or at least the most progressive methods used in several countries. It is important to distinguish between the delivery methods used for "Capital Projects" and "Maintenance Contracts." The details contained in this report are from data and information gathered mostly from the road sector, but they have implications that can be utilized in other infrastructure sectors, as well. The countries included in this study are Australia, Canada (Alberta, British Columbia \& Ontario), England, Finland, New Zealand, Sweden, and the USA.

Ryan, T. Innovative Project Development and Contracting Tools. Presentation. 2004-2006. http://ops.fhwa.dot.gov/ wz/workshops/sheet6.htm 
Relevance: High

Description: Contains presentations and papers to present several contracting methods for work zones.

Scott, S., and H. Klei. Innovative Contracting for Major Transportation Projects. 2006. http://onlinepubs.trb.org/ onlinepubs/archive/NotesDocs/20-24(43)_FR.pdf

Relevance: High

Description: This report summarizes the development and delivery of a workshop for state highway agency CEOs and senior managers responsible for highway construction contracting. The workshop was held at the AASHTO 2005 annual meeting in Nashville, Tennessee.

Thompson, S. Determining Innovative Contracting Methods to Reduce User Costs. Presentation. 2004-2006. http://ops .fhwa.dot.gov/wz/workshops/sheet6.htm

Relevance: High

Description: Contains presentations and papers to present several contracting methods for work zones.

Trauner Consulting Systems. Best-Value Procurement Methods for Highway Construction Projects. NCHRP Report 561. 2009. http://onlinepubs.trb.org/Onlinepubs/nchrp/nchrp_ rpt_561.pdf

Relevance: High

Description: Under NCHRP Project 10-61, "Best-Value Procurement Methods for Highway Construction Projects," Trauner Consulting Services, Inc., developed procurement methods, award algorithms, and rating systems for use in awarding best-value highway construction contracts. Screening criteria for selecting projects for application of bestvalue procurement, implementation strategies, and a model best-value specification were also developed. The research results, documented in NCHRP Report 561, will significantly enhance the capabilities of highway agencies in using best-value procurement methods in awarding highway construction contracts.

United Nations Development Program (UNDP). Transactional Procurement Strategies \& Procurement Planning. 2007.http://content.undp.org/go/userguide/cap/procurementstrategies-and-planning/\%3Bjsessionid = ajOyIC5r9wo5? lang $=\mathrm{en}$

Relevance: Low

Description: Procurement is an important function to ensure that UNDP meets its organizational goals. While Procurement is a support function for the organization, it is nevertheless a core function and critical to enhancing program/project delivery.
Zhu, Y., A. Irtishad, and L. Wang. Estimating Work Zone Road User Cost for Alternative Contracting Methods in Highway Construction Projects. 2009. http://cat.inist.fr/?a Modele $=$ afficheN\&cpsidt $=21724492$

Relevance: Moderate

Description: Highway construction often causes an additional road user cost to motorists due to traffic flow interruption and congestion in work zones. Consequently, facility owners, such as the Florida Department of Transportation (FDOT), are often interested in using alternative contracting methods such as $\mathrm{A}+\mathrm{B}$ contracting to expedite construction. Although many of these contracting methods rely on the RUC to determine incentives or disincentives, no standard method for RUC calculation is available to FDOT district engineers. In addition, existing methods are neither practical nor user-friendly for determining incentives or disincentives. This study intends to develop a RUC calculation procedure for the FDOT that focuses on using data that are easily accessible to FDOT district engineers, such as drawings and maintenance of traffic plans. The procedure is developed based on traffic analysis methods published in the Highway Capacity Manual, previous studies on user benefit analysis and work zones, and empirical data specific to Florida. Case studies are used to illustrate the procedure and to compare it with two other existing models, the Arizona model and the queue and user cost evaluation of work zone model, through correlation analysis, comparison of calculation assumptions, and data input analysis. This study shows that the suggested procedure produces consistent RUC estimates.

\section{Other Relevant Publications}

Anderson, S. Guidance for Cost Estimation and Management for Highway Projects During Planning, Programming and Preconstruction. NCHRP Report 574. 2007. http://online pubs.trb.org/onlinepubs/nchrp/nchrp_rpt_574.pdf

Relevance: High

Description: The objective of this research is to develop a guidebook on highway cost estimation management and project cost estimation procedures aimed at achieving greater consistency and accuracy between long-range transportation planning, priority programming, and preconstruction cost estimates. The guidebook should provide appropriate strategies, methods, and tools to develop, track, and document realistic cost estimates during each phase of the process.

Cammack, P. Year-Round Nebraska Traveler Information. Presentation. 2008.http://ops.fhwa.dot.gov/wz/workshops/ sheet2.htm 
Relevance: High

Description: Strategies and case studies for providing information to travelers regarding work zones.

Colorado DOT. Colorado Work Zone Best Practices Safety Guide. 2008. www.dot.state.co.us/Traffic_Manuals_Guide lines/Work_Zones/Work_Zone_Manuals/Work_Zone_ Safety_Guide_English_2007.pdf

Relevance: Low

Description: Guidebook for safety at work zones in Colorado.

Colorado DOT. Work Zone Safety Guidelines for Municipalities, Utilities and Contractors. 2005. www.dot.state.co.us/ Traffic_Manuals_Guidelines/Work_Zones/Work_Zone_ Manuals/Work_Zone_Safety_Guidelines_2005.pdf

Relevance: Low

Description: Guidelines in Colorado for managing traffic in work zones due to utilities, etc.

Costello, P. 511 Services “Hit the Road." Presentation. 2008. http://ops.fhwa.dot.gov/wz/workshops/sheet2.htm

Relevance: High

Description: Innovative technologies to provide safety for workers at work zones.

District of Columbia. District of Columbia Work Zone Safety and Mobility Policy. 2007. http://ddot.dc.gov/ddot/ lib/ddot/information/temp-traffic-cntrl/workzones/wz safety-n-mobility_policyreport.pdf

Relevance: Low

Description: The District Department of Transportation (DDOT) is committed to reducing congestion in and around work zones without compromising the safety of workers and the public. This policy provides guidance for assessing work zone impacts related to mobility and safety issues on the traveling public across the various stages of all Federal-Aid Highway-funded projects and to develop proper management strategies to reduce these impacts.

Hartmann, T., and G. Hawkins, Jr. Revised Process for WorkZone Decision Making Based on Quantitative Performance Measures. 2009. Source Data: Transportation Research Board Annual Meeting 2009 Paper \#09-1093.

Relevance: High

Description: A new decision-making process, which addresses the shortcomings in the current decision-making processes, was developed through the course of this research. The new process incorporates a Performance Measure/Treatment matrix, which recommends multiple performance measures, each of which is chosen to measure the mobility impacts particular to a specific work zone implementation. Most importantly, the revised decision-making process incorporates a feedback loop. Quantitative data collected in work zones is analyzed after the work zone is complete, to determine the impacts specific decisions had on mobility in the work zone. The lessons learned in previous work zones are then incorporated into the decision making process, lessening the mobility impacts of future work zones. This research develops the new decision-making process, and examines the issues with the application of the process.

Li, Z., and S. Madanu. Highway Project Level Life-Cycle Benefit/Cost Analysis under Certainty, Risk, and Uncertainty: A Methodology with Case Study. 2009. http://assetmanage ment.transportation.org/tam/aashto.nsf/All+Documents/ E2E4C8107CEAFA278525751B0071C74B/\$FILE/ ject-level $\% 20$ life-cycle $\% 20$ benefit-cost $\% 20$ analysis $\% 20$ under $\% 20$ certainty $\% 20$ risk $\% 20$ and $\% 20$ uncertainty- $\% 20$ a\%20methodology\%20with\%20case\%20study_JTE\%20 in\%20press.pdf

Relevance: Moderate

Description: This paper introduces an uncertainty-based methodology for highway project level life-cycle benefit/cost analysis that handles certainty, risk, and uncertainty inherited with input factors for the computation. A case study is conducted to assess impacts of risk and uncertainty considerations on estimating project benefits and on network-level project selection. First, data on system preservation and expansion, usage, and candidate projects for state highway programming are used to compute project benefits using deterministic, risk-based, and uncertainty-based analysis approaches, respectively.

Minnesota DOT. Work Zone Field Handbook. 2004-2009. www.dot.state.mn.us/trafficeng/workzone/2004-2009

Relevance: High

Description: Guidelines and rules for work zones in Minnesota.

Missouri DOT. MoDOT Work-Zone Guidelines. 2004. www .modot.org/business/documents/MoDOTWorkZonesGuide lines2.pdf

Relevance: High

Description: Practices and guidelines to reduce traffic impact in Missouri.

Ohio DOT. Project Development Process. 2005.

Relevance: High

Description: The Ohio Department of Transportation (ODOT) has developed and implemented a Project Development 
Process (PDP) that includes regular communication among technical disciplines, results in quality plans and minimizes cost overruns during right-of-way acquisition and project construction. Depending on project size, complexity, and/or potential impact to the environment, ODOT transportation projects are categorized as Minimal, Minor, or Major. The PDP consists of a certain number of steps depending on the project category.

Reynolds, K. Work Zone Liability. Presentation. 2008. http://ops.fhwa.dot.gov/wz/workshops/sheet2.htm

Relevance: High

Description: Legal Issues impacts on work zones.

Ryan, G. The Major Rehabilitation of the Eastbound McClugage Bridge. Paper\&Presentation. 2008. http://ops .fhwa.dot.gov/wz/workshops/sheet3.htm

Relevance: High

Description: Innovative technologies to provide safety for workers at work zones.

Uremovich, A. L. Interstate Highways Lane Closure Policy. 2004. www.in.gov/dot/div/contracts/standards/memos/ 0308-pc.pdf

Relevance: High

Description: Discusses general procedures and policies for lane closures, for traffic impact analysis in Indiana.

\section{Innovative Construction Techniques}

Bosler, R. Advanced Highway Maintenance and Construction Technology Research Center. 2008. http://ops.fhwa.dot .gov/wz/workshops/sheet3.htm

Relevance: Moderate

Description: Innovative technologies to provide safety for workers at work zones.

Neals, M. New Jersey State Police Construction Unit. Presentation. 2008. http://ops.fhwa.dot.gov/wz/workshops/ sheet4.htm

Relevance: Low

Description: The use of Enforcement in New Jersey to improve work zone safety.

Woo, D-C. Robotics in Highway Construction and Maintenance. 1995. www.tfhrc.gov/pubrds/winter95/p95wi26 .htm
Relevance: Moderate

Description: This research program has two major goals: to improve the existing techniques, equipment, and methods, and to develop new techniques, equipment, and methods. This is an applied research program based on existing robotics knowledge.

\section{Nighttime and Daytime Work Zone Experience}

Arditi, D., D-E. Lee, and G. Polat. Fatal Accidents in Nighttime vs. Daytime Highway Construction Work Zones. 2006. www.sciencedirect.com/science?_ob=ArticleURL\&_ udi $=$ B6V6F-4P6M8RB-2\&_user $=108 \_$rdoc $=18 \_\mathrm{fmt}=$ \& orig $=$ search \&_sort $=d \& \_d o c a n c h$ or $=\& v i e w=c \&$ searchStrId $=1068124958 \&$ \&_rerunOrigin $=$ google $\&_{-}$ acct $=$ C000050221\&_version $=18 \_$urlVersion $=0$ \&_userid $=10 \& \mathrm{md} 5=\mathrm{f} 7365 \mathrm{c} 4 \mathrm{~d} 0814759 \mathrm{dd} 813 \mathrm{f} 751969 \mathrm{e} 6 \mathrm{~b} 5 \mathrm{a}$

Relevance: Moderate

Description: This study investigates fatal accidents that occurred in Illinois highway work zones in the period 1996-2001 in order to determine the safety differences between nighttime and daytime highway construction. The lighting and weather conditions were included into the study as control parameters to see their effects on the frequency of fatal accidents occurring in work zones.

Bryden and Mace. A Procedure for Assessing and Planning Nighttime Highway Construction and Maintenance. NCHRP 475. 2002. http://onlinepubs.trb.org/onlinepubs/nchrp/ nchrp_rpt_475.pdf

Relevance: Moderate

Description: This report presents a decision process to assist highway agencies in evaluating night work alternatives against other work schedules. It provides a comprehensive, quantitative basis for selecting the most cost-effective plan for ensuring the safety of the public and workers, maintaining capacity, minimizing the impact on the community, and getting the work completed on schedule. This report will be of particular interest to engineers responsible for scheduling construction and maintenance work.

Bryden and Mace. Traffic Control Handbook for Mobile Operations at Night. 2003. SAIC has a copy.

Relevance: Moderate

Description: This Handbook is intended for use by a wide range of highway practitioners. It emphasizes that adequate advance planning and time to set up and remove good temporary traffic control are essential to ensure the safety of workers and road users. 
Elrahman, O. A. Night-Time Road Construction Operations Synthesis of Practice. 2008. https://www.nysdot.gov/ divisions/engineering/technical-services/trans-r-and-drepository/Final\%20Night\%20Time\%20Report.pdf

Relevance: High

Description: The Transportation Research \& Development Bureau (TRDB) performed a literature search on issues related to nighttime construction. This report synthesizes existing literature on nighttime construction operations, recognizes gaps in the current state of knowledge, and identifies research in progress.

Kennedy, G. Highway 125 Night. Work Presentation. 2008. http://ops.fhwa.dot.gov/wz/workshops/sheet5.htm

Relevance: Moderate

Description: Discusses safety strategies during night work zone on Highway 125.

Schexnayder, C. Effective Noise Control during Nighttime Construction. Presentation/paper. 2003. SAIC has copy of both.

Relevance: Low

Description: This presentation and paper discusses the urban work zones and how to control noise problem during construction. The first suggestion is controlling noise at the source with the type of equipments used and how to quiet the large machinery. The second suggestion is hindering the path of the noise with barriers, moving equipment farther away from the receiver, using landscaping as a shield and dissipater.

Ullman, G. L., and M. D. Finley. Traffic Safety Evaluation of Nighttime and Daytime Work Zones. Report NCHRP 627. 2008. http://144.171.11.107/Main/Public/Blurbs/Traffic Safety_Evaluation_of_Nighttime_and_Daytime_160500 .aspx

Relevance: High

Description: This report presents the findings of a research project to determine the crash rates for nighttime and daytime work zones, develop management practices that promote safety and mobility in work zones, and develop workzone crash reporting recommendations to further improve the data collected on work zone crashes.

\section{Relevant SHRP 2 Projects}

Title

Pub Type (Paper, Article, Presentation, Report)

Publication Source

Beginning and End of Study dates (in lieu of publication date)

TRB Lead Staff

Author(s)/Principal Investigator
SHRP 2 C02 A System-Based Performance Measurement Framework for Highway Capacity Decision Making Webpage on research in progress

http://144.171.11.40/cmsfeed/TRBNetProjectDisplay .asp?ProjectID $=2184$

2/28/2007-10/30/2009

Steve Andrle

J. Hugh Louch, Cambridge Systematics

Relevance: High

Description: To develop a performance measurement framework that informs a collaborative decision making process. The measures should reflect mobility, accessibility, economic, safety, environmental, watershed, habitat, community, and social considerations. This project will produce a framework for using performance measures. The framework will become an integral component of collaborative decision making and decision support tools.

Comments/Status: Report released on inventory of performance measures including PM for non-recurring congestion, including work zones-for reference in Task 2 and beyond.

SHRP 2 L03 Analytic Procedures for Determining the Impacts of Reliability Mitigation Strategies

Webpage on research in progress

http://144.171.11.40/cmsfeed/TRBNetProjectDisplay .asp?ProjectID $=2179$

2/22/2007-12/28/2009

William Hyman

Rich Margiotta

Relevance: High

Description: To develop technical relationships between reliability improvement strategies and reliability performance metrics.

Comments/Status: Project near completion; focus on nonrecurring events, incident management; strategic implications may apply to work zones-will monitor closely.

SHRP2 L1 1 Evaluating Alternative Operations Strategies to Improve Travel Time Reliability

Webpage on research in progress

http://144.171.11.40/cmsfeed/TRBNetProjectDisplay. asp?ProjectID $=2192$

9/3/2008-3/2/2010

William Hyman

John Zegeer (Kittleson \& Associates)

Relevance: High

Description: This research is intended to identify and evaluate strategies and tactics to satisfy the travel time reliability requirements of users of the roadway network - those engaged in both freight and person transport in urban and rural areas. The strategies must serve the near and more distant future and 
incorporate current and innovative approaches, both lowtech and high-tech.

Comment/Status: Project nearing completion, includes evaluation of performance measures, important for Task 2.

SHRP 2 L07 Evaluation of Cost-Effectiveness of Highway Design Features

Webpage on research in progress

http://144.171.11.40/cmsfeed/TRBNetProjectDisplay

.asp?ProjectID $=2181$

$1 / 7 / 2008-1 / 6 / 2012$

William Hyman

Ingrid Potts, Midwest Research Institute

Relevance: Moderate

Description: The objective of this project is to identify the full range of possible roadway design features used by transportation agencies on freeways and major arterials to improve travel time reliability, assess their costs, operational effectiveness, and safety, and provide recommendations for their use and eventual incorporation into appropriate design guides.

Comments/Status: Applications of geometric design, shoulders, etc., on capacity and movement can help in assessing lane strategies for renewal. At midpoint, will monitor closely.

SHRP 2 C10A Partnership to Develop an Integrated, Advanced Travel Demand Model and a Fine-Grained, TimeSensitive Network

Webpage on research in progress

http://144.171.11.40/cmsfeed/TRBNetProjectDisplay .asp?ProjectID $=2829$

$8 / 13 / 2009-2 / 12 / 2012$

Steve Andrle

Stephen Lawe, RSG

Relevance: Low/moderate

Description: The primary objective of this project is to make operational in two public agencies a dynamic integrated model-an integrated, advanced travel-demand model with a fine-grained, time-dependent network (integrated activities and networks). C10A is a collaborative case study in Jacksonville, FL.

Comments/Status: Not anticipated to be completed in time to be pertinent to our project, but we will monitor-relying on open-source software, could have relevance.

SHRP 2 C10B Partnership to Develop an Integrated Advanced Travel Demand Model with Mode Choice Capability and Fine-Grained, Time-Sensitive Networks

Webpage on research in progress

http://144.171.11.40/cmsfeed/TRBNetProjectDisplay .asp?ProjectID $=2828$

9/1/2009-2/28/2012

\section{Steve Andrle}

\section{Tom Rossi}

Relevance: Low/moderate

Description: C10B is a case study in Sacramento, CA.

Comments/Status: Not anticipated to be completed in time to be pertinent to our project, but we will monitor-relying on open-source software, could have relevance.

SHRP 2 L04 Incorporating Reliability Performance Measures in Operations and Planning Modeling Tools

Webpage on research in progress

http://144.171.11.40/cmsfeed/TRBNetProjectDisplay .asp?ProjectID $=2193$

$2 / 6 / 2009-2 / 6 / 2012$

William Hyman

Yannis Stogias (Delcan)

Relevance: Low/moderate

Description: One of its objectives is to develop performance measure for travel time reliability at work zones.

Comments/Status: Project just getting started; has increasing potential as it progresses, will monitor closely. "How to measure reliability” a potential key contribution.

SHRP 2 R04 Innovative Bridge Designs for Rapid Renewal Webpage on research in progress

http://144.171.11.40/cmsfeed/TRBNetProjectDisplay .asp?ProjectID $=2167$

$10 / 8 / 2007-10 / 7 / 2011$

Monica Starnes

Kenneth Price (HNTB)

Relevance: Moderate

Description: The objective of this project is to develop standardized approaches to designing, constructing, and reusing (including future widening) complete bridge systems that address rapid renewal needs and efficiently integrate modern construction equipment.

Comments/Status: This is project-based, but as bridges are often critical links in corridors and networks, we believe it has relevance to our study.

SHRP 2 C01 A Framework for Collaborative Decision Making on Additions to Highway Capacity

Webpage on research in progress

http://144.171.11.40/cmsfeed/TRBNetProjectDisplay .asp?ProjectID $=2161$

2/9/2007-2/8/2010

Steve Andrle

Janet D'Ignazio, ICF

Relevance: Low

Description: (1) Develop a systems-based, transparent, welldefined framework for consistently reaching collaborative 
decisions on transportation capacity enhancements and (2) identify a SHRP 2 research strategy for addressing gaps in supporting information systems.

Comments/Status: C01 "merged" into C07—overall project development review—no discernible impact on our study.

SHRP 2 C07 Integrating SHRP 2 Products into the Collaborative Decision making Process

Webpage-project not yet started

http://144.171.11.40/cmsfeed/TRBNetProjectDisplay .asp?ProjectID $=2346$

Not yet initiated-recently awarded to ICF sole source

Steve Andrle

Janet D'Ignazio, ICF

Relevance: Low

Description: The objectives of this research are (1) to integrate the results of SHRP 2 Capacity research into the collaborative decision-making and performance-measurement frameworks, especially Projects C02, C03, C06A\&B, C08, C09, C12, and C15, and L05; (2) Incorporate into the Collaborative Decision-making Framework the results of NCHRP 25-25 (27) and related work linking outputs from the highway planning and programming to project management

Comments/Status: C01 "merged" into C07—overall project development review-no discernible impact on our study.

SHRP 2 L05 Incorporating Reliability Performance Measures into the Transportation Planning and Programming Processes

Webpage

http://144.171.11.40/cmsfeed/TRBNetProjectDisplay .asp?ProjectID $=2194$

Relevance: Low

Description: Discusses how to incorporate the reliability measures as part of Planning and Programming.

Comments/Status: Just awarded, looking primarily at new capital programs; work zones are not a major component. "How to measure reliability" a potential key contribution. 


\section{APPENDIX B}

\section{Results of the Software Evaluation}

Traffic Analysis Toolbox Volume I: Traffic Analysis Tools Primer (2004), developed by the FHWA, provided the starting point for an exhaustive list of software tools (Generic Traffic Analysis Tools, Table B.1). These tools were classified based on the transportation modeling categories (i.e., sketch planning, travel demand model, traffic signal optimization, analytic/ deterministic, macroscopic, mesoscopic, microscopic, and whether it is a tool suite). From the identified packages that were listed, a short list of packages that have been used, or have the potential to be used, for work zone analysis was compiled. The packages were rated based on the total number of characteristics available in the software and the characteristics important to assessing their capability to evaluate work zone impacts. Based on the functionalities discussed in Chapter 2, the results of the software evaluation are tabulated in this appendix (Tables B.2-B.12). 
Table B.1 Generic Traffic Analysis Tools

Better Decisions

HDM (Highway Design and Management)

IDAS (ITS Deployment Analysis System)

IMPACTS

MicroBENCOST

QuickZone

SCRITS (Screening for ITS

Sketch Methods

SMITE (Spreadsheet Model for Induced Travel Estimation)

SPASM (Sketch Planning Analysis Spreadsheet Model)

STEAM (Surface Transportation Efficiency Analysis Model)

TEAPAC (Traffic Engineering Applications Package)/SITE

TrafikPlan

TransDec (Transportation Decision)

Trip Generation

Turbo Architecture

b-Node Model

CUBE/MINUTP

CUBE/TP+NViper

CUBE/TRANPLAN (Transportation Planning)

CUBE/TRIPS (Transport Improvement Planning System)

EMME/2TM

MicroTRIMS

QRS II (Quick Response System II)

SATURN (Simulation and Assignment of Traffic to Urban Road Network)

TModel

TransCAD®

TRANSIMS (Transportation Analysis Simulation System)

BTS (Bottleneck Traffic Simulator)

FREQ12

KRONOS

METACORMETANET

NETCELL

PASSER II-02

PASSER III-98

PASSER IV-96

SATURN

TRAF-CORFLO (Corridor Flow)

TRANSYT-7F

VISTA (Visual Interactive System for Transport Algorithms)

DynusT

DynaSmart

Dynamit

\begin{tabular}{|c|c|c|c|c|c|c|c|}
\hline & Sketch planning & $\begin{array}{l}\text { Travel Demand } \\
\text { Model }\end{array}$ & \begin{tabular}{|l} 
Traffic \\
Optimization
\end{tabular} & \begin{tabular}{|l} 
Analytical / \\
Deterministic
\end{tabular} & $\begin{array}{l}\text { Simulation } \\
\text { Macroscopic }\end{array}$ & $\begin{array}{l}\text { Simulation- } \\
\text { mesoscopic }\end{array}$ & $\begin{array}{l}\text { Simulation- } \\
\text { microscopic }\end{array}$ \\
\hline http://mctrans.ce.ufl.edu/store/description.asp?item & 1 & & & & & & \\
\hline http://hdm4.piarc.org & 1 & 1 & & & & & \\
\hline http://idas.camsys.com & 1 & & & & & & \\
\hline www.fhwa.dot.gov/steam/impacts.htm & 1 & & & & & & \\
\hline \multicolumn{8}{|l|}{ http://mctrans.ce.ufl.edu/store/description.asp?itemlD=166 } \\
\hline www.thrc.gov/its/quickzon.htm & 1 & & & & & & \\
\hline www.fhwa.dot.gov/steam/scrits.htm & 1 & & & & & & \\
\hline hitp://plan2op.thwa.dot.gov/toolbox/toolbox.htm & 1 & & & & & & \\
\hline www.fhwa.dot.gov/steam/smite.htm & 1 & & & & & & \\
\hline www.fhwa.dot.gov/steam/spasm.htm & 1 & & & & & & \\
\hline www.fhwa.dot.gov/steam/index.htm & 1 & & & & & & \\
\hline www.strongconcepts.com/Products.htm & 1 & & & & & & \\
\hline http://mctrans.ce.ufl.edu/store/description.asp?itemlD=162 & 1 & & & & & & \\
\hline http://tti.tamu.edu/researcher/v34n3/transdec.stm & 1 & & & & & & \\
\hline http://mctrans.ce.ufl.edu/store/description.asp?item|D=179 & 1 & & & & & & \\
\hline http://itsarch.iteris.com/tsarch/htm/turbo/turbooverview.htm & 1 & & & & & & \\
\hline http: //mctrans.ce.uff.edu/store/description.asp?itemlD=482 & & 1 & & & & & \\
\hline www.citilabs.com/minutp/index.html & & 1 & & & 1 & & \\
\hline www.citilabs.com/viper/index.html & & 1 & & & 1 & & \\
\hline www.citilabs.com/tranplan/index.html & & 1 & & & 1 & 4 & \\
\hline www.citilabs.com/trips/index.html & & 1 & & & 1 & & \\
\hline www.inro.ca/products/e2_products.html & & 1 & & & & & \\
\hline http://mctrans.ce.ufl.edu/store/description.asp?item|D=483 & & 1 & & & & & \\
\hline http://my.execpc.com/ ajh/index.html & & 1 & & & & & \\
\hline http://mctrans.ce.ufl.edu/store/description.asp?itemlD=157 & & 1 & & & & & \\
\hline www.tmodel.com & & 1 & & & & & \\
\hline www.caliper.com/tcovu.htm & & 1 & & & 1 & & \\
\hline http://transims.tsasa.lanl.gov & & 1 & & & & & \\
\hline \multicolumn{8}{|l|}{ http://mctrans.ce.ufl.edu/store/description.asp?itemlD=287 } \\
\hline \multicolumn{8}{|l|}{ www.ts.berkeley.edu/computing/software/FREQ.html } \\
\hline \multicolumn{8}{|l|}{ www.its.umn.edu/labs/itslab.html } \\
\hline \multirow{2}{*}{\multicolumn{8}{|c|}{$\begin{array}{l}\text { www.inrets.fr/ur/gretia/METACOR-Ang-H-HajSalem.htm } \\
\text { wwww.its.berkelev.edu/computing/software/netcell.html }\end{array}$}} \\
\hline \multicolumn{7}{|l|}{ Www.its.berkeley.edu/computing/software/netcell.html } & \\
\hline \multicolumn{8}{|l|}{ http://ttisoftware.tamu.edu/fraPasserll_02.htm } \\
\hline \multirow{2}{*}{\multicolumn{8}{|c|}{ hitp://ttisoffware.tamu.edu/fraPasserlll_98.htm }} \\
\hline & & & & & & & hitp://titisoftware.tamu.edu/fraPasserlV_96.htm \\
\hline \multicolumn{8}{|l|}{ www.its.leeds.ac.uk/software/saturn/index.html } \\
\hline \multicolumn{8}{|l|}{ http://mctrans.ce.ufl.edu/store/description.asp?itemID=441 } \\
\hline \multicolumn{8}{|l|}{ http://mctrans.ce.ufl.edu/store/description.asp?item|D=437 } \\
\hline \multicolumn{8}{|l|}{ http://its.civil.northwestern.edu/vista } \\
\hline \multicolumn{8}{|l|}{ http://dynust.net/wikibin/doku.php } \\
\hline \multicolumn{8}{|l|}{ http://mctrans.ce.ufl.edu/featured/dynasmart/ } \\
\hline http://mit.edu/its/dynamit.html & & & & & & 1 & \\
\hline
\end{tabular}

(continued) 
Table B.1 Generic Traffic Analysis Tools (continued)

Contram

Contram
AIMSUN2 (Advanced Interactive Microscopic Simulator for Urban and Non-Urban Ne ANATOLL

AUTOBAHN

CASIMIR

CORSIM/SIS (Traffic Software Integrated System)

DRACULA (Dynamic Route Assignment Combining User Learning and Microsimula FLEXSYT-II

HIPERTRANS (High-Performance Transport)

HUTSIM (Helsinki University of Technology Simulator)

INTEGRATION

MELROSE (Mitsubishi Electric Road Traffic Simulation Environment)

MicroSim

MICSTRAN (Microscopic Simulator Model for Traffic Networks)

MITSIM (Microscopic Traffic Simulator)

MIXIC

NEMIS

ADSIM (Probabilistic Adaptive Simulation Model)

PARAMICS

PHAROS (Public Highway and Road Simulator)

PLANSIM-T

ROADSIM (Rural Road Simulator)

SHIVA (Simulated Highways for Intelligent Vehicle Algorithms)

SIGSIM

SIMDAC

SIMNET

SimTraffic

SISTM (Simulation of Strategies for Traffic on Motorways)

SITRA B+

SITRAS

SmartPATH

TEXAS (TEXAS Model for Intersection Traffic)

TEXAS (TEXA

TWOPAS

VISSIM

WATSim (Wide Area Traffic Simulation)

PROGO

SOAP84

Synchro

TEAPAC/NOSTOP

TEAPAC/SIGNAL2000

TEAPAC/WARRANTS

TSDWIN

TS/PP-Draft

5-Leg Signalized Intersection Capacity

aaSIDRA (Signalized and Unsignalized Intersection Design and Research Aid)

ARCADY (Assessment of Roundabout Capacity and Delay)

ARTPLAN (Arterial Planning)

CATS (Computer-Aided Transportation Software)

\begin{tabular}{|c|c|}
\hline & Sketch planning \\
\hline \multicolumn{2}{|l|}{ http://www.contram.com/ } \\
\hline \multicolumn{2}{|l|}{$\mid \sqrt{\text { www.tss-bcn.com/aimsun.html }}$} \\
\hline \multicolumn{2}{|l|}{ www.its.leeds.ac.uk/projects/smartest/append3d.html\#a4 } \\
\hline \multicolumn{2}{|l|}{ wWw.its.leeds.ac.uk/projects/smartest/append3d.htm|\#a5 } \\
\hline \multicolumn{2}{|l|}{ www.its.leeds.ac.uk/projects/smartest/append3d.htm/\#a6 } \\
\hline \multicolumn{2}{|l|}{\begin{tabular}{|l|l} 
www.fhwa-tsis.com \\
\end{tabular}} \\
\hline \multicolumn{2}{|l|}{ idwww.its.leeds.ac.uk/software/dracula } \\
\hline \multicolumn{2}{|l|}{ www.flexsyt.nl/informatieuk.htm } \\
\hline \multicolumn{2}{|l|}{\begin{tabular}{|l} 
www.cpc.wmin.ac.uk/ traffic \\
\end{tabular}} \\
\hline \multicolumn{2}{|l|}{ www.hut.fi/Units/Transportation/HUTSIM } \\
\hline \multicolumn{2}{|l|}{\begin{tabular}{|l|l} 
www.intgrat.com \\
\end{tabular}} \\
\hline \multicolumn{2}{|l|}{ www.its.leeds.ac.uk/projects/smartest/append3d.htm|\#a14 } \\
\hline \multicolumn{2}{|l|}{ www.zpr.uni-koeln.de/GroupBachem/VERKEHR.PG } \\
\hline \multicolumn{2}{|l|}{ www.its.leeds.ac.uk/projects/smartest/append3d.html\#a16 } \\
\hline \multicolumn{2}{|l|}{ http://web.mit.edu/ts/products.html } \\
\hline \multicolumn{2}{|l|}{ www.its.leeds.ac.uk/projects/smartest/append3d.htm|\#a18 } \\
\hline \multicolumn{2}{|l|}{\begin{tabular}{|l} 
www.its.leeds.ac.uk/projects/smartest/append3d.htm|\#a19 \\
\end{tabular}} \\
\hline \multicolumn{2}{|l|}{ wWw.its.leeds.ac.uk/projects/smartest/append3d.htm|\#a21 } \\
\hline \multicolumn{2}{|l|}{\begin{tabular}{|l} 
www.paramics-online.com \\
\end{tabular}} \\
\hline \multicolumn{2}{|l|}{ WWw.its.leeds.ac.uk/projects/smartest/append3d.htm|\#a23 } \\
\hline \multicolumn{2}{|l|}{ www.its.leeds.ac.uk/projects/smartest/append3d.htm|\#a24 } \\
\hline \multicolumn{2}{|l|}{\begin{tabular}{|l} 
www.kldassociates.com/simmod.htm \\
\end{tabular}} \\
\hline \multicolumn{2}{|l|}{ wWw.its.leeds.ac.uk/projects/smartest/append3d.htm|\#a25 } \\
\hline wWw.tts.leeds.ac.uk/projects/smartest/append3d.htm|\#a26 & \\
\hline wWw.tts.leeds.ac.uk/projects/smartest/append3d.htm|\#a27 & \\
\hline www.its.leeds.ac.uk/projects/smartest/append3d.htm|\#a28 & \\
\hline \begin{tabular}{|l|} 
www.trafficware.com \\
\end{tabular} & \\
\hline wWw.its.leeds.ac.uk/projects/smartest/append3d.htm|\#\#29 & \\
\hline www.its.leeds.ac.uk/projects/smartest/append3d.htm/\#a30 & \\
\hline www.its.leeds.ac.uk/projects/smartest/append3d.htm|\#a31 & \\
\hline \begin{tabular}{|l|} 
www.path.berkeley.edu/PATH/Research \\
\end{tabular} & \\
\hline http://mctrans.ce.ufl.edu/store/description.asp?itemlD=449 & \\
\hline \begin{tabular}{|l} 
www.engr.umd.edu/ /ovell/lovmay94.html \\
\end{tabular} & \\
\hline Www.tfhrc.gov/safety/ihsdm/tamweb.htm & \\
\hline \begin{tabular}{|l|} 
www.itc-world.com \\
\end{tabular} & \\
\hline WWw.kldassociates.com/unites.html & \\
\hline http://mctrans.ce.ufl.edu/store/description.asp?item|D=78 & \\
\hline hitp://mctrans.ce.ufl.edu/store/description.asp?itemlD=435 & \\
\hline Www.trafficware.com & \\
\hline \begin{tabular}{|l|} 
www.strongconcepts.com/Products.htm \\
\end{tabular} & \\
\hline \begin{tabular}{|l} 
www.strongconcepts.com/Products.htm \\
\end{tabular} & \\
\hline \begin{tabular}{|l} 
www.strongconcepts.com/Products.htm \\
\end{tabular} & \\
\hline \begin{tabular}{|l|} 
www.fortrantraffic.com/whatsnew/new2.htm \\
\end{tabular} & \\
\hline www.tsppd.com & \\
\hline http://mctrans.ce.ufl.edu/store/description.asp?itemID=36 & \\
\hline wWw.aatraffic.com/SIDRA/aboutsidra.htm & \\
\hline www.trlsoftware.co.uk/productARCADY.htm & \\
\hline WWw.myflorida.com/planning/systems/sm/los/default.htm & \\
\hline http://tititamu.edu/product/software/cats & \\
\hline
\end{tabular}

\begin{tabular}{|c|c|c|c|c|c|}
\hline \begin{tabular}{|l} 
Travel Demand \\
Model
\end{tabular} & \begin{tabular}{|l} 
Traffic \\
Optimization
\end{tabular} & $\begin{array}{l}\text { Analytical// } \\
\text { Deterministic }\end{array}$ & $\begin{array}{l}\text { Simulation } \\
\text { Macroscopic }\end{array}$ & $\begin{array}{l}\text { Simulation- } \\
\text { mesoscopic }\end{array}$ & $\begin{array}{l}\text { Simulation- } \\
\text { microscopic }\end{array}$ \\
\hline & & & & 1 & \\
\hline & & & & 7 & \\
\hline & & & & & \\
\hline & & & & & \\
\hline & & & & & \\
\hline & & & & & \\
\hline & & & & & \\
\hline & & & & & 1 \\
\hline & & & & & 1 \\
\hline & & & & & \\
\hline & & & & & \\
\hline & & & & & 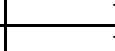 \\
\hline & & & & & 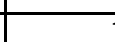 \\
\hline & & & & & 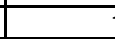 \\
\hline & & & & & 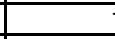 \\
\hline & & & & & - \\
\hline & & & & & - \\
\hline & & & & & \\
\hline & & & & & 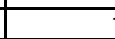 \\
\hline & & & & & 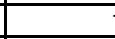 \\
\hline & & & & & \\
\hline & & & & & - \\
\hline & & & & & \\
\hline & & & & & \\
\hline & & & & & 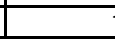 \\
\hline & & & & & \\
\hline & & & & & \\
\hline & & & & & \\
\hline & & & & & \\
\hline & & & & & \\
\hline & & & & & \\
\hline & 1 & & & & \\
\hline & 1 & & & & \\
\hline & 1 & & & & \\
\hline & 1 & & & & \\
\hline & 1 & & & & \\
\hline & $\overline{1}$ & & & & \\
\hline & 1 & & & & \\
\hline & 1 & & & & \\
\hline & & & & & \\
\hline & & & & & \\
\hline & & & & & \\
\hline & & & & & \\
\hline & & & 4 & & \\
\hline
\end{tabular}

(continued) 
Table B.1 Generic Traffic Analysis Tools (continued)

CCG/Calc2 (Canadian Capacity Guide)

$\mathrm{CINCH}$

CIRCAP (Circle Capacity)

DELAYE (Delay Enhanced)

FAZWEAVE

FREEPLAN (Freeway Planning)

FREWAY (Freeway Delay Calculation Program)

FRIOP (Freeway Interchange Optimization Model)

General Purpose Queuing Model

Generalized Annual Average Daily Service Volume Tables

Generalized Peak-Hour Directional Service Volume Tables

GradeDec 2000

HCM/CinemaC

HCS (Highway Capacity Software) 2000

HiCAPTM (Highway Capacity Analysis Package)

HIGHPLAN (Highway Planning)

Highway Safety Analysis

ICU (Intersection Capacity Utilization)

IQPAC (Integrated Queue Analysis Package)

Left-Turn Signal/Phase Warrant Program

NCAP (Intersection Capacity Analysis Package)

PICADY (Priority Intersection Capacity and Delay)

PROGO (Progression Graphics and Optimization)

Quality/Level of Service Handbook

Roadrunner

SIG/CinemaC

SIPA (Signalized Intersection Planning Analysis)

SIPA (Signal

SPARKS (Smart Parking Analysis)

TGAP (Traffic Gap Analysis Package)

TIMACS (Timing Implementation Method for Actuated Coordinated Systems)

Traffic Engineer's Toolbox

Traffic Noise Model

TRAFFIXTM

TSDWIN TM (Time-Space Diagram for Windows $\Theta$ )

TS/PP-Draft (Time-Space/Platoon-Progression Diagram Generator)

WEST (Workspace for Evaluation of Signal Timings)

WHICH (Wizard of Helpful Intersection Control Hints)

WinWarrants

\begin{tabular}{|c|c|c|c|c|c|c|c|}
\hline & Sketch planning & $\begin{array}{l}\text { Travel Demand } \\
\text { Model }\end{array}$ & \begin{tabular}{|l} 
Traffic \\
Optimization
\end{tabular} & $\begin{array}{l}\text { Analytical// } \\
\text { Deterministic }\end{array}$ & $\begin{array}{l}\text { Simulation } \\
\text { Macroscopic }\end{array}$ & $\begin{array}{l}\text { Simulation- } \\
\text { mesoscopic }\end{array}$ & $\begin{array}{l}\text { Simulation- } \\
\text { microscopic }\end{array}$ \\
\hline \multicolumn{8}{|l|}{ WWw.bagroup.com/Pages/software/CCGCALC.html } \\
\hline \multicolumn{8}{|l|}{ http://mctrans.ce.uffl.edu/store/description.asp?itemID=4 } \\
\hline \multicolumn{8}{|l|}{ www.teppllc.com/publications/CIRCAP.html } \\
\hline \multicolumn{8}{|l|}{ http://mctrans.ce.ufl.edu/store/description.asp?itemlD=407 } \\
\hline \multicolumn{8}{|l|}{ http://tigger.uic.edu/ jfazio/weaving } \\
\hline \multirow{2}{*}{\multicolumn{8}{|c|}{$\begin{array}{l}\text { www.11.myflorida.com/planning/systems/sm/los/default.htm } \\
\text { http://mctrans.ce.ufl.edu/store/description.asp?itemlD=291 }\end{array}$}} \\
\hline & & & & 1 & & & \\
\hline \multicolumn{8}{|l|}{ http://mctrans.ce.ufl.edu/store/description.asp?itemlD=408 } \\
\hline \multicolumn{8}{|l|}{ http://mctrans.ce.ufl.edu/store/description.asp?item|D=409 } \\
\hline \multicolumn{8}{|l|}{ www.11.myflorida.com/planning/systems/sm/los/default.htm } \\
\hline \multicolumn{8}{|l|}{ Www.11.myflorida.com/planning/systems/sm/los/default.htm } \\
\hline \multicolumn{8}{|l|}{ www.gradedec.com } \\
\hline \multicolumn{8}{|l|}{ www.kldassociates.com/unites.htm } \\
\hline \multicolumn{8}{|l|}{ http://mctrans.ce.ufl.edu/store/description.asp?item|D=48 } \\
\hline \multicolumn{8}{|l|}{ www.hicap2000.com } \\
\hline \multicolumn{8}{|l|}{ Www.11.myflorida.com/planning/systems/sm/los/default.htm } \\
\hline \multicolumn{8}{|l|}{ www.x32group.com/HSA_Soft.html } \\
\hline \multicolumn{8}{|l|}{ Www.trafficware.com/ICU/index.html } \\
\hline \multirow{2}{*}{\multicolumn{8}{|c|}{$\begin{array}{l}\text { http://mctrans.ce.uffledu/store/description.asp?itemlD=294 } \\
\text { http://mctrans.ce.ufl.edu/store/description.asp?itemlD=56 }\end{array}$}} \\
\hline \multicolumn{7}{|l|}{ http://mctrans.ce.uffl.edu/store/description.asp?item|D=56 } & \\
\hline \multicolumn{8}{|l|}{ www.tmodel.com } \\
\hline \multicolumn{8}{|l|}{ www.trlsoftware.co.uk/productPICADY.htm } \\
\hline \multicolumn{8}{|l|}{ http://mctrans.ce.ufl.edu/store/description.asp?item|D=78 } \\
\hline \multicolumn{8}{|l|}{ www.11.myflorida.com/planning/systems/sm/los/default.html } \\
\hline \multicolumn{8}{|l|}{ http://mctrans.ce.ufl.edu/store/description.asp?item|D=85 } \\
\hline \multicolumn{8}{|l|}{ www.kldassociates.com/unites.htm } \\
\hline http://mctrans.ce.ufl.edu/store/description.asp?item|D=22 & & & & 1 & & & \\
\hline hittp://mctrans.ce.ufl.edu/store/description.asp?item|D=304 & & & & 1 & & & \\
\hline http://mctrans.ce.ufl.edu/store/description.asp?item|D=305 & & & & 1 & & & \\
\hline \begin{tabular}{|l|l} 
www.tmodel.com \\
\end{tabular} & & & & 1 & & & \\
\hline http://mctrans.ce.ufl.edu/store/description.asp?item|D=92 & & & & 1 & & & \\
\hline http://home.pacifier.com/ jbtech & & & & 1 & & & \\
\hline www.thewalljournal.com/a1f04/nm & & & & 1 & & & \\
\hline \begin{tabular}{|l|} 
www.traffixonline.com \\
\end{tabular} & & & & 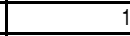 & & & \\
\hline www.fortrantraffic.com/whatsnew/new2.htm & & & & 1 & & & \\
\hline www.tsppd.com & & & & 1 & & & \\
\hline http://mctrans.ce.ufl.edu/store/description.asp?item|D=126 & & & & 1 & & & \\
\hline http://mctrans.ce.ufl.edu/store/description.asp?item|D=127 & & & & 1 & & & \\
\hline http://home.pacifier.com/ jbtech & & & & 1 & & & \\
\hline
\end{tabular}




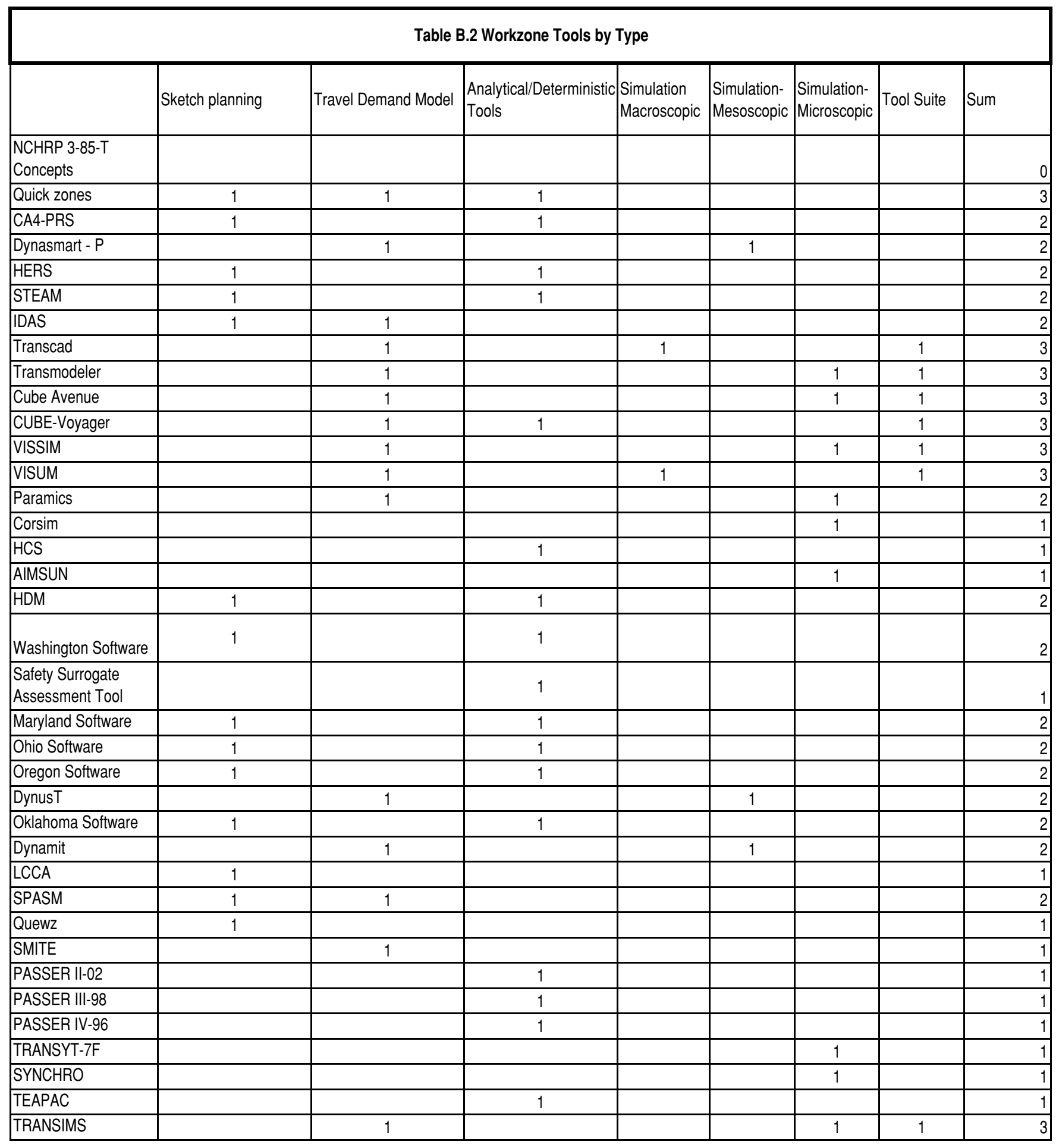


Table B.3 Functionality

\begin{tabular}{|c|c|c|c|c|c|}
\hline \multicolumn{6}{|c|}{ Functionality } \\
\hline & Planning & Operations & $\begin{array}{l}\text { Construction } \\
\text { management }\end{array}$ & Logistics & Sum \\
\hline $\begin{array}{l}\text { NCHRP 3-85-T } \\
\text { Concepts }\end{array}$ & & & & & 0 \\
\hline Quick zones & 1 & & 1 & 1 & 3 \\
\hline CA4-PRS & 1 & & 1 & 1 & 3 \\
\hline Dynasmart - $P$ & 1 & 1 & & & 2 \\
\hline HERS & 1 & & 1 & & 2 \\
\hline STEAM & 1 & & & & 1 \\
\hline IDAS & 1 & & & & 1 \\
\hline Transcad & 1 & & & & 1 \\
\hline Transmodeler & & 1 & & & 1 \\
\hline Cube Avenue & & 1 & & & 1 \\
\hline CUBE-Voyager & 1 & & & & 1 \\
\hline VISSIM & & 1 & & & 1 \\
\hline VISUM & 1 & & & & 1 \\
\hline Paramics & & 1 & & & 1 \\
\hline Corsim & & 1 & & & 1 \\
\hline $\mathrm{HCS}$ & 1 & 1 & & & 2 \\
\hline AIMSUN & & 1 & & & 1 \\
\hline HDM & 1 & & 1 & & 2 \\
\hline Washington Software & 1 & & & & 1 \\
\hline $\begin{array}{l}\text { Safety Surrogate } \\
\text { Assessment Tool }\end{array}$ & 1 & 1 & & & 2 \\
\hline Maryland Software & 1 & & 1 & 1 & 3 \\
\hline Ohio Software & 1 & & & & 1 \\
\hline Oregon Software & 1 & & 1 & 1 & 3 \\
\hline DynusT & 1 & 1 & & & 2 \\
\hline Oklahoma Software & 1 & & & & 1 \\
\hline Dynamit & 1 & 1 & & & 2 \\
\hline LCCA & 1 & & 1 & 1 & 3 \\
\hline SPASM & 1 & & & & 1 \\
\hline Quewz & 1 & 1 & & & 2 \\
\hline SMITE & 1 & & & & 1 \\
\hline PASSER II-02 & & 1 & & & 1 \\
\hline PASSER III-98 & & 1 & & & 1 \\
\hline PASSER IV-96 & & 1 & & & 1 \\
\hline TRANSYT-7F & & 1 & & & 1 \\
\hline SYNCHRO & & 1 & & & 1 \\
\hline TEAPAC & & 1 & & & 1 \\
\hline Transims & 1 & 1 & & & 2 \\
\hline
\end{tabular}


Table B.4 Users and Proprietary

\begin{tabular}{|c|c|c|c|c|c|}
\hline & \multicolumn{2}{|c|}{ Type of User } & \multirow{2}{*}{\begin{tabular}{|l} 
References \\
Case studies or \\
References - where \\
has software been \\
applied \\
\end{tabular}} & \multirow{2}{*}{\begin{tabular}{|l|} 
Proprietary or Not \\
1 if Proprietary else 0
\end{tabular}} & \multirow[t]{2}{*}{ Sum } \\
\hline & Engineer & Planner & & & \\
\hline \begin{tabular}{|l|} 
NCHRP 3-85-T \\
Concepts
\end{tabular} & & & & & 0 \\
\hline Quick zones & 1 & 1 & & 1 & 3 \\
\hline CA4-PRS & 1 & 1 & & & 2 \\
\hline Dynasmart - $\mathrm{P}$ & 1 & 1 & & & 2 \\
\hline HERS & & 1 & & 1 & 2 \\
\hline STEAM & & 1 & & 1 & 2 \\
\hline IDAS & & 1 & & & 1 \\
\hline Transcad & 1 & & & & 1 \\
\hline Transmodeler & & 1 & & & 1 \\
\hline Cube Avenue & 1 & & & & 1 \\
\hline CUBE-Voyager & & 1 & & & 1 \\
\hline VISSIM & 1 & & & & 1 \\
\hline VISUM & & 1 & & & 1 \\
\hline Paramics & 1 & & & & 1 \\
\hline Corsim & 1 & & & & 1 \\
\hline HCS & 1 & 1 & & & 2 \\
\hline AIMSUN & 1 & & & & 1 \\
\hline HDM & & 1 & & & 1 \\
\hline Washington Software & 1 & 1 & & 1 & 3 \\
\hline $\begin{array}{l}\text { Safety Surrogate } \\
\text { Assessment Tool }\end{array}$ & 1 & & & 1 & 2 \\
\hline Maryland Software & 1 & 1 & & 1 & 3 \\
\hline Ohio Software & 1 & 1 & & 1 & 3 \\
\hline Oregon Software & 1 & 1 & & 1 & 3 \\
\hline DynusT & 1 & 1 & & 1 & 3 \\
\hline Oklahoma Software & 1 & 1 & & 1 & 3 \\
\hline Dynamit & 1 & 1 & & & 2 \\
\hline LCCA & & 1 & & 1 & 2 \\
\hline SPASM & & 1 & & 1 & 2 \\
\hline Quewz & 1 & 1 & & & 2 \\
\hline SMITE & & 1 & & 1 & 2 \\
\hline PASSER II-02 & 1 & & & & 1 \\
\hline PASSER III-98 & 1 & & & & 1 \\
\hline PASSER IV-96 & 1 & & & & 1 \\
\hline TRANSYT-7F & 1 & & & & 1 \\
\hline SYNCHRO & 1 & & & & 1 \\
\hline TEAPAC & 1 & & & & 1 \\
\hline Transims & 1 & 1 & & 1 & 3 \\
\hline
\end{tabular}


Table B.5 Data Inputs

\begin{tabular}{|c|c|c|c|c|c|c|}
\hline \multicolumn{7}{|c|}{ Data inputs } \\
\hline & Traffic & Pavement & $\begin{array}{l}\text { Prior data of } \\
\text { production rates for } \\
\text { various strategies }\end{array}$ & $\begin{array}{l}\text { Prior data of cost for } \\
\text { various strategies }\end{array}$ & $\begin{array}{l}\text { Other data } \\
\text { requirements - list + } \\
\text { potential sources }\end{array}$ & Sum \\
\hline $\begin{array}{l}\text { NCHRP 3-85-T } \\
\text { Concepts }\end{array}$ & & & & & & \\
\hline Quick zones & 1 & & & & & 1 \\
\hline CA4-PRS & 1 & 1 & 1 & 1 & & 4 \\
\hline Dynasmart - $\mathrm{P}$ & 1 & & & & & 1 \\
\hline HERS & 1 & 1 & & 1 & Life cycle costs & 3 \\
\hline STEAM & 1 & 1 & & 1 & Economic impact & 3 \\
\hline IDAS & 1 & & & 1 & ITS & 2 \\
\hline Transcad & 1 & & & & & 1 \\
\hline Transmodeler & 1 & & & & & 1 \\
\hline Cube Avenue & 1 & & & & & 1 \\
\hline CUBE-Voyager & 1 & & & & & 1 \\
\hline VISSIM & 1 & & & & & 1 \\
\hline VISUM & 1 & & & & & 1 \\
\hline Paramics & 1 & & & & & 1 \\
\hline Corsim & 1 & & & & & 1 \\
\hline HCS & 1 & & & & & 1 \\
\hline AIMSUN & 1 & & & & & 1 \\
\hline HDM & 1 & 1 & & & & 2 \\
\hline Washington Software & 1 & & & & & 1 \\
\hline $\begin{array}{l}\text { Safety Surrogate } \\
\text { Assessment Tool }\end{array}$ & 1 & & & & $\begin{array}{l}\text { Lane Changing and } \\
\text { other microscopic data }\end{array}$ & \\
\hline Maryland Software & 1 & & & & & 1 \\
\hline Ohio Software & 1 & & & & & 1 \\
\hline Oregon Software & 1 & 1 & 1 & 1 & & 4 \\
\hline DynusT & 1 & & & & & 1 \\
\hline Oklahoma Software & 1 & & & 1 & Road User costs & 2 \\
\hline Dynamit & 1 & & & & & 1 \\
\hline LCCA & 1 & 1 & 1 & 1 & & 4 \\
\hline SPASM & 1 & & & & & 1 \\
\hline Quewz & 1 & & & & & 1 \\
\hline SMITE & 1 & & & & & 1 \\
\hline PASSER II-02 & 1 & & & & & 1 \\
\hline PASSER III-98 & 1 & & & & & 1 \\
\hline PASSER IV-96 & 1 & & & & & 1 \\
\hline TRANSYT-7F & 1 & & & & & 1 \\
\hline SYNCHRO & 1 & & & & & 1 \\
\hline TEAPAC & 1 & & & & & 1 \\
\hline Transims & & & 1 & 1 & Activity Data & 2 \\
\hline
\end{tabular}


Table B.6 Geographic

\begin{tabular}{|c|c|c|c|c|c|}
\hline & Isolated Location & Corridor & Network & Region & Sum \\
\hline $\begin{array}{l}\text { NCHRP 3-85-T } \\
\text { Concepts }\end{array}$ & & & & & 0 \\
\hline Quick zones & 1 & 1 & 1 & & 3 \\
\hline CA4-PRS & 1 & 1 & & & 2 \\
\hline Dynasmart - $P$ & & 1 & 1 & 1 & 3 \\
\hline HERS & & 1 & 1 & 1 & 3 \\
\hline STEAM & & & 1 & 1 & 2 \\
\hline IDAS & & 1 & 1 & & 2 \\
\hline Transcad & & & 1 & 1 & 2 \\
\hline Transmodeler & 1 & $\overline{1}$ & 1 & & 3 \\
\hline Cube Avenue & & & 1 & 1 & 2 \\
\hline CUBE-Voyager & 1 & 1 & 1 & & 3 \\
\hline VISSIM & 1 & 1 & 1 & & 3 \\
\hline VISUM & & & 1 & 1 & 2 \\
\hline Paramics & & 1 & 1 & & 2 \\
\hline Corsim & 1 & 1 & 1 & & 3 \\
\hline HCS & 1 & & 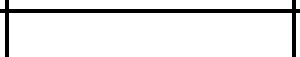 & & 1 \\
\hline$\overline{A I M S U N}$ & 1 & 1 & 1 & & 3 \\
\hline HDM & & & 1 & 1 & 2 \\
\hline Washington Software & 1 & 1 & & & 2 \\
\hline \begin{tabular}{|l|} 
Safety Surrogate \\
Assessment Tool
\end{tabular} & 1 & 1 & 1 & & 3 \\
\hline Maryland Software & 1 & 1 & & & 2 \\
\hline Ohio Software & 1 & 1 & & & 2 \\
\hline Oregon Software & 1 & 1 & 1 & 1 & 4 \\
\hline \begin{tabular}{|l|} 
DynusT \\
\end{tabular} & & 1 & 1 & 1 & 3 \\
\hline Oklahoma Software & 1 & 1 & & & 2 \\
\hline Dynamit & & 1 & 1 & 1 & 3 \\
\hline LCCA & 1 & 1 & & & 2 \\
\hline SPASM & & 1 & & & 1 \\
\hline Quewz & & $\overline{1}$ & & & 1 \\
\hline SMITE & & $\overline{1}$ & 1 & 1 & 3 \\
\hline PASSER II-02 & 1 & 1 & & & 2 \\
\hline PASSER III-98 & 1 & 1 & & & 2 \\
\hline PASSER IV-96 & 1 & 1 & & & 2 \\
\hline TRANSYT-7F & 1 & 1 & 1 & & 3 \\
\hline SYNCHRO & 1 & 1 & 1 & & 3 \\
\hline TEAPAC & 1 & $\overline{1}$ & 1 & & 3 \\
\hline Transims & & 1 & 1 & 1 & 3 \\
\hline
\end{tabular}




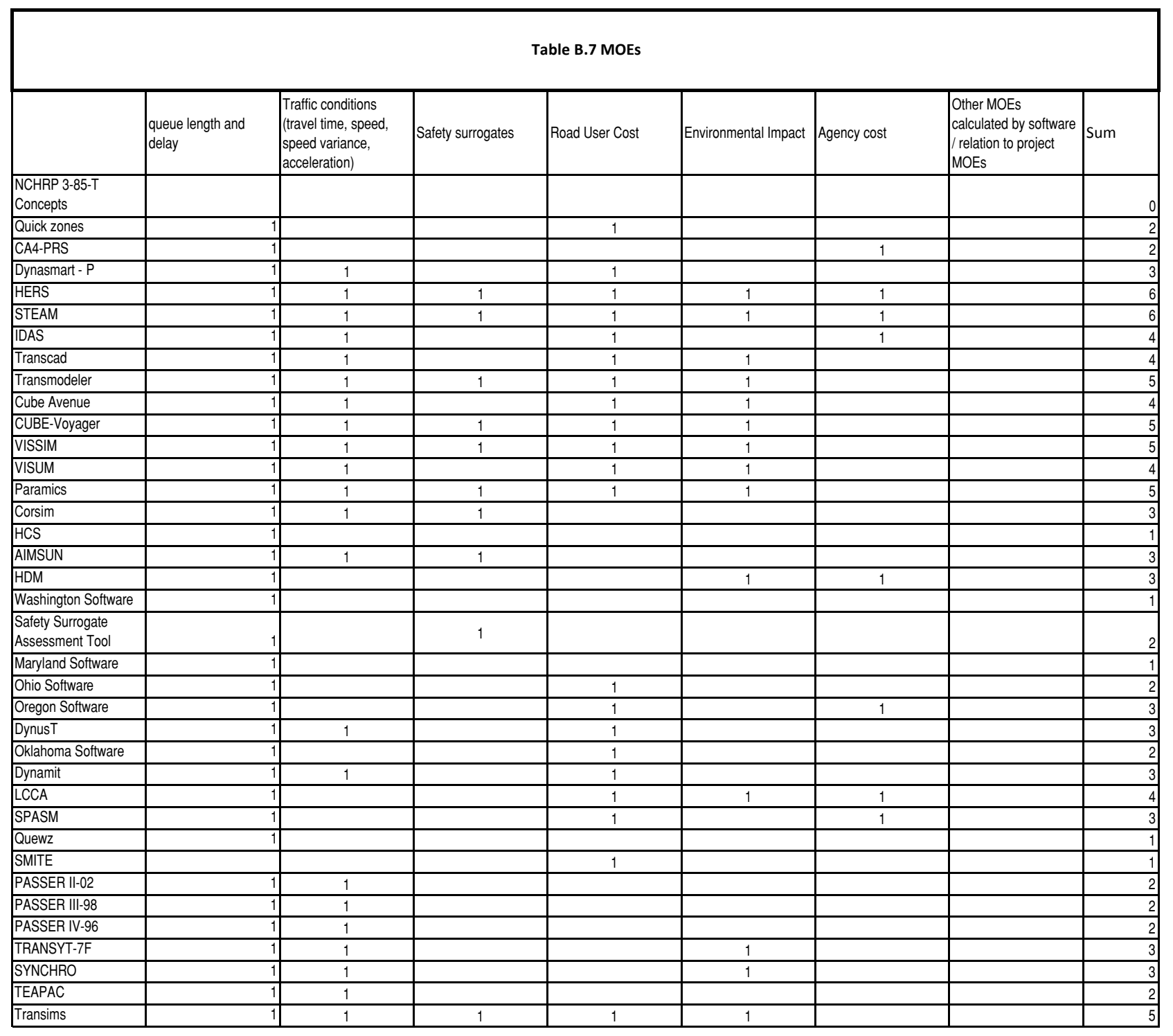


Table B.8 Resource Requirements

\begin{tabular}{|c|c|c|c|c|c|c|c|c|c|c|}
\hline & $\begin{array}{l}\text { Time and \$ } \$ \text { - Ease of } \\
\text { application - set up in } \\
1-2 \text { days? Y/N } \\
\end{array}$ & $\begin{array}{l}\text { Availability of source } \\
\text { code/ algorithms }\end{array}$ & $\begin{array}{l}\text { Memory if less } \\
\text { memory than } 1\end{array}$ & $\begin{array}{l}\text { Computational speed } \\
\text { if speed less than } 1\end{array}$ & $\begin{array}{l}\text { Tool capital cost } 1 \text { if } \\
\text { free }\end{array}$ & \begin{tabular}{|l|} 
Level of efforttraining \\
1 if less
\end{tabular} & $\begin{array}{l}\text { Animation / } \\
\text { presentation features }\end{array}$ & \begin{tabular}{|l} 
Excel based or \\
software based \\
(define)
\end{tabular} & $\begin{array}{l}\text { Transferability of data } \\
\text { to other software } \\
\text { packages }\end{array}$ & Sum \\
\hline $\begin{array}{l}\text { NCHRP 3-85-T } \\
\text { Concepts }\end{array}$ & & & & & & & & & & \\
\hline Quick zones & 1 & 1 & 1 & 1 & 1 & 1 & 1 & 1 & 1 & 9 \\
\hline CA4-PRS & 1 & & 1 & 1 & & 1 & 1 & & 1 & 6 \\
\hline Dynasmart - $P$ & & & & & & & 1 & & 1 & 2 \\
\hline HERS & & 1 & 1 & 1 & 1 & & 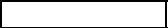 & & & 4 \\
\hline STEAM & & 1 & 1 & 1 & 1 & & & & & 4 \\
\hline IDAS & 1 & & 1 & 1 & & 1 & & & 1 & 5 \\
\hline Transcad & & & & & & & 1 & & 1 & 2 \\
\hline Transmodeler & & & & & & & 1 & & 1 & 2 \\
\hline Cube Avenue & & & & & & & 1 & & 1 & 2 \\
\hline CUBE-Voyager & & & & & & & 1 & & 1 & 2 \\
\hline VISSIM & & & & & & & 1 & & 1 & 2 \\
\hline VISUM & & & & & & & 1 & & 1 & 2 \\
\hline Paramics & & & & & & & 1 & & & 1 \\
\hline Corsim & 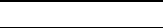 & & & & & & 1 & & & 1 \\
\hline $\mathrm{HCS}$ & 1 & & 1 & 1 & & 1 & , & & & 4 \\
\hline AIMSUN & & & & & & & 1 & & & 1 \\
\hline HDM & & 1 & 1 & & 1 & & . & & & 3 \\
\hline Washington Software & 1 & 1 & 1 & 1 & 1 & 1 & & 1 & 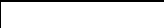 & 7 \\
\hline $\begin{array}{l}\text { Safety Surrogate } \\
\text { Assessment Tool }\end{array}$ & & 1 & & & 1 & & & & 1 & 3 \\
\hline Maryland Software & 1 & 1 & 1 & 1 & 1 & 1 & 1 & 1 & & 8 \\
\hline Ohio Software & 1 & 1 & 1 & 1 & 1 & 1 & 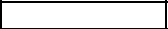 & 1 & & 7 \\
\hline Oregon Software & 1 & 1 & 1 & 1 & 1 & 1 & 1 & 1 & & 8 \\
\hline DynusT & & 1 & & & 1 & 7 & 1 & 1 & & 4 \\
\hline Oklahoma Software & 1 & & 1 & 1 & 1 & 1 & 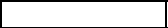 & & 1 & 6 \\
\hline Dynamit & & & & & 1 & & 1 & & 1 & 3 \\
\hline LCCA & 1 & 1 & 1 & 1 & 7 & & & 1 & & 5 \\
\hline SPASM & 1 & 1 & 1 & 1 & 1 & 1 & & 1 & & 7 \\
\hline Quewz & 1 & & 1 & 1 & 1 & 1 & & 1 & & 6 \\
\hline SMITE & 1 & 1 & 1 & 1 & 1 & 1 & & 1 & & 7 \\
\hline PASSER II-02 & 1 & & 1 & 1 & & & 1 & & & 4 \\
\hline PASSER III-98 & 1 & & 1 & 1 & & & 1 & & & 4 \\
\hline PASSER IV-96 & 1 & & 1 & 1 & & & 1 & & & 4 \\
\hline TRANSYT-7F & & & & & & & 1 & & & 1 \\
\hline SYNCHRO & & & & & & & 1 & & & 1 \\
\hline TEAPAC & 1 & & 1 & 1 & & 1 & 1 & & & 5 \\
\hline Transims & & 1 & & & 1 & & & & 1 & 3 \\
\hline
\end{tabular}

Table B.9 Strategies

\begin{tabular}{|c|c|c|c|c|c|c|c|c|c|c|c|c|c|c|c|}
\hline & \begin{tabular}{|l|} 
Total vs Partial \\
Shutdown
\end{tabular} & $\begin{array}{l}\text { Incentive/Disin } \\
\text { centive }\end{array}$ & \begin{tabular}{|l|} 
Short-Duration \\
Closures
\end{tabular} & $\begin{array}{l}\text { Grouping Non- } \\
\text { Traffic Tasks }\end{array}$ & $\begin{array}{l}\text { Programming } \\
\text { By Element }\end{array}$ & $\begin{array}{l}\text { Improve Signal } \\
\text { Timing }\end{array}$ & $\begin{array}{l}\text { Construct. Vs } \\
\text { Project } \\
\text { Delivery }\end{array}$ & \begin{tabular}{|l} 
Early and Late \\
Dynamic \\
Merging
\end{tabular} & $\begin{array}{l}\text { Workzone } \\
\text { Speed } \\
\text { Management }\end{array}$ & Workzone ITS & \begin{tabular}{|l|} 
Pavement \\
Programming
\end{tabular} & \begin{tabular}{|l|} 
Daytime / \\
Nighttime work
\end{tabular} & \begin{tabular}{|l|} 
Scheduling \\
under critical \\
events or \\
sensitive land \\
use
\end{tabular} & \begin{tabular}{|l|} 
Improving \\
Parallel Roads
\end{tabular} & Sum \\
\hline $\begin{array}{l}\text { NCHRP 3-85-T } \\
\text { Concepts }\end{array}$ & & & & & & & & & & & & & & & 0 \\
\hline \begin{tabular}{|l|} 
Quick zones \\
\end{tabular} & 1 & 1 & 1 & & 1 & & & & & & & 1 & & 1 & 6 \\
\hline \begin{tabular}{|l|} 
CA4-PRS \\
\end{tabular} & 1 & 1 & 1 & & 1 & & 1 & & & & 1 & 1 & & 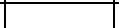 & 7 \\
\hline \begin{tabular}{|l|} 
Dynasmart - $P$ \\
\end{tabular} & 1 & 1 & 1 & & 1 & & & & 1 & 1 & & 1 & & 1 & 8 \\
\hline HERS & & & & & & & 1 & & & & 1 & t & & 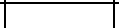 & 2 \\
\hline STEAM & & & & 1 & 1 & & 1 & & & & & 1 & 1 & 1 & 6 \\
\hline IDAS & 1 & & 1 & & & & & & & 1 & & 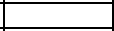 & & 1 & 4 \\
\hline Transcad & 1 & 1 & 1 & & 1 & & & & 1 & 1 & & 1 & 1 & 1 & 8 \\
\hline Transmodeler & 1 & 1 & 1 & & 1 & 1 & & 1 & 1 & 1 & & 1 & 1 & 1 & 11 \\
\hline \begin{tabular}{|l|} 
Cube Avenue \\
\end{tabular} & 1 & 1 & 1 & & 1 & & & & 1 & 4 & + & 1 & 1 & 1 & 8 \\
\hline CUBE-Voyager & 1 & 1 & 1 & & 1 & 1 & & 1 & 1 & 1 & to & 1 & 1 & 1 & 11 \\
\hline VISSIM & 1 & 1 & 1 & & 1 & 1 & & 1 & 1 & 1 & & 1 & 1 & 1 & 11 \\
\hline VISUM & 1 & 1 & 1 & & 1 & & & & 1 & 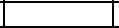 & & 1 & 1 & 1 & 8 \\
\hline Paramics & 1 & 1 & 1 & & 1 & & & 1 & 1 & 1 & & 1 & 1 & 1 & 10 \\
\hline Corsim & 1 & 1 & 1 & & 1 & & & 1 & 1 & 1 & & 1 & 1 & 1 & 10 \\
\hline HCS & 1 & 1 & 1 & & & 1 & & & 7 & 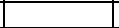 & & 1 & & 1 & 5 \\
\hline \begin{tabular}{|l|} 
AIMSUN \\
\end{tabular} & 1 & 1 & 1 & & 1 & 1 & & 1 & 1 & 1 & & 1 & 1 & 1 & 11 \\
\hline HDM & & & 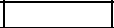 & 1 & 1 & & 1 & & & & 1 & 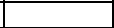 & & & 4 \\
\hline Washington Software & 1 & 1 & 1 & & & & & & & & & & & & 3 \\
\hline \begin{tabular}{|l|} 
Safety Surrogate \\
Assessment Tool
\end{tabular} & & & & & & & & 1 & 1 & & & & & & 2 \\
\hline \begin{tabular}{|l|} 
Maryland Software \\
\end{tabular} & 1 & 1 & 1 & & 1 & & & & & & & 1 & & 1 & 6 \\
\hline Ohio Software & 1 & 1 & 1 & & & & & & & & & & & to & 3 \\
\hline Oregon Software & 1 & 1 & 1 & & 1 & & & & & & & 1 & & 1 & 6 \\
\hline \begin{tabular}{|l|} 
DynusT \\
\end{tabular} & 1 & 1 & 1 & & 1 & & & & 1 & 1 & & 1 & & 1 & 8 \\
\hline \begin{tabular}{|l|} 
Oklahoma Software \\
\end{tabular} & 1 & 1 & 1 & & & & & & & & & 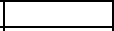 & & 1 & 3 \\
\hline \begin{tabular}{|l|} 
Dynamit \\
\end{tabular} & 1 & 1 & 1 & & 1 & & & & 1 & & & 1 & & 1 & 7 \\
\hline LCCA & 1 & 1 & 1 & & & & 1 & & & & 1 & 1 & & & 6 \\
\hline SPASM & 1 & 1 & 1 & & & & & & & & & 1 & & 1 & 5 \\
\hline Quewz & 1 & 1 & 1 & & & & & & & & & 1 & & & 4 \\
\hline SMITE & & & & & & & & & & & & & 1 & 1 & 2 \\
\hline \begin{tabular}{|l} 
PASSER II-02 \\
\end{tabular} & & & & & & 1 & & & & & & & & & 1 \\
\hline PASSER III-98 & & & & & & 1 & & & & & & & & & 1 \\
\hline PASSER IV-96 & & & & & & 1 & & & & & & & & & 1 \\
\hline TRANSYT-7F & & & & & & 1 & & & & & & & & & 1 \\
\hline SYNCHRO & & & & & & 1 & & & & & & & & & 1 \\
\hline TEAPAC & & & & & & 1 & & & & & & & & & 1 \\
\hline Transims & 1 & 1 & 1 & & & 1 & & & 1 & T & & 1 & & 1 & 7 \\
\hline
\end{tabular}


Table B.10 Type of Mode

\begin{tabular}{|c|c|c|c|c|c|c|c|c|c|}
\hline & SOV & $\mathrm{HOV}$ & Bus & Rail & Truck & Motorcycle & Bicycle & Pedestrian & Sum \\
\hline $\begin{array}{l}\text { NCHRP 3-85-T } \\
\text { Concepts }\end{array}$ & & & & & & & & & 0 \\
\hline Quick zones & 1 & & 1 & & 1 & & & & 3 \\
\hline CA4-PRS & 1 & & & & & & & & 1 \\
\hline Dynasmart - P & 1 & 1 & 1 & 1 & 1 & 1 & 1 & 1 & 8 \\
\hline HERS & 1 & & & & & & & & 1 \\
\hline STEAM & 1 & & & & & & & & 1 \\
\hline IDAS & 1 & & & & & & & & 1 \\
\hline Transcad & 1 & 1 & 1 & 1 & 1 & 1 & 1 & 1 & 8 \\
\hline Transmodeler & 1 & 1 & 1 & 1 & 1 & 1 & 1 & 1 & 8 \\
\hline Cube Avenue & 1 & 1 & 1 & 1 & 1 & 1 & 1 & 1 & 8 \\
\hline CUBE-Voyager & 1 & 1 & 1 & 1 & 1 & 1 & 1 & 1 & 8 \\
\hline VISSIM & 1 & 1 & 1 & 1 & 1 & 1 & 1 & 1 & 8 \\
\hline VISUM & 1 & 1 & 1 & 1 & 1 & 1 & 1 & 1 & 8 \\
\hline Paramics & 1 & 1 & 1 & 1 & 1 & 1 & 1 & 1 & 8 \\
\hline Corsim & 1 & 1 & 1 & & 1 & 1 & 1 & 1 & 7 \\
\hline HCS & 1 & & 1 & & 1 & - & 1 & 1 & 5 \\
\hline AIMSUN & 1 & 1 & 1 & 1 & 1 & 1 & 1 & 1 & 8 \\
\hline HDM & 1 & & & & 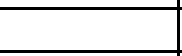 & & & & 1 \\
\hline \begin{tabular}{|l|} 
Washington \\
Software
\end{tabular} & 1 & & & & 1 & & & & 2 \\
\hline \begin{tabular}{|l|} 
Safety \\
Surrogate \\
Assessment \\
Tool
\end{tabular} & 1 & 1 & 1 & & 1 & & 1 & 1 & 6 \\
\hline $\begin{array}{l}\text { Maryland } \\
\text { Software }\end{array}$ & 1 & & & & 1 & & & & 2 \\
\hline Ohio Software & 1 & & & & 1 & & & & 2 \\
\hline $\begin{array}{l}\text { Oregon } \\
\text { Software }\end{array}$ & 1 & & & & 1 & & & & 2 \\
\hline \begin{tabular}{|l|} 
DynusT \\
\end{tabular} & 1 & 1 & 1 & & 1 & & & 1 & 5 \\
\hline \begin{tabular}{|l|} 
Oklahoma \\
Software
\end{tabular} & 1 & & & & & & & & 1 \\
\hline Dynamit & 1 & 1 & 1 & & 1 & & & 1 & 5 \\
\hline LCCA & 1 & & & & 1 & & & & 2 \\
\hline SPASM & 1 & 1 & 1 & 1 & 1 & 1 & 1 & 1 & 8 \\
\hline Quewz & 1 & & & & 1 & & & 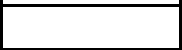 & 2 \\
\hline SMITE & 1 & 1 & 1 & 1 & 1 & 1 & 1 & 1 & 8 \\
\hline PASSER II-02 & 1 & 1 & 1 & 1 & 1 & 1 & 1 & 1 & 8 \\
\hline \begin{tabular}{|l|l|} 
PASSER III-98 \\
\end{tabular} & 1 & 1 & 1 & 1 & 1 & 1 & 1 & 1 & 8 \\
\hline PASSER IV-96 & 1 & 1 & 1 & 1 & 1 & 1 & 1 & 1 & 8 \\
\hline TRANSYT-7F & 1 & 1 & 1 & 1 & 1 & 1 & 1 & 1 & 8 \\
\hline SYNCHRO & 1 & 1 & 1 & 1 & 1 & 1 & 1 & 1 & 8 \\
\hline TEAPAC & 1 & 1 & 1 & 1 & 1 & 1 & 1 & 1 & 8 \\
\hline Transims & 1 & 1 & 1 & 1 & 1 & 1 & 1 & 1 & 8 \\
\hline
\end{tabular}


Table B.11 Traveler Response

\begin{tabular}{|c|c|c|c|c|c|c|c|}
\hline & \begin{tabular}{|l|} 
Pre-Trip Route \\
Diversion
\end{tabular} & \begin{tabular}{|l} 
En-Route Route \\
Diversion
\end{tabular} & Mode Shift & $\begin{array}{l}\text { Departure Time } \\
\text { Choice }\end{array}$ & \begin{tabular}{|l|} 
Destination \\
Change
\end{tabular} & $\begin{array}{l}\text { Induced/Foregone } \\
\text { Demand }\end{array}$ & Sum \\
\hline $\begin{array}{l}\text { NCHRP 3-85-T } \\
\text { Concepts }\end{array}$ & & & & & & & 0 \\
\hline Quick zones & & & & & & & 0 \\
\hline CA4-PRS & & & & & & & 0 \\
\hline Dynasmart - $P$ & 1 & 1 & 1 & 1 & & & 4 \\
\hline HERS & & & & & & & 0 \\
\hline STEAM & & & & & & & 0 \\
\hline IDAS & 1 & 1 & & & & & 2 \\
\hline Transcad & 1 & 1 & 1 & 1 & 1 & 1 & 6 \\
\hline Transmodeler & 1 & 1 & $\overline{1}$ & 1 & 1 & 1 & 6 \\
\hline Cube Avenue & 1 & 1 & 1 & 1 & 1 & 1 & 6 \\
\hline CUBE-Voyager & 1 & 1 & 1 & 1 & 1 & 1 & 6 \\
\hline VISSIM & 1 & 1 & 1 & 1 & 1 & 1 & 6 \\
\hline VISUM & 1 & 1 & 1 & 1 & 1 & 1 & 6 \\
\hline Paramics & 1 & 1 & 1 & 1 & 1 & 1 & 6 \\
\hline Corsim & & & & & & & 0 \\
\hline HCS & & & & & & & 0 \\
\hline AIMSUN & 1 & 1 & 1 & 1 & 1 & 1 & 6 \\
\hline HDM & & & & & & & 0 \\
\hline $\begin{array}{l}\text { Washington } \\
\text { Software }\end{array}$ & & & & & & & 0 \\
\hline $\begin{array}{l}\text { Safety Surrogate } \\
\text { Assessment Tool }\end{array}$ & & & & & & & 0 \\
\hline $\begin{array}{l}\text { Maryland } \\
\text { Software }\end{array}$ & & & & & & & 0 \\
\hline Ohio Software & & & & & & & 0 \\
\hline Oregon Software & & & & & & & 0 \\
\hline DynusT & 1 & 1 & 1 & 1 & & & 4 \\
\hline $\begin{array}{l}\text { Oklahoma } \\
\text { Software }\end{array}$ & & & & & & & 0 \\
\hline Dynamit & 1 & 1 & 1 & 1 & & & 4 \\
\hline LCCA & & & & & & & 0 \\
\hline SPASM & 1 & & 1 & & & & 2 \\
\hline Quewz & & & & & & & 0 \\
\hline SMITE & & & & & & 1 & 1 \\
\hline PASSER II-02 & & & & & & & 0 \\
\hline PASSER III-98 & & & & & & & 0 \\
\hline PASSER IV-96 & & & & & & & 0 \\
\hline TRANSYT-7F & & & & & & & 0 \\
\hline SYNCHRO & & & & & & & 0 \\
\hline TEAPAC & & & & & & & 0 \\
\hline Transims & 1 & & 1 & 1 & 1 & 1 & 5 \\
\hline
\end{tabular}


Table B.12 Software Evaluation Totals

\begin{tabular}{|c|c|c|}
\hline & Total & $\begin{array}{c}\text { Total for } \\
\text { Proprietary }\end{array}$ \\
\hline \begin{tabular}{|l|} 
NCHRP 3-85-T \\
Concepts
\end{tabular} & 0 & 0 \\
\hline Quick zones & 33 & 33 \\
\hline CA4-PRS & 29 & 0 \\
\hline Dynasmart - $P$ & 35 & 0 \\
\hline HERS & 25 & 25 \\
\hline STEAM & 27 & 27 \\
\hline IDAS & 24 & 0 \\
\hline Transcad & 36 & 0 \\
\hline Transmodeler & 41 & 0 \\
\hline Cube Avenue & 36 & 0 \\
\hline CUBE-Voyager & 41 & 0 \\
\hline VISSIM & 41 & 0 \\
\hline VISUM & 36 & 0 \\
\hline Paramics & 37 & 0 \\
\hline Corsim & 28 & 0 \\
\hline HCS & 22 & 0 \\
\hline AIMSUN & 36 & 0 \\
\hline HDM & 20 & 0 \\
\hline Washington Software & 22 & 22 \\
\hline \begin{tabular}{|l|} 
Safety Surrogate \\
Assessment Tool
\end{tabular} & 22 & 22 \\
\hline Maryland Software & 28 & 28 \\
\hline Ohio Software & 23 & 23 \\
\hline Oregon Software & 35 & 35 \\
\hline \begin{tabular}{|l|} 
DynusT \\
\end{tabular} & 35 & 35 \\
\hline Oklahoma Software & 22 & 22 \\
\hline Dynamit & 32 & 0 \\
\hline LCCA & 29 & 29 \\
\hline SPASM & 32 & 32 \\
\hline Quewz & 20 & 0 \\
\hline SMITE & 27 & 27 \\
\hline PASSER II-02 & 21 & 0 \\
\hline PASSER III-98 & 21 & 0 \\
\hline PASSER IV-96 & 21 & 0 \\
\hline TRANSYT-7F & 20 & 0 \\
\hline SYNCHRO & 20 & 0 \\
\hline TEAPAC & 23 & 0 \\
\hline Transims & 41 & 41 \\
\hline
\end{tabular}

\section{Reference}

FHWA, Traffic Analysis Toolbox Volume I: Traffic Analysis Tools Primer. Report FHWA-HRT-04-038. 2004. http://ops.fhwa.dot.gov/traffic analysistools/tat_vol1/vol1_primer.pdf. Accessed March 15, 2013. 


\author{
APPENDIX C \\ Interview Matrix
}




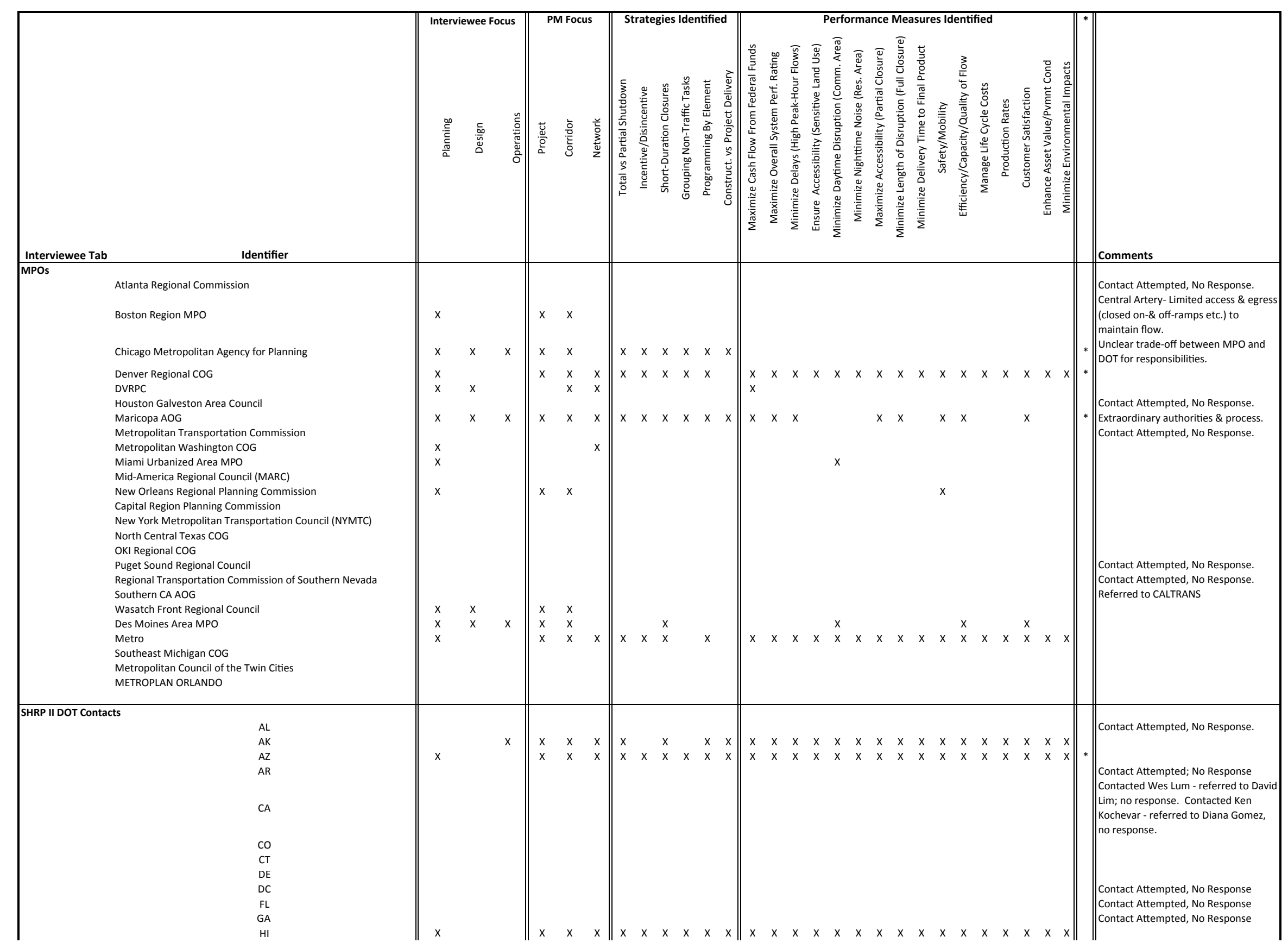




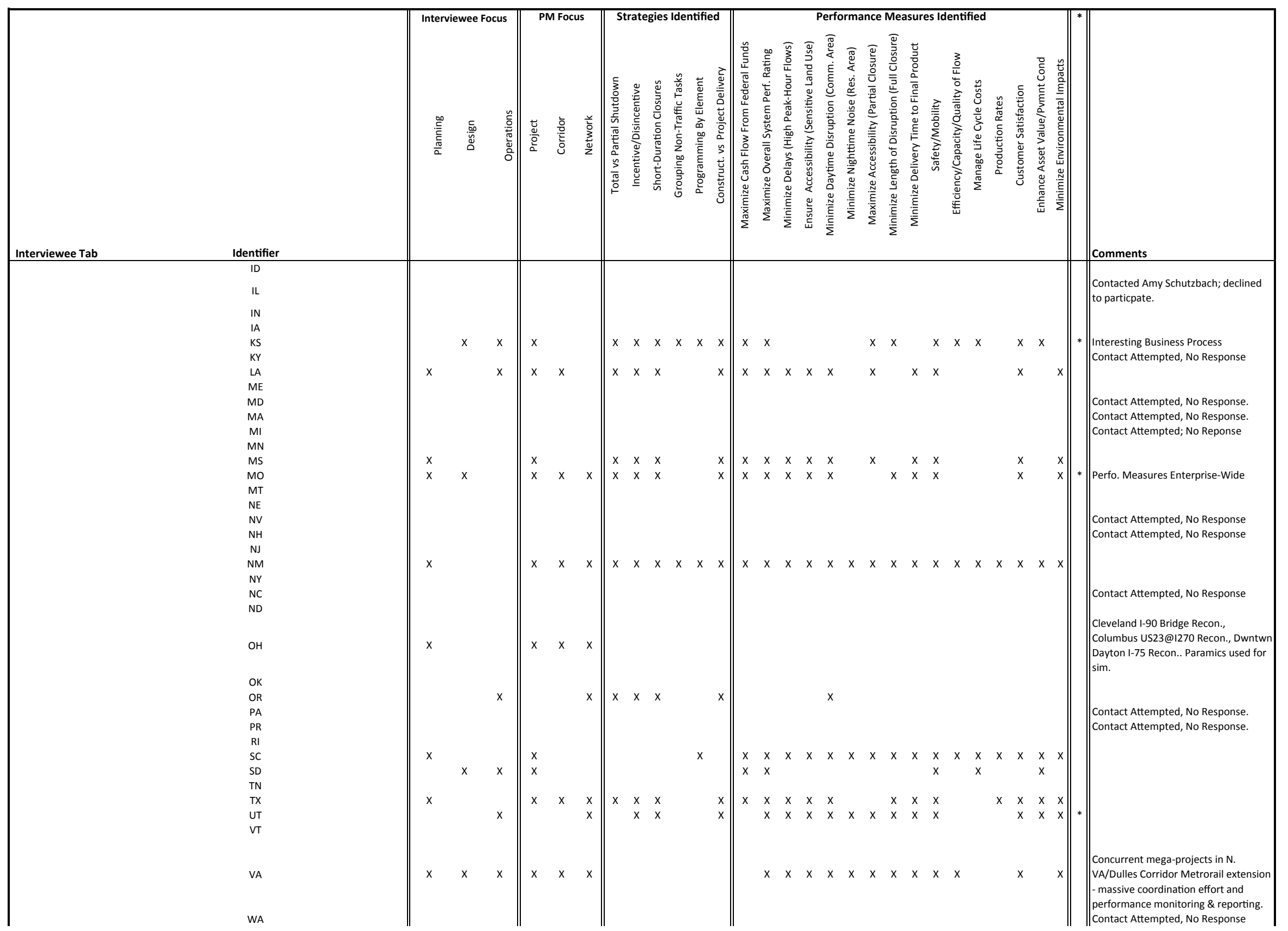




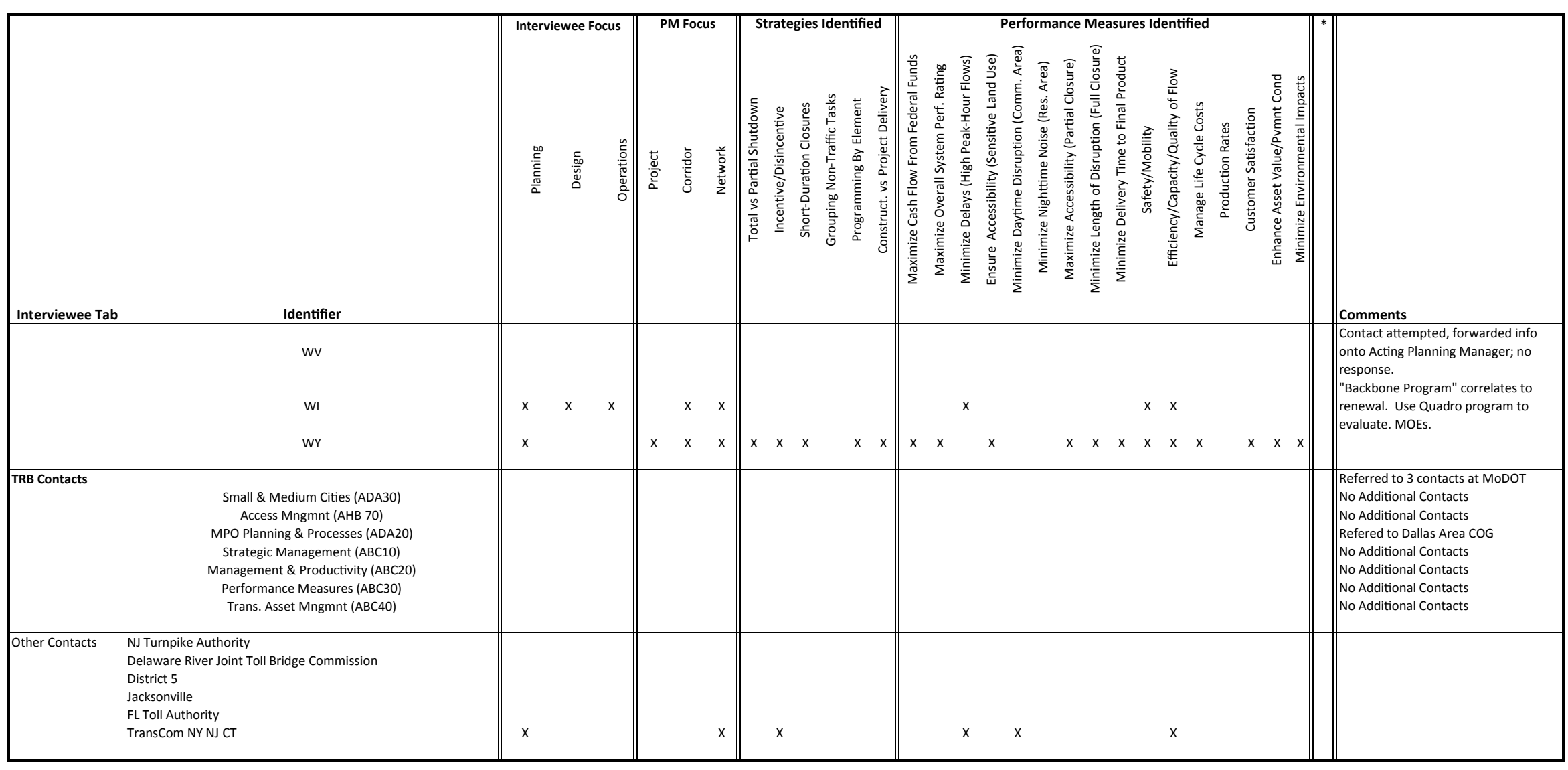

* Indicates Possible Participants in Initial Workshops. 


\title{
Work Zone Sequencing
}

\section{Hong Zheng}

\author{
University of Arizona
}

\section{Mathematical Formulation}

Given a set of work zone projects, the objective is to find a feasible project schedule such that the overall resultant generalized cost, including user and agency costs, is reduced to the minimum level. Let $\mathbb{P}$ be a set of projects subject to schedule, and $\mathbb{S}$ be the feasible set of schedule of $\mathbb{P}$, and denotes by $p(i, j, k)$ an individual project schedule, that project $i$ is open (namely in construction) at month $j$ with construction mode $k$. Denote by $P:=\{p(i, j, k)\}$ a combination of $p(i, j, k)$ that consists of a feasible schedule of $\mathbb{P}$ such that $P \in \mathbb{S}$. Let $x_{a}$ be the link flows on link $a$ with no work zone implementation (before scenario), and $t_{a}\left(x_{a}\right)$ be the corresponding link travel time; let $x_{a}^{\prime}$ be the redistributed flows on link $a$ considering traffic diverge due to $P$ (after scenario), and $t_{a, P}\left(x_{a}^{\prime}\right)$ be the resultant link travel time. Given a time horizon $T$ such that all projects must be completed before $T$, the objective is to find a pool (or combination) of $p(i, j, k)$, namely $P \in \mathbb{S}$, such that the resultant total traffic delay, plus the agency cost implementing $P$, is minimum among the entire $T$. The work zone schedule (WZS) problem is formulated as follows.

Two types of cost are evaluated in the objective function: user cost and agency cost. User cost was measured by the user travel time among all links in the network; the team used VOT to convert the user travel time into monetary dollars. Agency cost measured the out-of-pocket dollars to implement the work zone construction with a specified mode. The first term of Objective 1 is to minimize the summation of offset of travel time before and after the work zone construction among the entire horizon. Such an offset of travel time expresses the traffic delay caused by the work zone construction. The second term of Objective 1 is the corresponding agency cost expensed to implement work zone schedule $P$. It is noteworthy that some project schedules may reduce the user cost delay significantly; however, the matching agency cost to implement such a schedule might be expensive too. For instance, constructing a major freeway/arterial in nighttime could save user time delay greatly, because the peak demand occurring in the day time does not get impacted. However, it also costs the agency to spend much more money to implement such a construction strategy.

Constraints 2-7 in Table D.1 stand for the conventional traffic assignment formula, with and without work zone construction respectively. The first term in 1 ideally needs to call for a set of traffic assignment runs to evaluate traffic diverge involved in different combinations of $p(i, j, k)$, so virtually the problem is a combinatorial optimization problem, which ideally requires casting traffic assignment runs for all possible combinations of work zone schedules, which is obviously intractable. To solve WZS, the team suggests applying a heuristic method rather than comparing all possible combinations in a brute-force way. The key component is how to evaluate the traffic impact due to work zone construction. The WISE functionalities require a fast pass to evaluate traffic impact with high resolution. In this regard, the team proposes to estimate traffic diverge among a set of competitive paths, as discussed in detail in the following sections.

\section{Solution Approach}

\section{Neighborhood Search}

The heuristic starts from any feasible solution (e.g., initializing all work zone projects at the first month at a feasible mode that is regarded as the current local solution). The goal is to search an improved local solution in each iteration. Based upon the given solution, the team computed the monthly-specific traffic performance that varies due to each of work zone implementation and seasonal demand. Consider three projects as an example in Figure D.1, where it plots the initial solution. Suppose the length of three given projects is 3,4 , and 5 months if constructed in daytime (or nighttime), respectively. In 
Table D.1. Work Zone Sequencing Mathematical Formulation

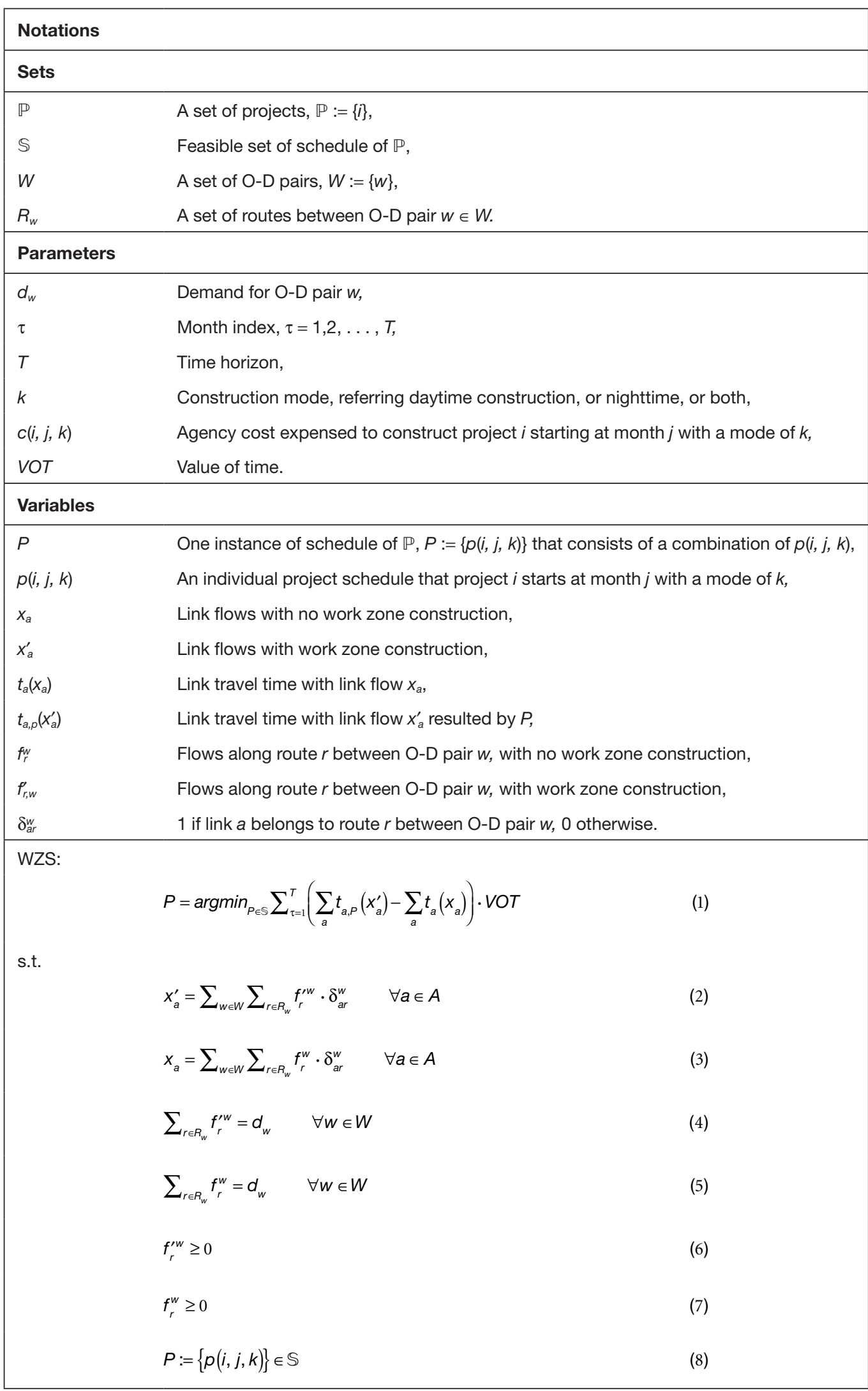




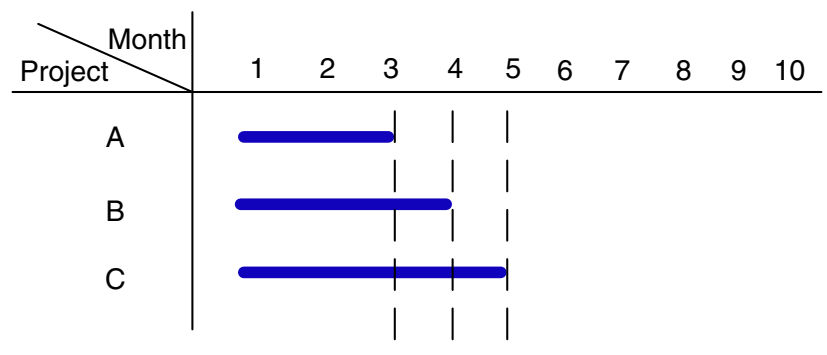

Figure D.1. An initial solution.

Figure D.1, the traffic performance in each month varies due to not only monthly-specific travel demand but also the network construction imposed by the presented work zone project schedule.

The algorithm then examines all possible/feasible schedule choices for each project. In each iteration, the team inspected each feasible starting time of each project and evaluated the resultant travel time, accounting for traffic diverge. The procedure is illustrated in Figure D.2.

Assume the total horizon of interest is 10 months; the holes with solid circles symbolize the feasible starting schedule when work zone construction begins. A "neighborhood search" is performed to determine the impacts of each work zone at every month subject to the current feasible schedule. At this stage of the solution, in the neighborhood search there are two iterative loops. The outer loop iterates every single project one by one at a fixed start time, and the inner loop iterates every other single project's starting point (dotted circles in Figure D.2) for each of the corresponding single projects. That is, two loops screen every circled hole in the legend shown in Figure D.2, and in each screen the team computed the resultant network-wide travel time, by assuming the screened project is scheduled at the screened starting time, if such a starting time is feasible. The research team then evaluated the resultant user cost plus agency cost that was summed among the whole time horizon (e.g., 10 months in the example shown in Figure D.2).

\begin{tabular}{|c|c|c|c|c|c|c|c|c|c|c|c|}
\hline Project & & 1 & 2 & 3 & 4 & 5 & 6 & 7 & 8 & 9 & 10 \\
\hline A & & $\bigcirc$ & i & ; & i & i & i & i & i & i) & i) \\
\hline B & & O & 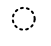 & i & i & i & i & i & i) & i) & (i) \\
\hline C & & 0 & i & ; & \% & i & i & () & i) & () & i) \\
\hline & O & \multicolumn{10}{|c|}{ Start time of current feasible schedules } \\
\hline & i & \multicolumn{10}{|c|}{ Start time of feasible schedules that will be evaluated } \\
\hline & i) & \multicolumn{10}{|c|}{ Start time which leads to infeasible schedules } \\
\hline
\end{tabular}

Figure D.2. Search domain in the heuristic.

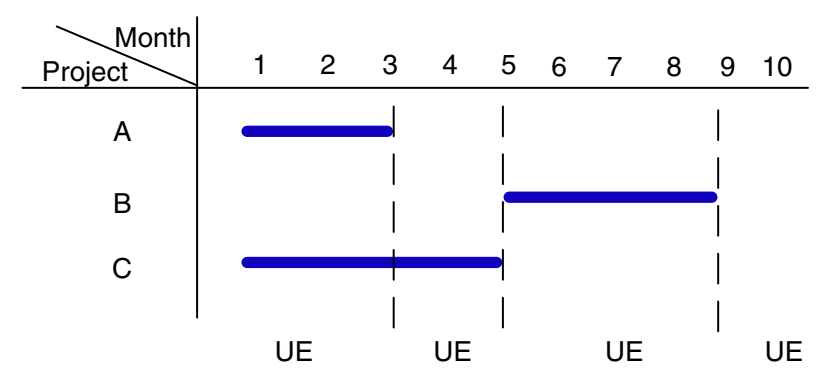

Figure D.3. Move to another feasible schedule.

After the outer- and inner-loops screening all the (feasible) circles in Figure D.2, the team selected the min-screen that was with the minimal "total-time horizon-cost" (user cost plus agency cost). If the cost led to a saving, the team rescheduled the corresponding project start to construct at the month that was identified by min-screen, and added the solution in a Tabu list before proceeding to the next iteration. By this step the team moved from one feasible solution to another, as shown in Figure D.3, where the min-screen was to schedule, say Project B of Figure D.3, to start at month five, and it led to a cost saving. Solutions in the Tabu list were restricted in the next few iterations so as to avoid being trapped at a local optimum. In the next iteration, the team continued outer and inner loops of screening, and so on. The algorithm stopped until no improvement could be found, or a certain number of iterations had been reached (stop criteria).

\section{Seasonal Demand Factor}

WISE supports the monthly-specific travel demand that leads to the monthly-specific travel time in the network wide. If modelers have traffic volume data on links produced by their own external travel demand model (TDM), then they can import those traffic volumes from TDM to WISE. Otherwise the modelers have an option to define the benchmark travel demand, and WISE can trigger the self-contained traffic assignment module to produce traffic volume on links based upon the user equilibrium assignment. WISE then uses a set of user-defined seasonal factors to adjust the equilibrium volume to produce the seasonal monthly-specific traffic volume data.

\section{Demand Reduction Factor}

Similar with the seasonal factor, demand reduction factor also adjusts the network traffic volume in the demand side. Agencies usually broadcast a heads-up announcement following the policy and/or legislative procedure, which may reduce the local travel demand nearby the projects. Given the inputs of an impact radius and a factor, the team first identified the link 
flows whose origin was within the radius of the work zone project, and then adjusted that portion of link flows by producing the factor.

\section{Construction Modes}

The work zone sequencing problem investigated in this paper supports different construction modes, classified by constructing in (1) daytime only, (2) nighttime only, and (3) both. Following the daytime and nighttime construction modes, the research team considered two sets of demand tables, day demand and night demand. Different construction modes come with variant demand inputs to obtain the link volume and variant agency cost; typically construction at nighttime budgets much more agency cost than in daytime.

The team extended the neighborhood search framework discussed at the beginning of this section to take into account three construction modes, as follows. The team created three search domain tables, representing constructing in daytime only, nighttime only, and both respectively. In each iteration, the team screened three tables, instead of just one table, and selected the feasible solution with the minimal user cost plus agency cost among all alternative-screening in three tables.

\section{Precedence Sequence}

It is common that several work zone projects may exhibit precedence sequence relationship (e.g., certain project must be constructed before/after another one). It is rather straightforward to bear the precedence constraint in the neighborhood search framework. Because the team evaluated each possible screening for each project one by one, the team first checked whether the current screening (e.g., schedule the project starting at the screened month in the specific mode) was feasible to meet the precedence constraint or not, provided that the schedules of all other projects (except the screened one) were given and fixed. If it met the precedence constraint, then the algorithm continued to evaluate the resultant user's and agency's costs; otherwise the team simply marked the current screening infeasible and continued to the next screening.

\section{Evaluate Network-Wide Travel Time Accounting for Traffic Diverge}

Ideally the traffic impact in the network wide involved in each screening calls for traffic assignment run, which is obviously computational intractable even though traffic assignment runs in modest time in the state-of-the-art commercial software, due to the large amount of screening in the neighborhood search framework. In this research, the team proposes to diverge traffic from the congested work zone route to a set of competitive routes, with a purpose to assess traffic impact due to work zone construction at a fine level in a quick manner.

\section{Identify a Set of Competitive Routes}

The team applied $k$-shortest path ( $k$-SP) algorithm to produce a set of alternative diverge routes competing to the route passing the work zone link. The assumption was that traffic divergence or reassignment due to work zone construction was restricted to the set of competitive routes.

The research of $k$-SP could be categorized as ranking SP routes (Azevedo et al. 1994; Martins 1983), loopless routes (Yen 1970), node-disjoint routes (Suurballe 1974), and arc-disjoint routes (Suurballe and Tarjan 1984). Those $k$-shortest paths studied in literature either use SP ranking algorithm to find routes that have the least cost but are very similar, or find nodedisjoint or edge-disjoint paths that are dramatically different between each other. To evaluate traffic diverge in the work zone domain, the team desired to find a set of $k$-shortest paths with no significance of similarity. In this regard, the team introduced the penalty function in a revised SP ranking algorithm, with forbidden repeated links or nodes. The purpose was to obtain $k$-shortest paths with less similarity.

Given a work zone link (or subpath), denoted by $(i, j)$, the team first identified a set of nodes upstream the work zone link, denoted by $s$, and a set of nodes downstream, denoted by $t$. $s$, and $t$ can be established by a simple search method, and supposedly $s \cap t=\Delta$. The distance between any node in $s$ and $i$ shall be restricted no more than a user-defined radius, $d$, and the distance between any node in $t$ and $j$ shall be no more than $d$. The assumption was that most traffic reroutes are restricted to diverge at $d$ miles upstream of the work zone link, and merge $d$ miles downstream; this was inconsistent with observations that most traffic diverge occurs nearby the work zone link. The team then created an extended network $\mathcal{N}$ as follows. Create a supersource $p$ and connect $p$ to all nodes in $s$ with zero length (or travel time), and create a supersink $q$ and connect all nodes in $t$ to $q$ with zero length. Delete the work zone link $(i, j)$ in $\mathcal{N}$ for the purpose of identifying alternative routes not traversing $(i, j)$. Now the team was ready to apply the $k$-SP algorithm to find $k$ ranked shortest paths from $p$ to $q$ in the network $\mathcal{N}$. Paths satisfying the following two conditions consist of the set of competitive routes: (1) produced by the $k$-SP algorithm; and (2) travel time is shorter than the one passing the work zone link. The concept is demonstrated in Figure D.4a. It is noteworthy that the design of solving $k$-SP in $\mathcal{N}$ is to let the algorithm determine the appropriate diverge and merge points of the competitive routes, rather than predefine them arbitrarily (see Figure D.4b).

\section{k-SP Algorithm}

The team applied the revised version of the ranking algorithm to solve $k$-shortest paths in $\mathcal{N}$, based on the work of Martins (1983). The flow chart of the algorithm is depicted in Figure D.5. 


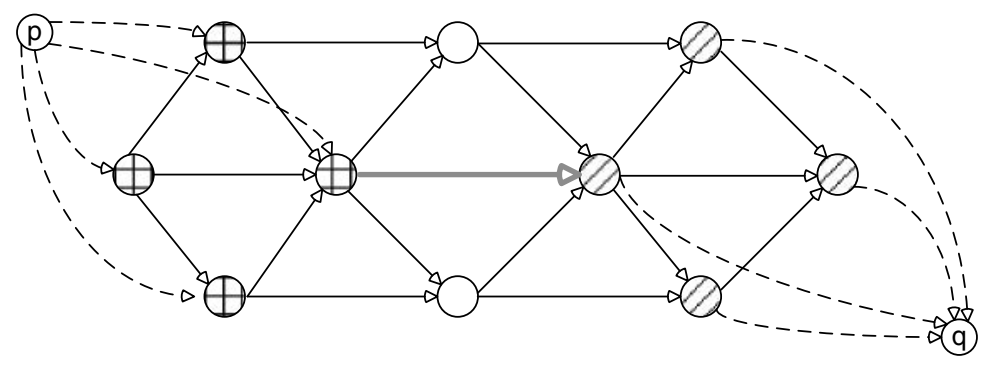

$\rightarrow$ Work zone link $\bigoplus$ Nodes belong to s Nodes belong to t

a. Construction of network $\mathcal{N}$.

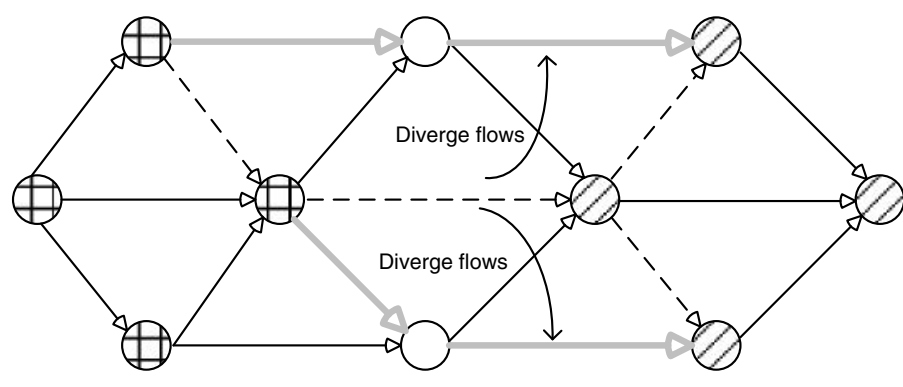

Competitive routes $\quad---\triangleright$ Routes passing the work zone

b. Generate competitive routes.

Figure D.4. Demonstration of generating competitive routes.

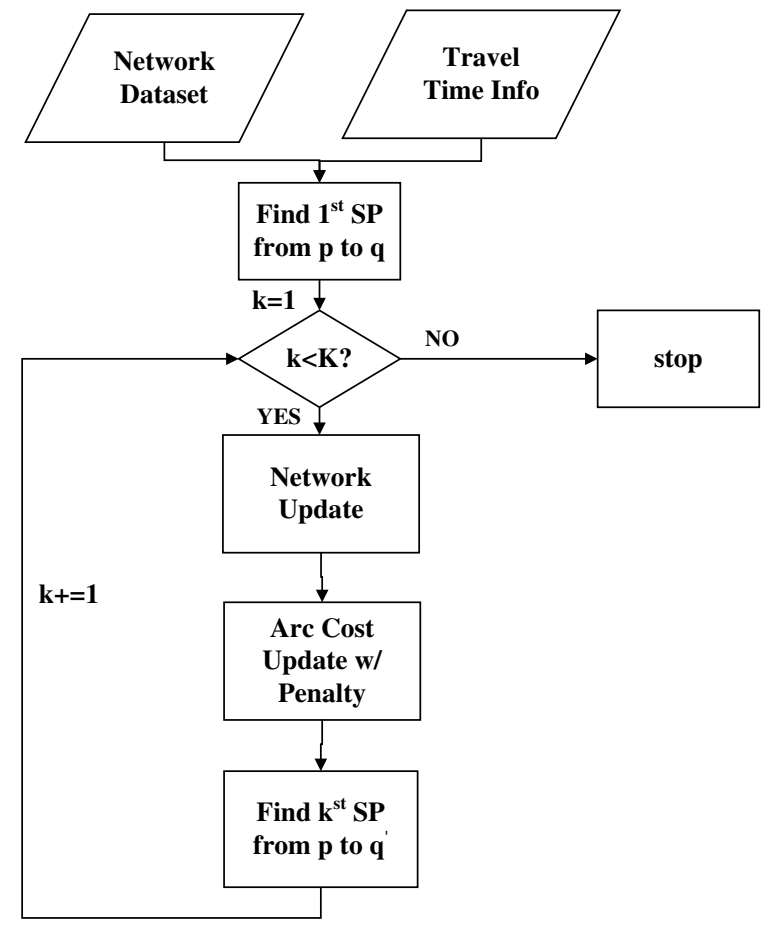

Figure D.5. Flow chart of k-SP algorithm.
Step 1: Initialization

Read the network structure and travel time information into the memory and construct the adjacency list for the nodes within the network.

Step 2: Find the first SP

Find the first shortest path from the given source to the sink. It would not matter which SP algorithm is used. Dial's implantation of Dijkstra algorithm or $\mathrm{A}^{\star}$ algorithm is suggested for this one-to-one SP problem.

Step 3: Stop criteria

If $k$ paths are found, stop; continue otherwise.

Step 4: Network update

Update the network based upon the SP found in the last iteration, denoted by $p$. Find the first node $n_{1}$ in $p$ with multiple incoming arcs, let $\left(n, n_{1}\right)$ be the arc that belongs to $p$. Delete arc $\left(n, n_{1}\right)$ in $\mathcal{N}$. This procedure ensures that the next path found in $\mathcal{N}$ must differ from $p$. For all arc $(i, j) \in p$, let the cost $c_{i j}$ be the original cost times a user defined penalty factor, $P F$. That is, $c_{i j} \leftarrow c_{i j} \times P F$. This penalty factor is designed to reduce the 


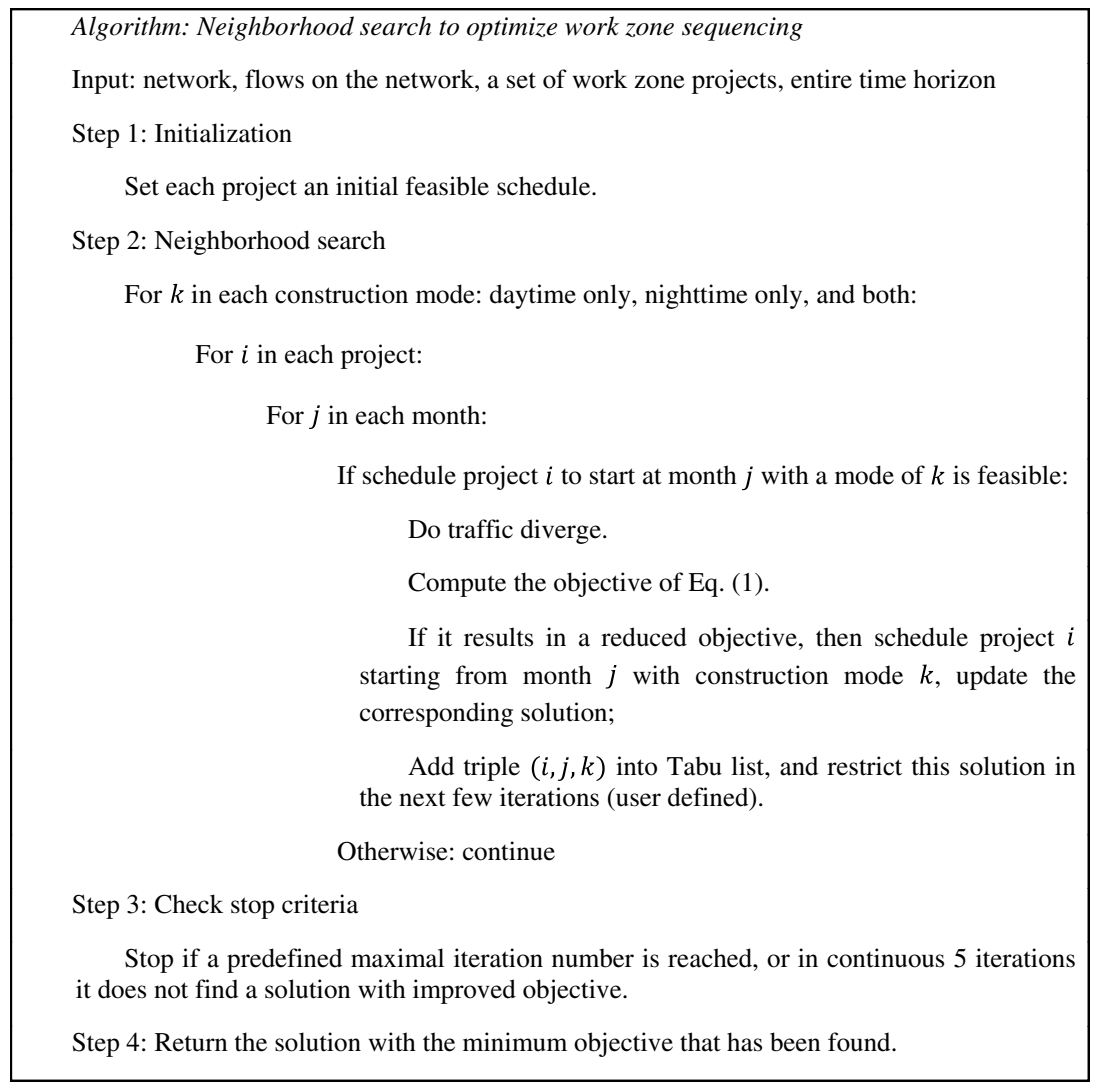

Figure D.6. Flow chart of the work zone sequencing algorithm.

similarity-i.e., the team has incentive to find a new path with less chance to use the same arc used by the paths found before.

Step 5: Find the next SP on the updated network

The algorithm guarantees to find a different route from others that have been found in the previous $(k-1)$ iterations.

\section{Shift Flows to Competitive Routes}

After the $k$-SP step, the team obtained a set of competitive routes and the corresponding routes passing the work zone link. Let $p$ be one of the competitive route and $\underline{x}, \underline{t}$ be its flow and travel time (namely cost), respectively. Let $\bar{p}$ be the route passing the work zone link with respect to $\underline{p}$, and $\bar{x}, \bar{t}$ be its flow and travel time, respectively. From the definition of competitive-route-set there is $\underline{t}(\underline{x}) \leq \bar{t}(\bar{x})$. The team then shifted $\Delta x$ units of flow from the long path $\bar{p}$ to the short one $p$, such that the travel time along two routes are the same-indicating an equilibrium-after traffic diverge (flow shifting) -i.e., $\underline{t}(\underline{x}+\Delta x)=\bar{t}(\bar{x}-\Delta x)$.

$\Delta x$ could be determined by the Newton method. Linearize the path-costs difference:

$\bar{t}(\bar{x}-\Delta x)-\underline{t}(\underline{x}+\Delta x) \approx \bar{t}(\bar{x})-\bar{t}^{\prime}(\bar{x}) \Delta x-\underline{t}(\underline{x})-\underline{t^{\prime}}(\underline{x}) \Delta x=0$
It solves for $\Delta x$ :

$\Delta x=\frac{\bar{t}(\bar{x})-\underline{t}(\underline{x})}{\bar{t}^{\prime}(\bar{x})+\underline{t^{\prime}}(\underline{x})}$

Note that the flow shifting between one pair of routes may impact the travel time of the other routes, so this shifting procedure should be conducted in an iterative manner.

\section{Overall Algorithm Procedure}

In summary, the neighborhood search algorithm proposed to solve the WZS is summarized in Figure D.6.

\section{References}

Azevedo, J., J. Madeira, E. Martins, and F. Pires. A Computational Improvement for a Shortest Paths Ranking Algorithm. European Journal of Operational Research, 73, 1994.

Martins, E. An Algorithm for Ranking Paths in Acyclic Networks. Operations Research Spektrum, 5, 1983.

Suurballe, J. Disjoint Paths in a Network. Networks, 4. 1974.

Suurballe, J., and R. Tarjan. A Quick Method for Finding Shortest Pairs of Disjoint Paths. Networks, 14. 1984.

Yen, J. An Algorithm for Finding Shortest Routes from all Source Nodes to a Given Destination in General Networks. Quarterly of Applied Mathematics, 27, 1970. 


\section{APPENDIX E}

\section{Traffic Tool Analysis}

1. QuickZone

- Excel spreadsheet.

- Traffic counts as demand input.

- Analyzes various impact mitigation strategies.

- Project life-cycling cost analysis.

- Travelers' response is needed as input.

- Small network based, project level.

- Easy to use and a short computation time.

2. Maryland software (Figure E.1)

- This software is an extension of QuickZone 2.0.

- Traffic counts are used as demand input.

- Analyzes various impact mitigation strategies.

- Conducts project life-cycling cost analysis.

- Travelers' responses are required for input.

- Small network based, project level.

- Very easy to use and a short computation time.

3. Washington software

- Assumes uniform delay (10 minutes), not queue length.

- Requires data input of capacity, closure capacity, detour percentages.

- Calculates queues.

- Issues: QuickZone better at generating queues.

4. Ohio software

- Spreadsheet based.

- Uses inputs from QueWZ percentages.

- Free flow capacity default values used as input.

- Very simple to use.

5. Oregon software (Figure E.2)

- Uses a GIS database.

- Started with spreadsheet tool.

- Built in-house.

- GIS based network systems.

- Automatically populated with DOT Highway number, distance milepost, etc.

- Does not incorporate detours and route diversions.
- Network consists of major state routes and interstates.

- Advantages: Can analyze multiple routes at the same time, project level-network based.

- Disadvantages: No emissions estimator, does not incorporate route diversion, cannot evaluate network-level impact.

6. Oklahoma software

- Includes fuel costs and delay costs.

- Used to determine lane rental costs.

- Calculates queues in 10-min increments.

- Calculations are project based.

\section{HERS-ST}

- Engineering and economic analysis tool.

- Uses traffic data to identify highway deficiencies, then uses economic data to select appropriate improvements.

- Broad, sketch-planning tool.

8. SMITE

- Excel 2003 platform.

- Network, gives estimate of induced demand.

9. SPASM

- Excel 2003, corridor analysis.

- Planning level, spreadsheet tool.

10. STEAM (Figure E.3)

- Network analysis tool.

- Planning level, sketch-planning tool.

- Has issues running on different operating systems.

- Requires data input from travel demand models.

- Has several modules that calculate costs and benefits:

○ Travel demand: Vehicle miles traveled, total travel time, person trips, etc.

○ Emissions: Particulate matter, NOX, CO, HC, emissions due to cold start and VMT. 


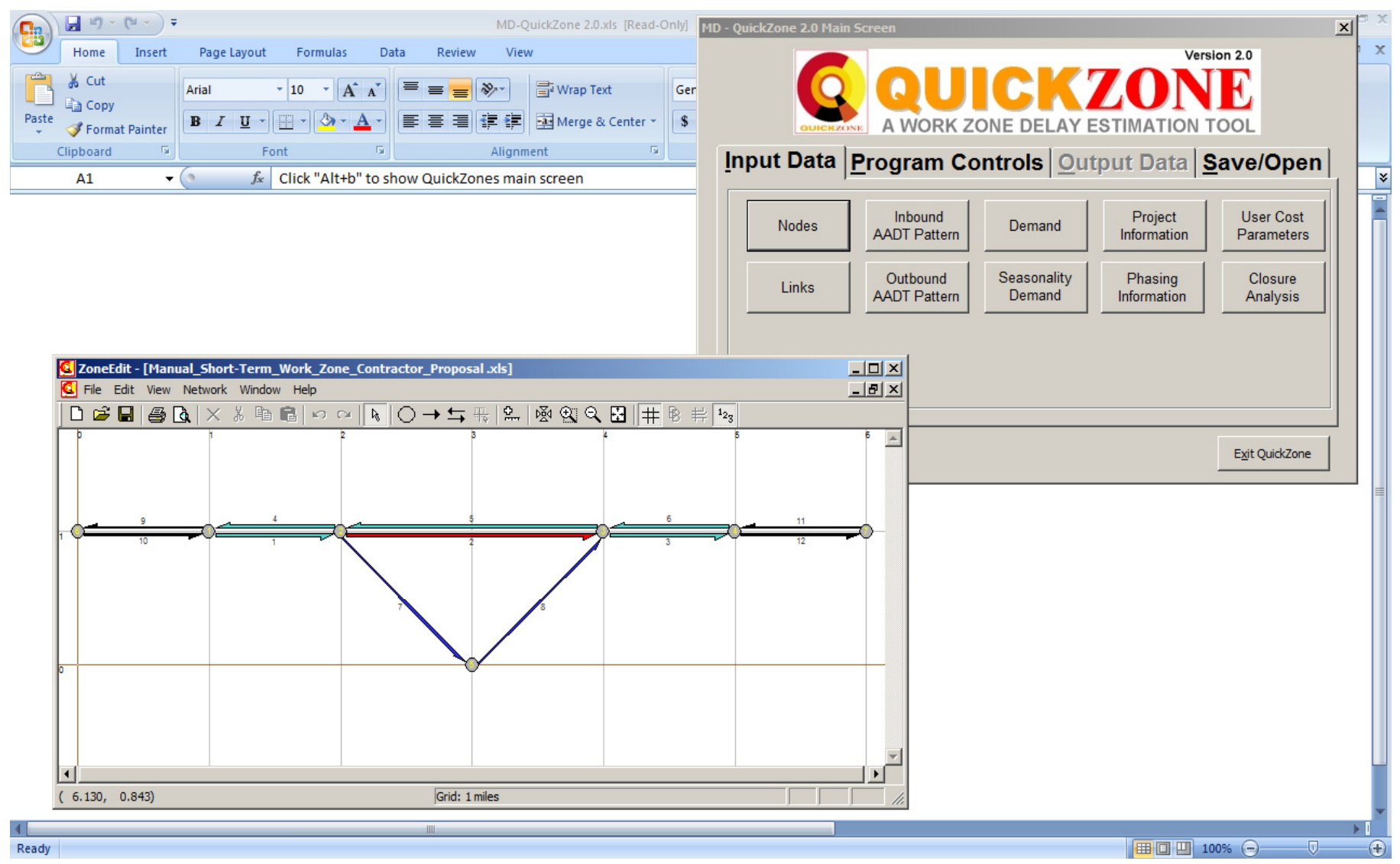

Figure E.1. Screenshot of Maryland software.

$\circ$ Accidents.

○ Fuel costs.

O Capital costs.

O Noise costs.

$\circ$ Accessibility measures.

○ Road user costs.

- Study risk associated to a project.

- FHWA developed product, but does not currently support it.

- Uses crash database to determine work zone exposure to study safety impacts.

11. LCCA (Figure E.4)

- Project-based tool.

- Planning level, sketch-planning tool.

- Evaluates alternative construction plans.

- Evaluates work zone impacts.

- Conducts multi-year analysis.

- Inputs consist of hourly traffic distribution, roadway characteristics, road-user cost.

- Carries out cost-benefit and queuing analysis, and analysis can be conducted with a deterministic output or a simulation to study risk associated with different alternatives.
12. DynusT (Figures E.5 and E.6)

- An open-source, regional, and corridor-level mesoscopic dynamic traffic assignment (DTA) software package.

- Driver behavior of vehicles and how a driver will determine the best route are defined by five classes of drivers. The percentages of user class distribution of simulated vehicles are user defined.

○ Historical/habitual.

O System optimal.

○ User equilibrium.

$\circ$ En route.

$\circ$ Pretrip.

- After some number of iterations, simulated vehicles have the ability to adapt to scenario-based network conditions and time-varying congestions by redirecting traffic to shorter travel time routes based upon previous iterations, travel time statistics, and driver behavior. Scenario-based network changes include

$\circ$ Incidents/work zone management.

$\circ$ Evacuation.

$\circ$ Tolling/pricing.

○ ITS evaluation.

○ Signal optimization management. 
- Advantages include

○ Analyzes short-term impact of work zone using congestion responsive route choice rules.

$\bigcirc$ Analyzes long-term impact of work zone using dynamic user equilibrium rules.

- Models traffic controls and information strategies for work zone mobility management.

$\circ$ Built-in conversion tool for integration with 4-step travel demand models as well as microscopic model VISSIM.

○ Capable of modeling various network sizes.

- Disadvantages include

○ Like any traffic simulation model, needs roadway and traffic control data inputs. Model parameters and origination and destination data need to be calibrated before applying to work zone scenarios.

\section{TRANSIMS}

- Regional-level transportation modeling software package with microscopic simulation capabilities.

- Advantages: Open source, broad set of programs included as part of the package.

- Many included programs make an easy transition from classic 4-step methodology to TRANSIMS methodology.

- Able to export the simulation output into a more conventional form to interpret, including ArcGIS and VISSIM.
- Disadvantages: Complexity of software, high computing power demand.

- The following figures show screenshots from sample network:

O Figure E.7 shows the overall network, including the heat plots that represent network congestion.

$\circ$ Figure E. 8 shows the effect of closing the interstate off completely.

O Figure E. 9 shows the effect of reducing the interstate to one lane.

14. Surrogate Safety Assessment Model (Figures E.10 and E.11)

- Computer software package that is used in conjunction with microsimulation models such as VISSIM, VISSIM, AIMSUN, and Paramics.

- Identifies conflict points between vehicles based on input simulation file.

- Can be used to study the safety effects of different work zone designs, dynamic merging, and lane closure setups.

- Figures E.10 and E.11 show the software using VISSIM. Safety impacts were analyzed at a toll plaza. Red circles show the work zone results in larger conflicts of moderate to high impact, but reduces the number of high-impact conflicts downstream (shown within the blue circle) due to the metering effect of the work zone. 
Home ATR Graphing Tool My Folders Profile Settings Logout Help

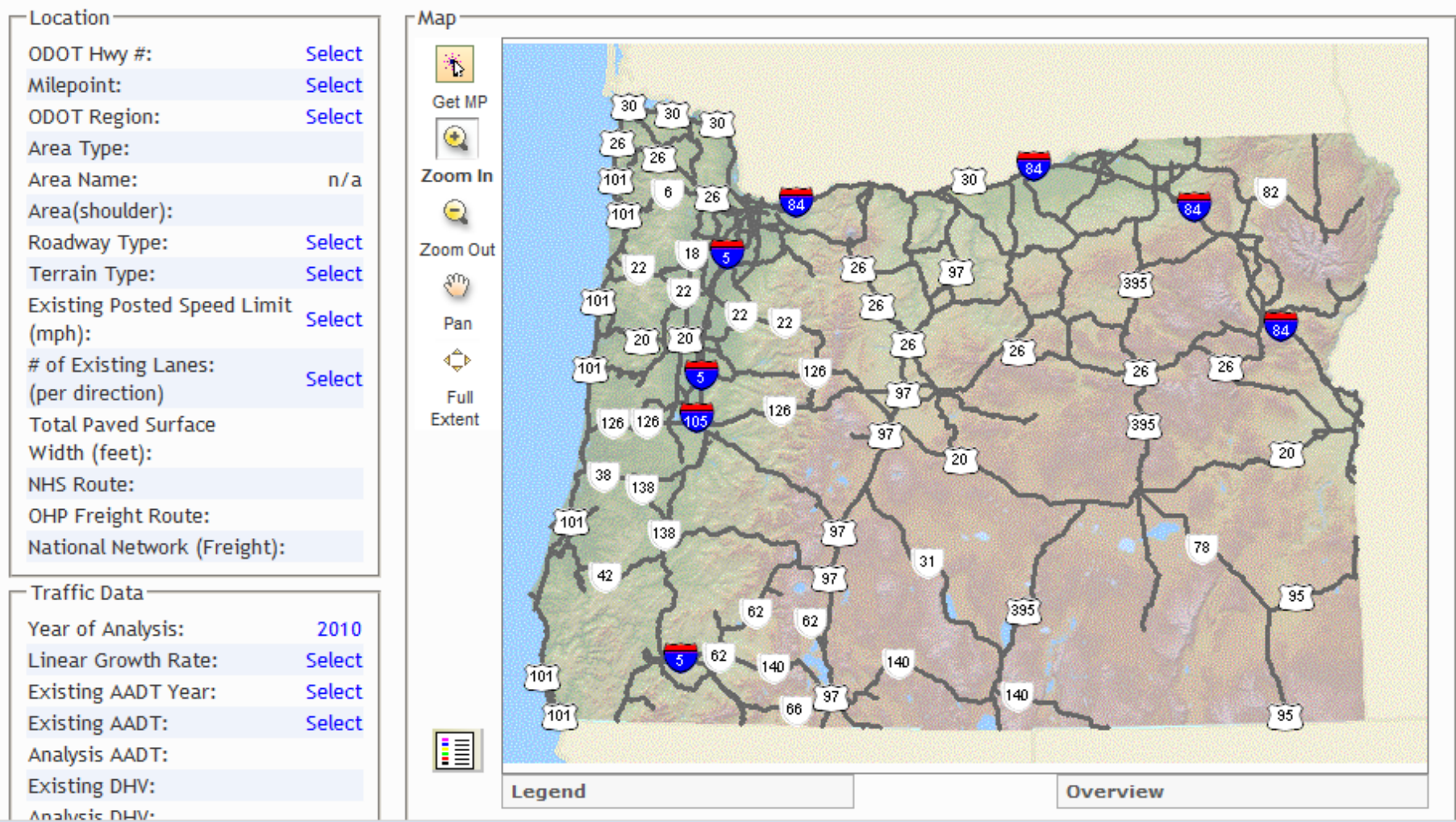

Figure E.2. Screenshot of Oregon software.

STEAM 2.0.1 - [C: \Program Files \STEAM 2.0 \Example \Demo 7.bsn]

File Edit View Run Results Tools Help

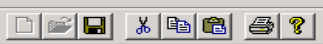

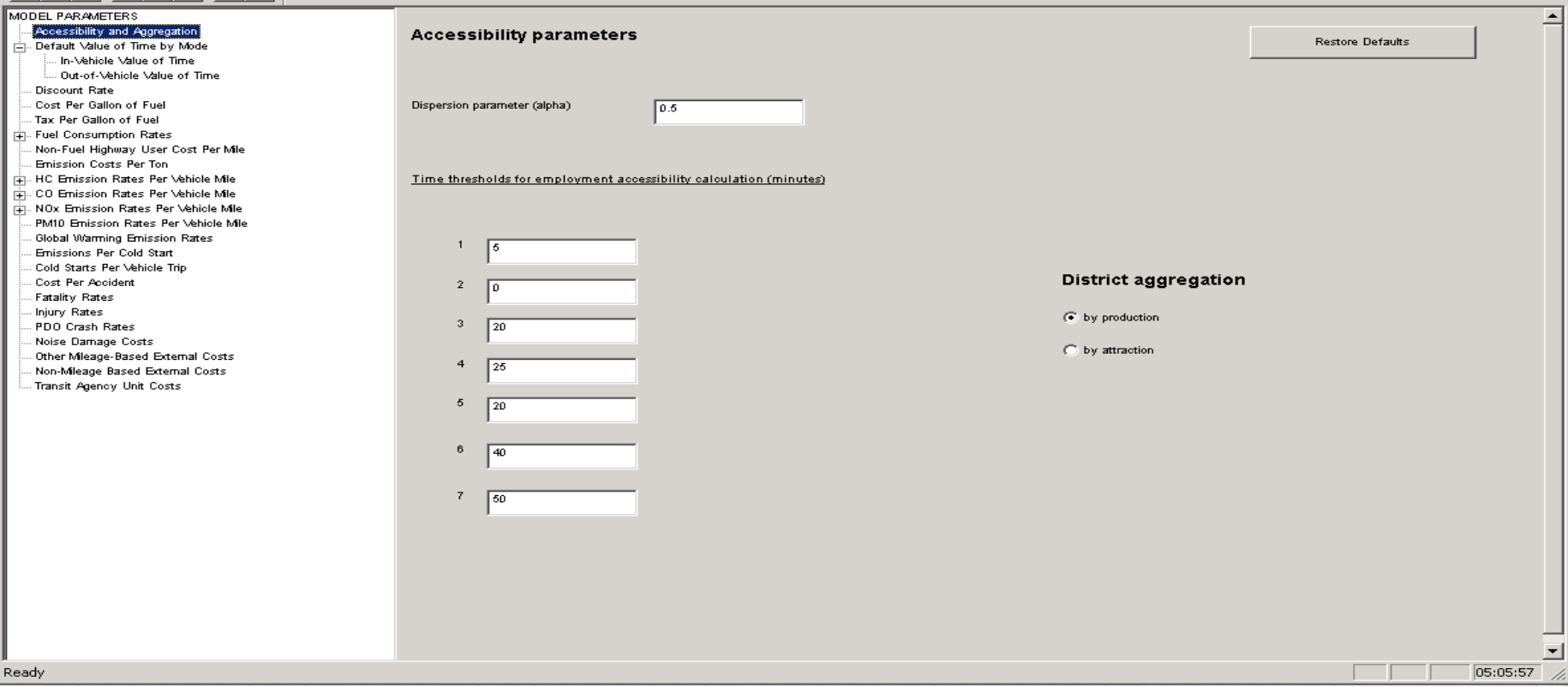

Figure E.3. Screenshot of STEAM. 


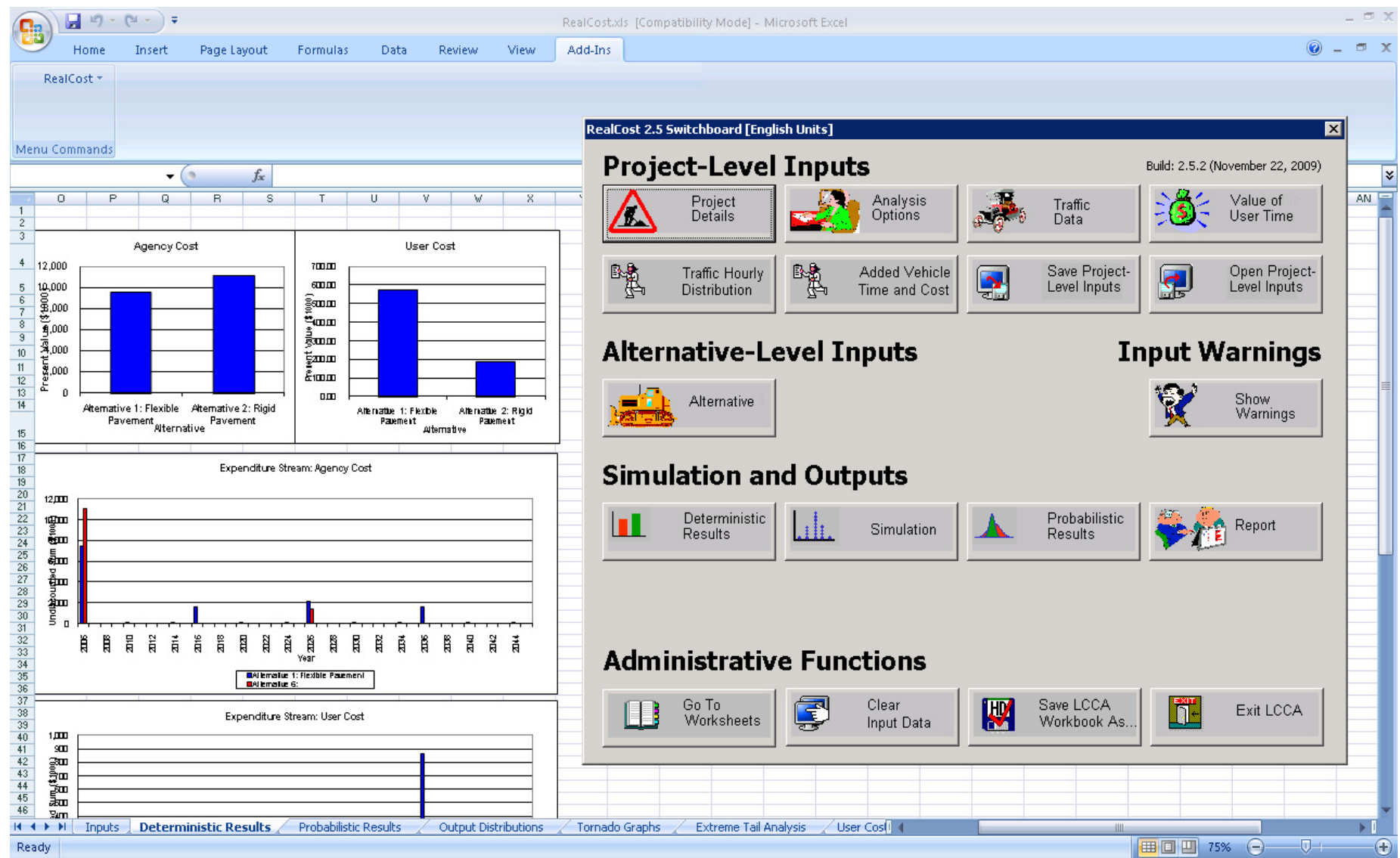

Figure E.4. Screenshot of LCCA. 


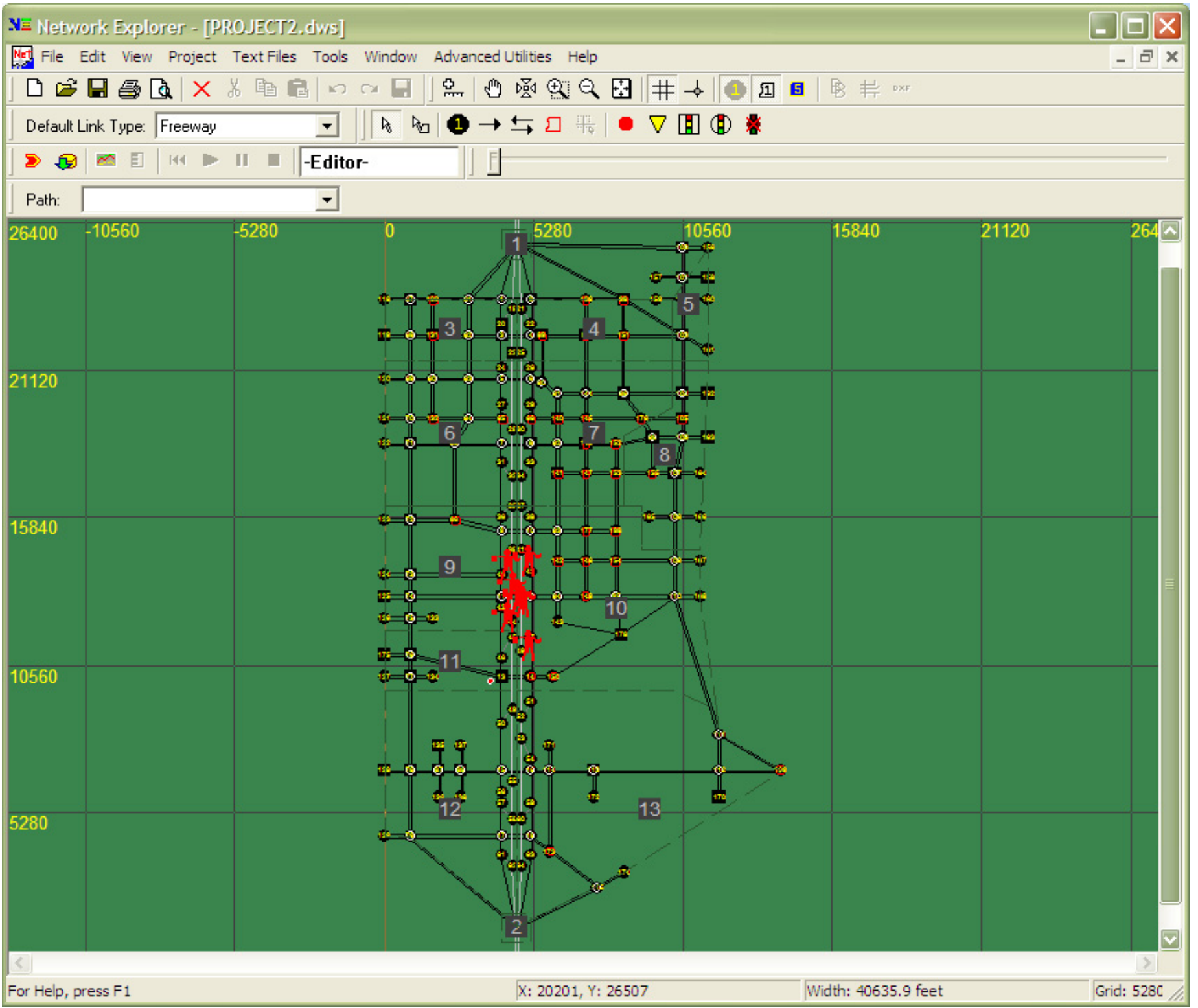

Figure E.5. Screenshot of DynusT. 


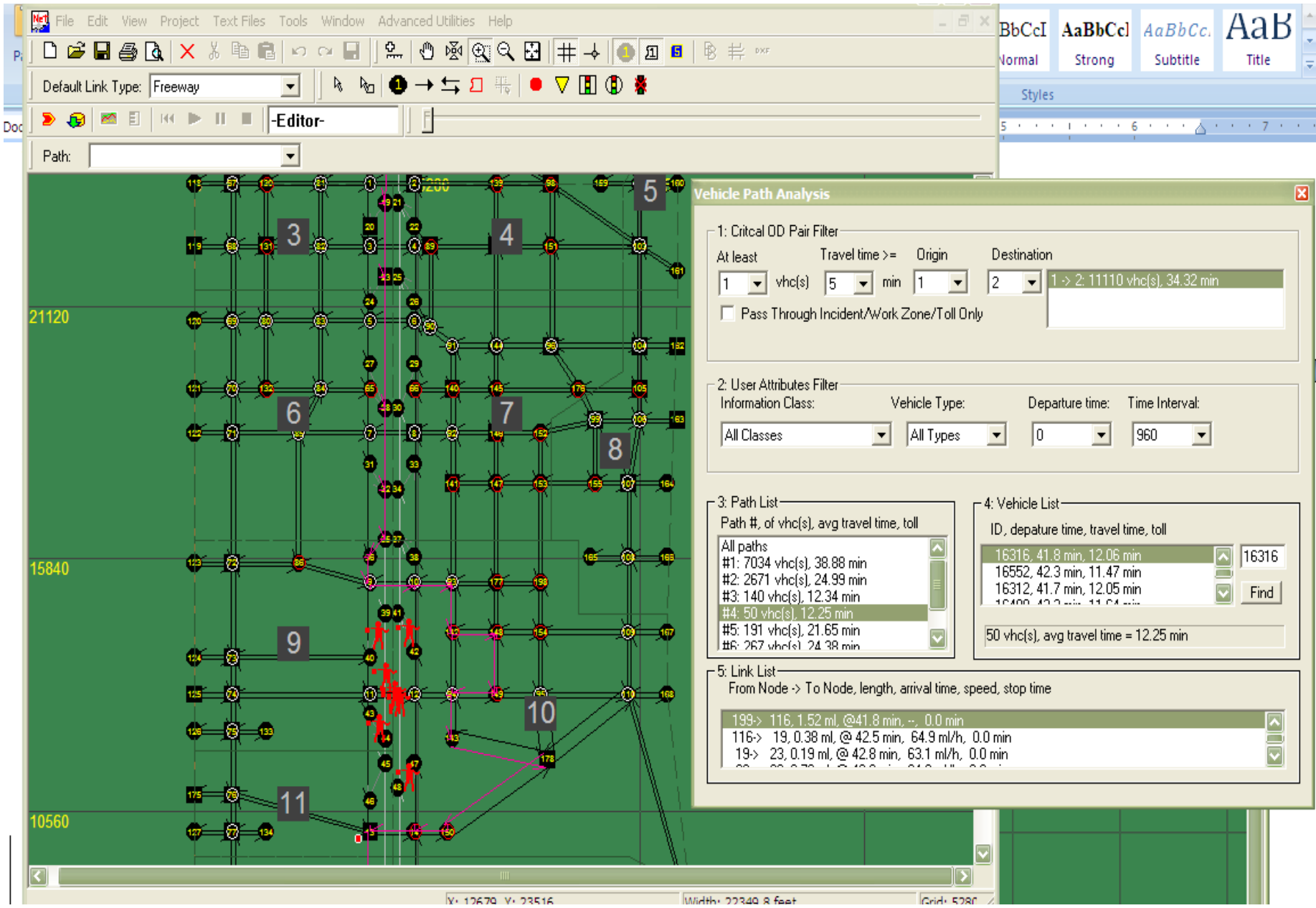

Figure E.6. Screenshot of DynusT, close-up of Figure E.5.

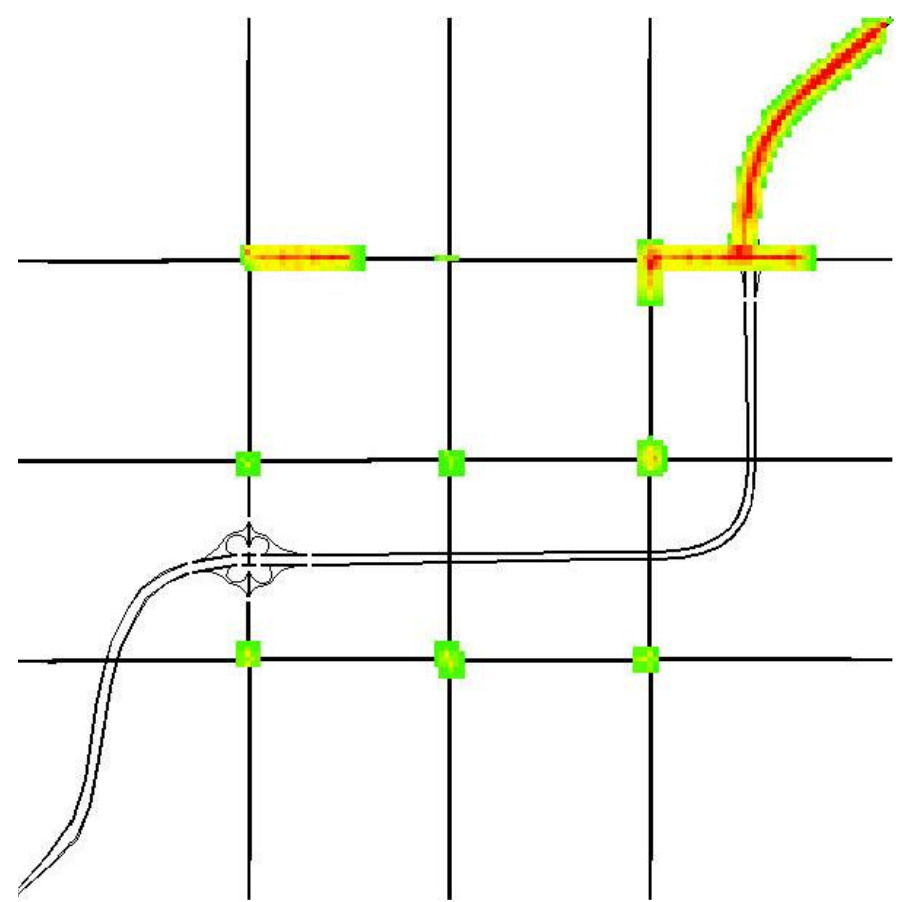

Figure E.7. Overall network, TRANSIMS. 


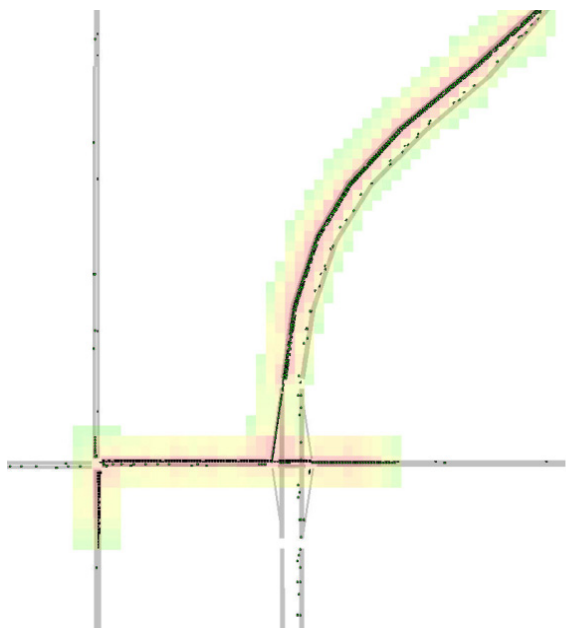

Figure E.8. Closing interstate completely, TRANSIMS.

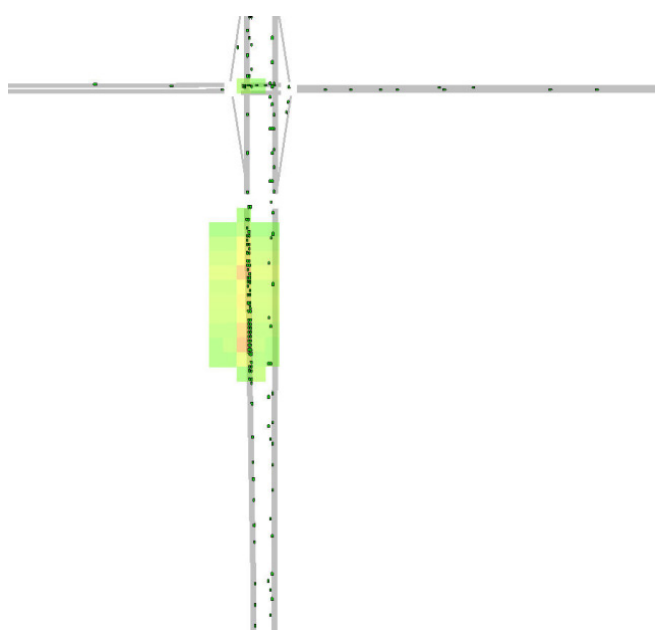

Figure E.9. Reducing interstate to 1 lane, TRANSIMS.

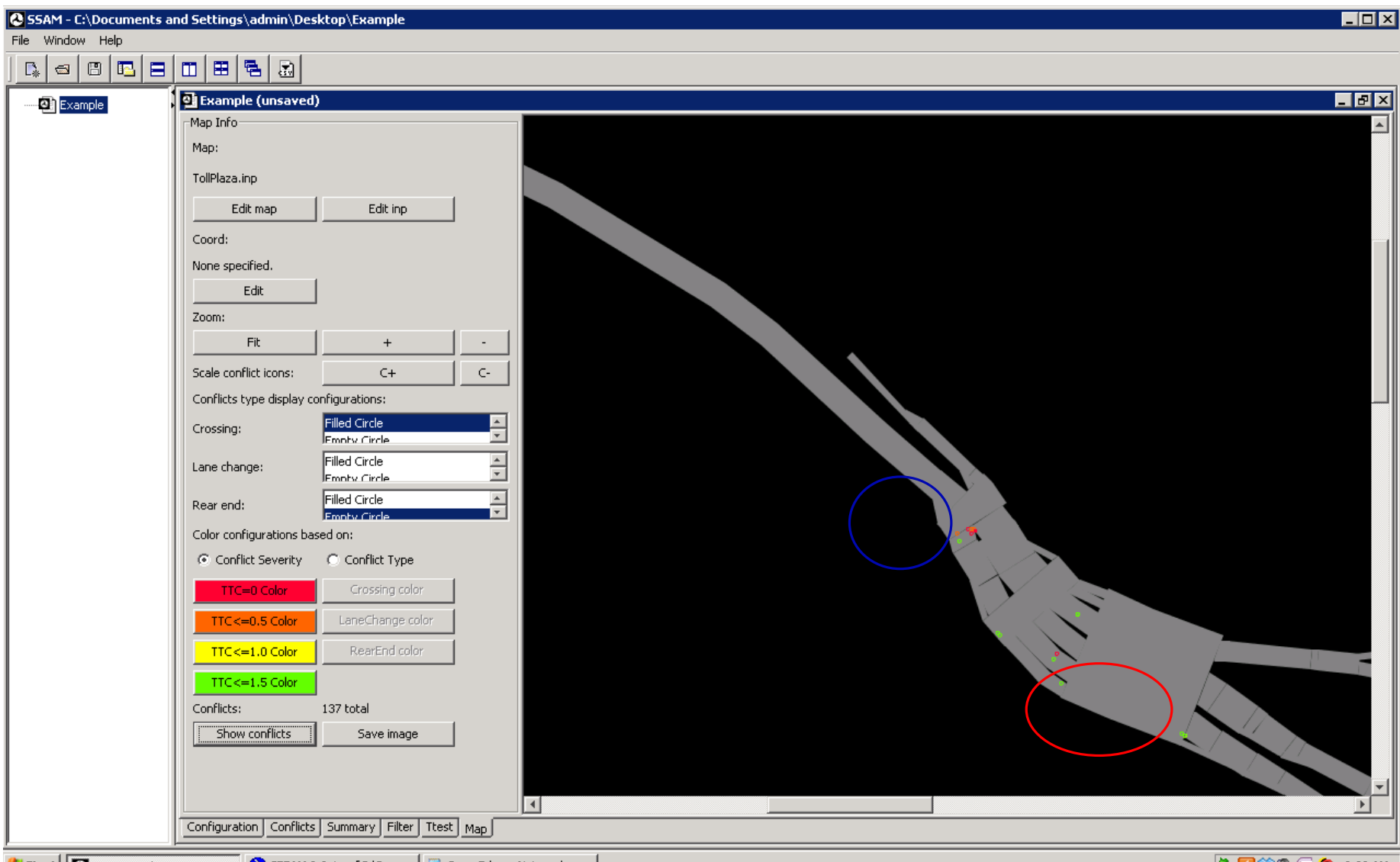

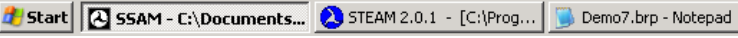

3:23 AM

Figure E.10. Screenshot of surrogate safety assessment model, VISSIM. 
File Window Help

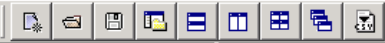

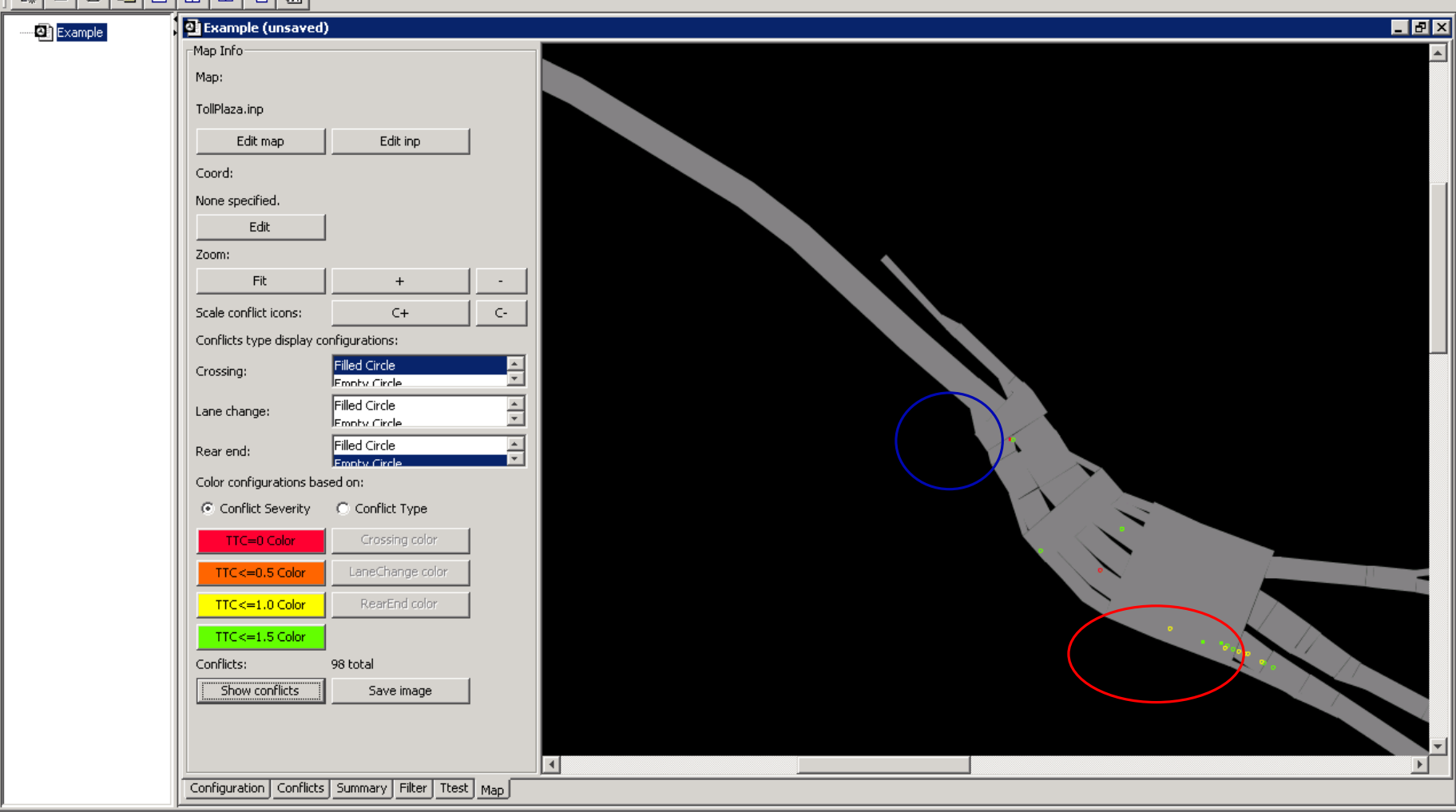

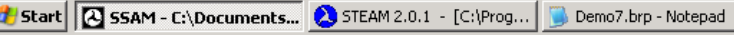

is

Figure E.11. Screenshot of surrogate safety assessment model, VISSIM. 


\section{TRB OVERSIGHT COMMITTEE FOR THE STRATEGIC HIGHWAY RESEARCH PROGRAM 2*}

CHAIR: Kirk T. Steudle, Director, Michigan Department of Transportation

\section{MEMBERS}

H. Norman Abramson, Executive Vice President (retired), Southwest Research Institute

Alan C. Clark, MPO Director, Houston-Galveston Area Council

Frank L. Danchetz, Vice President, ARCADIS-US, Inc.

Malcolm Dougherty, Director, California Department of Transportation

Stanley Gee, Executive Deputy Commissioner, New York State Department of Transportation

Mary L. Klein, President and CEO, NatureServe

Michael P. Lewis, Director, Rhode Island Department of Transportation

John R. Njord, Executive Director (retired), Utah Department of Transportation

Charles F. Potts, Chief Executive Officer, Heritage Construction and Materials

Ananth K. Prasad, Secretary, Florida Department of Transportation

Gerald M. Ross, Chief Engineer (retired), Georgia Department of Transportation

George E. Schoener, Executive Director, I-95 Corridor Coalition

Kumares C. Sinha, Olson Distinguished Professor of Civil Engineering, Purdue University

Paul Trombino III, Director, Iowa Department of Transportation

\section{EX OFFICIO MEMBERS}

Victor M. Mendez, Administrator, Federal Highway Administration

David L. Strickland, Administrator, National Highway Transportation Safety Administration

Frederick "Bud” Wright, Executive Director, American Association of State Highway and Transportation Officials

\section{LIAISONS}

Ken Jacoby, Communications and Outreach Team Director, Office of Corporate Research, Technology, and Innovation Management, Federal Highway Administration

Tony Kane, Director, Engineering and Technical Services, American Association of State Highway and Transportation Officials Jeffrey F. Paniati, Executive Director, Federal Highway Administration

John Pearson, Program Director, Council of Deputy Ministers Responsible for Transportation and Highway Safety, Canada

Michael F. Trentacoste, Associate Administrator, Research, Development, and Technology, Federal Highway Administration

${ }^{\star}$ Membership as of March 2014.

\section{RENEWAL TECHNICAL COORDINATING COMMITTEE*}

ChAIR: Daniel D’Angelo, Recovery Acting Manager, Director and Deputy Chief Engineer, Office of Design, New York State Department of Transportation

\section{MEMBERS}

Rachel Arulraj, President, InfoInnovation

Michael E. Ayers, Consultant, Technology Services, American Concrete Pavement Association

Thomas E. Baker, State Materials Engineer, Washington State Department of Transportation

John E. Breen, Al-Rashid Chair in Civil Engineering Emeritus, University of Texas at Austin

Steven D. DeWitt, Chief Engineer (retired), North Carolina Turnpike Authority

Tom W. Donovan, Senior Right of Way Agent (retired), California Department of Transportation

Alan D. Fisher, Manager, Construction Structures Group, Cianbro Corporation

Michael Hemmingsen, Davison Transportation Service Center Manager (retired), Michigan Department of Transportation

Bruce Johnson, State Bridge Engineer, Oregon Department of Transportation, Bridge Engineering Section

Leonnie Kavanagh, PhD Candidate, Seasonal Lecturer, Civil Engineering Department, University of Manitoba

Cathy Nelson, Technical Services Manager/Chief Engineer (retired), Oregon Department of Transportation

John J. Robinson, Jr., Assistant Chief Counsel, Pennsylvania Department of Transportation, Governor's Office of General Counsel

Ted M. Scott II, Director, Engineering, American Trucking Associations, Inc.

Gary D. Taylor, Professional Engineer

Gary C. Whited, Program Manager, Construction and Materials Support Center, University of Wisconsin-Madison

\section{AASHTO LIAISON}

James T. McDonnell, Program Director for Engineering, American Association of State Highway and Transportation Officials

\section{FHWA LIAISONS}

Steve Gaj, Leader, System Management and Monitoring Team, Office of Asset Management, Federal Highway Administration Cheryl Allen Richter, Assistant Director, Pavement Research and Development, Office of Infrastructure Research and Development, Federal Highway Administration

J. B. "Butch" Wlaschin, Director, Office of Asset Management, Federal Highway Administration

\section{CANADA LIAISON}

Lance Vigfusson, Assistant Deputy Minister of Engineering \& Operations, Manitoba Infrastructure and Transportation

\footnotetext{
${ }^{\star}$ Membership as of March 2014.
} 


\section{Related SHRP 2 Research}

Project Management Strategies for Complex Projects (R10)

Analytical Procedures for Determining the Impacts of Reliability Mitigation Strategies (LO3)

Evaluating Alternative Operations Strategies to Improve Travel Time Reliability (L11) 